MAURO SERGIO BRAGA

SENSOR DE IMAGEM PARA DETECÇÃO DE GASES 
MAURO SERGIO BRAGA

\section{SENSOR DE IMAGEM PARA DETECÇÃO DE GASES}

Dissertação apresentada à Escola

Politécnica da Universidade de São

Paulo para obtenção do título de Mestre em Engenharia

Área de Concentração:

Microeletrônica

Orientador: Prof. Livre-Docente

Walter Jaimes Salcedo 


\section{FICHA CATALOGRÁFICA}

\section{Braga, Mauro Sergio}

Sensor de imagem química para detecção de gases I M.S. Braga. -- São Paulo, 2008.

p.

Dissertação (Mestrado) - Escola Politécnica da Universidade de São Paulo. Departamento de Engenharia de Sistemas Eletrônicos.

1. Imagem química 2. Amplificador de transimpedância 3. Nariz eletrônico 4. Posicionador 5. Scanning Light Pulse Technique SLPT 6. Sensor MOS I. Universidade de São Paulo. Escola Politécnica. Departamento de Engenharia de Sistemas Eletrônicos II. t. 


\section{DEDICATÓRIA}

Dedico este trabalho aos meus pais Braga e Maria Augusta e a minha noiva Isabella. 


\section{AGRADECIMENTOS}

Agradeço a Deus por ter aproximado de mim tantas pessoas extraordinárias, tantos ombros amigos nos quais pude me apoiar no decorrer desses anos e que, direta ou indiretamente, contribuíram para a realização deste trabalho.

Aos meus pais Braga e Maria Augusta e irmãos Edmilson, Roberto e Solange, que desde os meus primeiros passos me instruíram a caminhar de modo honesto e digno pelas estradas da vida.

À minha futura esposa Isabella, que sempre de maneira companheira e afetiva esteve ao meu lado em todos os momentos.

Ao orientador e amigo Prof. Dr. Walter Jaimes Salcedo, companheiro de desafios e vitórias, de projetos e realizações.

Ao meu amigo Prof. Dr. Francisco Javier Ramirez Fernandez, pela sua receptividade no grupo do Laboratório de Microeletrônica e pelo apoio intelectual e financeiro durante o desenvolvimento da pesquisa.

Aos meus amigos Prof. Dr. Josemir Coelho Santos e Prof. Dr. Alexandre Simião Caporalli, que por inúmeras vezes me ajudaram a elucidar dúvidas, sugerindo possibilidades para melhoria do trabalho.

Aos colegas de pós-graduação, pelos valorosos comentários e discussões, e, em especial aos colegas de sala Danilo, Adriana, Daniel, Aldo e Rodrigo.

Ao meu amigo de laboratório Juliano, por contribuir na instrução dos métodos de processamento e reconhecimento dos padrões de imagens.

Aos meus amigos e alunos de iniciação científica Keth R. M. Matos, Daniela S. Santos, Adriana M. S. Santos e Jorge P. Silva, todos do CEFET-SP, unidade de Cubatão, que não economizaram esforços em colaborar na realização dos ensaios, ilustrações e no desenvolvimento de ferramentas computacionais de controle e aquisição de dados do projeto.

À Prof. Márcia, Prof. Humberto e Prof. Msc. Enzo, membros da direção do CEFETSP, unidade de Cubatão, pelos recursos oferecidos na divulgação e publicação dos trabalhos realizados em eventos nacionais e internacionais.

Aos amigos Michel e Kátia, pelo auxílio prestado durante a fabricação e caracterização dos dispositivos. 
Aos amigos Henrique e Pilar, que em suas atividades, na sala de medidas, proporcionaram-me ajuda incondicional na montagem do arranjo experimental.

Ao meu primo Prof. Marcelo Miranda, do Departamento de Elétrica da Escola Senai "Hessel H. Cherkassky", de Cubatão, pela contribuição na fabricação das aletas do modulador de luz, utilizadas no arranjo experimental.

Aos técnicos da sala limpa, da sala de medidas e anexos, pela dedicação no auxílio na confecção dos dispositivos. 
É melhor tentar e falhar, que preocupar-se e ver a vida passar. É melhor tentar ainda em vão, que sentar-se fazendo nada até o final. Eu prefiro na chuva caminhar, que em dias tristes em casa me esconder. Prefiro ser feliz, embora louco, que em conformidade, viver.

(Martin Luther King) 


\section{RESUMO}

O objetivo do presente trabalho é o desenvolvimento de um dispositivo MOS como sensor de imagem química para a detecção e classificação de gases de hidrogênio e amônia através da técnica de escaneamento de luz pulsada (TELP).

O dispositivo MOS foi fabricado sobre substrato de silício (100) e resistividade de $10 \Omega-\mathrm{cm}$. A porta do dispositivo foi constituída de um eletrodo bimetálico de Au-Pd com espessura nanométrica. Foi proposto um sistema automático de posicionamento $X Y$ para o escaneamento do feixe de luz pulsada baseado no controle PID e no software Labview ${ }^{\circledR}$. O processo de aquisição de dados foi também automatizado via instrumentação virtual definida pelo software Labview®.

A partir das curvas CxV dos capacitores MOS foram extraídos os parâmetros estruturais dos dispositivos mostrando-se estes valores concordantes com os valores definidos no projeto inicial. Adicionalmente foi determinada a largura máxima da camada de depleção sendo este parâmetro importante na sensibilidade da resposta do sensor. O dispositivo MOS em ambiente inerte $\left(\mathrm{N}_{2}\right)$ apresentou máxima sensibilidade de fotocorrente para polarização de $0,6 \mathrm{~V}$ correspondente à máxima largura de depleção. Em ambientes de $\mathrm{H}_{2}$ e $\mathrm{NH}_{3}$, o máximo de sensibilidade foi deslocado para tensões menores a $0,6 \mathrm{~V}$ atribuindo-se este fato à adsorção de átomos de Hidrogênio na interface metal/ $\mathrm{SiO}_{2}$.

As imagens químicas obtidas a partir da resposta do sensor MOS em modo de operação TELP para ambientes de $\mathrm{H}_{2}$ e $\mathrm{NH}_{3}$, respectivamente, apresentaram padrões característicos a cada tipo de gás independentemente da concentração utilizada permitindo a classificação plena destes gases.

Os resultados obtidos no presente trabalho sugerem a possibilidade de implementação de um sistema de nariz eletrônico apenas utilizando um único sensor.

Palavras-chave: Imagem química. Técnica de Escaneamento por Luz Pulsada (TELP). Posicionador. Amplificador de transimpedância. Sensor MOS. Nariz eletrônico. 


\begin{abstract}
The aim of the present work is the development of a MOS device as a sensor of chemical image, for the detection and classification of hydrogen and ammonia gases, through the Scanning Light Pulse Technique (SLPT).

The MOS device was fabricated onto silicon bulk (100) and resistivity of $10 \Omega$-cm. The gate of the device was built from an Au-Pd bimetallic electrode, with nanometric thickness. It was proposed an $X Y$ automatic position system for scanning the light pulsed beam, based on the PID control and on the Labview $®$ software. The data acquisition process was also automated via virtual instrumentation defined by the Labview $®$ software.

From the $\mathrm{C} \times \mathrm{V}$ characteristic curves of the MOS capacitors, the device structural parameters were extracted, showing accordance with values defined in the initial project. Furthermore, it was determined the maximum depletion layer width. This parameter is important for the sensibility response of the sensor. The MOS device, in inert environment $\left(\mathrm{N}_{2}\right)$, has shown photocurrent maximum sensibility for $0,6 \mathrm{~V}$ polarization, corresponding to the maximum depletion layer width. In $\mathrm{H}_{2}$ and $\mathrm{NH}_{3}$ environments, the maximum sensibility was dislocated for voltages lower than $0,6 \mathrm{~V}$, attributing it to the hydrogen atom adsorption at the metal/ $\mathrm{SiO}_{2}$ interface.

The chemical images obtained from the MOS sensor response, in SLPT operation mode for $\mathrm{H}_{2}$ and $\mathrm{NH}_{3}$ environments, respectively, showed characteristic patterns to each kind of gas, independent of the concentration used, allowing the complete classification of these gases.

The results obtained in the present work suggest the possibility of implementing an electronic nose system, using only one sensor.
\end{abstract}

Key-words: Chemical image. Scanning Light Pulse Technique (SLPT). Positioning. Transimpedance amplifier. MOS Sensor. Electronic noses 


\section{LISTA DE ILUSTRAÇÕES}

Figura 1 - Imagens químicas obtidas em ensaios com porfirinas para $\mathrm{P}\left(\mathrm{OC}_{2} \mathrm{H}_{5}\right)_{3}$, $\mathrm{P}\left(\mathrm{C}_{4} \mathrm{H}_{9}\right)_{3}, \mathrm{C}_{6} \mathrm{H}_{13} \mathrm{SH},\left(\mathrm{C}_{3} \mathrm{H}_{7}\right)_{2} \mathrm{~S}$ e acetona (RAKOW \& SUSLICK 2000). 4

Figura 2 - Diagrama esquemático do sensor potenciométrico de luz endereçável (YOSHINOBU, et al., 2001).

Figura 3 - Esquema da TELP obtido por um monitor de tubo de raios catódicos (FILIPPINI, 2002).

Figura 4 - Dispositivo Pd-MOS recoberto com oxigênio e exposto ao hidrogênio (PETERSSON, 1984).

Figura 5 - Estrutura MOS com portas metálicas paralelas com variação de espessura em direções opostas (LÖFDAHL, 2000)...................................... 10

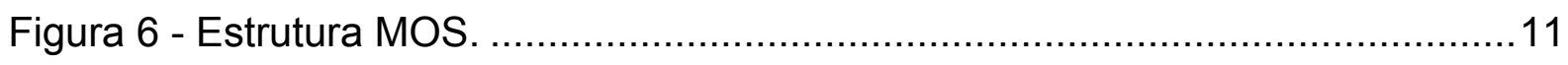

Figura 7 - Curva CxV - alta freqüência e baixa freqüência de um capacitor MOS (ALBERTIN, 2003). 12

Figura 8 - Diagrama de bandas de energia e de cargas espaciais para um capacitor MOS em (a) acumulação, (b) depleção e (c) inversão (ALBERTIN, 2003).

Figura 9 - Polarização de uma estrutura Pd-MOS e a tensão $\Delta \mathrm{V}$ criada pela camada de dipolos formada na interface metal/óxido.

Figura 10 - Deslocamento da curva CxV provocado pela presença de uma camada de dipolos na interface metal/óxido. 17

Figura 11 - Reação de formação de amônia através da combinação do nitrogênio, hidrogênio e o paládio e vice-versa.

Figura 12 - Monocamada de CO interrompendo a interação do hidrogênio em estruturas Pd-MOS.

Figura 13 - Diagrama experimental da geração de uma fotocorrente em um

dispositivo MOS, onde Фo é a intensidade de fótons. 20

Figura 14 - Intensidade dos pulsos de luz e sinais de corrente em função do tempo

(ENGSTRÖM \& CARLSSON, 1983). 21

Figura 15 - Tráfego de portadores de carga na interface para o tempo t1 (ENGSTRÖM \& CARLSSON, 1983). 
Figura 16 - Tráfego de portadores de carga na interface para o tempo t2 (ENGSTRÖM \& CARLSSON, 1983).

Figura 17 - Tráfego de portadores de carga na interface para o tempo t3 (ENGSTRÖM \& CARLSSON, 1983).

Figura 18 - Tráfego de portadores de carga na interface para o tempo t4 (ENGSTRÖM \& CARLSSON, 1983).

Figura 19 - Circuito equivalente de uma estrutura MOS foto-excitada com um feixe de luz pulsada

Figura 20- Diagrama seqüencial da Técnica de Escaneamento por Luz Pulsada para geração de padrões de imagens químicas.

Figura 21 - Dispositivos MOS utilizados no experimento.

Figura 22 - Etapas de fabricação do capacitor MOS.

Figura 23 - Esquema do sistema construído para a diluição do hidrogênio e amônia em nitrogênio.

Figura 24 - Diagrama eletrônico do amplificador de transimpedância.

Figura 25 - Curva característica de resposta do amplificador de transimpedância. ..41

Figura 26 - Diagrama do circuito de acionamento dos motores do posicionador $\mathrm{X} Y$.

Figura 27 - Sistema de posicionamento $X Y$ montado para realizar a varredura do laser sobre o sensor MOS.

Figura 28 - Detalhes construtivos da câmara de gás.

Figura 29 - Fotografia da câmara utilizada nos ensaios.

Figura 30 - Disco com aletas utilizado no chopper para modular a luz.

Figura 31 - Sistema de controle de posição desenvolvido em LabView ${ }^{\circledR}$.

Figura 32 - Blocos que compõe o programa de controle do posicionador.

Figura 33 - Sistema para determinar os pontos inicial e final de varredura.

Figura 34 - Diagrama de blocos do programa para determinar os pontos inicial e final da varredura.

Figura 35 - Sistema para determinar o tempo de adsorção e dessorção do sensor MOS.

Figura 36 - Diagrama de blocos do programa para determinar o tempo de adsorção e dessorção do capacitor MOS.

Figura 37 - Diagrama esquemático do arranjo experimental da TELP. 
Figura 38 - Fotografia do arranjo experimental do sistema de obtenção de imagens químicas.

Figura 39 - Curva CxV do capacitor MOS em forma de elipse.

Figura 40 - Circuito equivalente do capacitor MOS, representando em (a) a série dos capacitores $\mathrm{C}_{\mathrm{ox}}$ e $\mathrm{C}_{\mathrm{sc}}$ e em (b) o modelo equivalente de capacitâncias para um capacitor em regime de inversão, onde $\mathrm{C}_{\mathrm{sc}}\left(\mathrm{C}_{\mathrm{D}}+\mathrm{C}_{\mathrm{l}}\right)$ é a capacitância gerada pela camada de depleção. 54

Figura 41 - Curva CxV do capacitor MOS em forma de cunha. .56

Figura 42 - Curva u x Vp sob exposição na região de ouro, a 5000 ppm de $\mathrm{H}_{2}$ (linha vermelha), a $5000 \mathrm{ppm}$ de $\mathrm{NH}_{3}$ (linha verde) e a $\mathrm{N}_{2}$ (linha preta) com o dispositivo aquecido a $90^{\circ} \mathrm{C}$. O local de incidência do laser é indicado na figura ao lado (ponto vermelho).

Figura 43 - Curva u x Vp sob exposição na região de óxido, a 5000 ppm de $\mathrm{H}_{2}$ (linha vermelha), a 5000 ppm de $\mathrm{NH}_{3}$ (linha verde) e a $\mathrm{N}_{2}$ (linha preta) com o dispositivo aquecido a $90^{\circ} \mathrm{C}$. O local de incidência do laser é indicado na representação ao lado (ponto vermelho).

Figura 44 - Curva u x Vp sob exposição na região de paládio, a 5000 ppm de $\mathrm{H}_{2}$ (linha vermelha), a $5000 \mathrm{ppm}$ de $\mathrm{NH}_{3}$ (linha verde) e a $\mathrm{N}_{2}$ (linha preta) com o dispositivo aquecido a $90^{\circ} \mathrm{C}$. O local de incidência do laser é indicado na representação ao lado (ponto vermelho).

Figura 45 - Curva u x Vp sob exposição na região de ouro, a 5000 ppm de $\mathrm{H}_{2}$ (linha vermelha), a $5000 \mathrm{ppm}$ de $\mathrm{NH}_{3}$ (linha verde) e a $\mathrm{N}_{2}$ (linha preta) com o dispositivo aquecido a $90^{\circ} \mathrm{C}$. O local de incidência do laser é indicado na representação ao lado (ponto vermelho).

Figura 46 - Curva u x Vp sob exposição na região de ouro, a 5000 ppm de $\mathrm{H}_{2}$ (linha vermelha), a $5000 \mathrm{ppm}$ de $\mathrm{NH}_{3}$ (linha verde) e a $\mathrm{N}_{2}$ (linha preta) com o dispositivo aquecido a $90^{\circ} \mathrm{C}$. O local de incidência do laser é indicado na representação ao lado (ponto vermelho).

Figura 47 - Curva u x Vp sob exposição na região de ouro, a 5000 ppm de $\mathrm{H}_{2}$ (linha vermelha), a $5000 \mathrm{ppm}$ de $\mathrm{NH}_{3}$ (linha verde) e a $\mathrm{N}_{2}$ (linha preta) com o dispositivo aquecido a $90^{\circ} \mathrm{C}$. O local de incidência do laser é indicado na representação ao lado (ponto vermelho).

Figura 48 - Curva derivativa u $x$ Vp sob exposição nas regiões de ouro, óxido e paládio (elipse), a 5000 ppm de $\mathrm{H}_{2}$ (linha vermelha), a 5000 ppm de $\mathrm{NH}_{3}$ 
(linha verde) e a $\mathrm{N}_{2}$ (linha preta) com o dispositivo aquecido a $90^{\circ} \mathrm{C}$. Os locais de incidência do laser são indicados na representação ao lado (pontos vermelhos).

Figura 49 - Curva derivativa u $x$ Vp sob exposição nas regiões de ouro, óxido e paládio (cunha), a $5000 \mathrm{ppm}$ de $\mathrm{H}_{2}$ (linha vermelha), a $5000 \mathrm{ppm}$ de $\mathrm{NH}_{3}$ (linha verde) e a $\mathrm{N}_{2}$ (linha preta) com o dispositivo aquecido a $90^{\circ} \mathrm{C}$. Os locais de incidência do laser são indicados na representação ao lado (pontos vermelhos)

Figura 50 - Os pontos em vermelho sobre o sensor, no formato de elipse, representam os locais de incidência do laser para obtenção do tempo de adsorção e dessorção aos gases analisados.

Figura 51 - Os pontos em vermelho sobre o sensor, no formato de cunha, representam os locais de incidência do laser para obtenção do tempo de adsorção e dessorção aos gases analisados.

Figura 52 - Curva de resposta da interação dos gases de $\mathrm{H}_{2}$ na região do paládio para o sensor em formato de elipse.

Figura 53 - Curva de resposta da interação dos gases de $\mathrm{NH}_{3}$ na região do paládio para o sensor em formato de elipse.

Figura 54 - Curva de resposta da interação dos gases de $\mathrm{H}_{2}$ na região do paládio para o sensor em formato de cunha.

Figura 55 - Curva de resposta da interação dos gases de $\mathrm{NH}_{3}$ na região do paládio para o sensor em formato de cunha.

Figura 56 - Superfície do material adsorvente como um conjunto de "caixas". Cada caixa possui um sítio de adsorção (BARATTO, 1993).

Figura 57 - Amplitude da fotocorrente ao longo de uma linha de escaneamento para o sensor no formato de elipse sob exposição de 500 ppm de $\mathrm{H}_{2}$ (linha vermelha), a $500 \mathrm{ppm}$ de $\mathrm{NH}_{3}$ (linha verde) e $\mathrm{N}_{2}$ (linha preta) com o dispositivo aquecido a $90^{\circ} \mathrm{C}$. Os gases foram fornecidos a um fluxo de $200 \mathrm{ml} / \mathrm{min}$.

Figura 58 - Amplitude da fotocorrente ao longo de uma linha de escaneamento para o sensor no formato de cunha sob exposição de 500 ppm de $\mathrm{H}_{2}$ (linha vermelha), a $500 \mathrm{ppm}$ de $\mathrm{NH}_{3}$ (linha verde) e $\mathrm{N}_{2}$ (linha preta) com o dispositivo aquecido a $90^{\circ} \mathrm{C}$. Os gases foram fornecidos a um fluxo de $200 \mathrm{ml} / \mathrm{min}$. 
Figura 59 - Região de varredura dos pontos de incidência do laser sobre o sensor no formato de elipse.

Figura 60 - Região de varredura dos pontos de incidência do laser sobre o sensor no formato de cunha.

Figura 61 - Imagens químicas obtidas no primeiro ensaio pelo sensor em formato de elipse para diferentes concentrações com o sensor operando numa temperatura de $90^{\circ} \mathrm{C}$. As respostas foram normalizadas pelo máximo valor encontrado nos três ensaios. A escala em RGB codifica a amplitude de "u" aos gases ensaiados.

Figura 62 - Imagens químicas obtidas no segundo ensaio pelo sensor em formato de elipse para diferentes concentrações com o sensor operando numa temperatura de $90^{\circ} \mathrm{C}$. As respostas foram normalizadas pelo máximo valor encontrado nos três ensaios. A escala em RGB codifica a amplitude de "u" aos gases ensaiados. 80

Figura 63 - Imagens químicas obtidas no terceiro ensaio pelo sensor em formato de elipse para diferentes concentrações com o sensor operando numa temperatura de $90^{\circ} \mathrm{C}$. As respostas foram normalizadas pelo máximo valor encontrado nos três ensaios. A escala em RGB codifica a amplitude de "u" aos gases ensaiados.

Figura 64 - Imagens químicas obtidas no primeiro ensaio pelo sensor em formato de cunha para diferentes concentrações com o sensor operando numa temperatura de $90^{\circ} \mathrm{C}$. As respostas foram normalizadas pelo máximo valor encontrado nos três ensaios. A escala em RGB codifica a amplitude de "u" aos gases ensaiados.

Figura 65 - Imagens químicas obtidas no segundo ensaio pelo sensor em formato de cunha para diferentes concentrações com o sensor operando numa temperatura de $90^{\circ} \mathrm{C}$. As respostas foram normalizadas pelo máximo valor encontrado nos três ensaios. A escala em RGB codifica a amplitude de " $u$ " aos gases ensaiados.

Figura 66 - Imagens químicas obtidas no terceiro ensaio pelo sensor em formato de cunha para diferentes concentrações com o sensor operando numa temperatura de $90^{\circ} \mathrm{C}$. As respostas foram normalizadas pelo máximo valor encontrado nos três ensaios. A escala em RGB codifica a amplitude de "u" aos gases ensaiados. 
Figura 67 - Imagens químicas da diferença dos gases de $\mathrm{NH}_{3}$ e $\mathrm{H}_{2}$ em relação à ambiente inerte de $\mathrm{N}_{2}$ com o sensor operando numa temperatura de $90^{\circ} \mathrm{C}$ (sensor elipse). As respostas foram normalizadas pelo máximo valor das diferenças encontradas nos três ensaios. A escala em RGB codifica a amplitude de "u" aos gases ensaiados.

Figura 68 - Imagens químicas da diferença dos gases de $\mathrm{NH}_{3}$ e $\mathrm{H}_{2}$ em relação à ambiente inerte de $\mathrm{N}_{2}$ com o sensor operando numa temperatura de $90^{\circ} \mathrm{C}$ (sensor cunha). As respostas foram normalizadas pelo máximo valor das diferenças encontradas nos três ensaios. A escala em RGB codifica a amplitude de "u" aos gases ensaiados.

Figura 69 - Imagens químicas da diferença dos gases de $\mathrm{NH}_{3}$ e $\mathrm{H}_{2}$ em relação à ambiente inerte de $\mathrm{N}_{2}$ com o sensor operando numa temperatura de $90^{\circ} \mathrm{C}$ (sensor elipse). As respostas foram normalizadas pelo máximo valor das diferenças encontradas em cada ensaio individualmente. A escala em RGB codifica a amplitude de "u" aos gases ensaiados.

Figura 70 - Imagens químicas da diferença dos gases de $\mathrm{NH}_{3}$ e $\mathrm{H}_{2}$ em relação à ambiente inerte de $\mathrm{N}_{2}$ com o sensor operando numa temperatura de $90^{\circ} \mathrm{C}$ (sensor cunha). As respostas foram normalizadas pelo máximo valor das diferenças encontradas em cada ensaio individualmente. A escala em RGB codifica a amplitude de "u" aos gases ensaiados.

Figura 71 - Identificação da região metálica evidenciando a resposta lateral dos átomos de hidrogênio em regiões circunvizinhas ao filme de paládio. 89

Figura 72 - Modelo esquemático de um dispositivo MOS bidimensional representado por uma linha de transmissão. 


\section{LISTA DE TABELAS}

Tabela 1 - Etapas do processo de oxidação de Gettering ......................................33

Tabela 2 - Etapas do processo de oxidação térmica......................................... 34

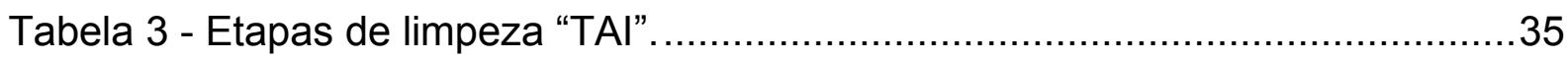

Tabela 4 - Parâmetros de ensaio para estudo do tempo de adsorção e dessorção ao gás de hidrogênio no sensor em forma de elipse e cunha......................64

Tabela 5 - Parâmetros de ensaio para estudo do tempo de adsorção e dessorção ao gás de amônia no sensor em forma de elipse e cunha.........................64 


\section{LISTA DE SÍMBOLOS, SIGLAS E DE ABREVIATURAS}

A: Área do capacitor MOS.

AC: Corrente alternada.

Al: Alumínio.

Au: Ouro.

$\mathrm{C}_{\mathrm{a}}$ : Capacitância da região de acumulação.

$\mathrm{C}_{\text {máx: }}$ : Capacitância máxima do capacitor MOS em regime de acumulação.

$\mathrm{C}_{\text {min: }}$ Capacitância mínima do capacitor MOS em regime de inversão a alta freqüência.

$\mathrm{C}_{\mathrm{FB}}$ : Capacitância de banda plana do capacitor MOS.

$\mathrm{Cl}$ : Circuito integrado.

$\mathrm{C}_{\mathrm{l}}$ : Capacitância de inversão.

$\mathrm{C}_{\mathrm{D}}$ : Capacitância de depleção.

$\mathrm{C}_{\text {Dminimo: }}$ Capacitância de depleção quando o capacitor MOS encontra-se na região de inversão forte.

$\mathrm{C}_{2} \mathrm{H}_{4}$ : Etil (Ethil).

$\mathrm{C}_{2} \mathrm{H}_{5} \mathrm{OH}$ : Etanol (Ethanol).

$\left(\mathrm{C}_{3} \mathrm{H}_{7}\right)_{2} \mathrm{~S}$ : Trimetiltiol (Trimethylthiol).

$\mathrm{C}_{6} \mathrm{H}_{13} \mathrm{SH}$ : Hexametiltiol (Hexamethylthiol).

CO: Monóxido de carbono.

$\mathrm{C}_{\text {ox: }}$ : Capacitância do óxido.

CPD: Diferencial de potencial de contato.

CxV AF: Curva Capacitância versus Tensão de Alta Freqüência.

CxV BF: Curva Capacitância versus Tensão de Baixa Freqüência.

$\mathrm{C}_{33}$ : Tricloro.

$\mathrm{C}_{\mathrm{e}}$ : Velocidade de absorção de hidrogênio, da interface externa, pelo corpo do paládio.

$\mathrm{C}_{\mathrm{i}}$ : Velocidade de adsorção de hidrogênio, do corpo do paládio, pela superfície interna do paládio.

$\mathrm{C}_{0}$ : Velocidade da reação (10) para adsorção de oxigênio. 
$\mathrm{C}_{1}$ : Velocidade de adsorção do hidrogênio, do ambiente, pela interface externa do paládio.

$\mathrm{C}_{2 n}$ : Velocidade da reação (9) para formação de $\mathrm{NH}$.

$\mathrm{C}_{20}$ : Velocidade da reação (10) para formação de $\mathrm{OH}$.

$\mathrm{C}_{3 n}$ : Velocidade da reação (9) para formação de $\mathrm{NH}_{2}$.

$\mathrm{C}_{30}$ : Velocidade da reação (10) para formação de $\mathrm{H}_{2} \mathrm{O}$.

$\mathrm{C}_{4 n}$ : Velocidade da reação (9) para formação de $\mathrm{NH}_{3}$.

$\mathrm{C}_{\mathrm{sc}}$ : Capacitância do semicondutor.

$\mathrm{C}_{\text {ss: }}$ : Capacitância dos estados de interface.

$D_{\mathrm{e}}$ : Velocidade de desabsorção, da interface externa, pelo corpo do paládio.

$D_{i}$ : Velocidade de dessorção do hidrogênio, do corpo do paládio, pela interface interna do paládio.

$D_{n}$ : Constante de difusão.

$D_{0}$ : Velocidade da reação inversa (10) para dessorção de oxigênio.

$D_{1}$ : Velocidade de dessorção do hidrogênio, do ambiente, pela interface externa.

$D_{2 n}$ : Velocidade da reação inversa (9) para dissociação de $\mathrm{NH}$.

$D_{20}$ : Velocidade da reação inversa (10) para dissociação de $\mathrm{OH}$.

$D_{3 n}$ : Velocidade da reação inversa (9) para dissociação de $\mathrm{NH}_{2}$.

$D_{30}:$ Velocidade da reação inversa (10) para dissociação de $\mathrm{H}_{2} 0$.

$\mathrm{D}_{4 \mathrm{n}}$ : Velocidade da reação inversa (9) para dissociação de $\mathrm{NH}_{3}$.

DC: Corrente contínua.

d.d.p.: Diferença de potencial.

DLV: Decapante Lento de Vidro.

$\Delta \mathrm{H}^{\circ}{ }_{\text {ad: }}$ Entalpia de adsorção.

$\Delta \mathrm{n}^{\circ}$ : Concentração de elétrons gerados opticamente.

$\Delta Q_{\text {tot: }}$ Carga total transportada através da estrutura.

$\Delta \Psi_{\mathrm{s}}$ : Mudança no potencial de superfície devido à coleta de elétrons gerados opticamente próximos à interface.

$\Delta \mathrm{V}$ : Diferença de potencial produzida pela camada de dipolos dos átomos de hidrogênio na interface Metal-óxido.

$\Delta \mathrm{V}_{\mathrm{o}}$ : Mudança de tensão no isolante.

$\Delta \mathrm{x}$ : Deslocamento do sistema de posicionamento no eixo $\mathrm{X}$.

$\Delta \mathrm{y}$ : Deslocamento do sistema de posicionamento no eixo $\mathrm{Y}$.

X: Afinidade eletrônica do silício. 
$E_{c}$ : Nível de condução.

$E_{b}$ : Altura da barreira de energia devido às moléculas ou átomos adsorvidos na superfície de Pd.

$E_{F}:$ Nível de Fermi.

$E_{\mathrm{FM}}$ : Nível de Fermi do Metal.

$E_{g}$ : Largura da banda proibida (1,11 eV para o Si).

$E_{\mathrm{i}}$ : Nível intrínseco.

EIS: Estrutura eletrólito-isolante-semicondutor.

$E_{v}$ : Nível de valência.

$E_{\infty}$ : Nível de vácuo.

$\varepsilon_{0}$ : Permissividade elétrica no vácuo $\left(8,84 \cdot 10^{-14} \mathrm{~F} / \mathrm{cm}\right)$.

$\varepsilon_{\text {ox: }}$ Permissividade elétrica do óxido $\left(3,9.10^{-13} \mathrm{~F} / \mathrm{cm}\right)$.

$\varepsilon_{\mathrm{si}}:$ Permissividade elétrica do silício $\left(11,7.10^{-13} \mathrm{~F} / \mathrm{cm}\right)$.

F: Fluxo de gás inserido à câmara.

$\varnothing_{\mathrm{Au}}$ : Função trabalho do ouro.

$\varnothing_{\mathrm{Pd}}$ : Função trabalho do paládio.

$\varnothing_{\text {médio: }}$ Valor médio das funções trabalho dos metais de ouro e paládio.

$\varnothing_{\mathrm{F}}$ : Potencial de Fermi.

$\varnothing_{\mathrm{M}}$ : Função trabalho do Metal.

$\varnothing_{\text {si: }}$ Função trabalho do Silício.

$\varnothing_{\mathrm{Ms}}$ : Diferença entre as funções trabalho entre metal e semicondutor.

$\varnothing_{\mathrm{O}}$ : Intensidade de fótons.

$\mathrm{H}^{+}$: ĺons de hidrogênio.

$\mathrm{H}_{2}$ : Hidrogênio.

$\mathrm{H}_{2} \mathrm{O}_{2}$ : Peróxido de hidrogênio.

$\mathrm{H}_{2} \mathrm{O}$ D.I.: Água deionizada.

$\mathrm{H}_{2} \mathrm{SO}_{4}$ : Ácido sulfúrico.

$\left(\mathrm{H}_{2}\right)_{\mathrm{x}}$ : Concentração relativa de hidrogênio no ponto $\mathrm{x}$.

$\mathrm{H}_{\mathrm{ae}}$ : Átomo de hidrogênio adsorvido na interface metal catalítico gás.

$\mathrm{H}_{\mathrm{ai}}$ : Átomo de hidrogênio adsorvido na interface metal catalítico-isolante.

$\mathrm{H}_{\mathrm{b}}$ : Átomo de hidrogênio no corpo do metal catalítico.

$\left(\mathrm{H}_{2} \mathrm{O}\right)_{\mathrm{x}}$ : Concentração de moléculas de água no ponto $\mathrm{x}$.

$\mathrm{H}_{2} \mathrm{O}$ : Água.

i: Sinal de corrente originário do capacitor MOS. 
$\mathrm{i}_{\mathrm{br}}$ : Corrente de recombinação do substrato.

$\mathrm{i}_{\mathrm{d}}$ : Corrente de deslocamento.

$\mathrm{i}_{\mathrm{g}}$ : Corrente de geração devida aos portadores de carga criados dentro da região de carga espacial.

Iph: Fotocorrente gerada.

$\mathrm{i}_{\mathrm{s} r}$ : Corrente de recombinação de superfície.

LabVIEW $^{\circledR}$ : Ambiente que utiliza o conceito de linguagem de programação gráfica aplicados a sistemas de medição baseado em instrumentação virtual.

LAPS: Light Addressable Potentiometric Sensor.

$L_{n}$ : Comprimento de difusão.

M: Massa da partícula.

MIS: Estrutura Metal-Isolante-Semicondutor.

MOS: Estrutura Metal-Óxido-Semicondutor.

MOSFET: MOS Fied-Effect-Transistor.

$\mathrm{N}_{2}$ : Nitrogênio.

$\mathrm{NH}_{3}$ : Amônia.

$\mathrm{NH}_{4} \mathrm{~F}$ : HF: Bifluoreto de amônio.

$\mathrm{NH}_{4} \mathrm{OH}$ : Hidróxido de Amônio.

$\left(\mathrm{N}_{2}\right)_{\mathrm{x}}$ : Concentração relativa de nitrogênio no ponto $\mathrm{x}$.

$\mathrm{NH}_{\mathrm{ae}}: \mathrm{NH}$ adsorvido na interface metal catalítico gás.

$\mathrm{NH}_{2 a e}: \mathrm{NH}_{2}$ adsorvido na interface metal catalítico gás.

$\left(\mathrm{NH}_{3}\right)_{\mathrm{x}}$ : Concentração relativa de amônia no ponto $\mathrm{x}$.

$\mathrm{N}_{\mathrm{A}}$ : Concentração efetiva de dopantes no substrato.

NA: Número de avogrado.

$\mathrm{n}_{\mathrm{i}}$ : Concentração intrínseca de portadores no silício $\left(1,45 \cdot 10^{10} \mathrm{~cm}^{-3}\right.$ para $\left.\mathrm{T}=300 \mathrm{~K}\right)$.

$\bar{N}_{s s}$ : Densidade média dos estados de interface.

$\mathrm{O}_{2}$ : Oxigênio.

$\left(\mathrm{O}_{2}\right)_{\mathrm{x}}$ : Concentração relativa de oxigênio no ponto $\mathrm{x}$.

$\mathrm{O}_{\mathrm{ae}}$ : Átomo de oxigênio adsorvido na interfase metal catalítico gás.

$\mathrm{OH}_{\mathrm{ae}}: \mathrm{OH}$ adsorvido na interface metal catalítico gás.

Pd: Paládio.

Pd-MOS: Estrutura de um capacitor MOS com porta de Paládio.

$\mathrm{p}$ : Pressão do gás. 
$\mathrm{pH}$ : Potencial de hidrogênio.

PID: Proporcional - Integral - Derivativo.

$\mathrm{P}\left(\mathrm{OC}_{2} \mathrm{H}_{5}\right)_{3}$ : Trietoxifosfeto (Triethyl Phosphurus).

$\mathrm{P}\left(\mathrm{C}_{4} \mathrm{H}_{9}\right)_{3}$ : Tributoxfosfeto (Tributil Phosphurus).

$\Psi_{s}:$ Potencial de superfície do silício.

$\Psi_{\text {smáx }}$ : Potencial de superfície máximo do silício.

q: carga elementar do elétron $\left(1,6 \cdot 10^{-19} \mathrm{C}\right)$.

$Q_{\mathrm{ss}}$ : Densidade de carga efetiva.

R: Fator de amplificação do transimpedância $(\Omega)$.

RPM: Rotações por minuto.

$\mathrm{R}_{\mathrm{s}}$ : Resistência série.

s: Taxa de recombinação de superfície.

Si: Silício.

Si-p: Silício dopado com impurezas do tipo $\mathrm{p}$.

$\mathrm{SiO}_{2}$ : Dióxido de silício.

SLPT: Scanning Light Pulse Technique.

$\sigma:$ Sítios de adsorção ocupados na superfície do paládio.

$\sigma_{0}:$ Sítios de adsorção na superfície externa do paládio.

$\tau$ : Tempo de adsorção.

T: Temperatura.

TAI: Solução de limpeza formada por Tricloro, Acetona e Isopropanol.

TELP: Técnica de Escaneamento por Luz Pulsada.

$t_{o x}$ : Espessura do óxido.

u: Quantidade de carga transportada pelo dispositivo durante um intervalo de tempo de duração da fotocorrente.

unid. arbitr.: Unidades arbitrárias.

USP: Universidade de São Paulo.

VCC: Tensão contínua.

$\mathrm{V}_{\mathrm{FB}}$ : Tensão de banda plana.

$\mathrm{V}_{\mathrm{p}}$ : Tensão aplicada na porta do capacitor MOS.

$\mathrm{V}_{\text {ox: }}$ : Tensão que está caindo sobre o óxido.

$V_{R}$ : Tensão sobre o amplificador de transimpedância $R$.

$V_{S}$ : Tensão de saída do amplificador de transimpedância.

$\mathrm{V}_{\mathrm{T}}$ : Tensão de limiar. 
Wd: Largura da região de depleção.

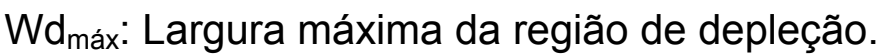

$W d_{p}$ : Largura da região de depleção causada pela tensão de polarização $V p$.

$W d_{h}$ : Largura da região de depleção acrescida à tensão $\mathrm{Vp}$, devido a formação da camada de dipolos dos átomos de hidrogênio difundidos na interface metal/ $/ \mathrm{SiO}_{2}$. $\mathrm{x}_{\mathrm{o}}$ : Largura de corte em analogia à largura do canal de um transistor MOS. $x_{\text {ox: }}$ Espessura do óxido. 


\section{SUMÁRIO}

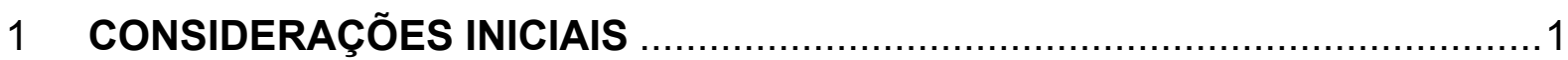

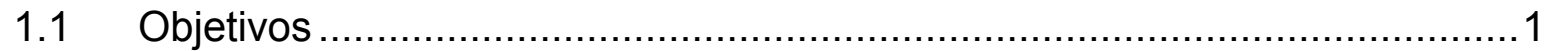

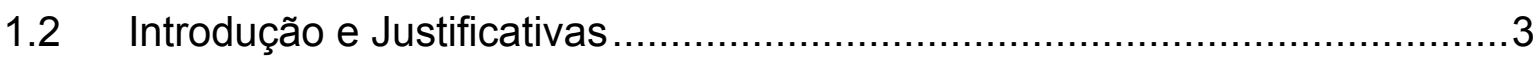

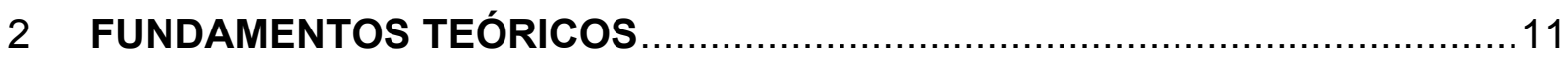

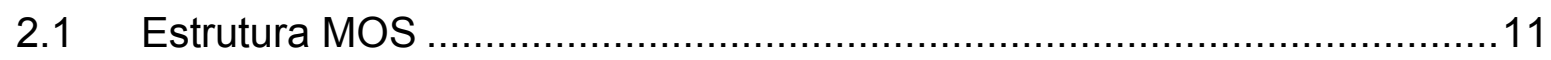

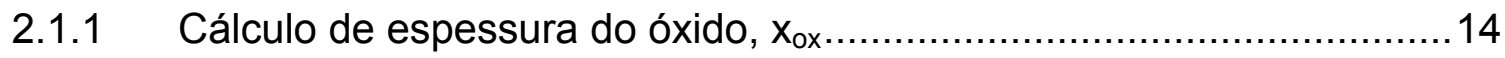

2.1.2 Cálculo da largura máxima da camada de depleção, $W_{\text {dmáx }}$................14

2.1.3 Cálculo da concentração de portadores majoritários do substrato, $\mathrm{N}_{\mathrm{A}} 14$

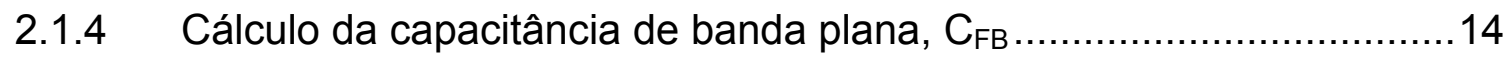

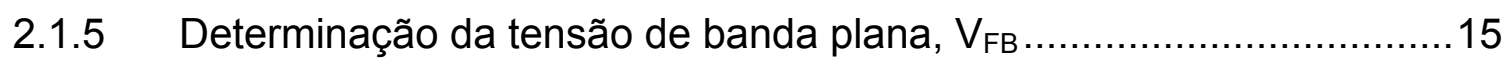

2.1.6 Cálculo da densidade efetiva de cargas no óxido, (Qss/q) ................15

2.1.7 Cálculo da tensão de limiar, $\mathrm{V}_{\mathrm{T}}$ (início da inversão) .........................15

2.2 Estrutura MOS sensíveis a hidrogênio e amônia ....................................15

2.3 Técnica de escaneamento por luz pulsada ..........................................19

2.4 Determinação da fotocorrente gerada em estruturas MOS (ENGSTRÖM \&

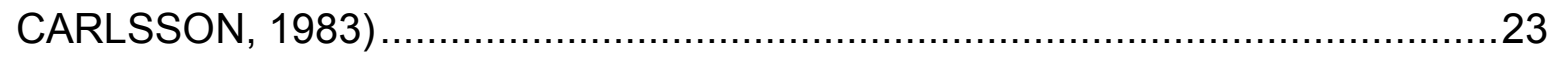

2.5 Influência dos estados de interface...............................................28

3 PROCEDIMENTOS EXPERIMENTAIS ............................................... 31

3.1 Fabricação dos capacitores MOS ................................................... 32

3.2 Etapas de fabricação do capacitor MOS ........................................... 33

a. Limpeza química inicial da lâmina Si-p ............................................. 33

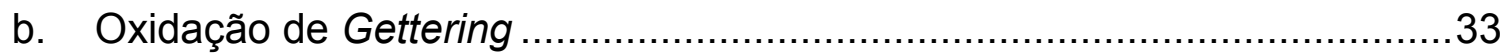

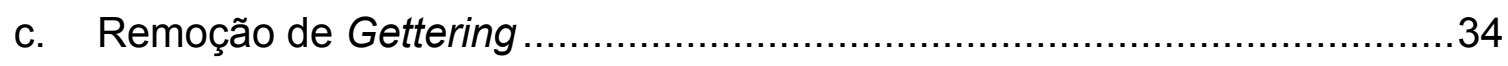

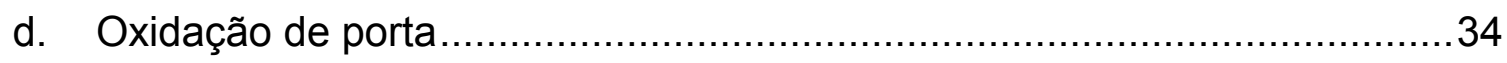

e. Proteção do óxido de porta na parte frontal da lâmina com fotoresiste. .....34

f. Remoção do óxido das "costas" da lâmina ................................................ 34

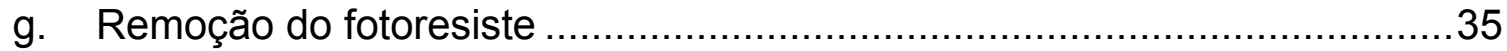

h. Deposição de Alumínio no lado inferior da lâmina ....................................35

i. Fotogravação dos filmes de Paládio ................................................... 35

j. $\quad$ Abertura de janela para deposição de Paládio ...................................... 36 
k. Deposição de Paládio sobre a camada de óxido .........................................36

I. Remoção do excesso de Paládio pelo processo Lift-Off..............................36

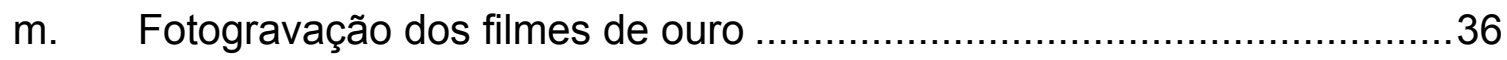

n. Abertura de janela para deposição de ouro ………...................................

o. Deposição de ouro sobre a camada de óxido ............................................37

p. Remoção do excesso de ouro pelo processo Lift-Off..................................37

q. Realização do processo de sinterização para a formação da liga Al-Si ......37

3.3 Sistema de obtenção de imagens químicas pela TELP............................38

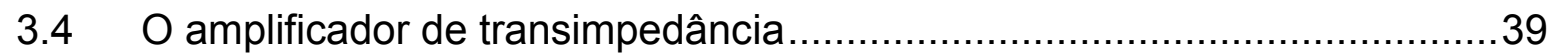

3.5 Circuito de acionamento dos motores do sistema de posicionamento X Y.41

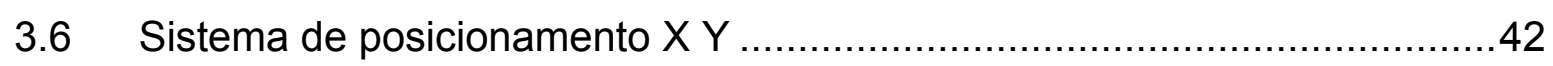

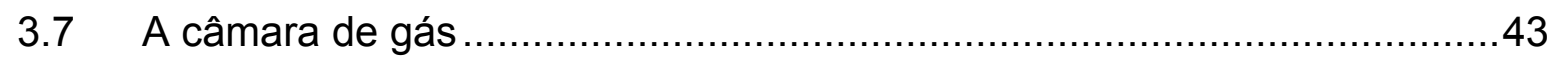

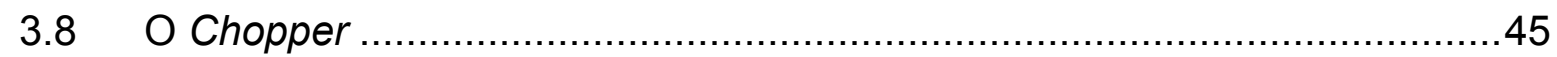

3.9 Sistema de posicionamento $X Y$ e aquisição de sinais .............................45

3.10 Ferramenta computacional para determinar os pontos inicial e final da

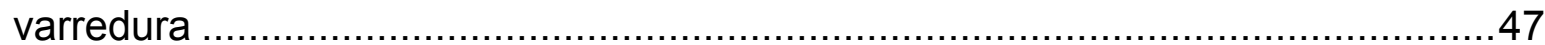

3.11 Ferramenta computacional para determinar o tempo de adsorção e

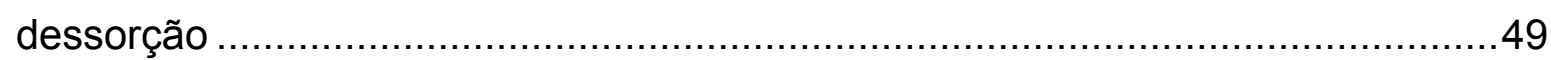

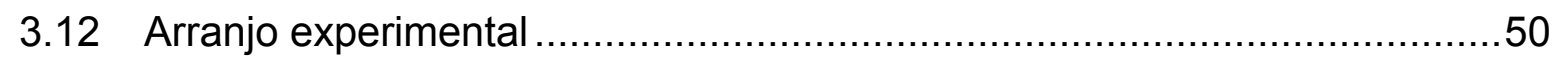

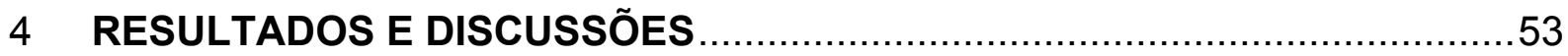

4.1 Curva capacitância-tensão (CxV) em alta e baixa freqüência.....................53

4.2 Estudo do comportamento da sensibilidade para diferentes tensões de

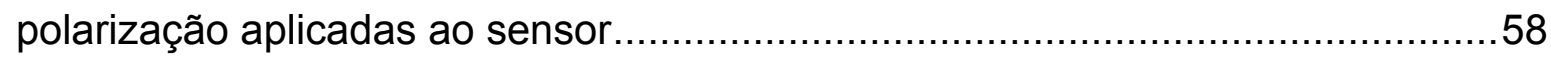

4.3 Estudo do tempo de adsorção e dessorção aos gases de hidrogênio e

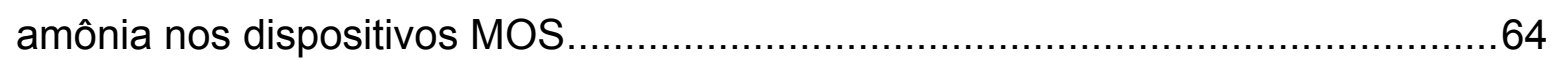

4.4 Estudo do perfil de resposta espacial do sensor aos gases de hidrogênio e amônia nos dispositivos MOS....................................................................73

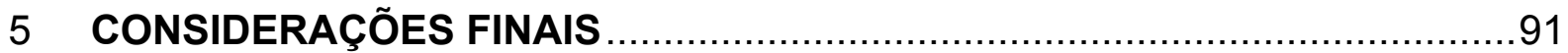

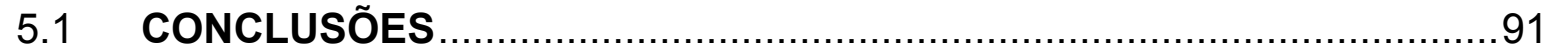

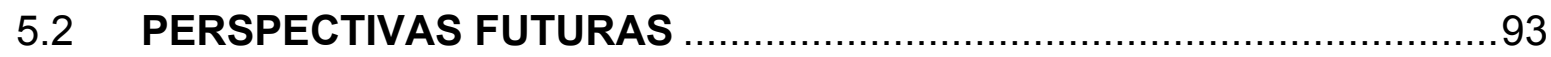

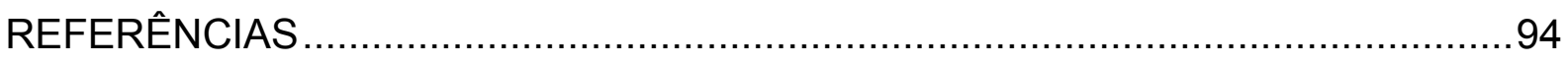

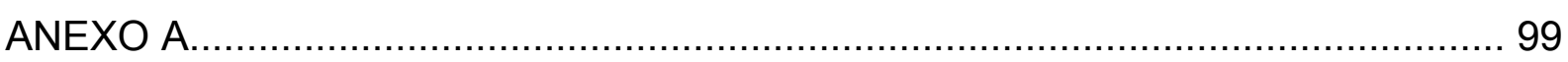




\section{CONSIDERAÇÕES INICIAIS}

\subsection{Objetivos}

O escopo do presente projeto consiste no desenvolvimento de um sistema de obtenção de imagens químicas para identificação de gases, baseado na técnica de escaneamento por luz pulsada (TELP, scanned light pulse technique - SLPT), em dispositivos MOS, por meio da qual foram obtidas imagens químicas como resposta do sensor em função de diferentes tipos de gases para diferentes concentrações dos gases em análise. A sensibilidade do sensor foi analisada em diferentes temperaturas de operação e diferentes potenciais de polarização da porta do dispositivo. Para isso, foram construídos capacitores MOS utilizando-se filmes de paládio e ouro para atuar como portas sensíveis para os diferentes gases utilizados no ensaio experimental $\left(\mathrm{NH}_{3}, \mathrm{H}_{2}, \mathrm{~N}_{2}\right)$. Os dispositivos sensores MOS foram projetados em duas diferentes geometrias de porta constituídas pelos filmes catalíticos de $\mathrm{Au}$ e $\mathrm{Pd}$, respectivamente, o que possibilitou obter padrões de imagem química característicos a cada tipo de gás analisado. Esses padrões mostraram que o dispositivo sensor de imagem química pode ser usado em um sistema de nariz eletrônico constituído apenas de um único sensor. Os detalhes e discussões dos resultados atingidos no presente trabalho foram sistematicamente organizados em cinco capítulos.

No capítulo 1 apresentamos os objetivos gerais do projeto, além do relato das principais técnicas para identificação de gases por imagens químicas reportadas na literatura.

Na seqüência, no capitulo 2, apresentamos os fundamentos teóricos sobre a estrutura MOS, indicando as partes de sua composição, funcionamento, ponto de operação. A partir dos princípios de funcionamento do dispositivo MOS é descrito também o princípio de obtenção de imagens químicas utilizando a técnica de escaneamento de luz pulsada (TELP). Adicionalmente, neste capitulo, foram discutidos os processos de interação das estruturas Pd-MOS com meios gasosos contendo hidrogênio. 
No capítulo 3, é descrito o procedimento experimental, detalhando-se todo o roteiro seguido para a fabricação dos dispositivos MOS. Também é descrito o processo de aquisição de dados a partir da resposta dos sensores MOS indicando o procedimento da construção das imagens químicas como resposta final dos sensores.

No capitulo 4, são apresentados os resultados experimentais e discussões, onde, a partir das curvas CxV, são extraídas informações dos parâmetros estruturais do dispositivo MOS que definiram a sensibilidade do sensor. Neste capitulo também são apresentadas as discussões sobre os resultados de imagens químicas obtidas a partir da resposta dos sensores MOS, mostrando-se o potencial deste tipo de dispositivo para sua aplicação em sistemas de nariz eletrônico.

No capitulo 5, são apresentadas as conclusões obtidas no presente trabalho, indicando suas repercussões para futuros trabalhos.

Finalmente, no Anexo A, apresentamos os códigos desenvolvidos em LabVIEW ${ }^{\circledR}$ para a aquisição dos sinais provenientes dos sensores e o controle de posicionamento $\mathrm{X} Y$ responsável pelo escaneamento do feixe de laser para obtenção dos padrões de imagens químicas. 


\subsection{Introdução e Justificativas}

O avanço desordenado na elaboração, fabricação e aplicação de produtos químicos, observado nas últimas décadas, tem sido causa de sérios problemas de poluição no meio ambiente. Vários órgãos de controle e proteção ambiental têm cobrado mecanismos mais rápidos e eficientes de controle dos processos na busca pela redução de contaminações do meio ambiente (MEIXNER et al., 1993) e (GRABER et al., 1990).

Neste contexto, a geração de imagens químicas distintivas vem sendo utilizada há muitos anos como uma importante técnica para a identificação e o monitoramento de gases, com o propósito de minimizar os possíveis danos por eles causados ao meio ambiente em sua utilização.

As respostas obtidas dos sistemas de sensores de imagem em geral são denominadas figuras químicas, mapas químicos ou imagens olfativas, dependendo da sua área de aplicação (MIZSEI, 2003). Todavia, por tratar-se o presente projeto de estudo de compostos químicos, independentemente de seus estados físicos, adotaremos aqui a denominação generalizada de "imagens químicas" para as respostas apresentadas.

GÖPEL (1998), em sua pesquisa na concepção da geração de imagens químicas, discutiu dentro de um amplo contexto, o uso da característica de arranjos de sensores químicos em uma área de sensoriamento disponível, o que torna possível o reconhecimento de várias espécies de gases como uma "impressão digital do odor", quando comparados a dados de imagens químicas previamente calibradas (MIZSEI, 2003 e FILIPPINI \& LUNDSTRÖM, 2003). Esses padrões de imagens químicas podem ser obtidos com o uso da técnica de escaneamento por luz pulsada.

Um dispositivo sensor químico de imagem é um sistema quimicamente sensível baseado em estruturas semicondutoras que possibilitam gerar um padrão bidimensional, permitindo visualizar a distribuição espacial de espécies químicas em contato com sua superfície. O princípio de geração de imagens químicas vem sendo aplicado há muitos anos em sistemas denominados narizes eletrônicos e línguas eletrônicas, em analogia a sistemas biológicos olfativos e de degustação, que basicamente se constituem de diferentes tipos de receptores distribuídos 
regularmente no sistema sensorial (YOSHINOBU, et al., 2001). Sistemas de laboratório mais sofisticados, como os cromatográficos, têm sido utilizados para o reconhecimento e determinação quantitativa de gases e líquidos (PILLING, et al.,2003). Um tipo de sensor de imagem utilizado para a detecção e o reconhecimento de gases já foi implementado com matrizes de porfirinas de diferentes estruturas moleculares, sendo o princípio de detecção deste sistema, embasado na mudança espectral do coeficiente de absorção óptica, o que resultou numa mudança de cor das moléculas, gerando, assim, imagens com diferentes padrões, como, por exemplo, as mostradas na Figura 1 (RAKOW \& SUSLICK 2000).
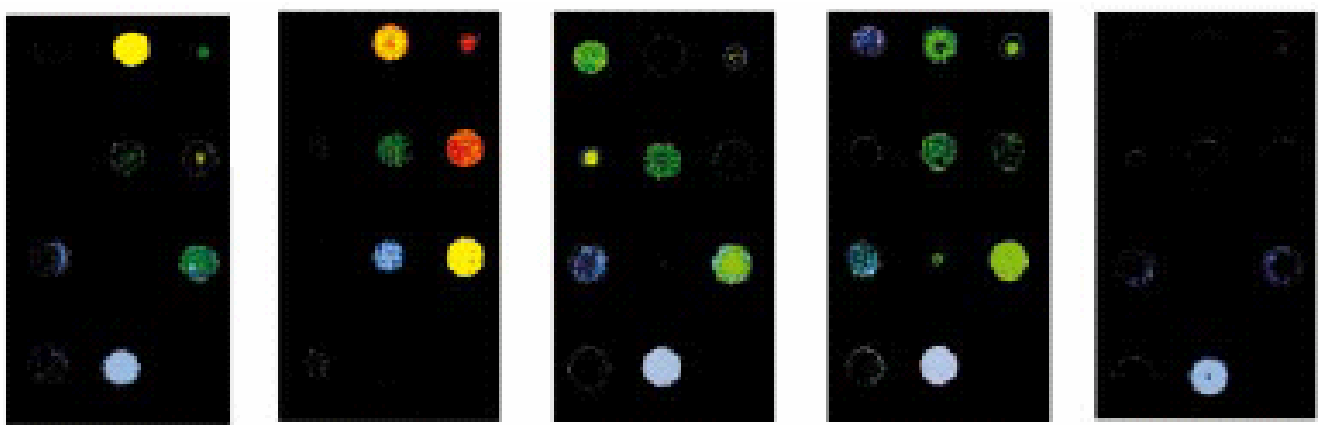

Figura 1 - Imagens químicas obtidas em ensaios com porfirinas para $\mathrm{P}\left(\mathrm{OC}_{2} \mathrm{H}_{5}\right)_{3}, \mathrm{P}\left(\mathrm{C}_{4} \mathrm{H}_{9}\right)_{3}$, $\mathrm{C}_{6} \mathrm{H}_{13} \mathrm{SH},\left(\mathrm{C}_{3} \mathrm{H}_{7}\right)_{2} \mathrm{~S}$ e acetona (RAKOW \& SUSLICK 2000).

Um outro exemplo de sensor que permite a geração de imagens químicas para a detecção de concentrações iônicas em soluções é o sensor potenciométrico de luz endereçada (LAPS), que utiliza uma estrutura Eletrólito-Isolante-Semicondutora (EIS), na qual uma tensão de polarização DC é aplicada de forma a proporcionar uma camada de depleção no semicondutor (YOSHINOBU, et al., 2001). A largura da camada de depleção depende do potencial de superfície do isolante, que varia em função do valor de $\mathrm{pH}$ ou da concentração iônica da solução em contato com a superfície sensível. A capacitância da camada de depleção pode ser lida em forma de fotocorrente AC induzida por iluminação do semicondutor com uma luz modulada. Dessa maneira, o potencial de superfície e, assim, o valor de $\mathrm{pH}$ ou a concentração iônica da solução, podem ser determinados. Na mencionada técnica, um feixe laser focalizado é empregado como uma fonte de luz para varrer a área sensível. Através da medição da fotocorrente em cada ponto, um mapa de distribuição bidimensional é obtido (LUNDSTRÖM et al., 1991). A Figura 2 ilustra o diagrama esquemático de um sensor potenciométrico de luz endereçável. 


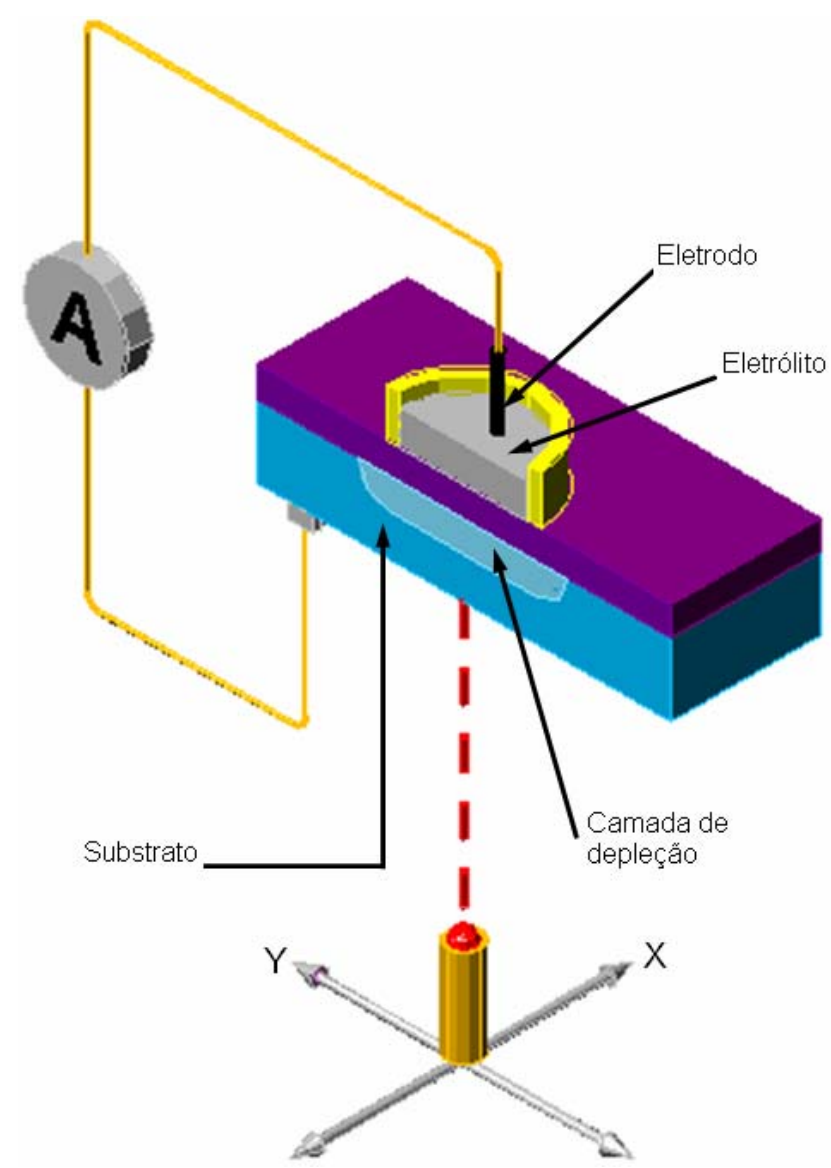

Figura 2 - Diagrama esquemático do sensor potenciométrico de luz endereçável (YOSHINOBU, et al., 2001).

Em Mizsei (1998), foi apresentado um arranjo com capacitor de vibração (método Kelvin) como uma ferramenta para medição de mudança na diferença de potencial de contato (CPD) entre um eletrodo de referência vibrante e a superfície do semicondutor. Este potencial depende da diferença entre as funções trabalho do metal-semicondutor e defeitos de interface na superfície do semicondutor. Adicionalmente, a adsorção de íons e dipolos promoverá mudança do potencial CPD, podendo ser aplicado na detecção de gases (MIZSEI \& LANTTO, 1991 \& MIZSEI, 1995). A monitoração da mudança do potencial CPD, no capacitor de vibração, é realizada através da medida da intensidade de corrente alternada (AC) tomando como referência a corrente $A C$ antes da adsorção do gás na superfície do semicondutor. Convencionalmente, a mudança do potencial CPD é medida através do monitoramento de um potencial de compensação aplicado externamente, de tal forma que o capacitor vibrante retorne a sua condição inicial. Este método apresenta algumas complicações principalmente devido à interferência da adsorção de íons ou dipolos na superfície do eletrodo metálico que em geral muda a função trabalho do 
metal. No entanto, Mizsei (2004) propôs a utilização de um sistema metal (eletrodo de referência)-óxido-semicondutor, sendo que o eletrodo de referência não fica em contato direto com a interface do óxido. Neste caso, a monitoração do potencial CPD foi realizada através da monitoração da fotocorrente induzida por uma excitação luminosa.

A geração de imagens químicas, neste caso, é possível por meio de escaneamento com a ponta do capacitor de vibração, utilizando-se ferramentas de processamento e geração de imagens computacionais.

Outra técnica empregada para esse fim é a chamada técnica de escaneamento por luz pulsada (TELP). Enquanto o método Kelvin permite investigar mudanças no potencial CPD entre o eletrodo metálico e a superfície do semicondutor, a técnica de escaneamento por luz pulsada (TELP) utiliza mecanismo de deteç̧ão das mudanças nas características da interface isolante-semicondutor em uma estrutura Metal-Óxido-Semicondutor (MOS).

DISTEFANO \& VIGGIANO (1974) desenvolveram um método para a investigação das propriedades das interfaces da estrutura MOS, baseado na fotoemissão e na foto-tensão induzida na interface isolante-semicondutor do dispositivo. A técnica TELP tem sido utilizada com sucesso no estudo de defeitos de interface e íons na camada isolante. Neste contexto, ENGSTRÖM \& CARLSSON (1983) apresentaram estudos da TELP para determinar a concentração de defeitos de rede na superfície do silício e concentração de íons de sódio na camada de óxido de silício. O processo de medida consistiu na monitoração dos pulsos de intensidade de fotocorrente induzida pela excitação do capacitor MOS com uma fonte de luz pulsada.

Em FILIPPINI (2002), o método TELP foi empregado para detecção de gases utilizando-se estruturas MOS com diferentes eletrodos metálicos como porta sensível do dispositivo. Nesse trabalho, os autores reportaram a utilização de uma tela de computador de tubo de raios catódicos padrão como fonte de fotoexcitação do dispositivo com precisão espacial da ordem de pixels, possibilitando um fácil controle computacional da varredura de fotoexcitação. A porta dos dispositivos MOS foi constituída de eletrodos catalíticos de platina e paládio numa geometria espacialmente distribuída. A realização do escaneamento foi realizado com um feixe de luz branca de seção quadrada de $4 \mathrm{~mm}$ de lado sobre a superfície do detector. Essa luz realizou varreduras simétricas numa região quadrada de $35 \mathrm{~mm}$ de lado, que foram divididas em 100 passos para cada lado, produzindo uma amostragem de 
10000 medições sobre a superfície do detector. Para cada sinal emitido pela tela do computador, observou-se um sinal de corrente que proporcionou a formação de imagens químicas demonstradas simultaneamente em um outro campo da tela (Figura 3).

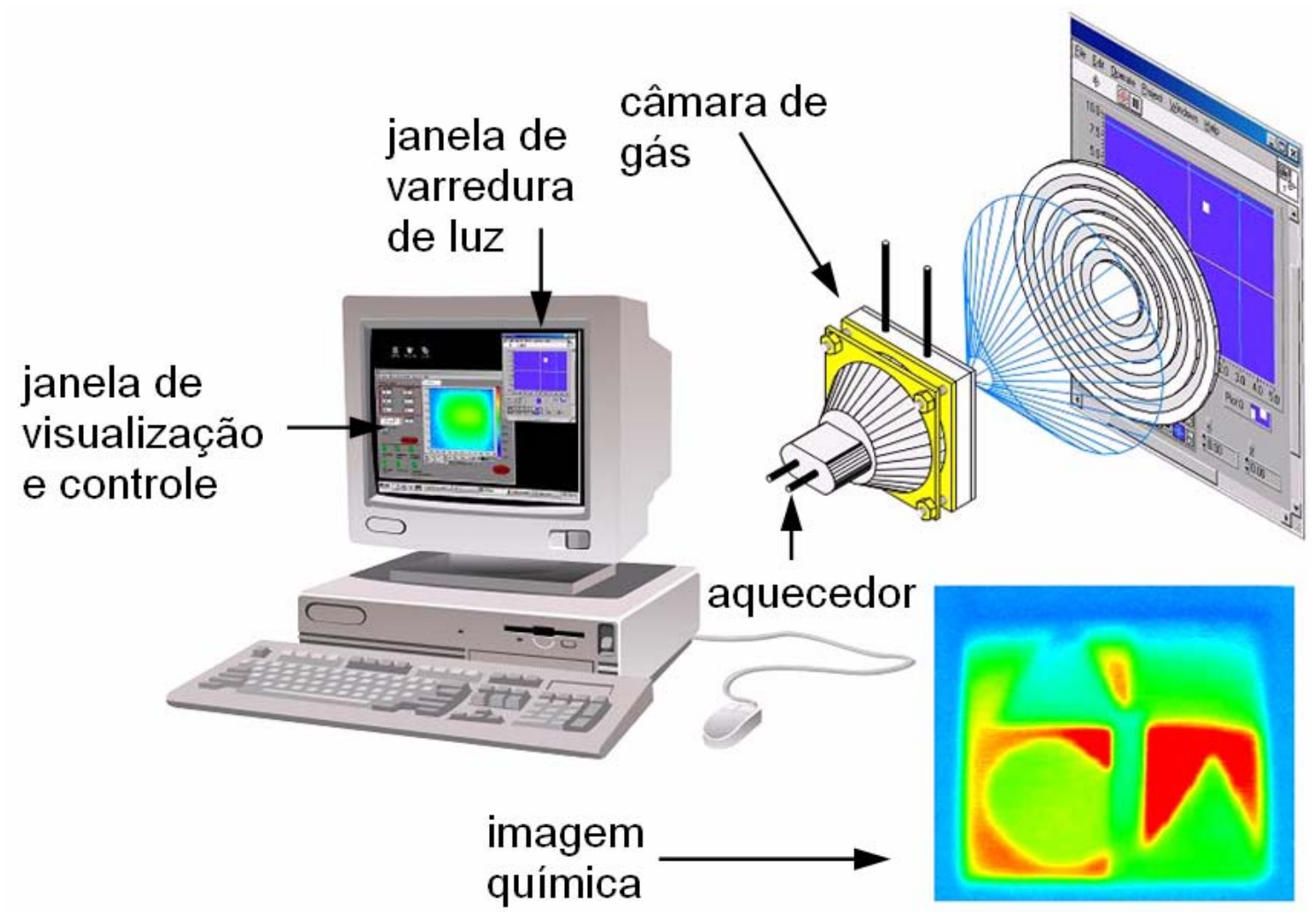

Figura 3 - Esquema da TELP obtido por um monitor de tubo de raios catódicos (FILIPPINI, 2002).

As propriedades elétricas das estruturas MOS e sua interação com meios gasosos, quando a eles expostas, têm sido objeto de estudos desde a década de 70 (LUNDSTRÖM, 1975), sendo aprimorados até os dias atuais para a melhoria dos resultados analíticos e das técnicas de detecção de hidrogênio (SPETZ, et al., 1988) e (LUNDSTRÖM, 1981), amônia (WINQUIST, et al.,1983), dióxido de nitrogênio (FILLIPINI, et al., 2001a \& FILLIPINI, 2001b), sulfeto de hidrogênio, (SHIRAVAMAN, 1976), monóxido de carbono (ZUBKANS, et al., 1995), vapores orgânicos e hidrocarbonetos (HORNIK, 1990), além de medidas dos estados de superfície, através da medição quase-estática $\mathrm{CxV}$ e estudos da fotoemissão.

Como parte da utilização dos dispositivos de efeito de campo na deteç̧ão de diferentes gases, os capacitores MOS com portas de paládio têm se tornado alvo da implementação de técnicas que possibilitam uma análise qualitativa e quantitativa das concentrações de vários compostos químicos, em especial o hidrogênio, 
apresentando grandes vantagens por sua simplicidade de fabricação, baixo custo, elevada estabilidade, baixos níveis de histereses e resistência a ambientes corrosivos (WAGNER \& WIRTH, 2000). Entretanto, quando o paládio se encontra em um ambiente de oxigênio, algumas reações indesejáveis na superfície poderão acontecer, comprometendo significativamente sua eficiência como elemento sensor a compostos que tenham o hidrogênio na sua estrutura molecular, pois o hidrogênio prefere combinar-se com o oxigênio adsorvido para a formação de água. Isso acontece devido à grande mobilidade lateral do hidrogênio que se desloca pela superfície do paládio (PETERSSON, 1984).

$\mathrm{Na}$ Figura 4 é ilustrado um dispositivo MOS com porta de paládio, recoberto com oxigênio e exposto ao hidrogênio.

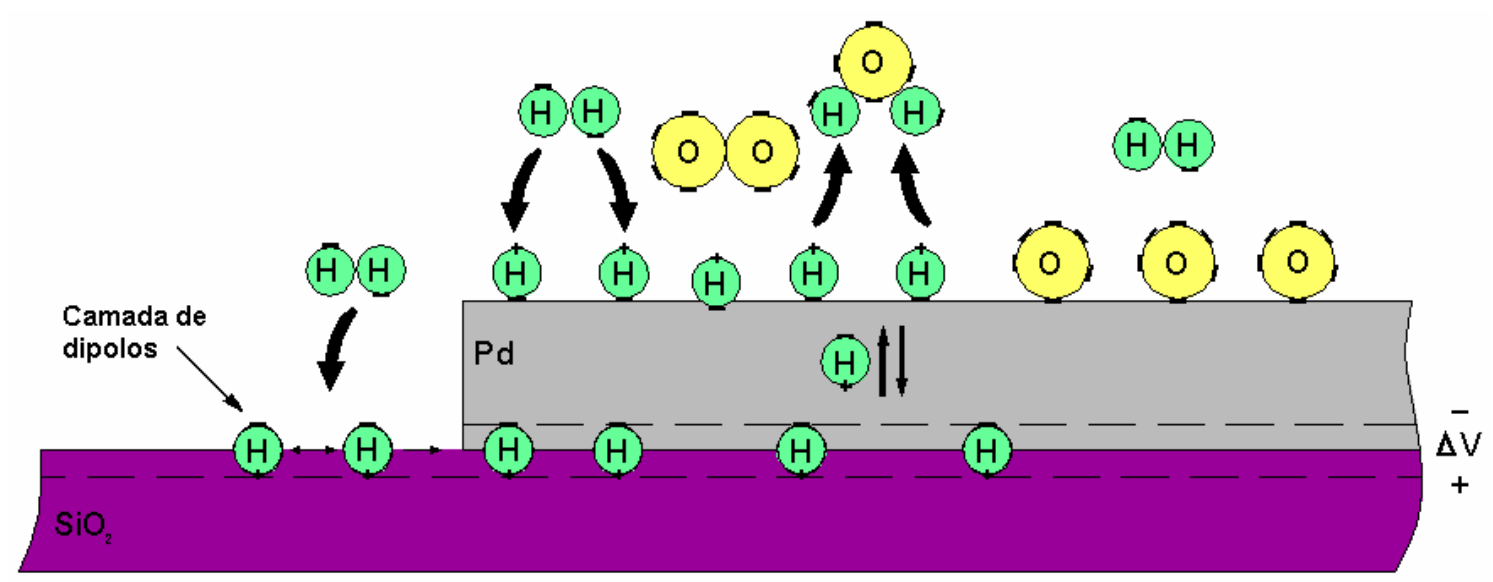

Figura 4 - Dispositivo Pd-MOS recoberto com oxigênio e exposto ao hidrogênio (PETERSSON, 1984).

A técnica de escaneamento por luz pulsada (TELP) se apresenta como uma das soluções possíveis para esse problema, uma vez que a luz incide sobre diferentes arranjos de áreas grandes das portas metálicas catalíticas para produzir imagens químicas características para as misturas gasosas (LUNDSTRÖM et al., 1991). Dessa forma, as respostas obtidas possuem uma diversidade de variáveis pontuais que torna desprezível, para o reconhecimento dos padrões, a interferência do oxigênio presente na atmosfera.

Além disso, tais imagens fornecem padrões complexos de respostas, devido a diferentes sensibilidades e variações na seletividade das partes que compõem as portas metálicas que agem como superfícies sensíveis do dispositivo. Esta sensibilidade distinta ocorre, muito provavelmente, por causa das mudanças locais de temperatura, bem como das constantes reações químicas que acontecem na 
superfície do dispositivo, e das variações na ação catalítica dos diferentes metais. Uma outra causa provável de alteração na resposta do dispositivo, está na possível mudança da composição do gás em contato com o filme. Portanto, dada a complexidade do princípio de detecção, o potencial da técnica da exploração de superfícies de estruturas MOS pela varredura de um feixe luminoso pulsado mostrase vantajosa para medir localmente a resposta do dispositivo (LÖFDAHL, 1999). Isto oferece duas vantagens:

- Efeito de difusão lateral em dispositivos com portas metálicas com descontinuidade: A TELP, como já discutido anteriormente, permite o monitoramento local do processo de interação dispositivo-gás, ou seja, a resposta do dispositivo depende da composição local da mistura do gás sobre a superfície sensível. No entanto, em dispositivos com portas metálicas com descontinuidade existe a possibilidade de que o elemento sensibilizador $(H)$ possa deslocar-se lateralmente através de um processo de difusão, a partir da tríplice interface isolante-metal-ambiente (Figura 4). Como resultado desta difusão lateral, mesmo as regiões passivadas $\left(\mathrm{CO}, \mathrm{O}_{2}\right)$ poderão ser sensibilizadas (LUNDSTRÖM et al., 2007). Esta característica pode, por exemplo, ser usada para estudar reações químicas e fenômenos de difusão nas superfícies do metal, além de ser aplicada em um projeto de sistemas de sensibilidade química distribuída, onde a seletividade da disposição de sensores químicos discretos é realçada pela variação catalítica ao longo do arranjo geométrico do sensor (EKLÖV, 1997 \& EKLÖV, 1999). Com esta técnica, uma grande variedade de configurações geométricas de porta de um mesmo metal pode ser testada facilmente num único dispositivo.

- Dispositivos com portas de diferentes metais e descontínuas: A segunda vantagem da TELP, associada a sua característica de sensibilidade local, pode ser otimizada, utilizando-se, neste caso, diferentes tipos de metais catalíticos na porta descontínua do dispositivo, constituindo um mosaico de diferentes metais (HUGHES, 1987 \& HUGHES, 1992).

Adicionalmente, a TELP, associada à formação de imagens químicas, possibilita a utilização de filmes metálicos com gradiente de espessura, proporcionando padrões de resposta que dependem da característica catalítica e espessura dos filmes metálicos utilizados como porta do dispositivo (LÖFDAHL 2000). LÖFDAHL et al. reportaram a utilização de filmes metálicos como o paládio, platina e irídio com 
espessura em gradiente tendo obtido imagens químicas diferentes para os diferentes gases analisados $\left(\mathrm{H}_{2}, \mathrm{NH}_{3}, \mathrm{C}_{2} \mathrm{H}_{5} \mathrm{OH}, \mathrm{C}_{2} \mathrm{H}_{4}\right)$. Na Figura 5 é mostrado um diagrama esquemático deste tipo de dispositivo.

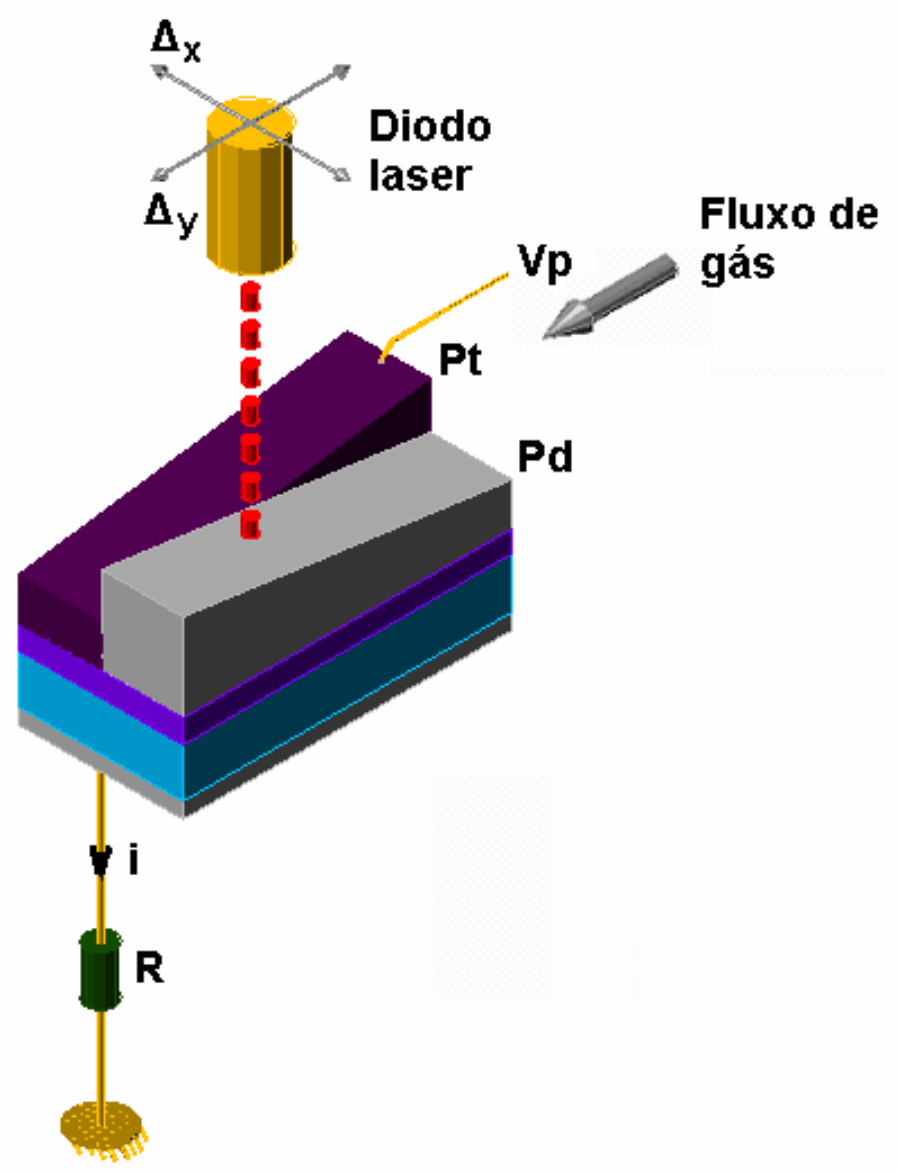

Figura 5 - Estrutura MOS com portas metálicas paralelas com variação de espessura em direções opostas (LÖFDAHL, 2000).

Dentro deste contexto, a proposta do presente trabalho foi o projeto e desenvolvimento de um dispositivo MOS para detecção de gases baseada na técnica de escaneamento por luz pulsada (TELP), proporcionando a formação de imagens químicas a partir da intensidade de fotocorrente induzida no dispositivo. Para tal fim, as estruturas MOS foram fabricadas com diferentes filmes metálicos catalíticos ( $\mathrm{Pd}$ e $\mathrm{Au}$ ), às quais foi dada maior ênfase quanto as suas características fotossensíveis, apresentando-a como uma técnica de alto potencial para instrumentação analítica. 


\section{FUNDAMENTOS TEÓRICOS}

\subsection{Estrutura MOS}

O dispositivo MOS constitui-se numa estrutura formada por metal, óxido e semicondutor (Figura 6). Normalmente, o material isolante (óxido) pode ser óxido de silício ou oxinitreto de silício (NICHOLLIAN, 1982), porém podem ser utilizados outros materiais para o mesmo efeito. Por isso, a literatura costuma reportar essa camada simplesmente por isolante, levando a estrutura a ser também denominada como MIS.

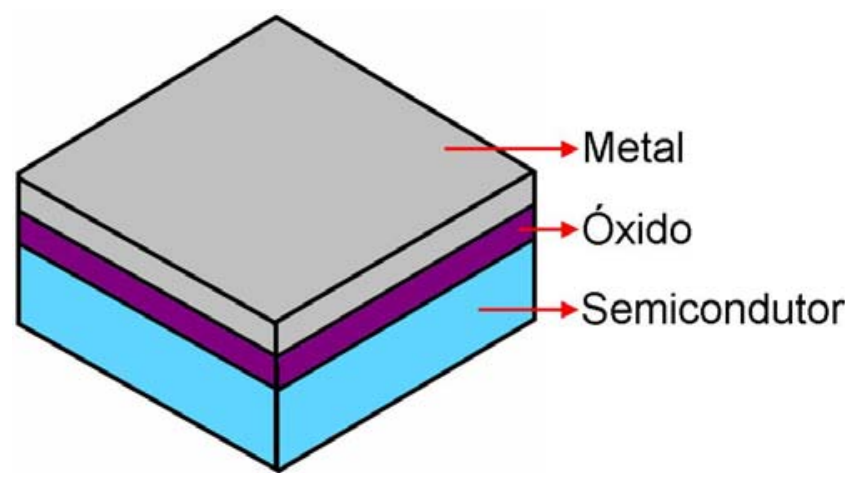

Figura 6 - Estrutura MOS.

Considerando que a camada metálica e o semicondutor são bons condutores, a estrutura MOS também é usualmente chamada de capacitor MOS. Esse capacitor apresenta uma diferença em relação aos capacitores tradicionais: ter uma das placas condutoras substituída pelo semicondutor. Os capacitores convencionais, constituídos de dois eletrodos metálicos, apresentam uma capacitância totalmente dependente das suas características geométricas e da característica do dielétrico utilizado. No caso dos capacitores MOS, os eletrodos são constituídos por uma região semicondutora e outra metálica (porta). A região semicondutora apresenta uma região de carga espacial de largura modulável por polarização externa. Desta forma, a capacitância do dispositivo MOS ideal pode ser modelada por dois capacitores em série, um correspondente ao eletrodo metálico e outro correspondente à região de carga espacial do semicondutor. Assim, a capacitância total passa a depender da tensão aplicada nos terminais do capacitor, gerando uma 
curva característica de capacitância em função da tensão (curva CxV). Adicionalmente, a capacitância MOS depende da freqüência do sinal de excitação devido ao tempo de relaxamento dos portadores no semicondutor. A Figura 7 apresenta um esboço das curvas CxV de um capacitor MOS de semicondutor tipo P para sinais de excitação de baixa e alta freqüência, respectivamente, em função da tensão de polarização.

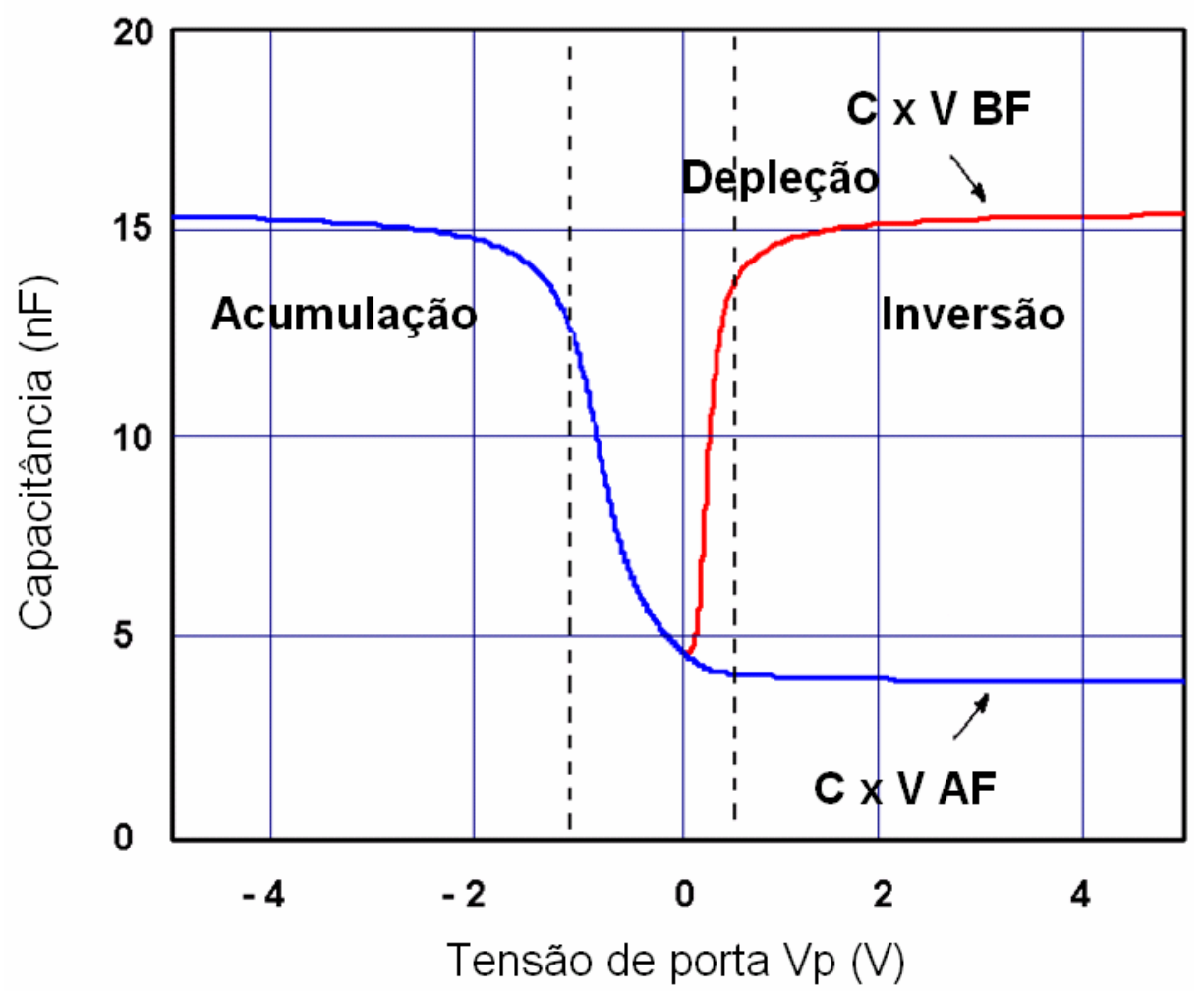

Figura 7 - Curva CxV - alta freqüência e baixa freqüência de um capacitor MOS (ALBERTIN, 2003).

A Figura 8 mostra o diagrama de bandas de energia e de cargas espaciais para um capacitor MOS.

No caso do dispositivo MOS em silício tipo P, o estado de acumulação (Figura 8-a) acontece quando a porta está polarizada negativamente em relação à tensão de banda plana (tensão na qual a região de carga espacial no silício desaparece). Como conseqüência, os portadores majoritários (lacunas) se acumulam numa faixa muito fina da interface $\mathrm{SiO}_{2} / \mathrm{Si}$ desaparecendo praticamente a camada de depleção, e isto faz com que a capacitância do dispositivo seja máxima nesta região (Figura 7) independentemente da freqüência do sinal de excitação. Em polarizações positivas, o semicondutor apresenta um outro efeito chamado de estado de inversão (Figura 8c). Neste caso, os portadores minoritários (elétrons) são concentrados numa camada 
fina da interface $\mathrm{SiO}_{2} / \mathrm{Si}$. Neste estado, a capacitância em alta freqüência apresenta seu valor mínimo, pois os portadores minoritários apresentam um tempo de relaxamento maior que ao período do sinal de excitação. No entanto, a capacitância de baixa freqüência atinge um valor próximo à capacitância máxima (Figura 7), já que os portadores, neste caso, podem relaxar-se completamente. Na região de transição do estado de acumulação para a inversão, o dispositivo passa pelo estado de depleção, ou seja, a camada de depleção aumenta sua largura até atingir um valor máximo (início de inversão), promovendo um decrescimento no valor da sua capacitância (Figura 7 e Figura 8-b).

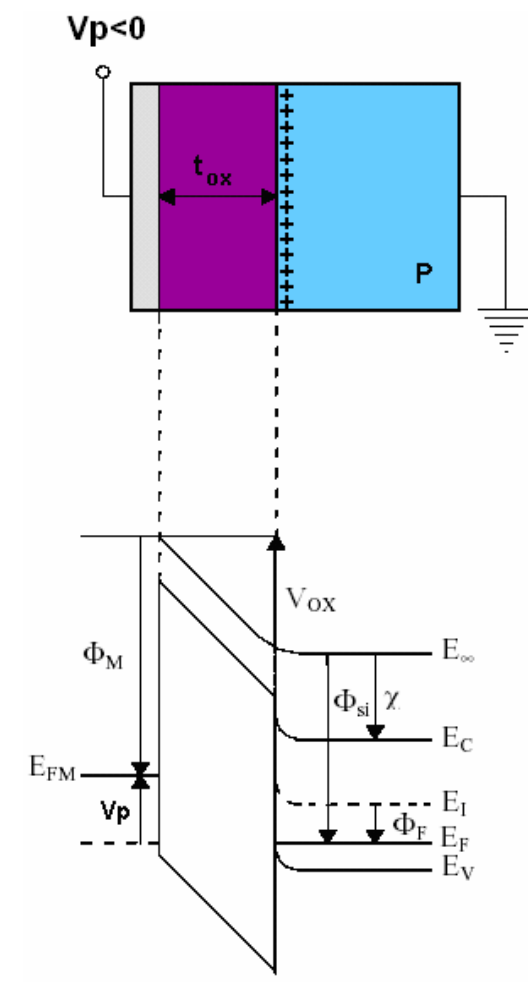

a)

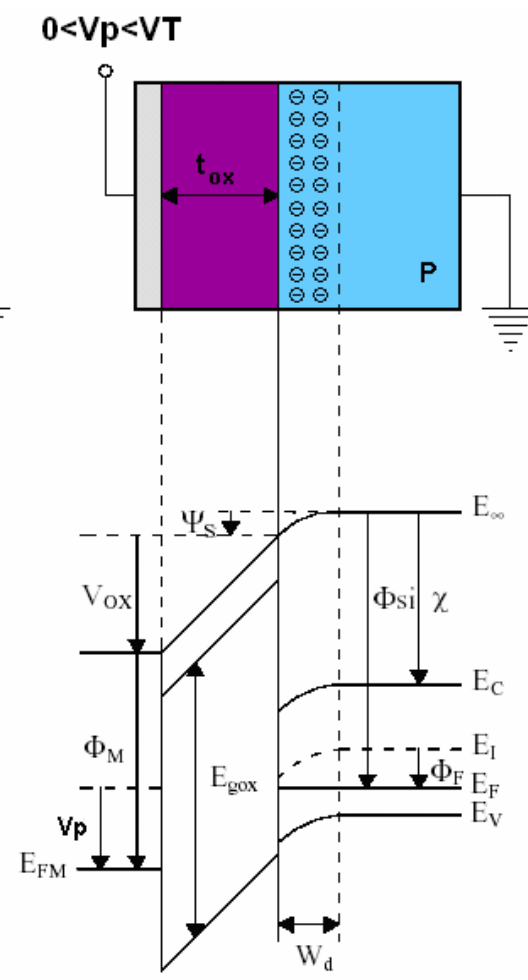

b)

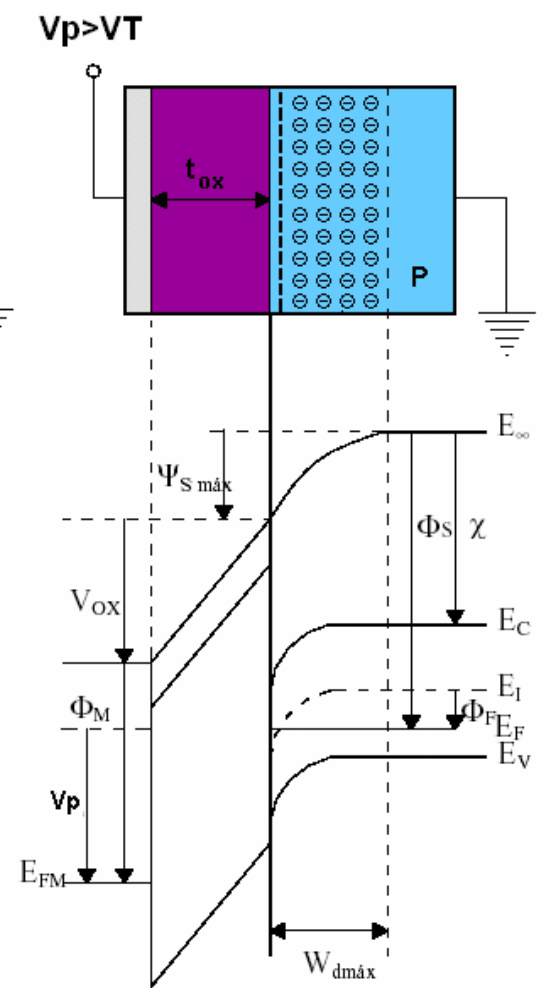

c)

Figura 8 - Diagrama de bandas de energia e de cargas espaciais para um capacitor MOS em (a) acumulação, (b) depleção e (c) inversão (ALBERTIN, 2003).

A partir das medidas experimentais CxV podem ser extraídos parâmetros tecnológicos do dispositivo MOS desde que conhecidas as dimensões geométricas do dispositivo. Em particular, a partir da curva CxV em alta freqüência, podem ser extraídos os parâmetros descritos a seguir: 
2.1.1 Cálculo de espessura do óxido, $x_{o x}$

$$
\begin{gathered}
C \max =C o x=\frac{C a}{\text { Area }} \\
t_{o x}=\frac{\varepsilon_{o x}}{C_{o x}}
\end{gathered}
$$

2.1.2 Cálculo da largura máxima da camada de depleção, $\mathbf{W}_{\text {dmáx }}$

$$
W d_{\max }=A \cdot \varepsilon_{s i}\left(\frac{C_{\text {máx }}-C_{\text {min }}}{C_{\text {máx }} \cdot C_{\text {min }}}\right)
$$

2.1.3 Cálculo da concentração de portadores majoritários do substrato, $\mathbf{N}_{\mathrm{A}}$

Para a obtenção do valor de $\mathrm{N}_{\mathrm{A}}{ }^{*}$, atribui-se um valor inicial a $\mathrm{N}_{\mathrm{A}}{ }^{*}$, utilizando-o recursivamente até que haja consistência entre os dois parâmetros $N_{A}^{*}$ da equação.

$$
N_{A}^{*}=\frac{4 \cdot \varepsilon_{s i}}{q \cdot d^{2} \max } \cdot \frac{k \cdot T}{q} \cdot \ln \frac{N_{A} *}{n_{i}}
$$

2.1.4 Cálculo da capacitância de banda plana, $\mathrm{C}_{\mathrm{FB}}$

$$
C_{F B}=\frac{\varepsilon_{o x}}{t_{o x+\frac{\varepsilon_{o x}}{\varepsilon_{s i}}} \cdot \sqrt{\frac{k \cdot T \cdot \varepsilon_{s i}}{q^{2} \cdot N_{A} *}}}
$$




\subsubsection{Determinação da tensão de banda plana, $\mathrm{V}_{\mathrm{FB}}$}

Localizando-se $\mathrm{o}$ valor de $\mathrm{C}_{\mathrm{FB}}$ no gráfico da curva $\mathrm{CxV}$ (alta freqüência), determinamos a abscissa que corresponde à tensão de banda plana aplicada à porta, $\mathrm{V}_{\mathrm{FB}}$.

\subsubsection{Cálculo da densidade efetiva de cargas no óxido, $\left(Q_{s s} / q\right)$}

$$
\begin{gathered}
V_{F B}=-\frac{Q_{s s}}{C_{o x}}+\phi_{W S} \\
\frac{Q S S}{q}=\frac{\left(\phi_{W S}-V_{F B}\right)}{q} \cdot \frac{\varepsilon_{o x}}{t_{o x}}
\end{gathered}
$$

\subsubsection{Cálculo da tensão de limiar, $\mathrm{V}_{\mathrm{T}}$ (início da inversão)}

$$
V_{T}=\frac{q \cdot N_{A} \cdot d_{\max }}{C_{o x}}+2 \cdot \phi_{F}-\frac{Q_{s s}}{C_{o x}}+\phi_{M S}
$$

\subsection{Estrutura MOS sensíveis a hidrogênio e amônia}

Quando uma estrutura Pd-MOS é exposta a uma atmosfera com gases que contêm hidrogênio na sua estrutura molecular, por exemplo, $\mathrm{H}_{2}$ e $\mathrm{NH}_{3}$ (BARATTO, 1993), podem haver reações que permitam a liberação do hidrogênio atômico para que este seja adsorvido na superfície do metal e posteriormente difundido por ele até atingir a interface metal-SiO 2 .

Se considerarmos uma atmosfera inerte com gás hidrogênio, como a utilizada na implementação deste trabalho, uma das reações que acontecem na superfície do paládio é a dissociação da molécula de hidrogênio liberando seus átomos para 
serem adsorvidos e difundidos pelo metal até atingirem a interface $\mathrm{Pd}-\mathrm{SiO}_{2}$, gerando-se dipolos nesta interface como ilustrado na Figura 4.

A camada de dipolos formada pelos átomos de hidrogênio na interface metal-SiO produz uma diferença de potencial $\Delta \mathrm{V}$. Se a estrutura MOS for polarizada com uma tensão externa $\vee p$, como mostrado na Figura 9, essa d.d.p. criada pela camada de dipolos é somada à tensão de polarização, aumentando a largura da camada de depleção (Wd) no substrato do semicondutor (LUNDSTRÖM et al., 2007). Dessa forma, considerando a largura da camada de depleção causada pela tensão de polarização $\mathrm{Vp}$ como sendo $\mathrm{Wd}$, com a formação da camada de dipolos pelos átomos de hidrogênio difundidos, a largura da camada de depleção aumenta em Wdh (Figura 9).

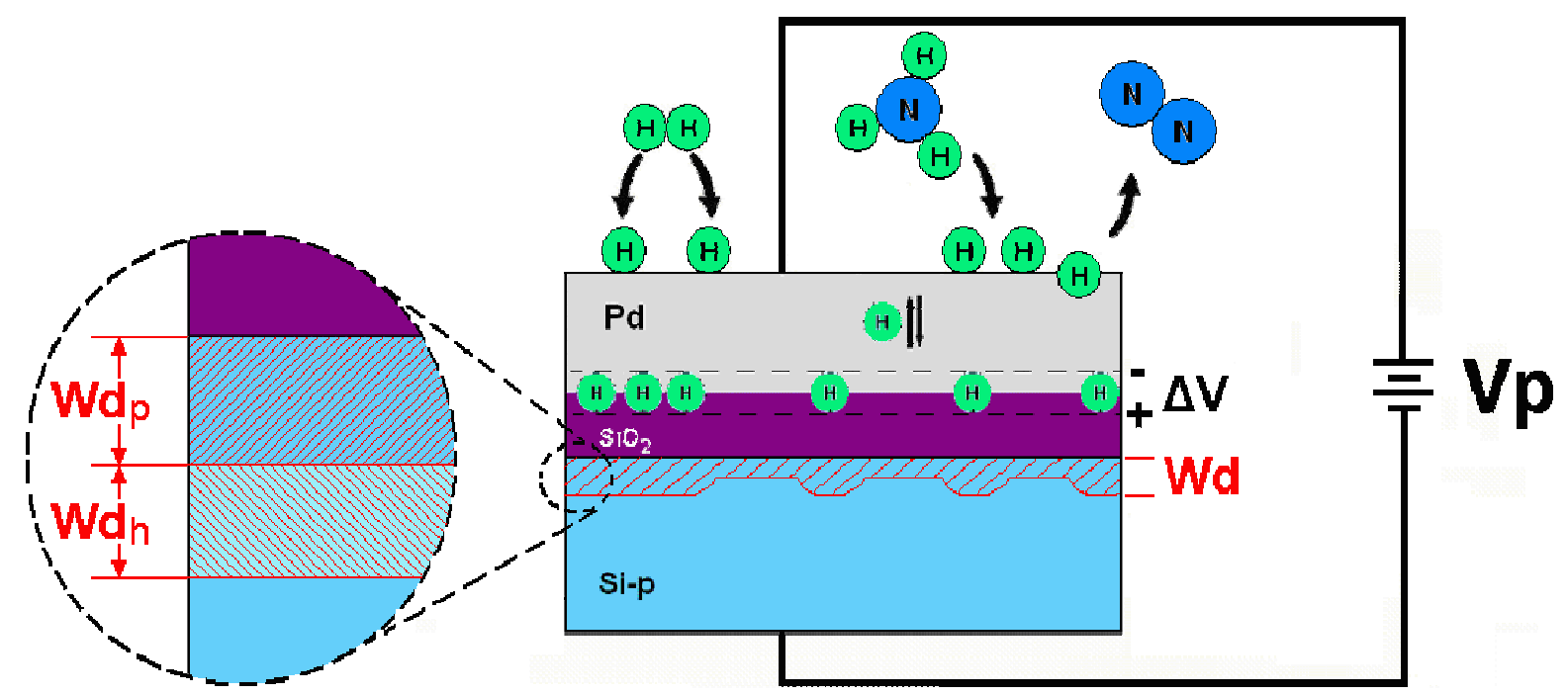

Figura 9 - Polarização de uma estrutura Pd-MOS e a tensão $\Delta V$ criada pela camada de dipolos formada na interface metal/óxido.

A tensão $\Delta \mathrm{V}$ pode ser observada também na caracterização $\mathrm{CxV}$ do dispositivo nas condições de atmosfera inerte e com presença de hidrogênio (Figura 10). 


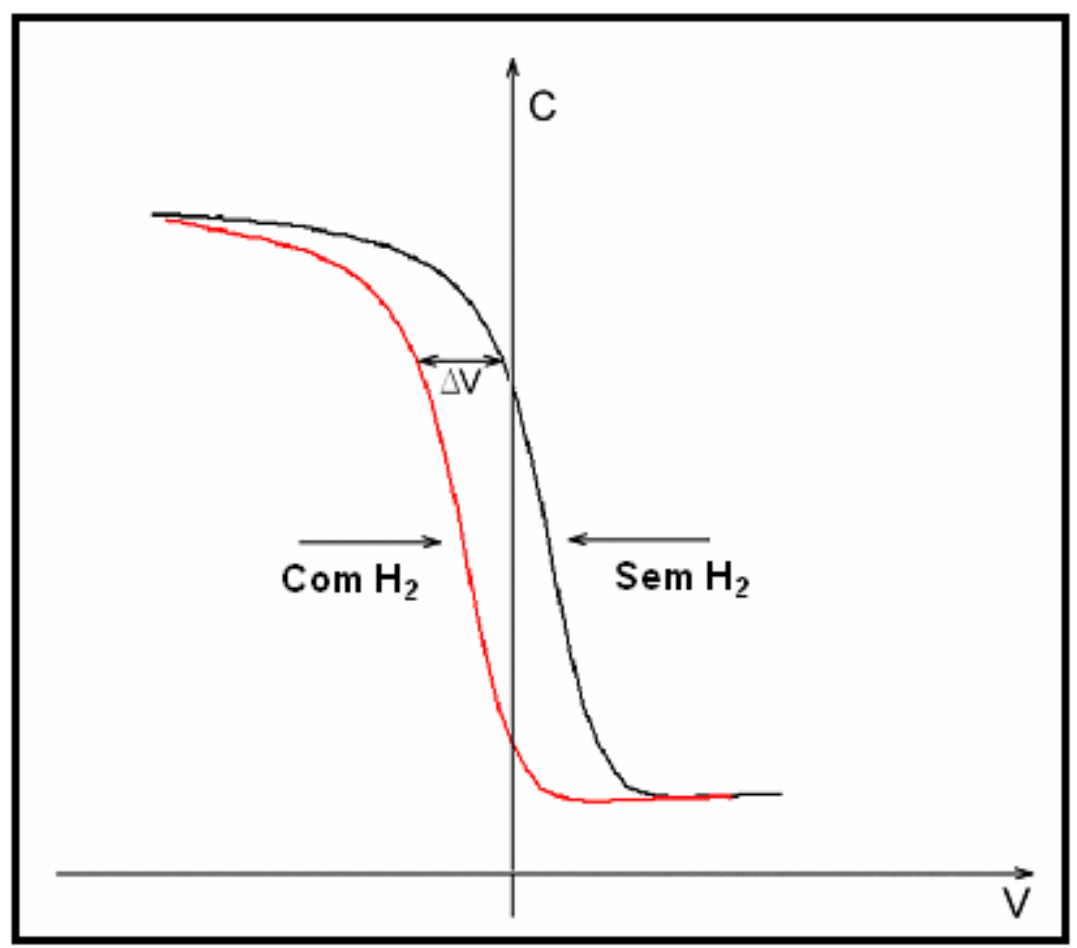

Figura 10 - Deslocamento da curva CxV provocado pela presença de uma camada de dipolos na interface metal/óxido.

Se o dispositivo for excitado com um feixe de fótons de energia igual ou maior que da banda proibida do silício então serão gerados pares elétrons-lacunas no substrato de silício; os portadores gerados na região da camada de depleção estarão sujeitos à ação de um campo elétrico podendo ser separados e assim contribuir com o aparecimento de uma fotocorrente. Desta forma, quanto mais larga a camada de depleção, mais intensa será a fotocorrente gerada. Como discutido acima, a adsorção de íons de $\mathrm{H}^{+}$na interface metal/ $\mathrm{SiO}_{2}$ do dispositivo promove mudança na largura da camada de depleção, o que será refletido na fotocorrente gerada para a detecção do gás de $\mathrm{H}_{2}$ no ambiente analisado.

No entanto, é importante mencionar que num ambiente de $\mathrm{N}_{2}$ e $\mathrm{H}_{2}$ existe a possibilidade de formação de amônia através da combinação do nitrogênio com o hidrogênio catalisado pelo paládio (LUNDSTRÖM, 1977) e vice-versa. Dessa maneira, considerando amônia diluída em atmosfera inerte de nitrogênio para filmes de $\mathrm{Pd}$, existe a formação de hidrogênio, passível de ser difundido. Essa reação, propiciada pela alta capacidade catalítica do paládio, possibilita a detecção de amônia usando estruturas Pd-MOS pelo princípio de detecção de hidrogênio (Figura 11). 


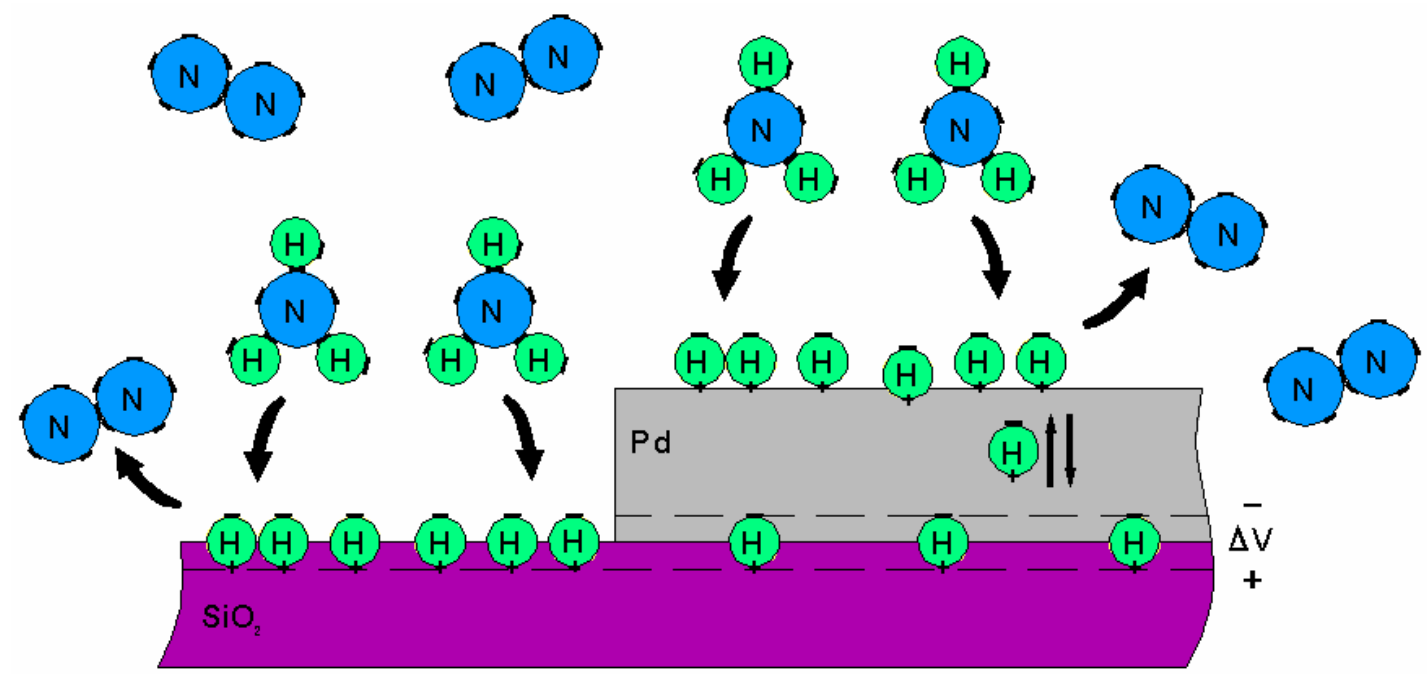

Figura 11 - Reação de formação de amônia através da combinação do nitrogênio, hidrogênio e o paládio e vice-versa.

As etapas possíveis dessa reação são descritas na seguinte expressão (LUNDSTRÖM et al., 1975):

$$
\begin{aligned}
& \mathrm{H}_{2 \mathrm{~g}} \underset{\mathrm{D}_{1}}{\stackrel{\mathrm{C}_{1}}{\rightleftarrows}} 2 \mathrm{H}_{\mathrm{ae}} \stackrel{\mathrm{C}_{\mathrm{e}}}{\rightleftarrows} 2 \mathrm{H}_{\mathrm{b}} \underset{\mathrm{D}_{\mathrm{e}}}{\stackrel{\mathrm{C}_{\mathrm{i}}}{\rightleftarrows}} 2 \mathrm{H}_{\mathrm{ai}} \\
& \mathrm{N}_{2 \mathrm{~g}}+2 \mathrm{H}_{\mathrm{ae}} \stackrel{\mathrm{C}_{2 n}}{\underset{\mathrm{D}_{2 n}}{\leftrightarrows}} 2(\mathrm{NH})_{\mathrm{ae}} \\
& (\mathrm{NH})_{\mathrm{ae}}+\mathrm{H}_{\mathrm{ae}} \stackrel{\mathrm{C}_{3 n}}{\rightleftarrows}\left(\mathrm{NH}_{2}\right)_{\mathrm{ae}} \\
& \left(\mathrm{NH}_{2}\right)_{\mathrm{ae}}+\mathrm{H}_{\mathrm{ae}} \underset{\mathrm{D}_{4 n}}{\stackrel{\mathrm{C}_{4 n}}{\rightleftarrows}} \mathrm{NH}_{3 \mathrm{~g}}
\end{aligned}
$$

Em atmosferas que contêm oxigênio, este pode reagir com o hidrogênio adsorvido formando água, reduzindo assim a capacidade de adsorção de gases do dispositivo (LUNDSTRÖM et al., 2007).

As etapas dessa reação são apresentadas na expressão a seguir (LUNDSTRÖM, 1989):

$$
\begin{aligned}
& \mathrm{H}_{2 \mathrm{~g}} \underset{\mathrm{D}_{1}}{\stackrel{\mathrm{C}_{1}}{\rightleftarrows}} 2 \mathrm{H}_{\mathrm{ae}} \underset{\mathrm{D}_{\mathrm{e}}}{\stackrel{\mathrm{C}_{\mathrm{e}}}{\rightleftarrows}} 2 \mathrm{H}_{\mathrm{b}} \underset{\mathrm{D}_{\mathrm{i}}}{\stackrel{\mathrm{C}_{\mathrm{i}}}{\rightleftarrows}} 2 \mathrm{H}_{\mathrm{ai}} \\
& \mathrm{O}_{2 \mathrm{~g}} \underset{\mathrm{D}_{\mathrm{o}}}{\stackrel{\mathrm{C}_{0}}{\rightleftarrows}} 2 \mathrm{O}_{\mathrm{ae}} \\
& \mathrm{O}_{2 \mathrm{~g}}+2 \mathrm{H}_{\mathrm{ae}} \underset{\mathrm{D}_{20}}{\stackrel{\mathrm{C}_{20}}{\rightleftarrows}} 2(\mathrm{OH})_{\mathrm{ae}} \\
& (\mathrm{OH})_{\mathrm{ae}}+\mathrm{H}_{\mathrm{ae}} \underset{\mathrm{D}_{30}}{\stackrel{\mathrm{C}_{30}}{\rightleftarrows}}\left(\mathrm{H}_{2} \mathrm{O}\right)_{9}
\end{aligned}
$$


A presença de outras moléculas também pode influenciar na resposta do sensor ao hidrogênio. Por exemplo, se $\mathrm{CO}$ for adsorvido sobre a porta de paládio $(\mathrm{Pd})$ do dispositivo, existirá uma repulsão entre $\mathrm{CO}$ e hidrogênio promovendo uma diminuição na concentração de hidrogênio sobre a superfície sensível do dispositivo (ERIKSSON \& EKEDAHL, 1997 e ERIKSSON \& EKEDAHL, 1998). Uma monocamada adsorvida de $\mathrm{CO}$ pode inibir a adsorção e dessorção de hidrogênio no interior do filme metálico de Pd. O CO pode então ser usado como uma "válvula química" para absorção de hidrogênio, Figura 12.
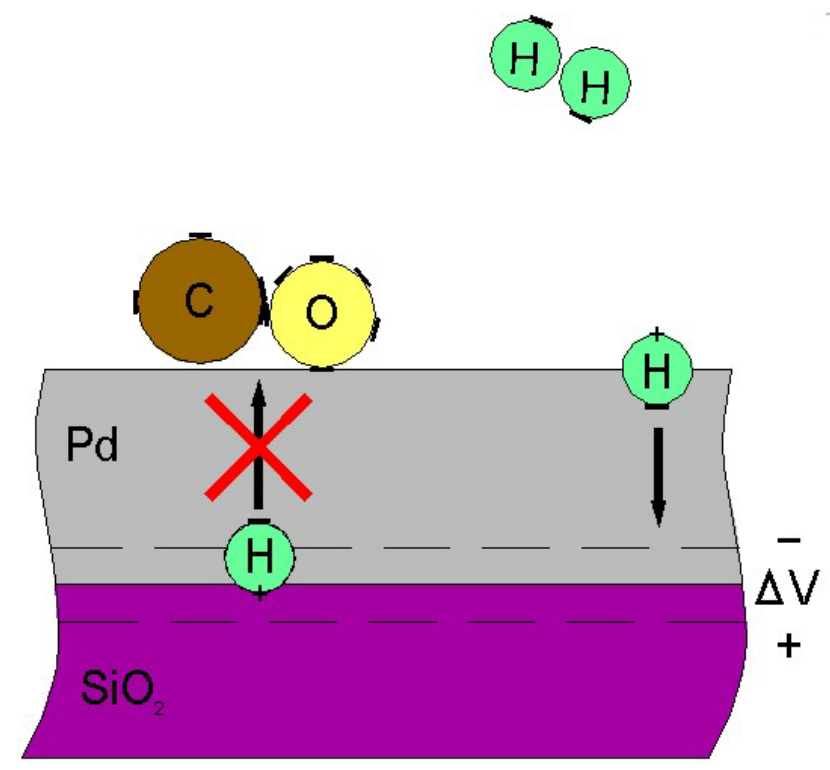

Figura 12 - Monocamada de CO interrompendo a interação do hidrogênio em estruturas PdMOS.

\subsection{Técnica de escaneamento por luz pulsada}

A técnica de escaneamento por luz pulsada (TELP) é uma alternativa para dispositivos discretos (FILIPPINI \& LUNDSTRÖM, 2001), que possibilita o estudo de dispositivos de efeito de campo (MOS - Metal-Óxido-Semicondutor). Esta técnica pode ser aplicada na detecção de substâncias químicas através da sua resposta em um padrão de imagem. Para tal fim, os dispositivos são fabricados utilizando-se diferentes metais catalíticos (portas ativas) que promovam mudanças significativas do potencial de superfície do semicondutor após ser submetido a ambientes com substâncias gasosas ou líquidas. O princípio da técnica está baseado na geração de uma fotocorrente na região de depleção do semicondutor após a incidência de um 
feixe de luz pulsado de intensidade constante e comprimento de onda fixo. A imagem química bidimensional é obtida após uma varredura do feixe sobre a superfície metálica da estrutura MOS. A varredura é realizada por meio de um sistema de posicionamento. Um diagrama esquemático da implementação desta técnica é mostrada na Figura 13 (LUNDSTRÖM et al., 1991).

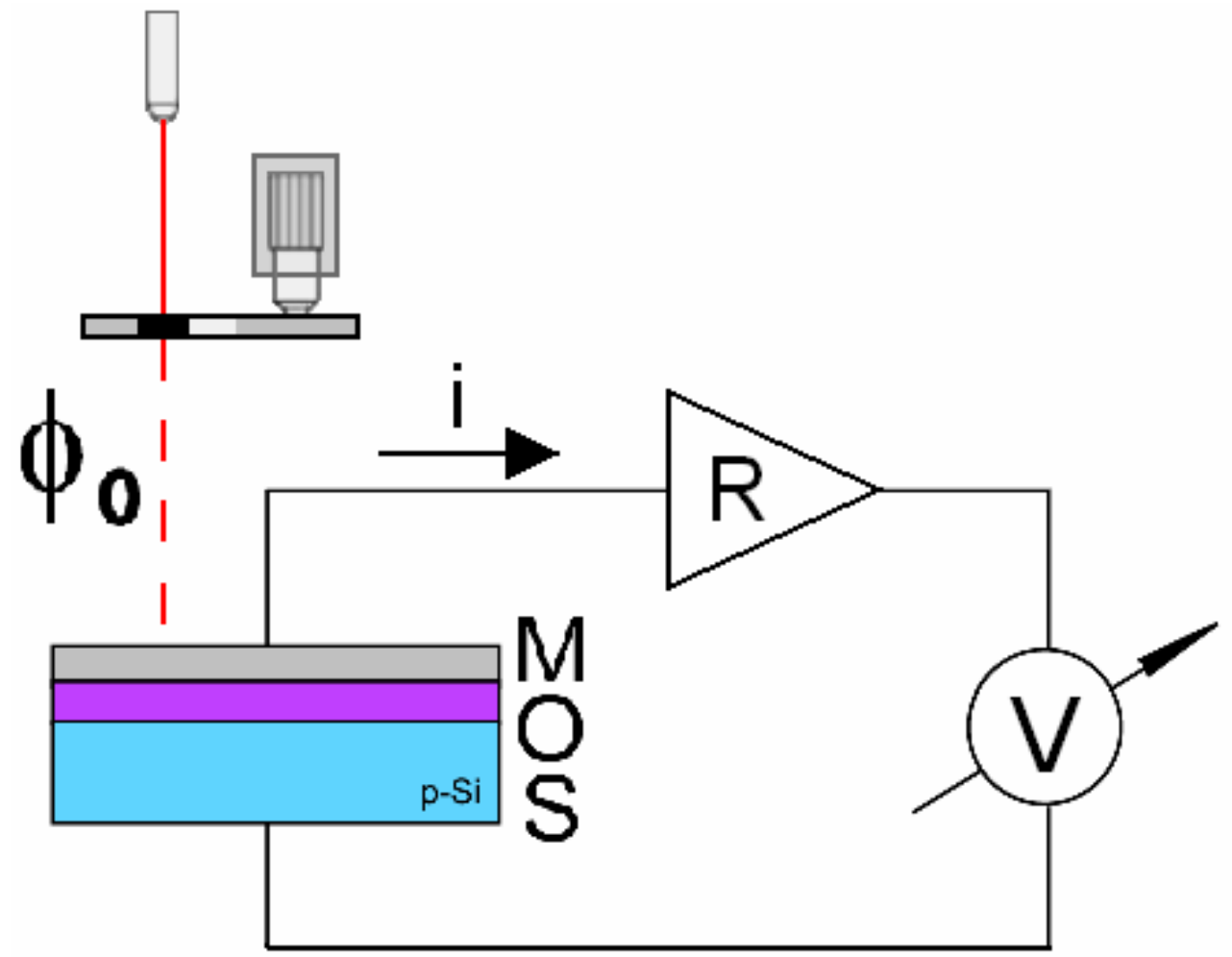

Figura 13 - Diagrama experimental da geração de uma fotocorrente em um dispositivo MOS, onde Фo é a intensidade de fótons.

O feixe de luz (visível) incidente com intensidade Фo, passa através do eletrodo metálico semitransparente e do óxido de silício, sendo posteriormente absorvido no substrato de silício, preferencialmente na camada de depleção. O processo de absorção da luz visível no substrato de silício é devido a transições eletrônicas da banda de valência para a banda de condução do silício. O resultado disto é a geração de pares elétron-lacunas (portadores de carga) (NICOLLIAN, 1982).

Parte dos pares gerados é separada pelo campo elétrico da camada de depleção, confinando os elétrons na região de interface (Figura 16), e as lacunas sendo ejetadas para a região neutra do substrato, dando origem à fotocorrente observada externamente. Uma outra parte desses portadores irá recombinar-se na interface e no corpo do semicondutor, não contribuindo com a corrente externa. A fotocorrente 
induzida será diferente de zero até que a concentração de elétrons no potencial de interface alcance o equilíbrio térmico (Figura 14), eliminando a camada de depleção.

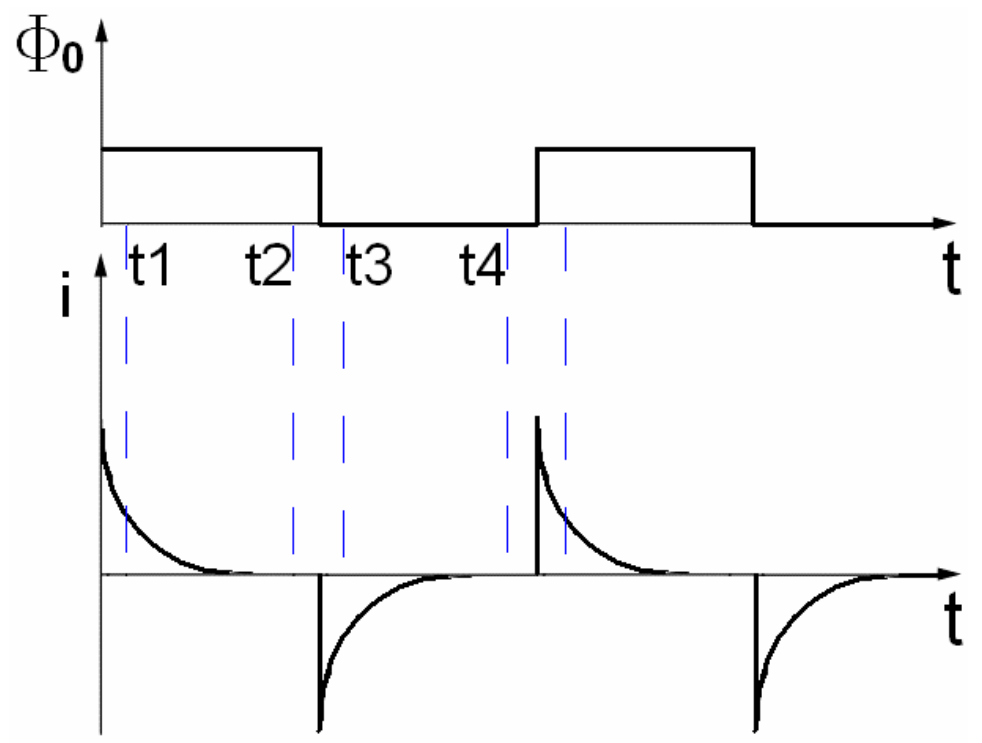

Figura 14 - Intensidade dos pulsos de luz e sinais de corrente em função do tempo (ENGSTRÖM \& CARLSSON, 1983).

Na Figura 15 até à Figura 18, são apresentados os esquemas da estrutura de bandas, associados à geração da fotocorrente na região de carga espacial do semicondutor para diferentes intervalos de tempo (Figura 14).

A Figura 15 mostra os possíveis mecanismos de transporte dos portadores fotogerados a partir do instante em que a fonte de luz é ligada (t1). Nesta condição, alguns portadores em desequilíbrio podem ser recombinados na interface. Já outros portadores (pares elétron-lacuna) serão separados pelo campo elétrico existente na camada de depleção. Neste último caso, os elétrons são confinados numa fina camada da interface e as lacunas são recombinadas na região neutra do substrato. As lacunas recombinadas na região neutra do semicondutor são as responsáveis pela intensidade de corrente foto-gerada que pode ser medida externamente. Este processo continua até que os elétrons acumulados na interface compensem o potencial inicial na interface, o que promove o decrescimento da largura da camada de depleção (Figura 16). 


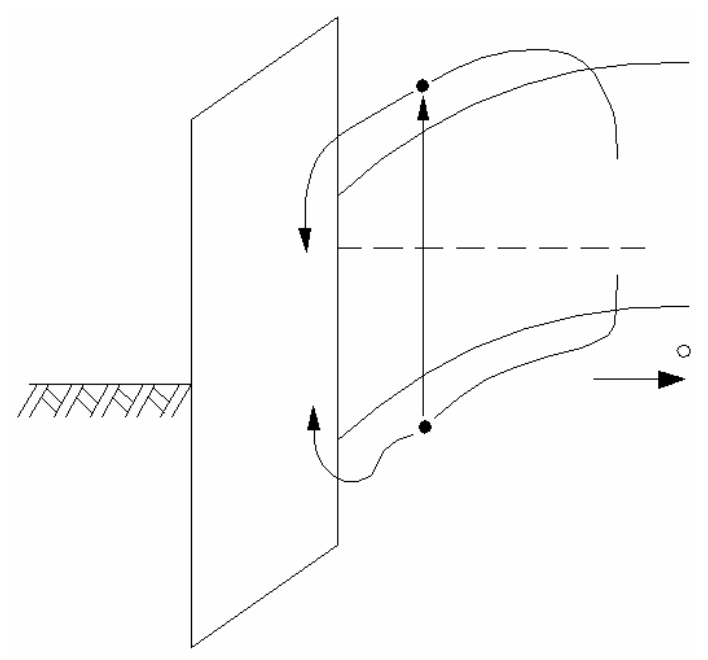

Figura 15 - Tráfego de portadores de carga na interface para o tempo t1 (ENGSTRÖM \& CARLSSON, 1983).

Mantendo-se a intensidade de luz constante, a densidade de elétrons da interface e as cargas positivas na porta atingem um limite tal que praticamente a camada de depleção é eliminada devido ao potencial gerado pelas cargas acima descritas. Isto ocorre de tal forma que os pares elétrons-lacunas gerados se recombinam rapidamente, não contribuindo para a corrente do circuito externo. Assim, em t2, a fotocorrente praticamente tende a zero, atingindo um estado de equilíbrio (Figura 16).

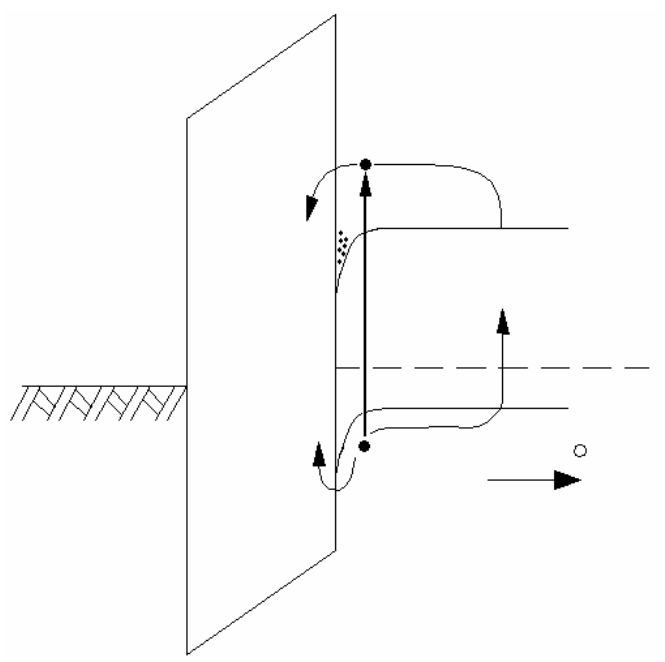

Figura 16 - Tráfego de portadores de carga na interface para o tempo t2 (ENGSTRÖM \& CARLSSON, 1983).

Quando a luz é apagada (t3 mostrado na Figura 14), os elétrons coletados no potencial de interface são emitidos para dentro do corpo do semicondutor, onde se recombinam com as lacunas provenientes da porta do capacitor MOS (Figura 17). 
Estas lacunas criam uma corrente negativa no circuito externo, continuando até que a concentração de elétrons no potencial de interface alcance o equilíbrio térmico (Figura 18).

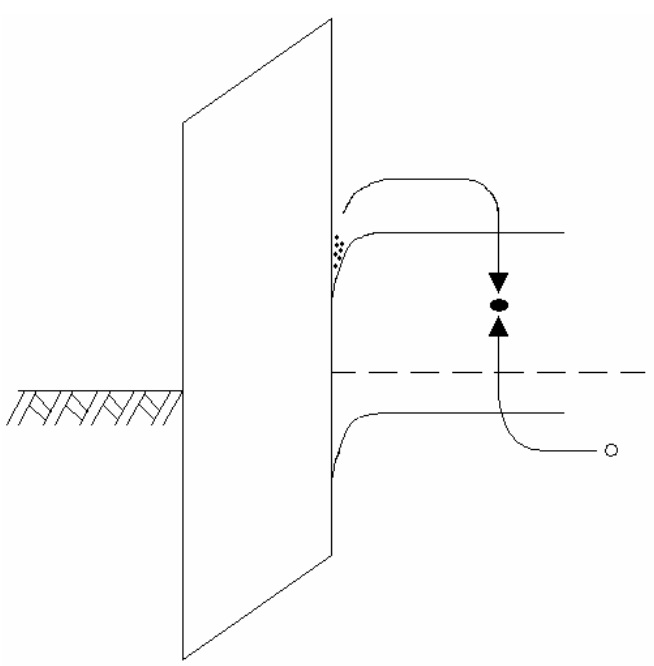

Figura 17 - Tráfego de portadores de carga na interface para o tempo t3 (ENGSTRÖM \& CARLSSON, 1983).

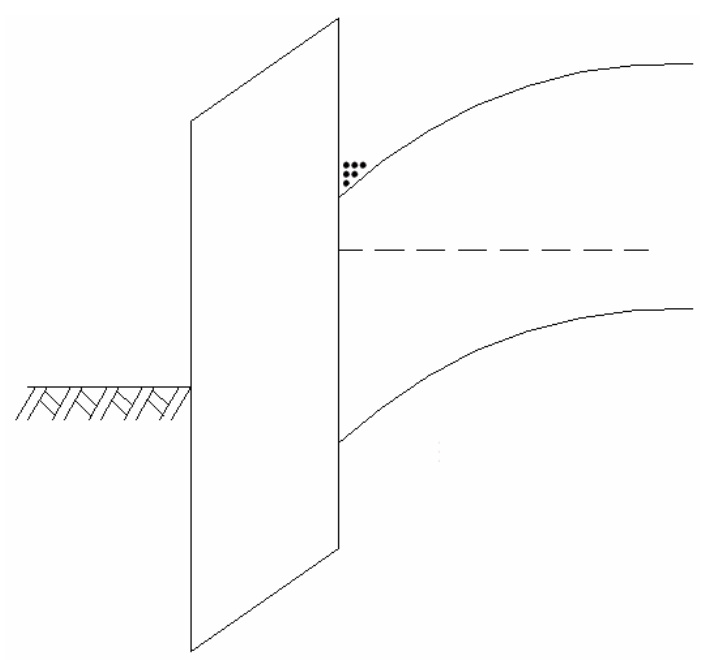

Figura 18 - Tráfego de portadores de carga na interface para o tempo t4 (ENGSTRÖM \& CARLSSON, 1983).

\subsection{Determinação da fotocorrente gerada em estruturas MOS (ENGSTRÖM \& CARLSSON, 1983)}

Dada uma estrutura MOS ideal sem estados de interface e com semicondutor tipo $\mathrm{P}$, o modelo elétrico para fotocorrente gerada no dispositivo MOS, pela TELP, pode ser 
representado por um modelo de circuito equivalente como mostrado na Figura 19 (ENGSTRÖM \& CARLSSON, 1983). Neste caso, assume-se que o substrato do semicondutor é do tipo $\mathrm{P}$ e que o laser de excitação tem um comprimento de onda de $632,8 \mathrm{~nm}$. Para esta fonte de luz, a profundidade de penetração do feixe incidente é da ordem de $3 \mu \mathrm{m}$ que é aproximadamente igual à largura da camada de depleção do silício tipo $P$ ou $N$ com resistividade entre 10 a $20 \Omega-\mathrm{cm}$. Assim, assume-se que no instante 11 cada fóton incidente gera um par elétron-lacuna dentro da camada de depleção. No instante t2 esta assunção não é mais válida desde que a camada de depleção colapsa para uma fina camada próxima da interface.

Neste sentido, a corrente de geração $\mathrm{i}_{g}$ devida aos portadores de carga criados dentro da região de carga espacial pode ser expressa pela seguinte equação:

$$
i_{g}=q \cdot \phi_{o}
$$

onde: q é a carga do elétron e $\phi_{0}$ é a intensidade de luz do feixe incidente.

Esta corrente é dividida em três partes diferentes, denominadas de corrente de recombinação de superfície $i_{s r}$, corrente de recombinação do substrato $i_{b r}$ e corrente de deslocamento $i_{d}$. Uma parte da corrente de deslocamento $i_{d}$ será responsável pela corrente no circuito externo. A estrutura MOS pode por isso ser representada por um circuito equivalente como mostrado na Figura 19.

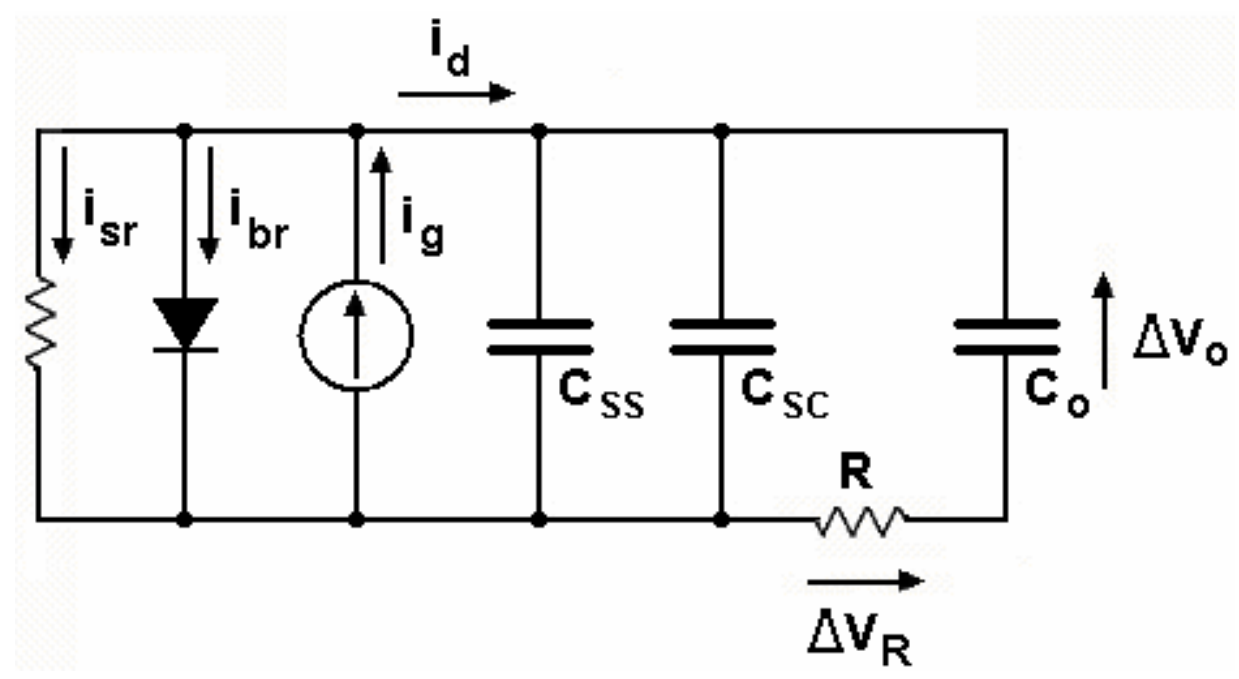

Figura 19 - Circuito equivalente de uma estrutura MOS foto-excitada com um feixe de luz pulsada. 
Quando os eletrodos da estrutura MOS não estão conectados ao circuito externo, a capacitância pode ser dividida em duas contribuições diferentes: a capacitância do óxido $\mathrm{C}_{\mathrm{o}}$ conectada em série com a capacitância do semicondutor $\mathrm{C}_{\mathrm{sc}}$. No caso de circuito fechado, entretanto, os eletrodos são conectados através de uma resistência de carga $\mathrm{R}$ tal que, neste caso, o circuito pode ser considerado como uma conexão paralela entre a capacitância $C_{s c}$, e a ligação série entre a capacitância $C_{o}$ e a resistência de carga $\mathrm{R}$ (Figura 19). Na montagem experimental utilizada no presente trabalho, a resistência de carga $\mathrm{R}$ corresponde à transimpedância do amplificador cujo fator de amplificação é determinado por R. Assim, a corrente medida no circuito externo é a corrente que circula em $\mathrm{C}_{\mathrm{o}}$ e no amplificador de transimpedância $\mathrm{R}$.

A corrente de recombinação de superfície $i_{s r}$, representada por um resistor na Figura 13 pode ser escrita como:

$$
i_{s r}=q s \Delta n^{o}
$$

onde s é a taxa de recombinação de superfície e $\Delta \mathbf{n}^{\circ}$ é a concentração de elétrons gerados opticamente que foram coletados no poço de potencial de interface.

Parte destes elétrons é emitida dentro do corpo do semicondutor, onde eles se recombinam com as lacunas opticamente geradas e que foram direcionados para a região neutra do substrato pelo campo elétrico na região de carga espacial. Esta corrente $\mathrm{i}_{\mathrm{br}}$ pode ser modelada como a corrente através de um diodo semicondutor como representada na Figura 19, podendo ser expressa pela seguinte equação:

$$
i_{b r}=q \frac{D_{n}}{L_{n}} \Delta n^{o} \exp \left(-\frac{q\left(\Psi_{s}-\Delta \Psi_{s}\right)}{k T}\right)
$$

onde $D_{n}$ e $L_{n}$ referem-se à constante de difusão e ao comprimento de difusão, respectivamente, para elétrons no semicondutor tipo $P$. $\boldsymbol{\Psi}_{\mathrm{s}}$ é o potencial de superfície do semicondutor, e $\boldsymbol{\Delta} \boldsymbol{\Psi}_{\mathrm{s}}$ é a mudança no potencial de superfície devido à coleta de elétrons gerados opticamente próximos à interface.

A corrente $i_{d}$, que passa através dos capacitores $C_{o}, C_{s c}$ e $C_{s s,}$ pode ser expressa como: 


$$
i_{d}=\frac{d}{d t}\left(\Delta Q_{t o t}\right)
$$

onde $\boldsymbol{\Delta} \mathbf{Q}_{\text {tot }}$ é a carga total transportada através da estrutura, devido à mudança no potencial de superfície $\Delta \Psi \mathrm{s}$, desde que a corrente gerada opticamente representada pela fonte de corrente $\mathrm{i}_{g}$ da Figura 19 seja igual à soma das contribuições de corrente $i_{s r}$, $i_{b r}$ e $i_{d}$. As eq.(11) à eq.(14) podem ser combinadas resultando na seguinte expressão:

$$
q \Phi_{o}=q \Delta n^{o} s+q \frac{D_{n}}{L_{n}} \Delta n^{o} \exp \left(-\frac{q\left(\Psi_{s}-\Delta \Psi_{s}\right)}{k T}\right)+\frac{d}{d t}\left(\Delta Q_{t o t}\right)
$$

se $\Delta \Psi_{\mathrm{s}}$ é pequeno, comparado com $\Psi_{\mathrm{s}}$, então a capacitância $\mathrm{C}_{\mathrm{sc}}$ pode ser considerada como constante durante o período de iluminação. Assim, $\Delta \mathrm{Q}_{\text {tot }}$ pode ser expresso como:

$$
\Delta Q_{\text {tot }}=C_{s c} \Delta \Psi_{s}+C_{o} \Delta V_{o}
$$

onde $\mathbf{\Delta} \mathbf{V}_{\mathrm{o}}$ é a mudança de tensão no isolante. Esta tensão diferencia-se da mudança no potencial de superfície $\Delta \Psi_{\mathrm{s}}$ num valor igual à queda de tensão na resistência de carga R. Quando $\Delta \mathrm{V}_{\mathrm{o}}$ e $\Delta \Psi_{\mathrm{s}}$ são iguais à carga coletada no poço de potencial na interface, o resultado torna-se aproximadamente igual à carga transportada através da estrutura. Em conseqüência, a carga total pode ser expressa por:

$$
\Delta Q_{t o t}=q \Delta n^{o} x_{o}
$$

onde $\mathbf{x}_{\mathbf{o}}$ é uma largura de corte em analogia à largura do canal de um transistor MOS. No entanto, a diferença do transistor MOS, onde a inversão (formação do canal) acontece quando a camada de depleção atinge seu máximo; no caso da fotocorrente induzida no dispositivo MOS, teremos a corrente externa igual a zero quando a largura da camada de depleção atinge um valor mínimo.

Assim, para grandes valores de tempo, a derivada do $\Delta Q_{\text {tot }}$ em relação ao tempo tenderá a zero, fazendo $\Delta V_{\mathrm{o}}$ aproximar-se de $\Delta \Psi_{\mathrm{s}}$. Sob essas condições as eq.(16) e eq.(17) darão como resultado a seguinte expressão: 


$$
\Delta \Psi_{s}=\frac{\Phi_{o} x_{o}}{\left(C_{s c}+C_{o}\right)\left(s+\frac{D_{n}}{L_{n}} \exp \left(-q \Psi_{s} / k T\right)\right)}
$$

Como a tensão $V_{R}$ sobre $\circ$ amplificador de transimpedância $R$ é medida pela integração no tempo, o sinal de saída desse instrumento irá constituir uma medição da carga transportada através da capacitância $C_{o}$, multiplicada pelo valor da resistência de carga $\mathrm{R}$ (fator do amplificador de transimpedância), isto é:

$$
u=\int_{0}^{\infty} V_{R}(t) d t=R C_{o} \Delta \Psi_{s}
$$

O parâmetro "u" definido na equação (18) constitui-se no parâmetro experimental que pode ser medido externamente e a partir do qual poderão ser determinados os diferentes parâmetros internos do dispositivo MOS. Inserindo a eq.(18) na eq.(19) obtém-se uma expressão que relaciona o parâmetro experimental com os parâmetros elétricos da estrutura MOS descrita por:

$$
u=\frac{C_{o}}{C_{o}+C_{s c}} \cdot \frac{R \Phi_{o} x_{o}}{s+\frac{D_{n}}{L_{n}} \exp \left(-q \Psi_{s} / k T\right)}
$$

Como pode ser visto na eq.(20), o sinal de saída "u" é dependente do potencial de superfície $\Psi_{\mathrm{s}}$, pelo fator exponencial relacionado com a corrente de recombinação no corpo do semicondutor, mas sua dependência em $\Psi_{\mathrm{s}}$ também está relacionada à capacitância do semicondutor $\mathrm{C}_{\mathrm{sc}}$, que é dependente desse parâmetro. A fim de comparar a teoria com os dados medidos, primeiro precisa-se determinar a relação entre o potencial de superfície e a voltagem aplicada Vp. Além disso, a capacitância do semicondutor $\mathrm{C}_{\mathrm{sc}}$, como uma função do potencial de superfície, precisa ser conhecida. Esta última relação poderá ser obtida da curva $\mathrm{CxV}$ em alta freqüência. Esse tipo de análise, todavia, está bem embasado em NICOLLIAN, 1982.

Dever-se-ia esperar também que as taxas de recombinação na superfície "s" fossem dependentes do potencial de superfície. No entanto, em ENGSTRÖM \& 
CARLSSON, 1983, foi mostrado que o parâmetro "s" é pouco sensível ao potencial de superfície do dispositivo MOS.

O modelo acima descrito pode ser facilmente transportado para um semicondutor tipo $\mathrm{N}$.

\subsection{Influência dos estados de interface}

No caso real, é necessário considerar os estados de interface (defeitos de superfície). Estes níveis de energia podem ser considerados como centros de armadilha para portadores, comportando-se como um capacitor. Desde que as taxas de emissão e captura nos níveis de interface sejam elevadas, se comparadas à freqüência de modulação da luz, a contribuição da capacitância $\mathrm{C}_{\mathrm{ss}}$ dos estados de interface pode ser expressa por (ENGSTRÖM \& CARLSSON, 1983):

$$
C_{s s}=q \bar{N}_{s s}\left(\psi_{s}\right)
$$

onde $\bar{N}_{s s}\left(\psi_{s}\right)$ é a densidade média dos estados de interface com seus níveis de energia igual à energia de Fermi na interface, quando o potencial de superfície for $\psi_{s}$.

A contribuição dos estados de interface $\left(C_{s s}\right)$ na capacitância do dispositivo MOS deve ser considerada como uma capacitância $\mathrm{C}_{\mathrm{ss}}$ em paralelo com a capacitância de carga espacial $\mathrm{C}_{\mathrm{sc}}$ (Figura 19).

Assim, quando os estados de interface são levados em consideração, a eq.(20) muda para a seguinte expressão (ENGSTRÖM \& CARLSSON, 1983):

$$
u=\frac{C_{o}}{C_{o}+C_{s c}+C_{s s}} \cdot \frac{R \Phi_{o} x_{o}}{s+\frac{D_{n}}{L_{n}} \exp \left(q \Psi_{s} / k T\right)}
$$

Na prática, o sinal de corrente opticamente induzido é detectado medindo-se seu conteúdo de carga nos transitórios positivo e negativo. Integrando a fotocorrente para cada pulso de excitação óptica, assim, pode-se determinar a quantidade de 
carga transportada pelo dispositivo durante o intervalo de tempo de duração da fotocorrente através da seguinte expressão:

$$
u=R \int_{0}^{t 2} i d t
$$

onde: $\mathbf{u}$ representa a quantidade de portadores gerados; $\mathbf{R}$ é o fator de amplificação do transimpedância $(\Omega)$ e i é o sinal de corrente originário do capacitor MOS.

Para cada posição do feixe de luz sobre a superfície do sensor será observada uma fotocorrente, que poderá ser gravada como característica da região atingida pela luz, para a geração de uma figura representativa das propriedades da interface do sistema MOS. No caso da utilização do dispositivo MOS como sensor de gás, a adsorção das moléculas de gás na interface metal/ $\mathrm{SiO}_{2}$ promoverá mudança no potencial de superfície $\Psi_{\mathrm{s}}$, podendo ser monitorada através da medida do parâmetro "u".

Dessa forma, podemos utilizar uma estrutura Pd-MOS para detecção de hidrogênio e amônia através do reconhecimento de padrões de imagens representativas. $\mathrm{Na}$ Figura 20 é apresentado o diagrama seqüencial de geração de padrões de imagens químicas utilizando a técnica de escaneamento por luz pulsada. 

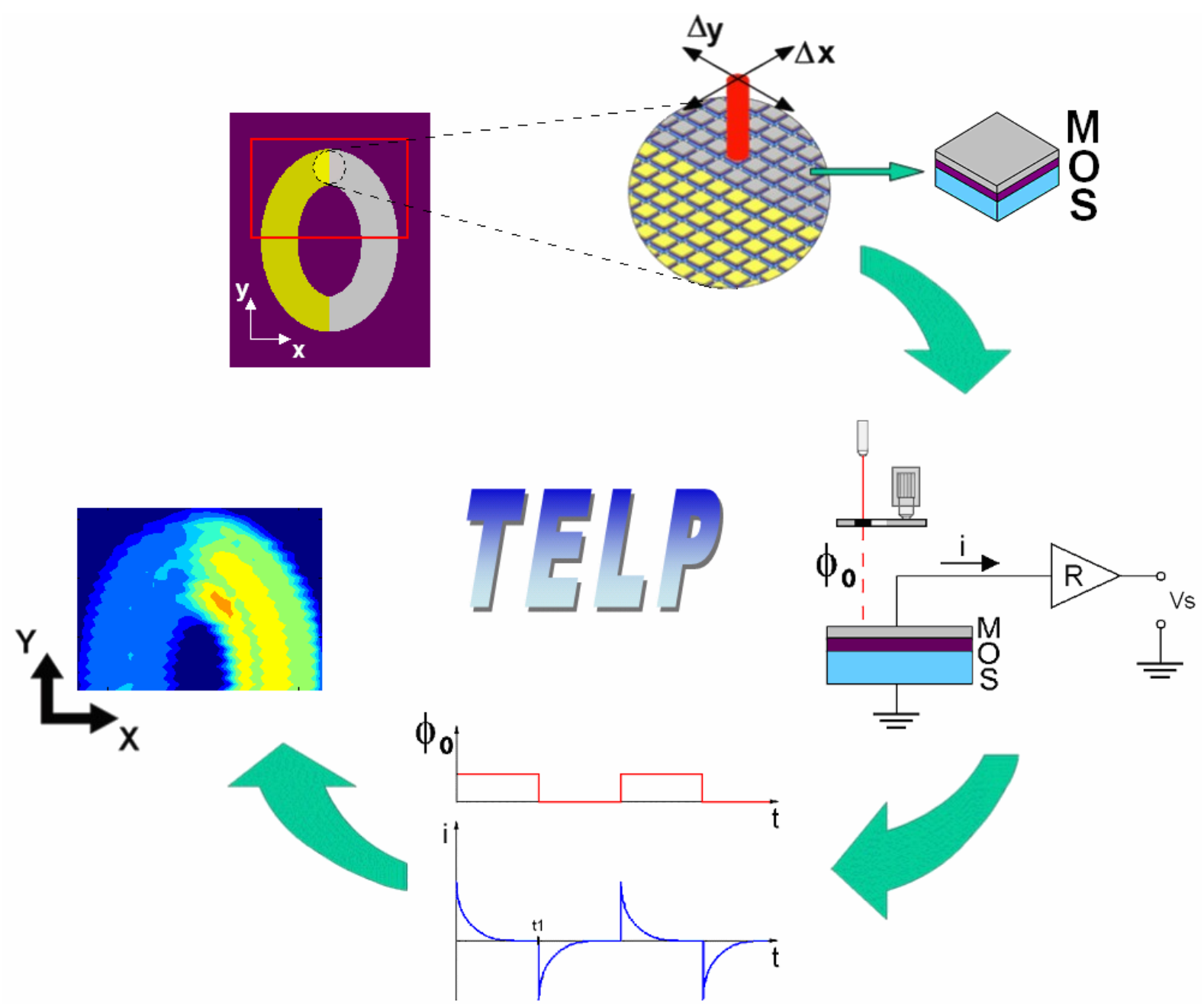

Figura 20- Diagrama seqüencial da Técnica de Escaneamento por Luz Pulsada para geração de padrões de imagens químicas.

O sinal de corrente originário do capacitor MOS é condicionado para a leitura através de um amplificador de transimpedância e os valores de pico da corrente lidos (Iph), assim como os valores de "u", são armazenados em uma matriz de correspondência referenciados às diferentes posições de incidência do laser. Com isso, pode-se facilmente construir mapas com imagens representativas das misturas gasosas às quais o dispositivo está exposto. 


\section{PROCEDIMENTOS EXPERIMENTAIS}

A contribuição do presente trabalho foi o reconhecimento de diferentes gases utilizando-se apenas um único sensor baseado na geração de imagens químicas pela técnica de escaneamento por luz pulsada em estruturas MOS. Para tal fim, foi desenvolvido um sistema de controle eletrônico automatizando, possibilitando a aquisição de dados e o tratamento dos sinais.

Para a otimização do processo de fabricação e futuras análises dos dispositivos semicondutores, foram fabricados, inicialmente, quatro capacitores MOS com duas diferentes estruturas: a primeira apresentando duas portas metálicas convergentes, formando uma cunha; e a segunda apresentando duas portas metálicas na forma de uma elipse bipartida. Foi utilizada uma lâmina de silício tipo $P$ circular de $50,8 \mathrm{~mm}$ de diâmetro e resistividade de 3 a $10 \Omega-\mathrm{cm}$, onde foi crescido um filme de óxido térmico para atuar como material isolante $\left(\mathrm{SiO}_{2}\right)$. Posteriormente, em cima do óxido, foram depositados os dois tipos de metais (paládio e ouro) constituindo a porta do dispositivo MOS. Na parte inferior do substrato foi depositada uma camada de alumínio para contato elétrico entre o substrato e o circuito externo.

A Figura 21 mostra, em corte, a região de dois sensores diferentes fabricados na lâmina. O processo de fabricação mais detalhado destes dispositivos é descrito no texto a seguir.

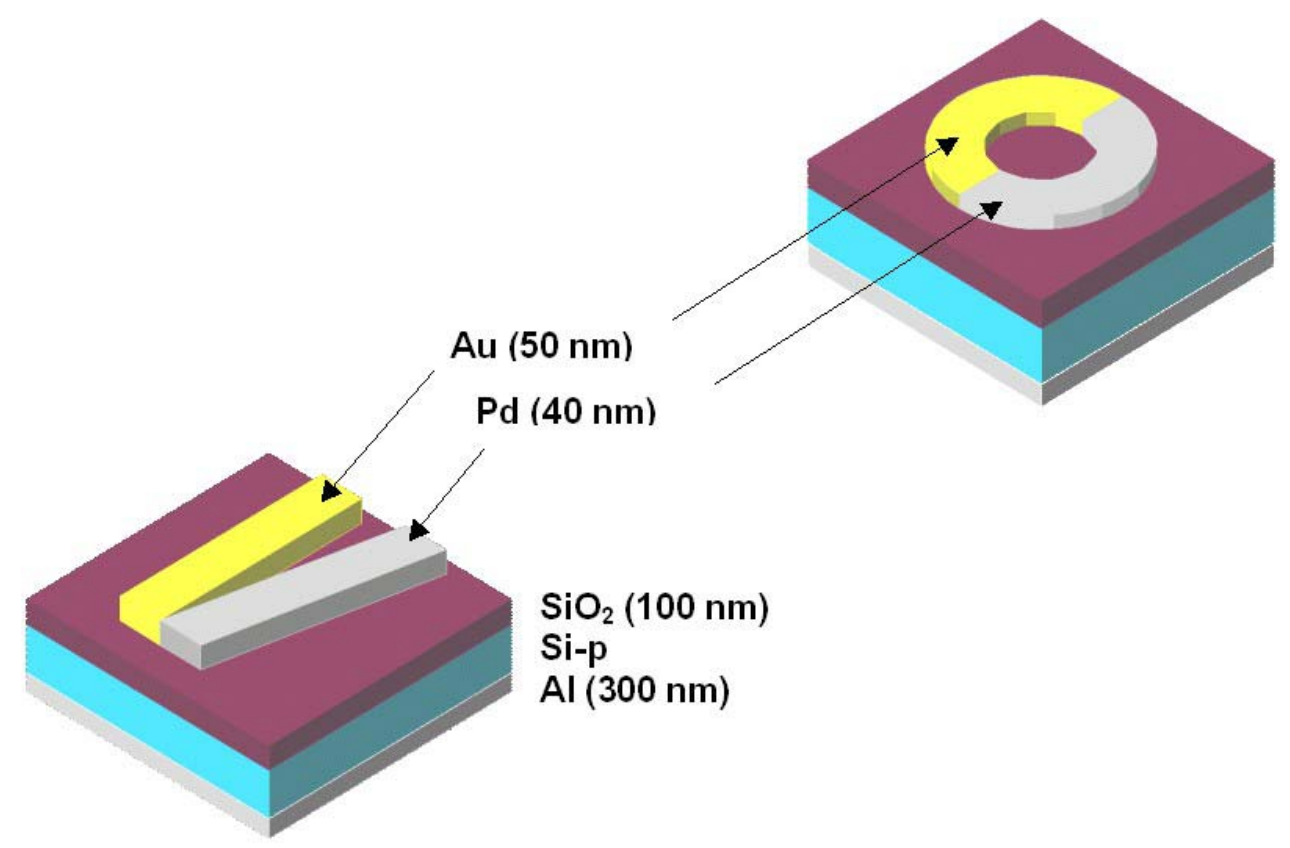

Figura 21 - Dispositivos MOS utilizados no experimento. 


\subsection{Fabricação dos capacitores MOS}

Para fabricação dos capacitores MOS foi utilizada uma lâmina de Si tipo P com orientação cristalográfica $<100>$ e resistividade de 3-10 $\Omega-\mathrm{cm}$. A fabricação seguiu as etapas descritas a seguir. Na Figura 22 é mostrado um diagrama esquemático das diferentes etapas de fabricação do capacitor MOS (Figura 21) seguidas no presente trabalho.

a.

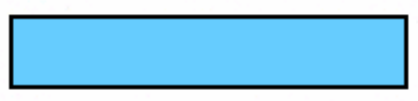

d.

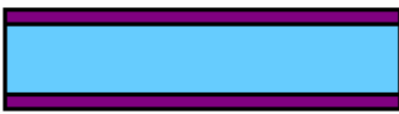

e.

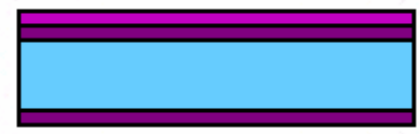

g.
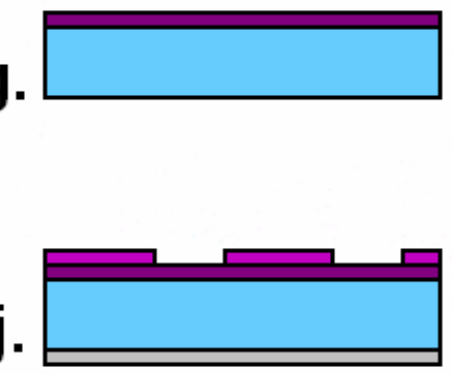

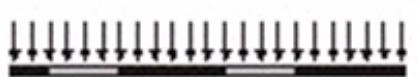

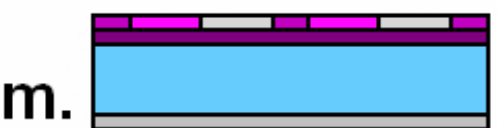

n

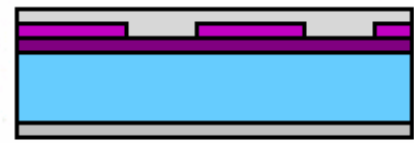

h.

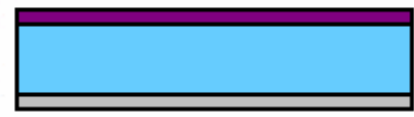

k.

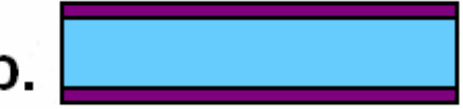

C.

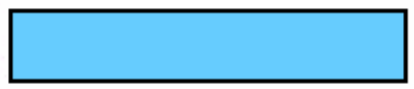

$f$

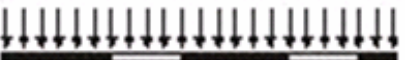

1.

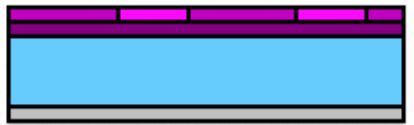

I.

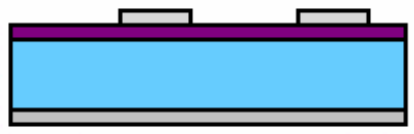

O.

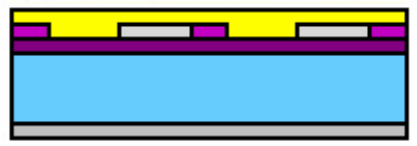

p.

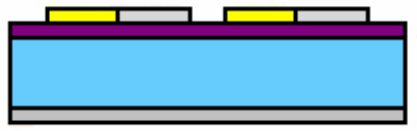

q.

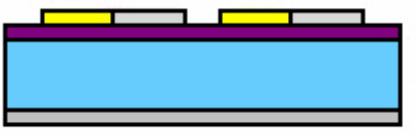

Figura 22 - Etapas de fabricação do capacitor MOS.

As etapas do processo são descritas no texto a seguir: 


\subsection{Etapas de fabricação do capacitor MOS}

\section{a. Limpeza química inicial da lâmina Si-p}

Esta etapa é de suma importância nos processos de fabricação de dispositivos MOS, pois a presença de impurezas (metais, compostos orgânicos e particulados) supostamente presentes na superfície das lâminas provocam alterações significativas no funcionamento do capacitor MOS. O roteiro ao qual a lâmina foi submetida à limpeza inicial é listado a seguir:

- 15 min em $\mathrm{H}_{2} \mathrm{SO}_{4}: \mathrm{H}_{2} \mathrm{O}_{2}(3: 1)$ a $105^{\circ} \mathrm{C}$;

- 10 min em água deionizada (D.I.);

- 5 min em cascatinha;

- 15 min em $\mathrm{H}_{2} \mathrm{O}$ D.I. : $\mathrm{NH}_{4} \mathrm{OH}: \mathrm{H}_{2} \mathrm{O}_{2}(5: 1: 1)$ a $75^{\circ} \mathrm{C}$;

- 10 min em água deionizada;

- 5 min em cascatinha.

\section{b. Oxidação de Gettering}

A oxidação de Gettering foi realizada no forno de oxidação MOS, onde as lâminas foram ambientalizadas com fluxos de $\mathrm{O}_{2}, \mathrm{C}_{33}$ e $\mathrm{N}_{2}$, o que permite a conversão de certas impurezas no silício em clorados voláteis permitindo a eliminação de falhas de empilhamento (stacking faults), e reduzindo as densidades de cargas de interface $\left(Q_{s s}\right)(S Z E, 1983)$. De maneira resumida, o processo de oxidação de gettering teve os seguintes passos (WOLF, 1969):

Tabela 1 - Etapas do processo de oxidação de Gettering.

\begin{tabular}{c|c|c|c|c|c}
\hline Etapa & 1 & 2 & 3 & 3 & 4 \\
\hline $\begin{array}{c}\text { Tempo } \\
\text { processo }\end{array}$ & $15 \mathrm{~min}$ & $90 \mathrm{~min}$ & $10 \mathrm{~min}$ & $20 \mathrm{~min}$ & $10 \mathrm{~min}$ \\
\hline Temperatura & $\begin{array}{c}\text { Entrada } \\
\text { forno }\end{array}$ & $1200{ }^{\circ} \mathrm{C}$ & $1200{ }^{\circ} \mathrm{C}$ & $1200{ }^{\circ} \mathrm{C}$ & $\begin{array}{c}\text { Saída } \\
\text { forno }\end{array}$ \\
\hline Gás & $\mathrm{O}_{2}$ & $\mathrm{O}_{2}+\mathrm{C}_{33}$ & $\mathrm{O}_{2}$ & $\mathrm{~N}_{2}$ & $\mathrm{~N}_{2}$ \\
\hline
\end{tabular}




\section{c. Remoção de Gettering}

A remoção do óxido de Gettering foi realizada com a aplicação de Decapante Lento de Vidro (DLV) que contém $\mathrm{NH}_{4} \mathrm{~F}: \mathrm{HF}(49 \%)$, na proporção (6:1), por 4 minutos.

\section{d. Oxidação de porta}

O óxido de porta de $100 \mathrm{~nm}$ de espessura foi obtido no forno de oxidação MOS pelo princípio de oxidação térmica, por oferecer boa estabilidade e baixa densidade de defeitos.

A temperatura do substrato foi mantida em $1000^{\circ} \mathrm{C}$ e as etapas do processo de oxidação seguiram a seqüência descrita na Tabela 2 (WOLF, 1969):

Tabela 2 - Etapas do processo de oxidação térmica

\begin{tabular}{c|c|c|c|c|c}
\hline Etapa & 1 & 2 & 3 & 3 & 4 \\
\hline $\begin{array}{c}\text { Tempo } \\
\text { processo }\end{array}$ & $15 \mathrm{~min}$ & $90 \mathrm{~min}$ & $10 \mathrm{~min}$ & $20 \mathrm{~min}$ & $10 \mathrm{~min}$ \\
\hline Temperatura & $\begin{array}{c}\text { Entrada } \\
\text { forno }\end{array}$ & $1000^{\circ} \mathrm{C}$ & $1000^{\circ} \mathrm{C}$ & $100{ }^{\circ} \mathrm{C}$ & $\begin{array}{c}\text { Saída } \\
\text { forno }\end{array}$ \\
\hline Gás & $\mathrm{O}_{2}$ & $\mathrm{O}_{2}+\mathrm{C}_{33}$ & $\mathrm{O}_{2}$ & $\mathrm{~N}_{2}$ & $\mathrm{~N}_{2}$ \\
\hline
\end{tabular}

\section{e. Proteção do óxido de porta na parte frontal da lâmina com fotoresiste.}

Aplicação de fotoresiste no lado onde foram posteriormente depositados os dois metais catalíticos, com a finalidade de proteger o óxido na etapa de remoção do óxido no lado inferior.

\section{f. Remoção do óxido das "costas" da lâmina}

A remoção do óxido foi realizada com a aplicação de Decapante Lento de Vidro (DLV) que contém $\mathrm{NH}_{4} \mathrm{~F}: \mathrm{HF}$ (49\%), na proporção (6:1), por 4 minutos. 


\section{g. Remoção do fotoresiste}

A remoção do fotoresiste da lâmina foi realizada em temperatura ambiente com a aplicação de acetona seguida de limpeza, conforme a seqüência a seguir:

Tabela 3 - Etapas de limpeza "TAl".

\begin{tabular}{c|c|c|c}
\hline Etapa & 1 & 2 & 3 \\
\hline $\begin{array}{c}\text { Tempo } \\
\text { processo }\end{array}$ & $15 \mathrm{~min}$ & $90 \mathrm{~min}$ & $10 \mathrm{~min}$ \\
\hline Temperatura & $80^{\circ} \mathrm{C}$ & $80^{\circ} \mathrm{C}$ & $80^{\circ} \mathrm{C}$ \\
\hline $\begin{array}{c}\text { Produto } \\
\text { químico }\end{array}$ & Tricloro & Acetona & Isopropanol \\
\hline
\end{tabular}

\section{h. Deposição de Alumínio no lado inferior da lâmina}

Foram depositados $300 \mathrm{~nm}$ de alumínio, para o contato de substrato das lâminas, utilizando-se o equipamento Electro-Beam Balzers BAE 370 Coating System e, logo após, as lâminas foram recozidas num ambiente de gás verde (forming gas - 10\% de $\mathrm{H}_{2}+90 \%$ de $\mathrm{N}_{2}$ ) durante 30 minutos a $450{ }^{\circ} \mathrm{C}$ com a finalidade de obter um contato do tipo ôhmico.

\section{i. Fotogravação dos filmes de Paládio}

As lâminas foram cobertas com uma fina camada de fotoresiste, sendo aplicada com o uso do Spin Coater P-6204, numa rotação de 3000 RPM, durante 30 segundos. A definição da imagem na superfície da lâmina foi obtida por meio de exposição à luz ultravioleta sobre uma máscara fotográfica com a impressão da geometria do filme de paládio. 


\section{j. Abertura de janela para deposição de Paládio}

Após o processo de fotogravação, as lâminas foram condicionadas durante 2 minutos em solução de mono clorobenzeno. A abertura das janelas foi obtida utilizando-se o revelador fotoresiste 351.

\section{k. Deposição de Paládio sobre a camada de óxido}

Foram depositados $40 \mathrm{~nm}$ de Paládio, utilizando-se o Electro-Beam Balzers BAE 370 Coating System.

\section{Remoção do excesso de Paládio pelo processo Lift-Off}

A remoção do paládio excedente foi realizada com a aplicação de acetona à temperatura de $80^{\circ} \mathrm{C}$ seguida de limpeza "TAl", conforme Tabela 3 .

\section{m. Fotogravação dos filmes de ouro}

As lâminas foram cobertas com uma fina camada de fotoresiste, sendo aplicada com o uso do Spin Coater P-6204, numa rotação de 3000 RPM, durante 30 segundos. A definição do padrão geométrico na superfície da lâmina foi obtida por meio de exposição à luz ultravioleta sobre uma máscara fotográfica com a impressão da geometria do filme de ouro. O alinhamento da máscara em relação à lâmina foi realizado com auxílio de foto-alinhamento por marcas localizadas nas extremidades do fotolito. 


\section{n. Abertura de janela para deposição de ouro}

Após o processo de fotogravação, as lâminas foram acondicionadas durante 2 minutos em solução de mono clorobenzeno. A abertura das janelas foi obtida utilizando-se o revelador fotoresiste 351.

\section{o. Deposição de ouro sobre a camada de óxido}

Foram depositados $50 \mathrm{~nm}$ de ouro, utilizando-se o Electro-Beam Balzers BAE 370 Coating System.

\section{p. Remoção do excesso de ouro pelo processo Lift-Off}

A remoção do ouro excedente foi realizada com a aplicação de acetona à temperatura de $80^{\circ} \mathrm{C}$ seguida de limpeza "TAl", conforme Tabela 3

\section{q. Realização do processo de sinterização para a formação da liga Al-Si}

Executou-se $\circ$ recozimento das estruturas metal/semicondutor e metal/óxido/semicondutor em ambiente de gás verde (forming gas - $10 \%$ de $\mathrm{H}_{2}+$ $90 \%$ de $\mathrm{N}_{2}$ ) durante 30 minutos a $450{ }^{\circ} \mathrm{C}$. Esta etapa serviu para reestruturar as camadas e reduzir os defeitos nas interfaces das estruturas, que eventualmente poderiam ter sido gerados durante o processo de evaporação dos metais. 


\subsection{Sistema de obtenção de imagens químicas pela TELP.}

A técnica utiliza o princípio de geração de portadores através de excitação luminosa na região de depleção de uma estrutura MOS aliado ao efeito de seletividade do $\mathrm{Pd}$ ao hidrogênio e à amônia.

A fotoexcitação é realizada localmente $\left(0,7 \mathrm{~mm}^{2}\right)$ de tal forma que através de uma varredura espacial obtém-se uma imagem bidimensional da fotocorrente induzida no dispositivo MOS. A intensidade da fotocorrente é proporcional ao número de portadores gerados na região de depleção. A largura dessa região é dependente da tensão de polarização aplicada ao sensor MOS e da quantidade de dipolos na interface do isolante devido aos átomos de hidrogênio adsorvidos na interface metal/ $\mathrm{SiO}_{2}$. A varredura dos pontos de incidência do laser é feita utilizando-se um posicionador $\mathrm{X} Y$, e os valores dos picos de corrente e " $u$ " (definidos na seção 2.5) são armazenados em uma matriz que relaciona os valores $X$ e $Y$ da posição do laser e o valor da corrente é lido por uma placa de aquisição de dados. A placa de aquisição pré-condiciona o sinal de fotocorrente por intermédio de um amplificador de transimpedância. Os detalhes do funcionamento e construção do sistema de posicionamento $X Y$ e do amplificador de transimpedância serão vistos nas próximas seções.

Para condicionamento do sensor em ambiente de ensaio foi utilizada uma câmara de ensaio que foi construída em aço inox, teflon e vidro (seção 3.7). A mistura gasosa injetada na câmara de ensaio foi obtida através de uma associação de rotâmetros da Brooks Instrument Division - Emerson Process, modelo 1355. Esses rotâmetros possuem uma característica não linear principalmente no início de sua escala. Assim, o fluxo de gás foi medido usando uma tabela ${ }^{1}$ de calibração fornecida pelo fabricante. A Figura 23 mostra o diagrama esquemático do sistema utilizado para a obtenção da mistura gasosa.

\footnotetext{
1 Brooks Instrument Division - Emerson Process. Recursos e dados disponíveis em: <http://www.emersonprocess.com/brooks/>. Acesso em: 21 ago. 2007.
} 


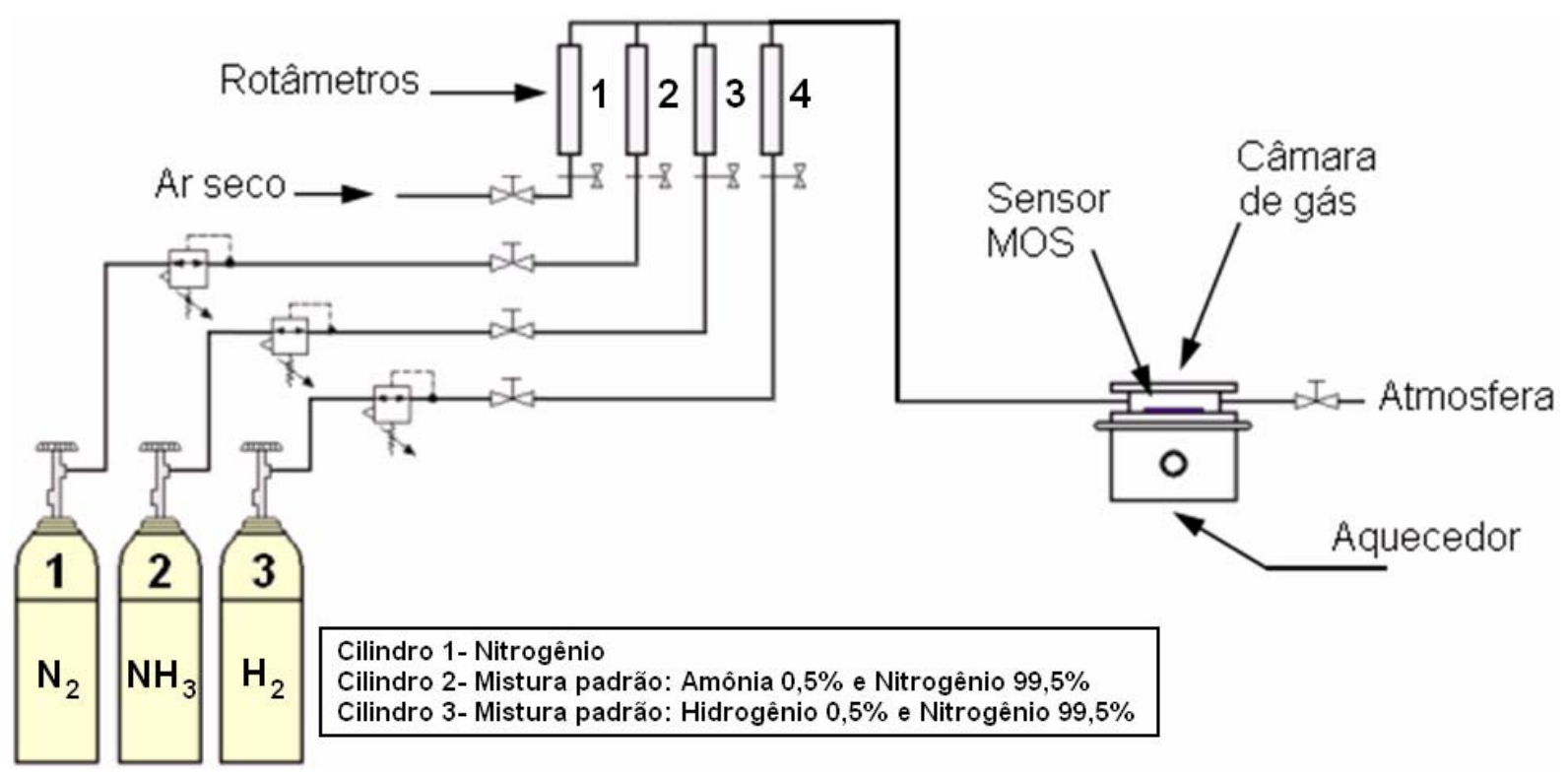

Figura 23 - Esquema do sistema construído para a diluição do hidrogênio e amônia em nitrogênio.

Os rotâmetros 3 e 4 são do tipo R-2-15-AAA, o rotâmetro 2 é do tipo R-2-15-AA e o rotâmetro 1 é do tipo R-2-15-B, todos da Emerson. Todos são baseados em flutuadores esféricos. Para os ensaios das seções 4.2 e 4.3, todos os flutuadores utilizados tinham esferas de vidro. Porém, para a diluição dos gases de $\mathrm{H}_{2}$ e $\mathrm{NH}_{3} \mathrm{em}$ concentrações na faixa de 100 ppm a 500 ppm, utilizadas na seção 4.4, o rotâmetro 2 teve a esfera de vidro substituída por esfera de aço.

O controle do posicionador e a gravação dos sinais de resposta do sensor foram realizados automaticamente através de um instrumento virtual projetado com o software LabView $®$, versão 5.

\subsection{O amplificador de transimpedância}

De acordo com o diagrama esquemático mostrado na Figura 24, a fonte de corrente, neste caso, o capacitor MOS, é conectada na entrada inversora do amplificador operacional Cl 1 (LMC6001). 


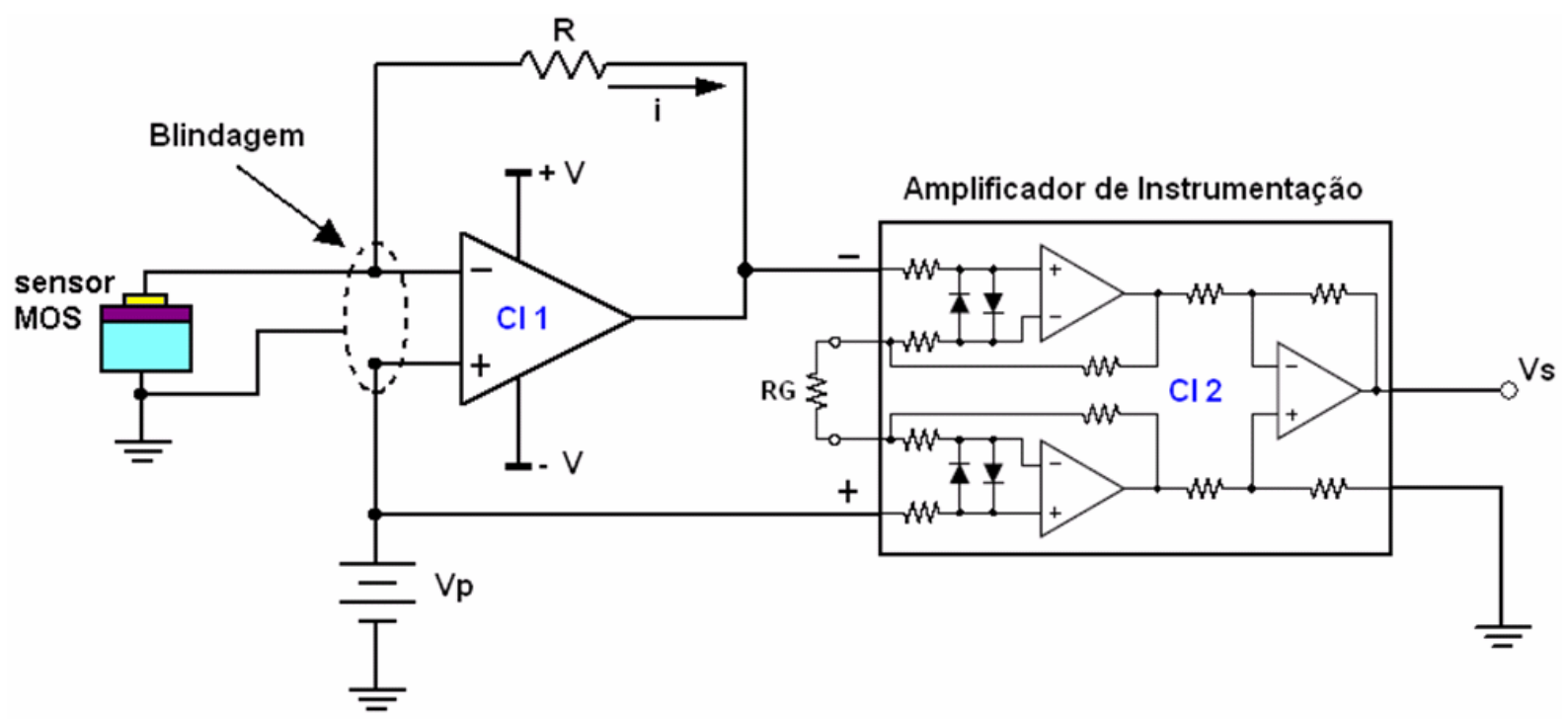

Figura 24 - Diagrama eletrônico do amplificador de transimpedância.

Um resistor de realimentação $\mathrm{R}$ com valor de $192 \mathrm{k} \Omega$ é conectado entre a saída do amplificador e sua entrada inversora para ajustar o fator de escala de conversão, ou seja, sua impedância de transferência (transimpedância). O sensor MOS é polarizado por uma tensão $\mathrm{Vp}$, devido ao efeito de tensão de modo comum do $\mathrm{Cl} 1$. A corrente que passa por $\mathrm{R}$ é equivalente a um valor $\mathrm{i}$, proveniente do sensor MOS, causando uma queda de tensão $\mathrm{V}_{\mathrm{R}}$ sobre $\mathrm{R}$ igual a $-i \cdot R$. Esse potencial é somado a Vp e um amplificador de instrumentação de ganho unitário $\mathrm{Cl} 2(\mathrm{RG}=\infty)$, subtrai a tensão de polarização da saída do amplificador operacional, deixando $V_{R}$ no terminal de saída do circuito, fazendo $V_{S}=V_{R}$, como desejado. O uso de uma malha de blindagem aterrada ao redor das entradas no $\mathrm{Cl} 1$ reduz significativamente erros resultantes de correntes de fuga e rotas com capacitâncias parasitas.

Talvez a vantagem mais significativa pertinente a este leiaute é que a medição é feita permitindo polarizar o dispositivo sensor com uma tensão Vp em relação ao terra do sistema.

$\mathrm{O}$ valor de $\mathrm{R}$ e o modelo do dispositivo amplificador $(\mathrm{Cl} 1)$ podem ser otimizados dependendo da aplicação do circuito, especificamente com respeito à faixa de freqüência de interesse e a ordem de grandeza da corrente medida.

O Cl amplificador de instrumentação utilizado foi o INA101, por possuir características interessantes tais como: alta imunidade a ruídos e boa resposta às freqüências dos sinais envolvidos no experimento. 
A calibração e a verificação da resposta linear do amplificador de transimpedância foram realizadas no caracterizador de dispositivos semicondutores HP4156 A da Hewlett-Packard $^{\circledR}$. A curva de resposta para o circuito amplificador de transimpedância (Figura 25) mostrou que o circuito apresenta um fator de transimpedância $(R)$ de aproximadamente $192 \mathrm{k} \Omega$ e uma resposta linear.

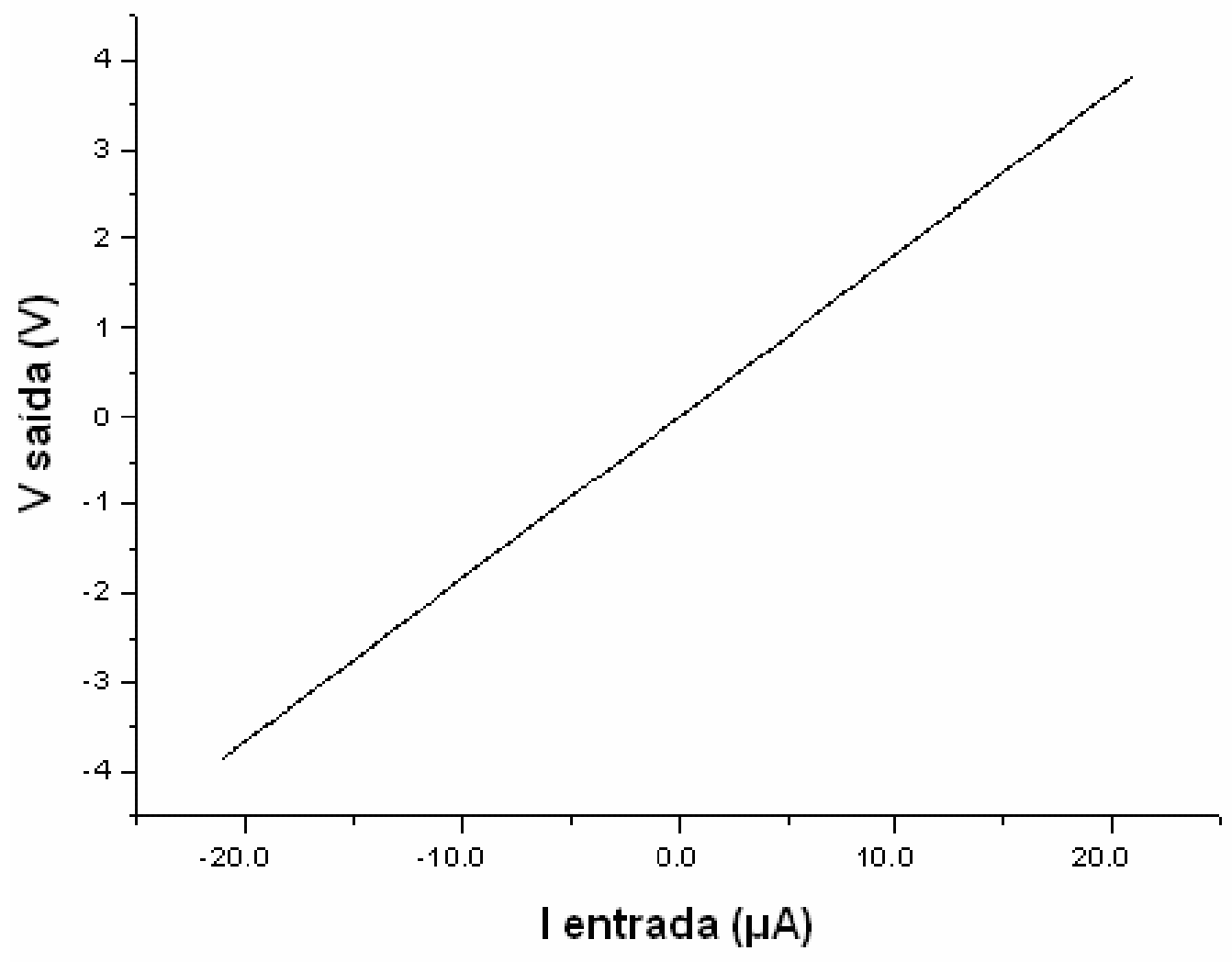

Figura 25 - Curva característica de resposta do amplificador de transimpedância.

\subsection{Circuito de acionamento dos motores do sistema de posicionamento $X Y$}

Para o acionamento dos motores, foi desenvolvido o circuito da Figura 26 que possui quatro chaves analógicas $(\mathrm{Cl} 4066 \mathrm{~N})$ que determinam o sentido de rotação dos motores. O CI L-298 é responsável pela interface de potência e o Cl 7812 (regulador de tensão) por fornecer um ponto com tensão estável VCC de $12 \mathrm{~V}$ em conjunto com filtros capacitivos.

As entradas do circuito são acopladas à placa de aquisição utilizada no arranjo experimental e o controle é realizado pelos aplicativos desenvolvidos em LabVIEW®, versão 5. 


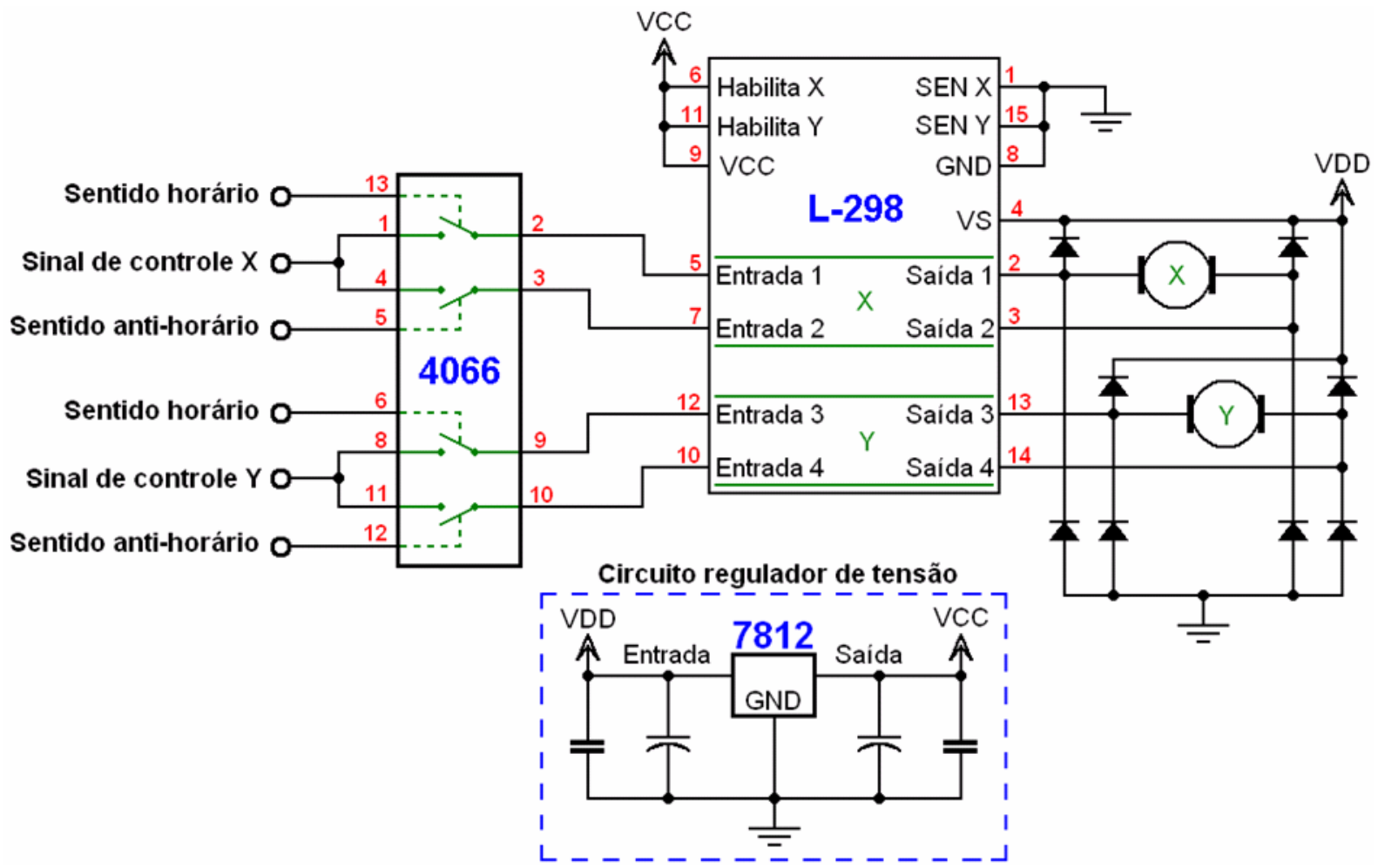

Figura 26 - Diagrama do circuito de acionamento dos motores do posicionador X Y.

\subsection{Sistema de posicionamento $X Y$}

Para realizar o posicionamento do feixe laser, foi necessário construir um sistema mecânico de posicionamento. Para isso, foi utilizado um posicionador unidirecional $(X)$ da FESTO $\circledast$ que possui um eixo sem fim acoplado a um motor $\mathrm{CC}$ que desloca uma base metálica de maneira linear.

Como havia a necessidade de executar a varredura em uma área sobre a superfície do sensor MOS, desenvolveu-se um sistema mecânico de posicionamento para ser fixado sobre a base do posicionador FESTO®. Este segundo posicionador $(\mathrm{Y})$ foi montado utilizando a peça de ajuste de foco de um microscópio que havia disponível no Laboratório de Microeletrônica da Escola Politécnica da Universidade de São Paulo. Um sistema moto-redutor (motor CC acoplado a uma caixa redutora) foi acoplado ao eixo desta peça, além de um potenciômetro multivoltas para envio do sinal de posicionamento do eixo $\mathrm{Y}$.

Em seguida foi confeccionado um suporte para o laser e fixado na parte móvel do posicionador $\mathrm{Y}$. 
O sistema completo compõe o posicionador $X Y$ utilizado para realizar a varredura do laser sobre a superfície do sensor MOS. A Figura 27 mostra a fotografia do posicionador montado.

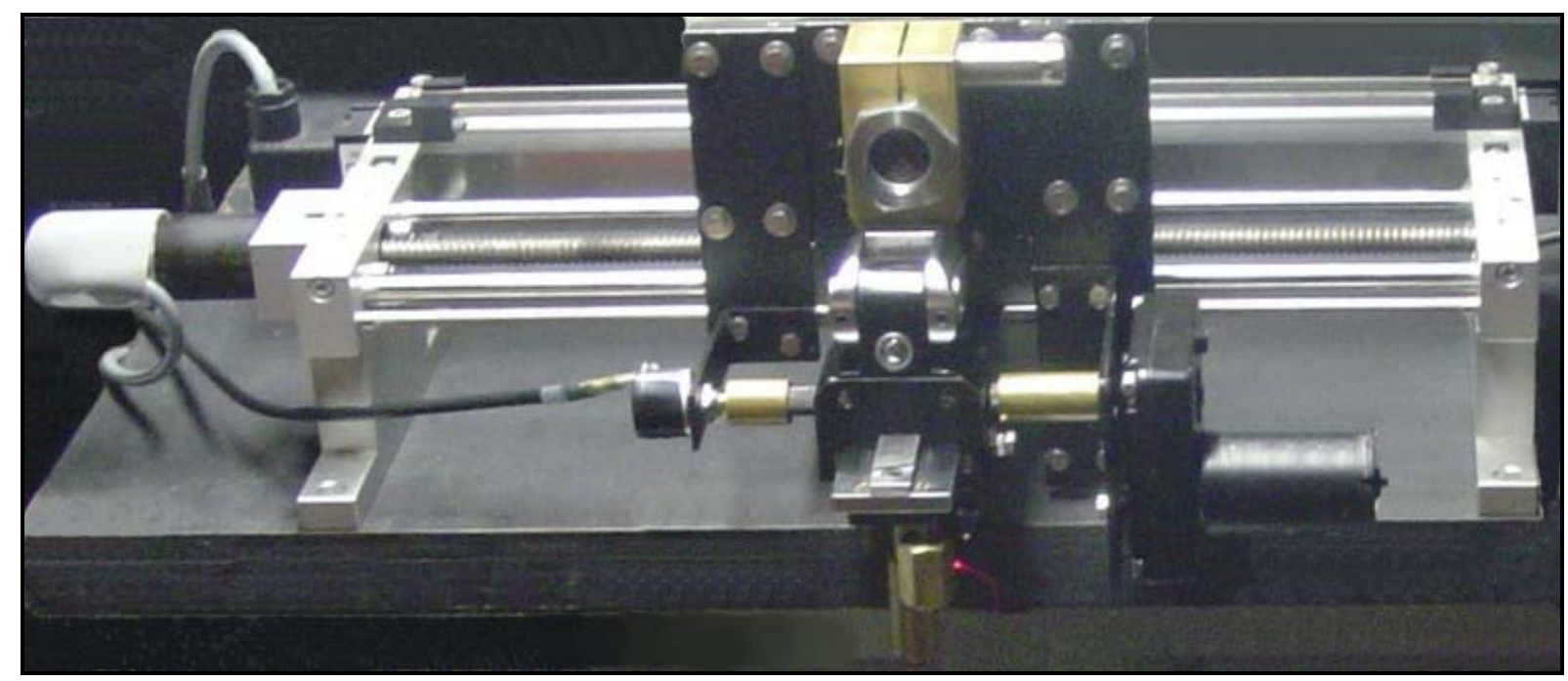

Figura 27 - Sistema de posicionamento $X Y$ montado para realizar a varredura do laser sobre 0 sensor MOS.

\subsection{A câmara de gás}

A câmara utilizada para condicionamento do ambiente com o dispositivo sensor foi idealizada para permitir que a luz proveniente do laser posicionado nas coordenadas $(\mathrm{x}, \mathrm{y})$ consiga atingir a superfície do sensor. Desta maneira, uma janela de vidro transparente foi colocada em uma das faces, de tal forma que o lado traseiro do dispositivo MOS estivesse em contato com uma face metálica, de forma a prover um contato elétrico além de contato físico, permitindo a transferência de calor de um aquecedor externo.

Foram colocados quatro eletrodos isolados para contato com as portas metálicas dos quatro sensores MOS fabricados na lâmina de substrato de Si. A ligação desses eletrodos com a superfície metálica dos capacitores MOS é feita utilizando um fino fio de cobre e a solda é feita com tinta condutiva (solução de prata).

A câmara possui ainda dois tubos para entrada e saída dos gases utilizados nos ensaios e seu volume interno é relativamente pequeno, evitando assim que fosse inserida mais uma capacitância volumétrica. Na Figura 28 são apresentados os detalhes construtivos da câmara de gás. 


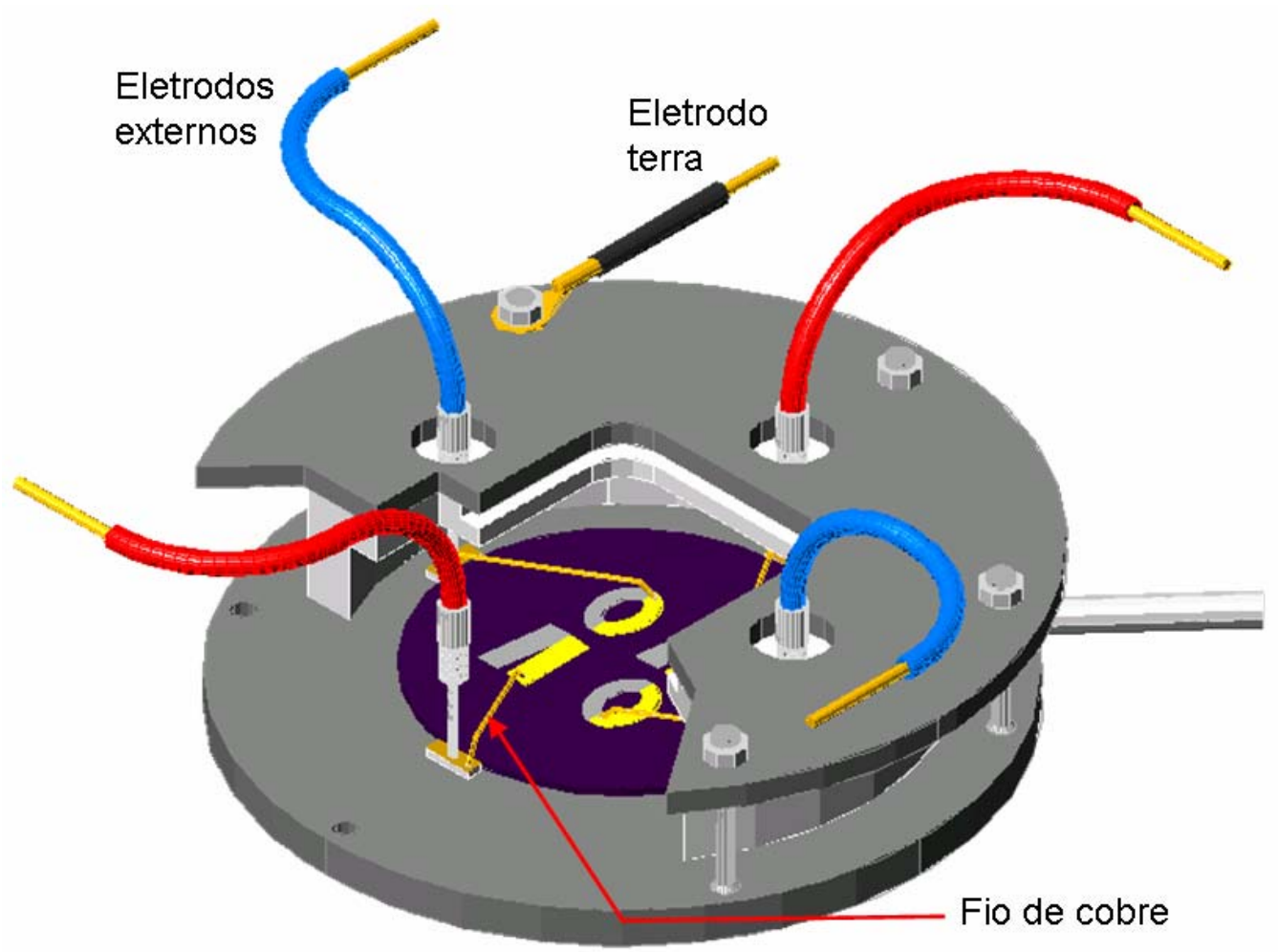

Figura 28 - Detalhes construtivos da câmara de gás.

Na Figura 29 pode ser vista a fotografia da câmara de gás com os detalhes do tubo de acesso para entrada e saída dos gases e os cabos elétricos para obtenção dos sinais provenientes do sensor MOS.

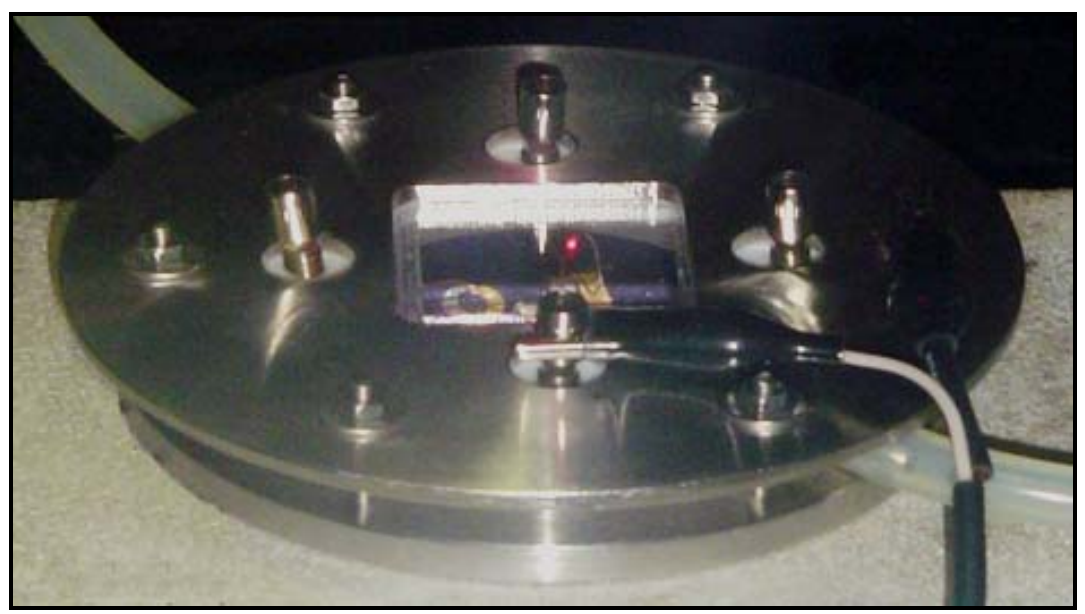

Figura 29 - Fotografia da câmara utilizada nos ensaios. 


\subsection{O Chopper}

A TELP baseia-se na excitação com feixe de luz pulsada. Para isto, foi utilizado um sistema de "Chopper". Este equipamento é composto por um disco acoplado a um motor CC, posicionado de forma perpendicular ao feixe luminoso, como mostrado na Figura 30. Desta maneira, as aletas interrompem o feixe luminoso em intervalos simétricos, modulando a luz e fazendo com que o sensor seja excitado com um sinal de luz com formato de trem de pulsos, numa freqüência de $250 \mathrm{~Hz}$.

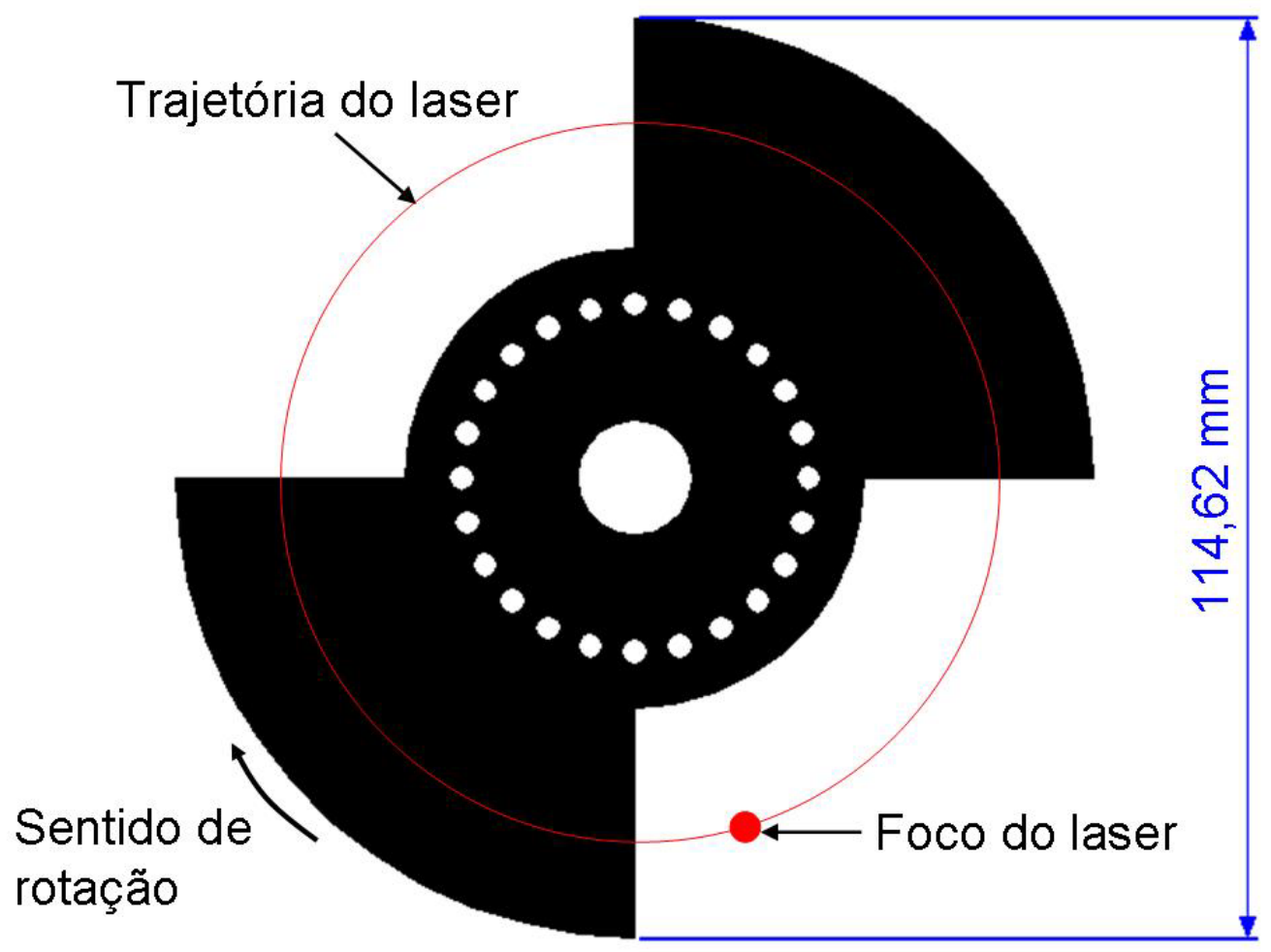

Figura 30 - Disco com aletas utilizado no chopper para modular a luz.

O equipamento utilizado é do modelo CTX-534 da Laser Precision Corp., que possui um circuito eletrônico de controle de velocidade do motor, além de enviar um sinal de sincronismo para a placa de aquisição utilizada no arranjo experimental.

\subsection{Sistema de posicionamento $X Y$ e aquisição de sinais}

A varredura do sensor inicialmente era realizada manualmente por um posicionador $\mathrm{X} Y$, onde o usuário posicionava o laser e através de um osciloscópio obtinha os 
dados para determinar a presença e a concentração dos gases $\mathrm{H}_{2}, \mathrm{NH}_{3}$ e $\mathrm{N}_{2}$. Desta maneira, a precisão e o número de pontos da varredura eram limitados à habilidade do usuário, e os dados obtidos eram armazenados e tratados manualmente. $O$ tempo médio para realizar esse procedimento era de cerca de duas horas.

Desenvolveu-se então uma ferramenta computacional que aplica controle PID a motores elétricos de corrente contínua, para controlar e automatizar a varredura do capacitor MOS. A obtenção dos dados experimentais e aplicação dos sinais de controle foram realizados pela placa de aquisição de dados AT-MIO-16X da

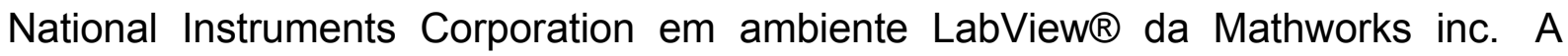
exatidão de cada passo de varredura é de $10 \mu \mathrm{m}$, sendo de suma importância para a correta caracterização da superfície de resposta da fotocorrente. Insere-se a posição inicial, a posição final e o número de passos desejado entre os dois intervalos. Os valores a serem varridos são, então, gerados automaticamente e os dados adquiridos tratados em tempo real para que a resposta do sensor seja analisada. A implementação do sistema desenvolvido ocasionou a diminuição do tempo de varredura. Essa era realizada manualmente em 2 horas e, através do sistema automatizado, em cerca de 4 minutos. A Figura 31 mostra o sistema de controle de posição, aquisição e pré-processamento do sinal de resposta do sensor programado no ambiente LabView $\Re$. No anexo do presente trabalho são apresentados os códigos do programa correspondente ao sistema de posicionamento $\mathrm{X} Y$, préprocessamento do sinal (cálculo da integral da fotocorrente pulsada) e controle PID. 


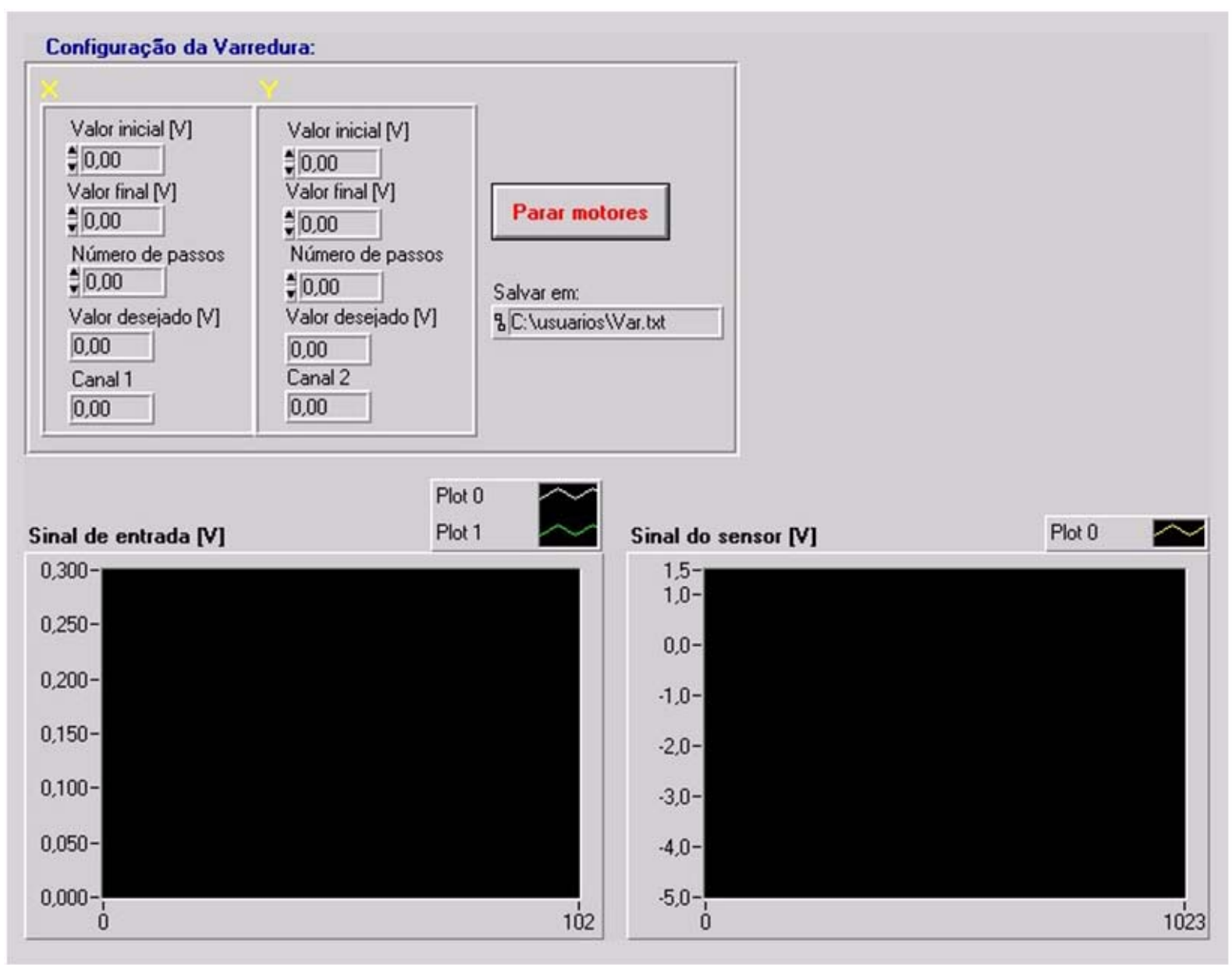

Figura 31 - Sistema de controle de posição desenvolvido em LabView ${ }^{\circledR}$.

A Figura 32 mostra os blocos que compõem o programa de controle do posicionador.

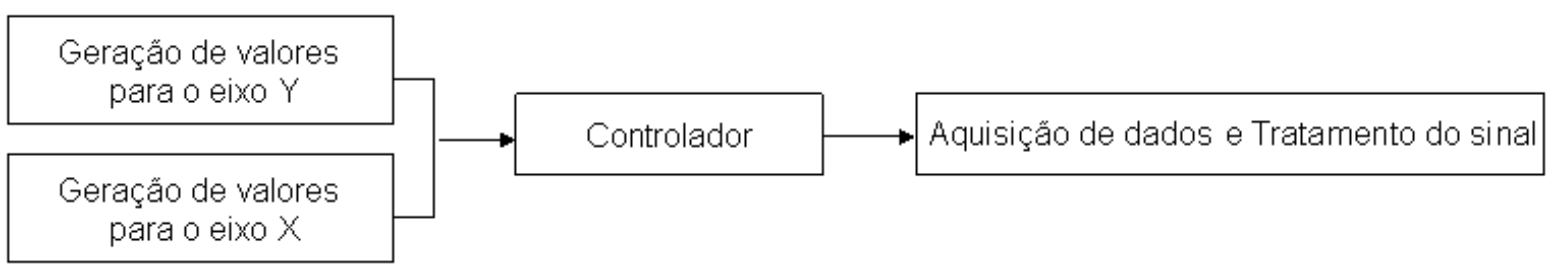

Figura 32 - Blocos que compõe o programa de controle do posicionador.

\subsection{Ferramenta computacional para determinar os pontos inicial e final da varredura}

O sistema desenvolvido traz ainda uma ferramenta computacional para determinar os pontos inicial e final da varredura. $\mathrm{O}$ ajuste pode ser feito local ou remotamente. 
Quando configurado para operar localmente, o operador deve inserir no campo do programa "valor desejado", o valor que deve ser buscado. Se configurado para operar remotamente, o operador utiliza um potenciômetro multivoltas ligado às entradas analógicas da placa de aquisição de dados AT-MIO-16X da National Instruments Corporation para determinar os pontos de leitura. A Figura 33 mostra o sistema desenvolvido para determinar os pontos inicial e final de varredura, e o código do programa é apresentado no anexo A.

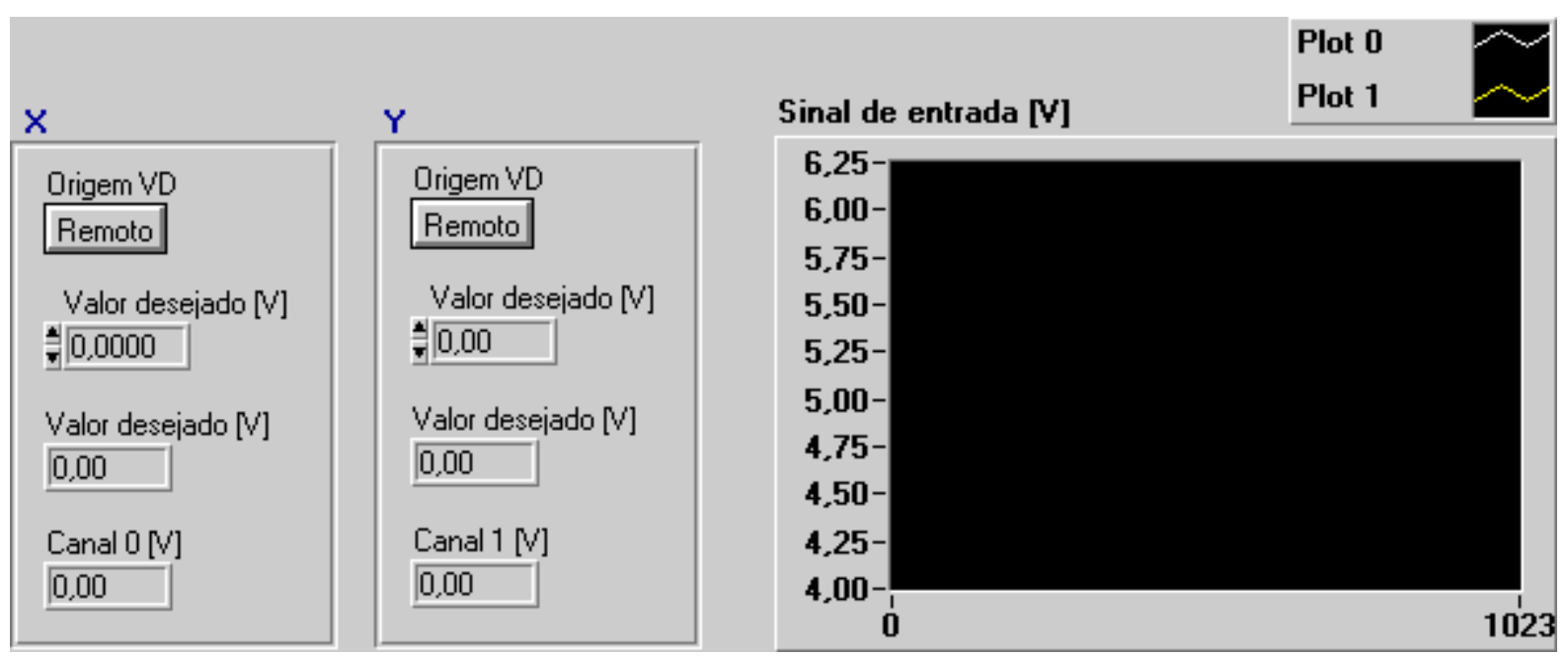

Figura 33 - Sistema para determinar os pontos inicial e final de varredura.

O diagrama de blocos do programa é mostrado na Figura 34.

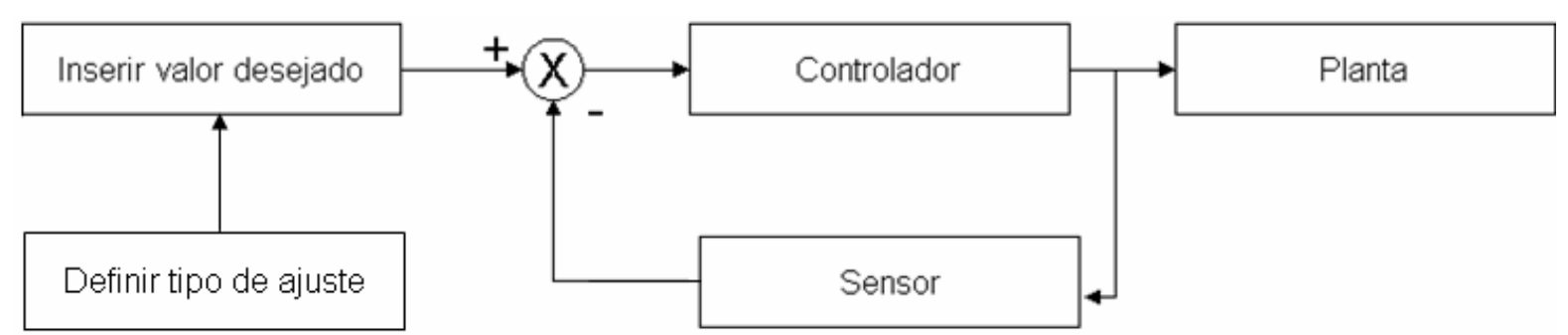

Figura 34 - Diagrama de blocos do programa para determinar os pontos inicial e final da varredura. 


\subsection{Ferramenta computacional para determinar o tempo de adsorção e dessorção}

Foi desenvolvida uma ferramenta para determinar o tempo de adsorção e dessorção dos gases (Figura 35). Nesse programa o valor do eixo $Y$ é mantido fixo e os valores do eixo $X$ são gerados em tempo-real pela inserção dos valores inicial e final do número de medições e do intervalo de tempo entre elas nos pontos que devem ser varridos. O programa informa o tempo corrente da varredura e o tempo necessário para que ela seja concluída.

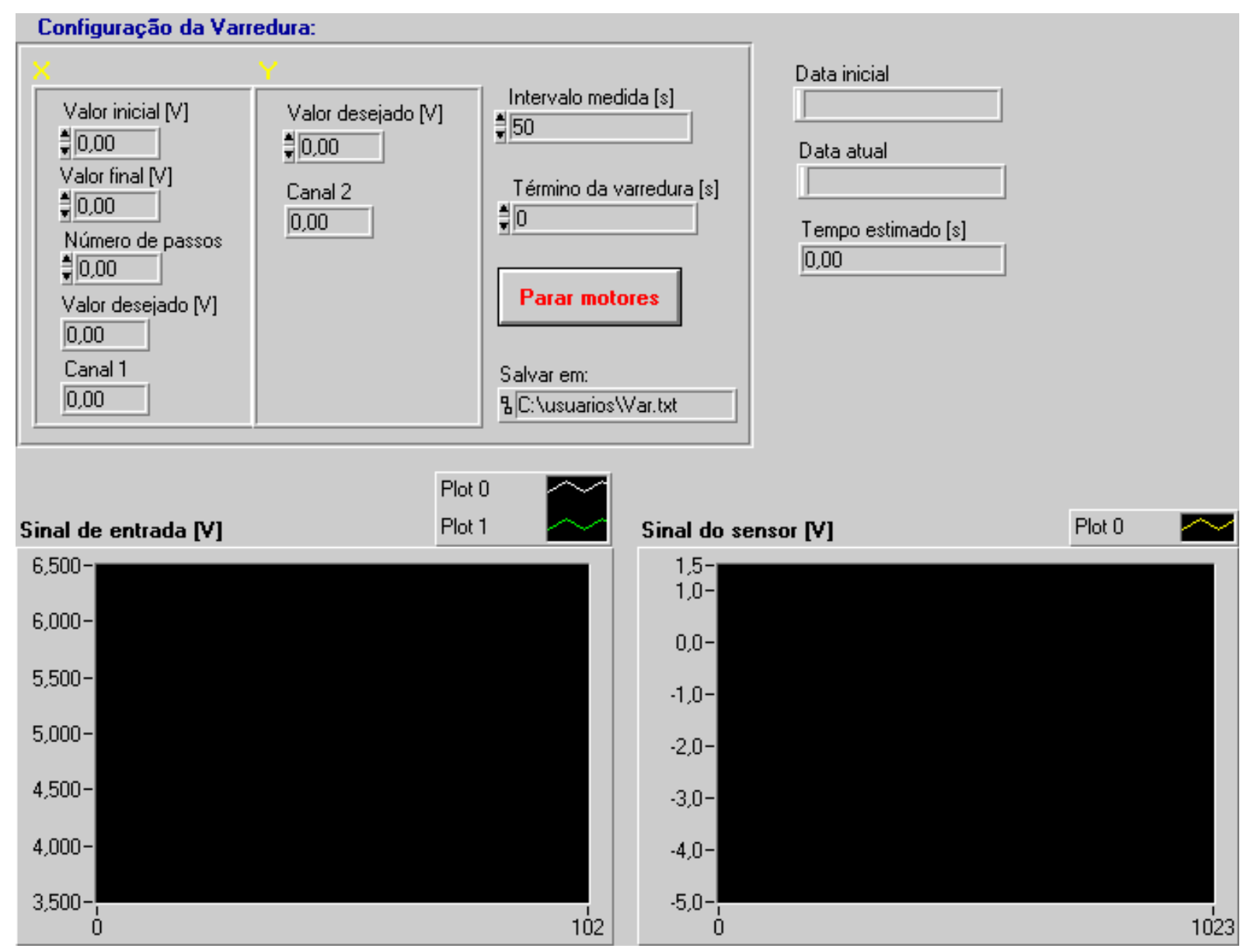

Figura 35 - Sistema para determinar o tempo de adsorção e dessorção do sensor MOS.

O diagrama de blocos do programa é mostrado na Figura 36 


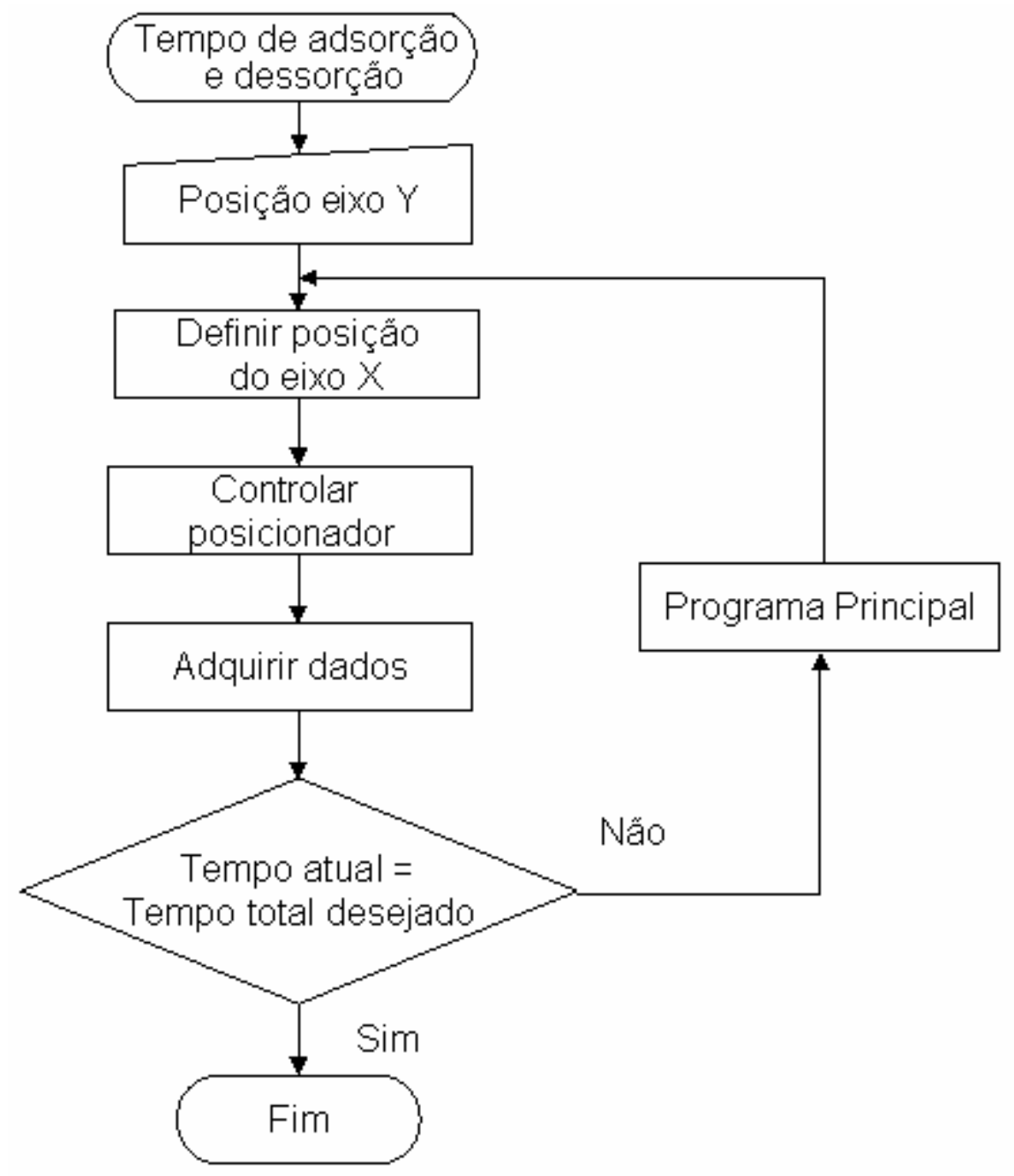

Figura 36 - Diagrama de blocos do programa para determinar o tempo de adsorção e dessorção do capacitor MOS.

\subsection{Arranjo experimental}

O arranjo experimental foi montado a fim de implementar a TELP nos ensaios. Desta maneira, o posicionador, utilizado para fazer a varredura através do deslocamento do diodo laser ( $650 \mathrm{~nm}, 3 \mathrm{~mW}$ ), foi instalado de forma que o feixe luminoso incidisse sobre a janela do chopper CTX-534, Laser Precision Corp., utilizado para modular a luz, e também sobre a janela de vidro da câmara.

A fotocorrente gerada pela incidência da luz condicionada com uso de um amplificador de transimpedância é lida utilizando-se a placa de aquisição NATIONAL INSTRUMENTS modelo AT-MIO-16X. O instrumento virtual desenvolvido 
simultaneamente apresenta os controles para o sistema de posicionamento e aquisição dos sinais.

O chopper é composto de um motor com velocidade controlada com um disco de aletas que, ao girar, interrompe e permite a passagem da luz em intervalos definidos. A freqüência da modulação da luz utilizada nos ensaios foi de $250 \mathrm{~Hz}$.

A mistura gasosa foi realizada por um sistema de diluição de gases com medidores de fluxo do tipo rotâmetro (Figura 23).

A Figura 37 mostra o diagrama esquemático do arranjo experimental da TELP.

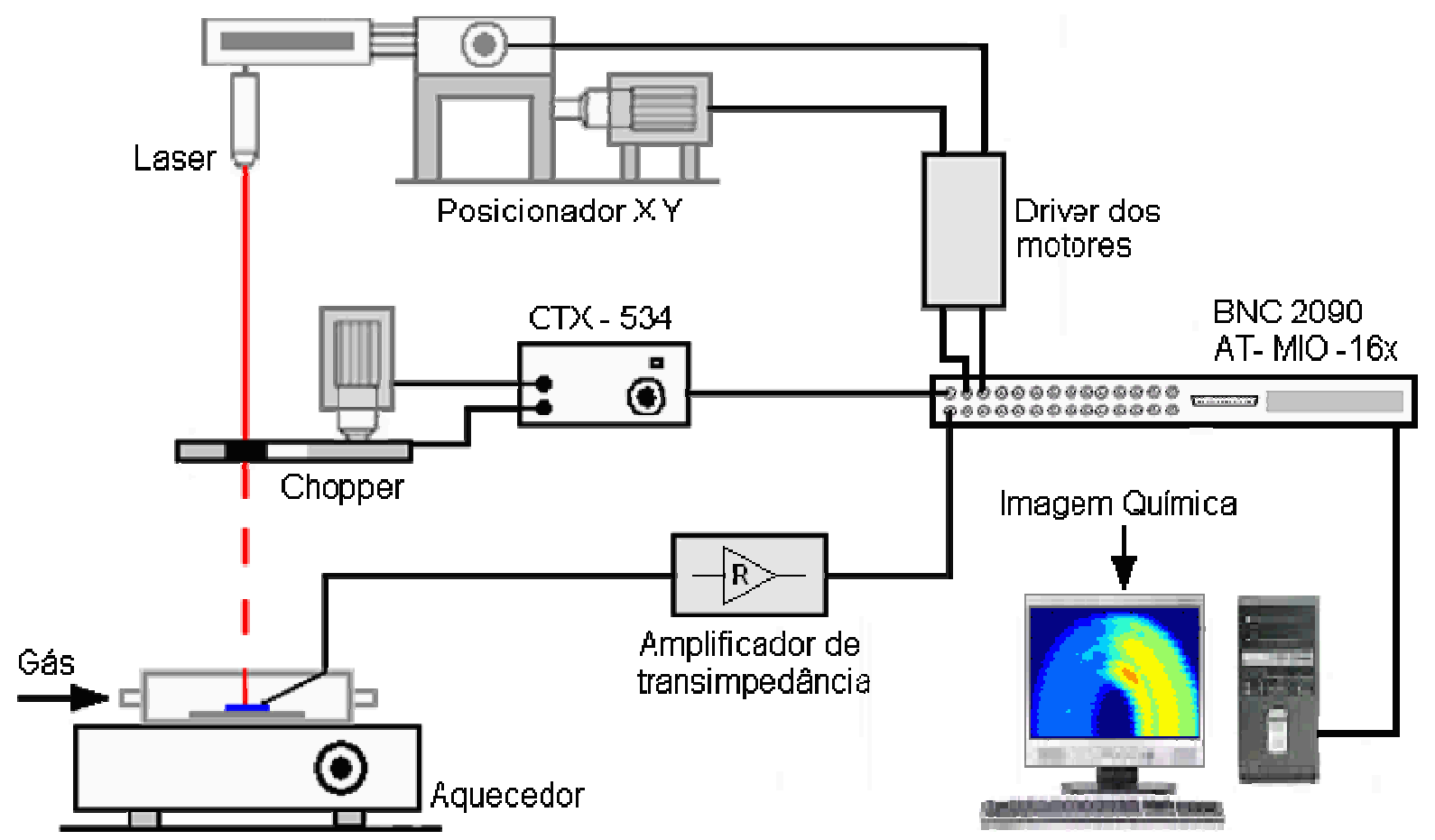

Figura 37 - Diagrama esquemático do arranjo experimental da TELP.

O Sistema real de obtenção de imagens químicas representativas pela TELP é mostrado na Figura 38. 


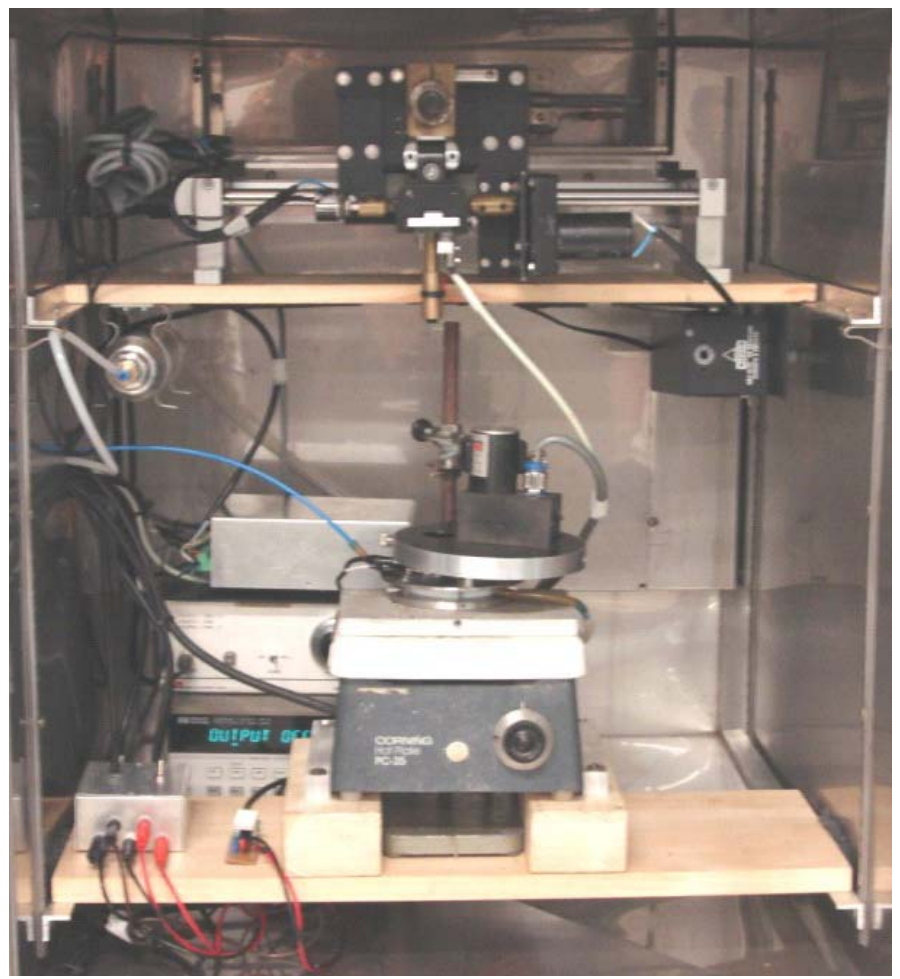

Figura 38 - Fotografia do arranjo experimental do sistema de obtenção de imagens químicas. 


\section{RESULTADOS E DISCUSSÕES}

Neste capítulo serão apresentados os resultados experimentais dos ensaios elétricos, aos quais os dispositivos foram submetidos. Ao mesmo tempo, os resultados serão interpretados discutindo-se suas conseqüências. Primeiramente, serão apresentados e discutidos os resultados das curvas CxV de cada dispositivo, a partir das quais serão extraídos os parâmetros tecnológicos e de projeto dos dispositivos. A seguir, serão apresentadas as respostas dos dispositivos em diferentes ambientes gasosos, discutindo-se sua sensibilidade, tempo de resposta e perfil de resposta em relação à posição na superfície do sensor, para finalmente apresentar as imagens químicas dos sensores como resposta à exposição aos diferentes gases utilizados nos ensaios experimentais.

\subsection{Curva capacitância-tensão (CxV) em alta e baixa freqüência}

As curvas da capacitância diferencial em função da tensão de polarização dos dispositivos MOS foram obtidas por excitação, com sinais senoidais de amplitude 50 $\mathrm{mV}$ e freqüências de $100,1 \mathrm{k}, 10 \mathrm{k}$ e $100 \mathrm{kHz}$, respectivamente. As curvas $\mathrm{CxV}$, obtidas a $100 \mathrm{~Hz}$ são denominadas de curvas $\mathrm{CxV}$ de baixa freqüência. Já as obtidas a $100 \mathrm{kHz}$ são denominadas de curvas $\mathrm{CxV}$ em alta freqüência.

As curvas $\mathrm{CxV}$ de alta e baixa freqüência foram obtidas utilizando-se o equipamento FRA $\mu$ AutoLab Type III existente no Laboratório de Microeletrônica, fazendo-se uma varredura da tensão de polarização de $-3 \vee$ até $2,5 \vee$. $O$ ensaio foi realizado à temperatura ambiente $\left(25^{\circ} \mathrm{C}\right)$ e na ausência de luz.

Na Figura 39 são apresentadas as curvas CxV para o sensor MOS com formato de elipse e a respectiva estrutura deste sensor. 


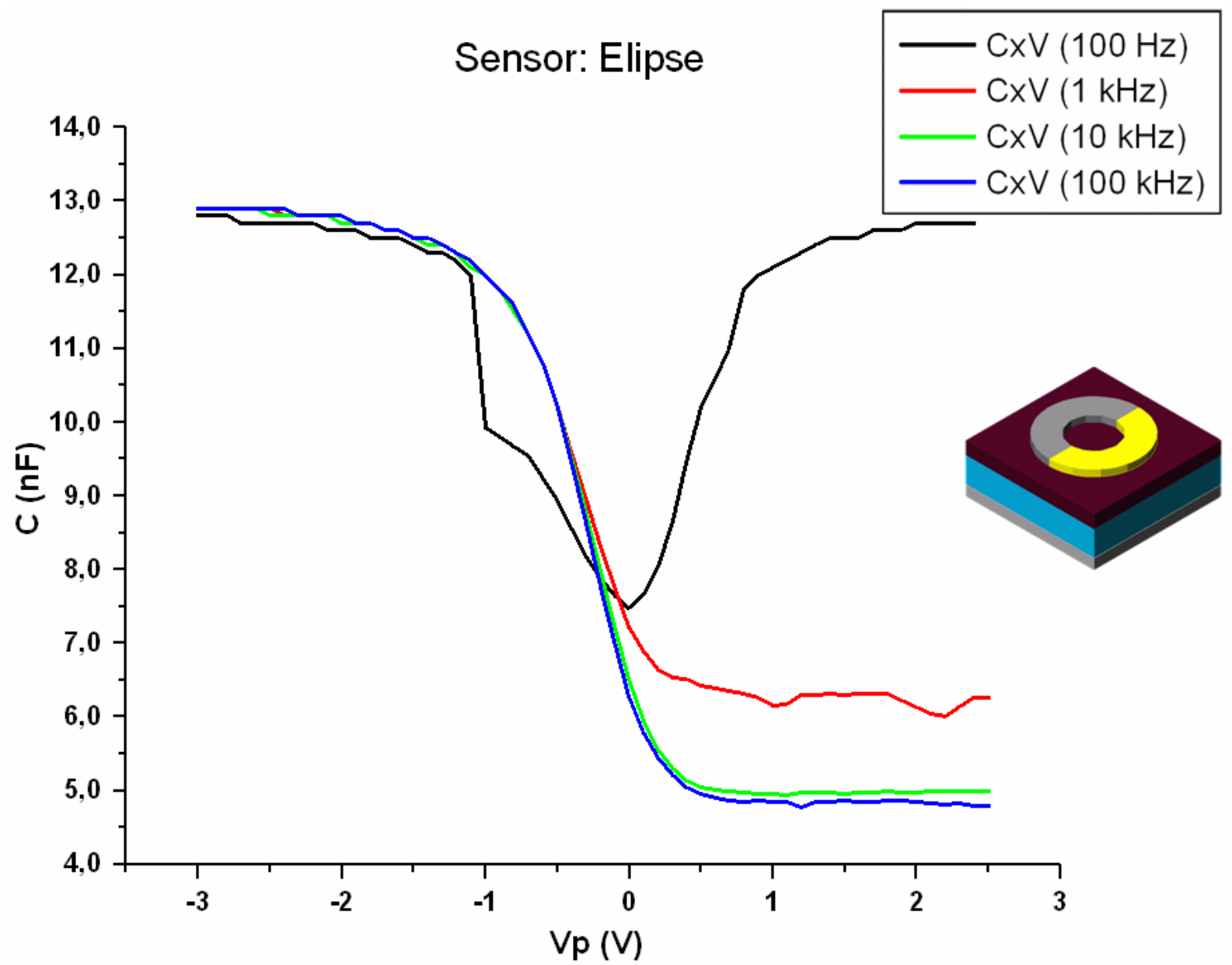

Figura 39 - Curva CxV do capacitor MOS em forma de elipse.

A capacitância do dispositivo MOS convencionalmente pode ser modelada por um circuito série equivalente a dois capacitores: um correspondente à capacitância do óxido, denominada $\mathrm{C}_{\mathrm{ox}}$, e a outra correspondente à capacitância do semicondutor, denominada de $\mathrm{C}_{\mathrm{sc}}$ (Figura 40-a).

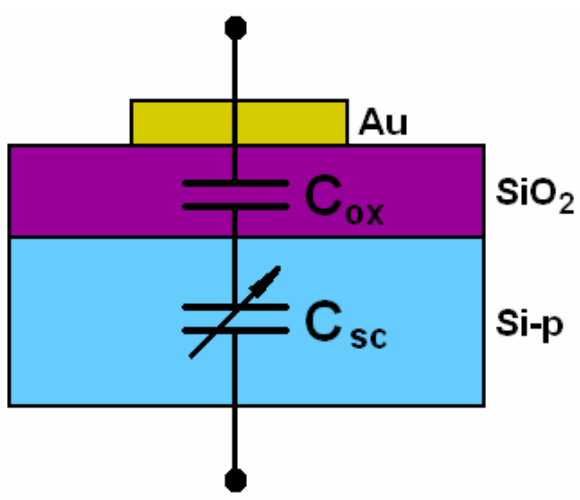

a)

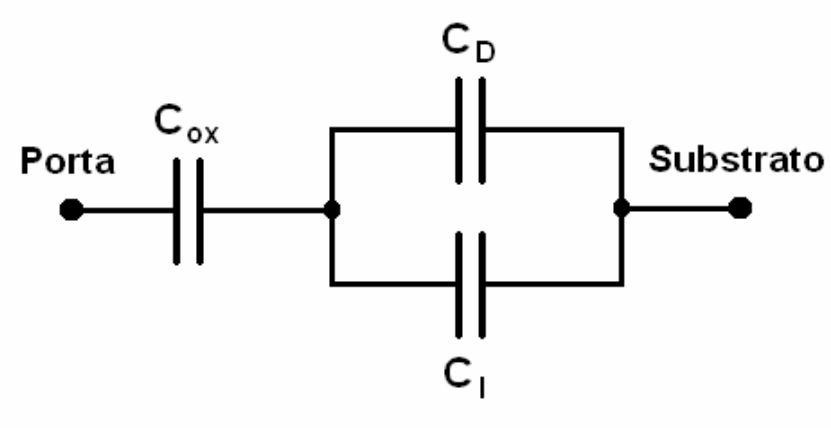

b)

Figura 40 - Circuito equivalente do capacitor MOS, representando em (a) a série dos capacitores $\mathrm{C}_{\mathrm{ox}}$ e $\mathrm{C}_{\mathrm{sc}}$ e em (b) o modelo equivalente de capacitâncias para um capacitor em regime de inversão, onde $C_{s c}\left(C_{D}+C_{1}\right)$ é a capacitância gerada pela camada de depleção. 
Na região de acumulação, a densidade de portadores majoritários na interface $\mathrm{SiO}_{2} / \mathrm{Si}$ supera a concentração no substrato. Assim, $\mathrm{C}_{\mathrm{sc}}$ começa a ser muito maior do que $\mathrm{C}_{\mathrm{ox}}$, resultando numa capacitância do dispositivo MOS, aproximadamente igual a $\mathrm{C}_{\mathrm{ox}}$. Considera-se que na região de acumulação, a $\mathrm{C}_{\mathrm{sc}}$ é devida a portadores majoritários, cuja resposta em tempo é muito rápida $\left(10^{-12} \mathrm{~s}\right)$, de tal forma que facilmente responde a sinais de elevada freqüência. Isto significa que a capacitância MOS independe da freqüência nesta região, como pode ser observado na Figura 39 $(\mathrm{Vp}<-1 \mathrm{~V})$. Na região de transição ou depleção $(-1 \mathrm{~V}<\mathrm{Vp}<1 \mathrm{~V})$, a capacitância $\mathrm{C}_{\mathrm{sc}}$ é controlada pela camada de depleção $\left(C_{D}\right), C_{S C}=C_{D}$. À medida que a tensão aplicada é aumentada no sentido positivo, a largura da camada de depleção cresce, promovendo o decrescimento de $C_{D}\left(<C_{0 x}\right)$. Assim, a capacitância do dispositivo MOS decresce nesta região (Figura 39). Nesta região, $C_{s c}$ é controlada pelos portadores majoritários (lacunas), sugerindo que a capacitância do dispositivo MOS seja independente da freqüência. No entanto, na curva de baixa freqüência observamos uma diferença da curva $\mathrm{CxV}$ em relação às obtidas em outras freqüências. Este resultado pode ser devido à existência de cargas móveis no interior do óxido, às quais, em baixas freqüências, conseguem acompanhar a variação do sinal de excitação. Já em freqüências intermediárias e altas, seu efeito é desprezível devido ao seu longo tempo de relaxamento. Na região de inversão (Vp > $1 \mathrm{~V}$ ), a capacitância $\mathrm{C}_{\mathrm{sc}}$ passa a ter uma contribuição de portadores minoritários (elétrons) confinados na interface $\mathrm{SiO}_{2} / \mathrm{Si}$. Neste caso, $\mathrm{C}_{\mathrm{sc}}$ pode ser modelado por uma conexão em paralelo formada pelas capacitâncias de depleção $C_{D}$ e de inversão $C_{\mid}$(Figura 40-b). Em baixa freqüência, tanto os portadores minoritários como os majoritários conseguem acompanhar o sinal de excitação, e como $C_{\mid}>C_{D}$ e $C_{o x}$, então a capacitância do dispositivo MOS apresenta o valor de $C_{o x}$ (Figura 39). No entanto, para sinais de alta freqüência os portadores minoritários não conseguem acompanhar o sinal de excitação, já que o tempo de resposta destes portadores é da ordem de $10 \mathrm{~ms}$ até $1 \mathrm{~s}$. Assim, $\mathrm{C}_{\mathrm{S}}$ passa a ser praticamente igual a $\mathrm{C}_{\text {Dminimo }}<$ $\mathrm{C}_{\mathrm{ox}}$. Assim, a capacitância do dispositivo MOS na região de inversão forte, resulta numa capacitância mínima, como observado na Figura 39. No caso das curvas CxV do dispositivo MOS em formato de cunha (Figura 41), a argumentação para seu comportamento em baixa e alta freqüência são as mesmas em relação às descritas anteriormente. No entanto, pode ser observado que a curva de baixa freqüência mostrou-se diferente em relação ao dispositivo da Figura 39. Este resultado pode ser 
devido à diferença na concentração de níveis de armadilha no substrato que como veremos mais adiante compromete o tempo de resposta dos sensores.

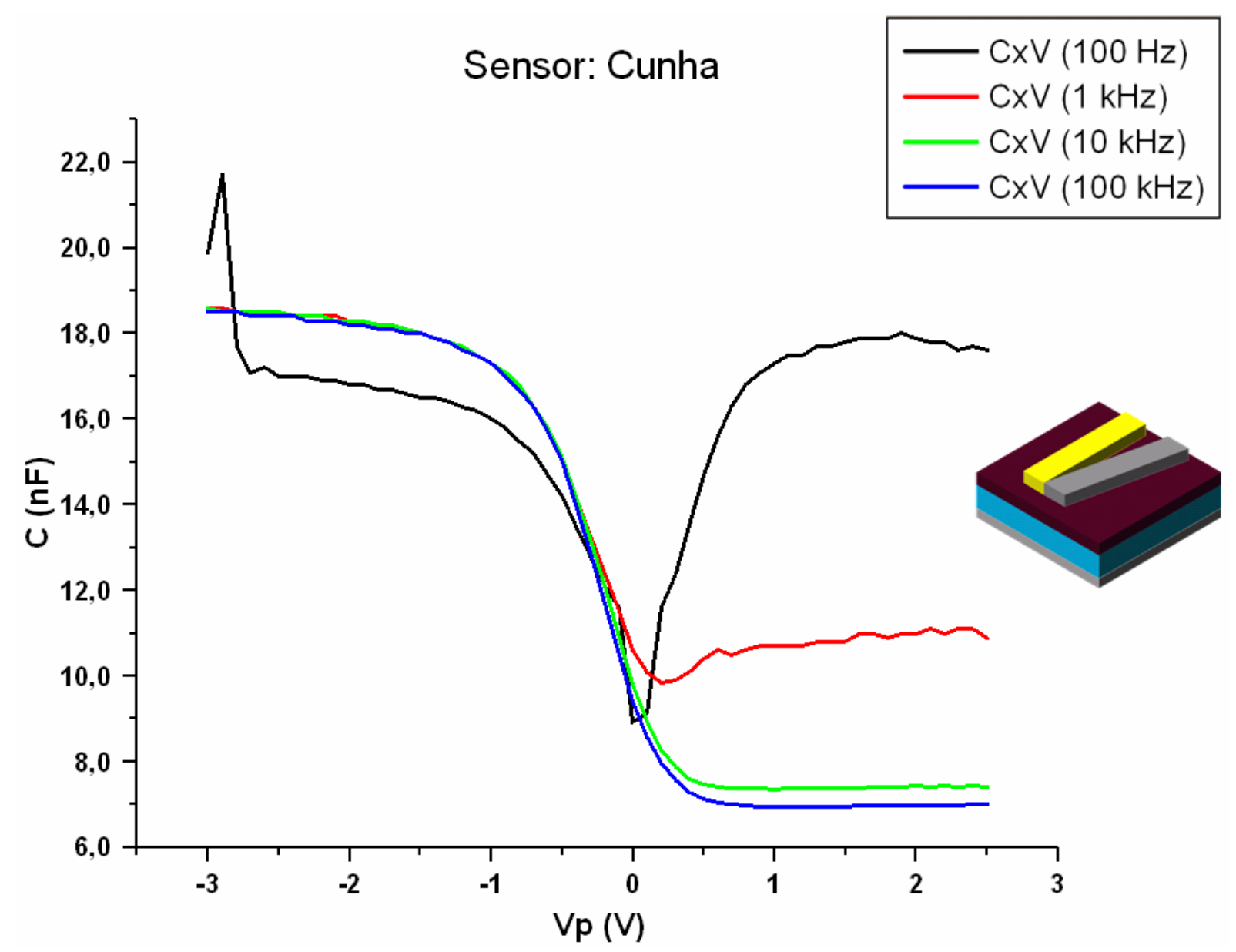

Figura 41 - Curva CxV do capacitor MOS em forma de cunha.

A partir da curva $\mathrm{CxV}$ em alta freqüência $(100 \mathrm{kHz})$ foram determinados os parâmetros tecnológicos dos dispositivos. Para tal fim, foram utilizados os valores de capacitância máxima e mínima da curva, utilizando CxV juntamente com as eq.(1) a eq.(8) da seção 2.1. Os dispositivos MOS, projetados no presente trabalho, apresentam eletrodos de porta formados por dois metais e denominados de portas bimetálicas, sendo necessário, nestes casos, considerar o valor médio das funções trabalho de ambos os metais, desde que os seus valores sejam aproximadamente iguais, $\phi \mathrm{Au}=5.10 \mathrm{eV}$ e $\phi \mathrm{Pd}=5.12 \mathrm{eV}$; resultando assim, num $\phi_{\text {médio }}=5,11 \mathrm{eV}$. Utilizando-se este valor, foram determinados os parâmetros tecnológicos do sensor no formato de elipse: 
Espessura do óxido: $113 \mathrm{~nm}$

Concentração efetiva do substrato $=2,410^{15} \mathrm{~cm}^{-3}$

Largura máxima da camada de depleção $=5,710^{-5} \mathrm{~cm}$

Cargas efetivas no óxido $=1,1610^{11}$ cargas $/ \mathrm{cm}^{2}$

Tensão de banda plana $=-0,5 \mathrm{~V}$

De forma semelhante ao dispositivo anterior, foram determinados os parâmetros tecnológicos do dispositivo com eletrodos bimetálicos de padrão tipo cunha (Figura 41), obtendo-se os seguintes valores:

Espessura do óxido: $112 \mathrm{~nm}$

Concentração efetiva do substrato $=2,610^{15} \mathrm{~cm}^{-3}$

Largura máxima da camada de depleção $=5,510^{-5} \mathrm{~cm}$

Cargas efetivas no óxido $=1,1710^{11}$ cargas $/ \mathrm{cm}^{2}$

Tensão de banda plana $=-0,5 \mathrm{~V}$

Os resultados para ambos os dispositivos foram aproximadamente iguais, independentemente do padrão geométrico dos dispositivos, como era esperado, já que os parâmetros tecnológicos independem da geometria adotada para o dispositivo. A espessura do óxido calculada foi da ordem de 112 a $113 \mathrm{~nm}$ (valor próximo de $100 \mathrm{~nm}$ que seria o valor esperado para o procedimento de oxidação térmica adotado). No caso da concentração de dopantes no substrato, o valor calculado foi da ordem de $10^{15} \mathrm{~cm}^{-3}$, sendo concordante com a resistividade do substrato de $10 \Omega-\mathrm{cm}$, que corresponderia a um substrato com densidade de impurezas aceitadoras da ordem de $10^{15}$ a $10^{16} \mathrm{~cm}^{-3}$. Os resultados acima sugerem que os dispositivos fabricados no laboratório de Microeletrônica da USP são de boa qualidade, podendo ser aplicados para a utilização como sensores químicos.

A seguir serão apresentadas as respostas dos dispositivos MOS submetidos a diferentes ambientes de gás. Desde que a resposta elétrica é dependente da polarização dos dispositivos, será discutida e analisada a sensibilidade de resposta dos sensores em função da tensão da polarização, particularmente no caso de modo de operação TELP. 


\subsection{Estudo do comportamento da sensibilidade para diferentes tensões de polarização aplicadas ao sensor}

Como foi discutida anteriormente, a TELP depende da fotocorrente induzida, sendo esta sensível à largura da camada de depleção na região do Si. Isto implica que a sensibilidade de resposta do dispositivo depende da modulação da camada de depleção através de uma polarização externa. Neste sentido, com a finalidade de identificar a região de maior sensibilidade da fotocorrente, foram realizados ensaios de medição da fotocorrente induzida para diferentes tensões de polarização do dispositivo e em diferentes atmosferas de gás.

Da Figura 42 a Figura 47, mostram-se as curvas características $u \times V p$, onde os valores da magnitude "u" definida na secção 2.5 pela eq.(23) foram obtidos pela integração do sinal do pulso de fotocorrente. O pulso de fotocorrente foi obtido após o dispositivo ser excitado com o feixe do laser modulado com o chopper a uma freqüência de $250 \mathrm{~Hz}$. As respostas dos sensores foram obtidas em três diferentes regiões sobre a superfície dos sensores, isto é, o feixe de laser foi incidido sobre a porta de ouro, sobre a porta de paládio e sobre a região de $\mathrm{SiO}_{2}$, exposto entre elas. A magnitude " $u$ " representa a energia dos portadores gerados na região da camada de depleção e confinados na interface $\mathrm{SiO}_{2} / \mathrm{Si}$ dos dispositivos MOS. Na prática, "u" é expressa simplesmente em unidades arbitrárias (unid. arbitr.), já que especialmente para aplicações em sensores, o mais importante são as mudanças em relação à resposta de uma condição inicial de ambiente bem definida.

Da Figura 42 a Figura 47, observa-se que a magnitude "u" cresce monotonicamente à medida que a tensão de polarização passa da região de acumulação para a região de inversão. Este resultado é esperado já que, neste caso, a largura da camada de depleção cresce no mesmo sentido. Quando o feixe laser incide na região de ouro, as curvas $u \times V p$ são iguais dentro do erro experimental, mostrando-se pouco sensível ao $\mathrm{H}_{2}$ e $\mathrm{NH}_{3}$. Já na região do óxido, o sensor mostrou-se levemente sensível aos gases utilizados no ensaio. Na região de paládio, a resposta do sensor mostrou-se mais sensível, como esperado. 


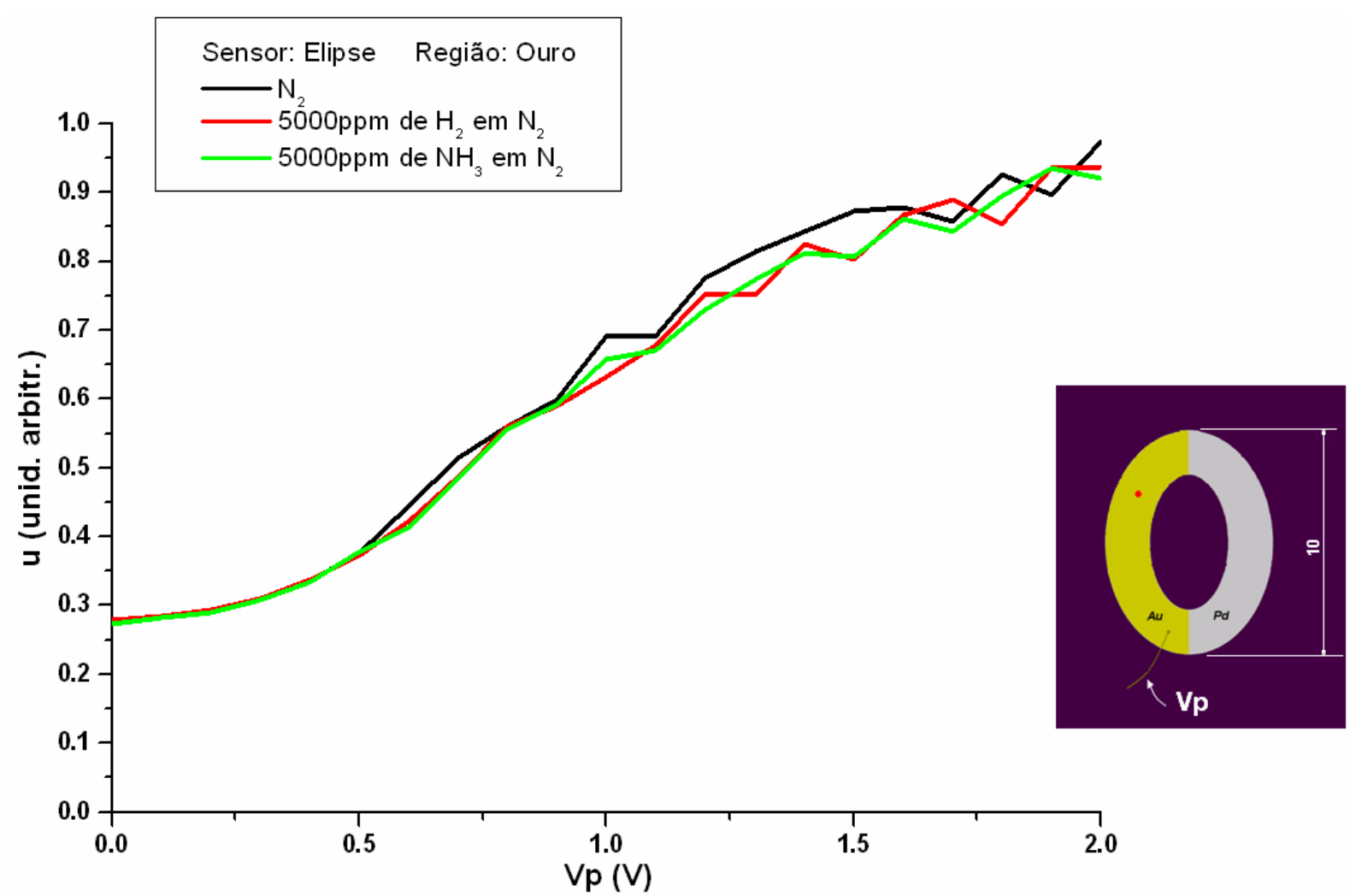

Figura 42 - Curva u x Vp sob exposição na região de ouro, a 5000 ppm de $\mathrm{H}_{2}$ (linha vermelha), a $5000 \mathrm{ppm}$ de $\mathrm{NH}_{3}$ (linha verde) e a $\mathrm{N}_{2}$ (linha preta) com o dispositivo aquecido a $90^{\circ} \mathrm{C}$. 0 local de incidência do laser é indicado na figura ao lado (ponto vermelho).

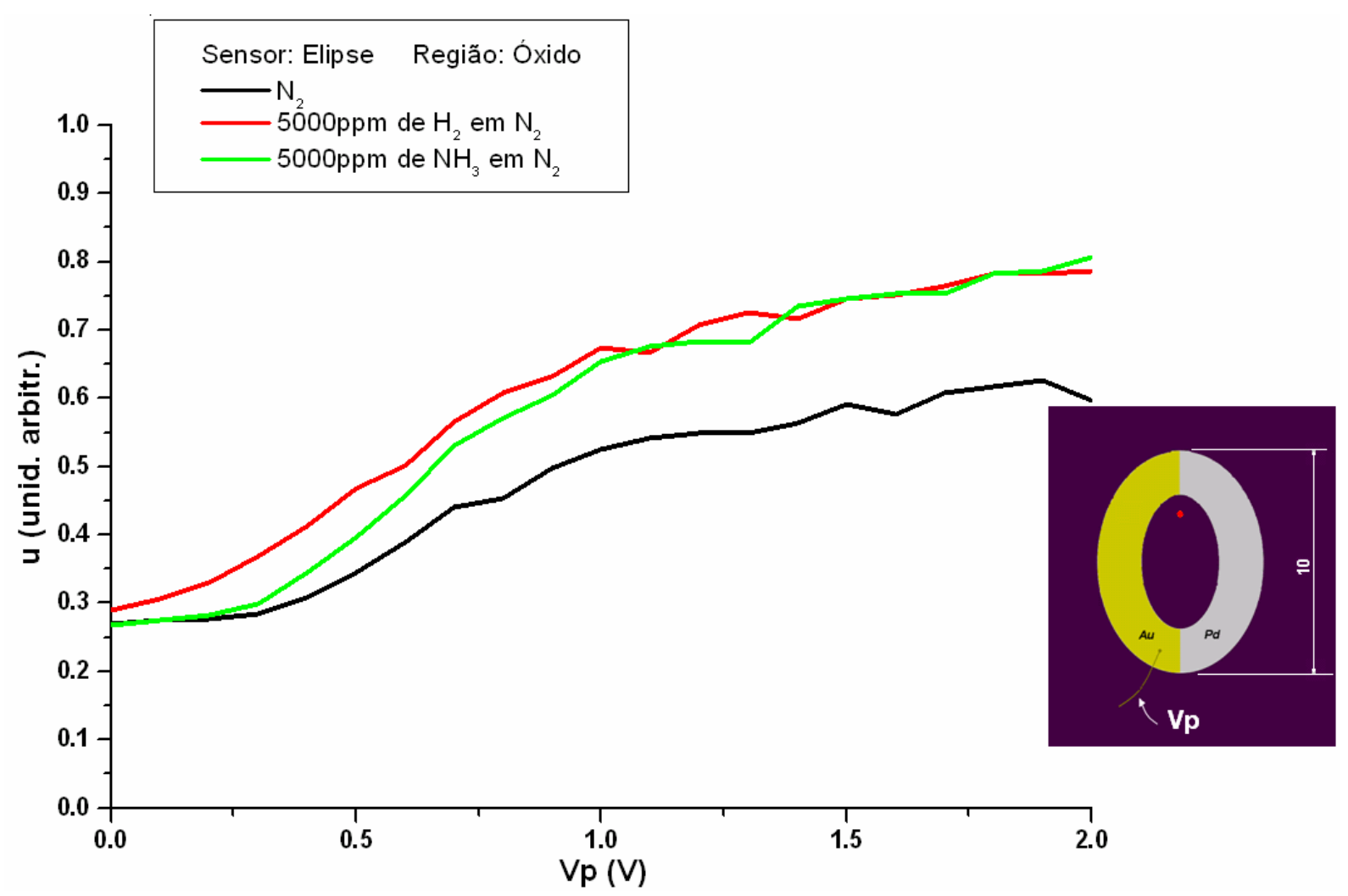

Figura 43 - Curva u $x$ Vp sob exposição na região de óxido, a $5000 \mathrm{ppm}$ de $\mathrm{H}_{2}$ (linha vermelha), a $5000 \mathrm{ppm}$ de $\mathrm{NH}_{3}$ (linha verde) e a $\mathrm{N}_{2}$ (linha preta) com o dispositivo aquecido a $90^{\circ} \mathrm{C}$. 0 local de incidência do laser é indicado na representação ao lado (ponto vermelho). 


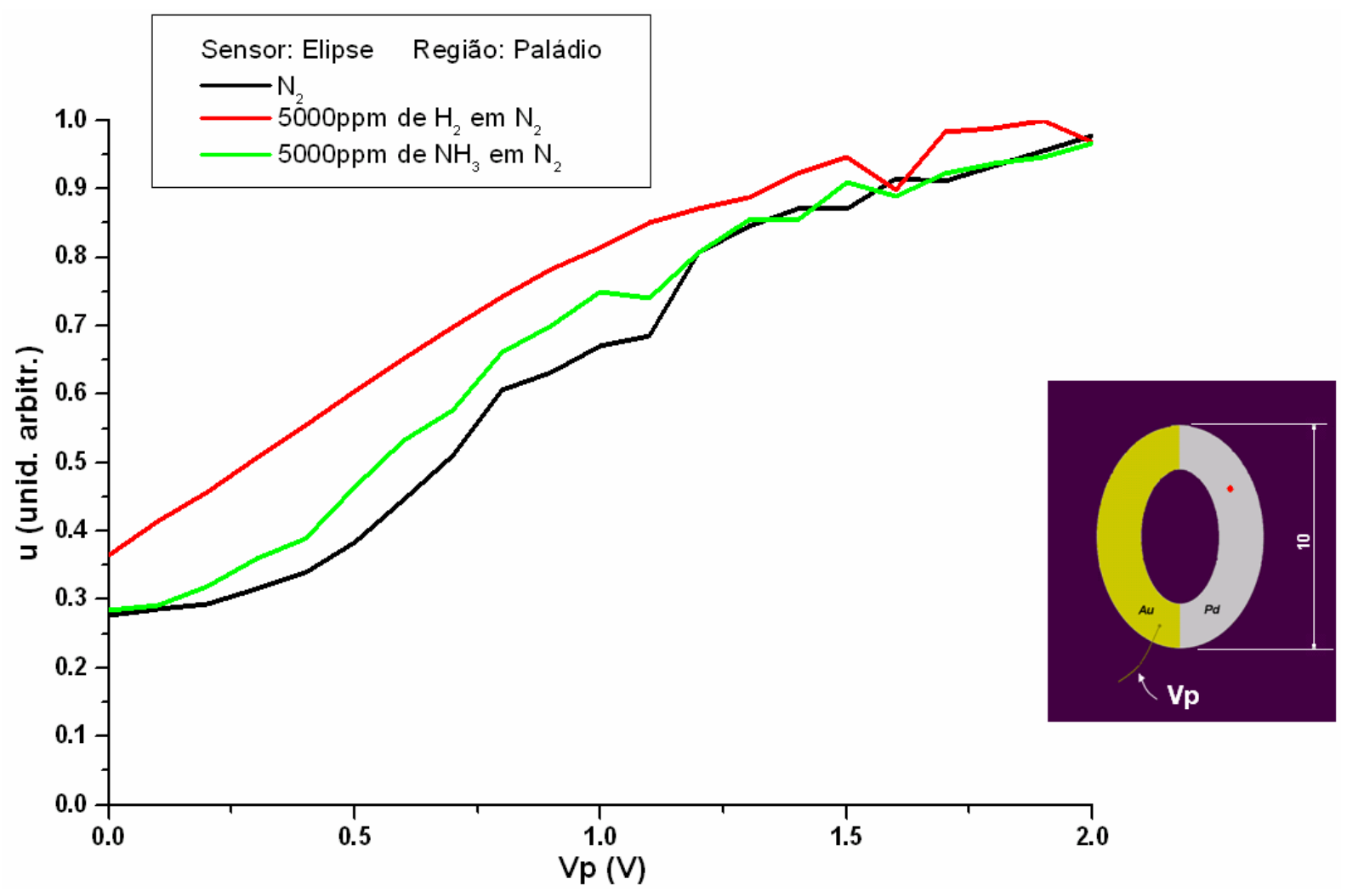

Figura 44 - Curva u $x$ Vp sob exposição na região de paládio, a 5000 ppm de $\mathrm{H}_{2}$ (linha vermelha), a $5000 \mathrm{ppm}$ de $\mathrm{NH}_{3}$ (linha verde) e a $\mathrm{N}_{2}$ (linha preta) com o dispositivo aquecido a $90^{\circ} \mathrm{C}$. O local de incidência do laser é indicado na representação ao lado (ponto vermelho).

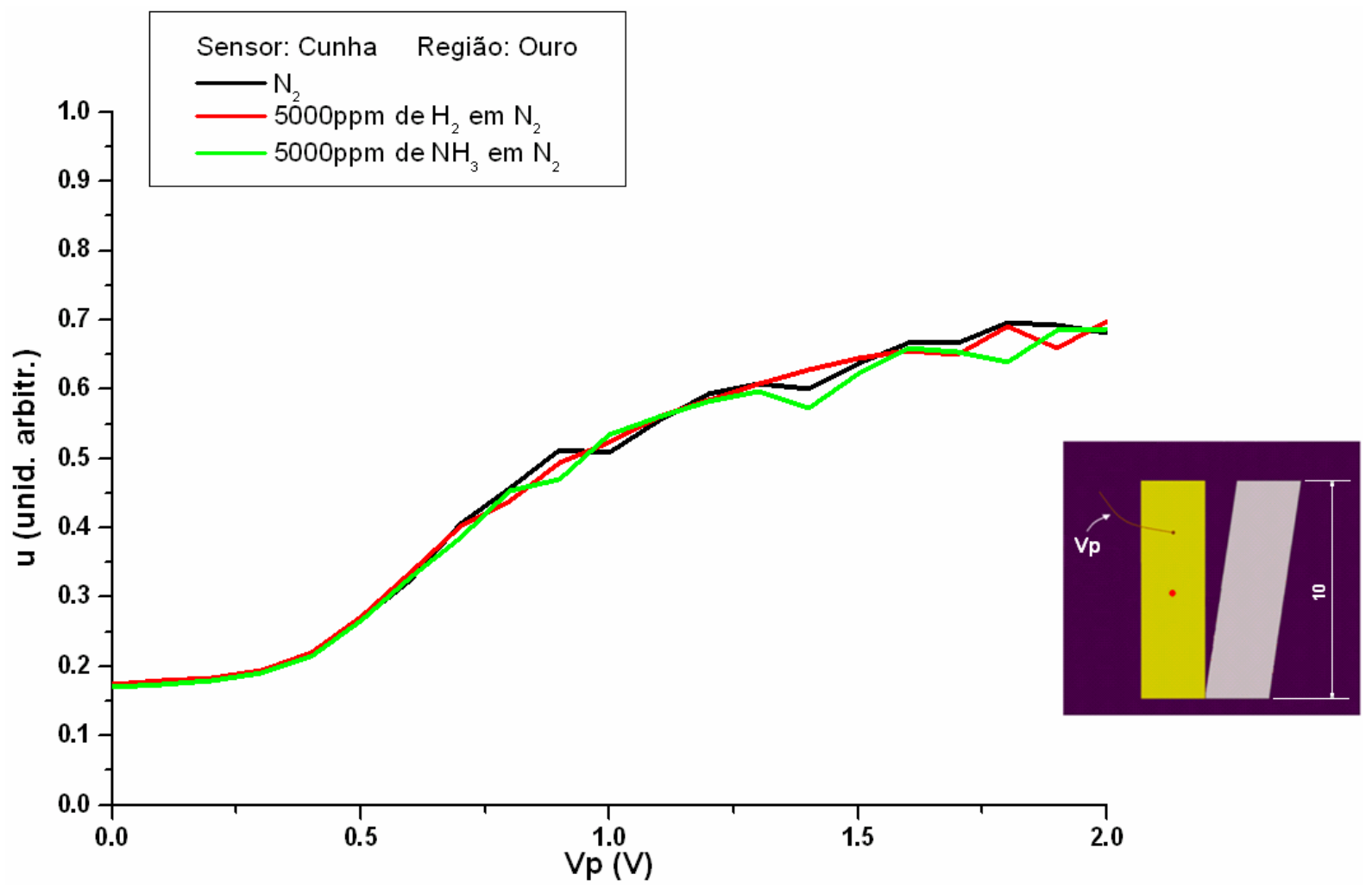

Figura 45 - Curva u x Vp sob exposição na região de ouro, a 5000 ppm de $\mathrm{H}_{2}$ (linha vermelha), a $5000 \mathrm{ppm}$ de $\mathrm{NH}_{3}$ (linha verde) e a $\mathrm{N}_{2}$ (linha preta) com o dispositivo aquecido a $90^{\circ} \mathrm{C}$. 0 local de incidência do laser é indicado na representação ao lado (ponto vermelho). 


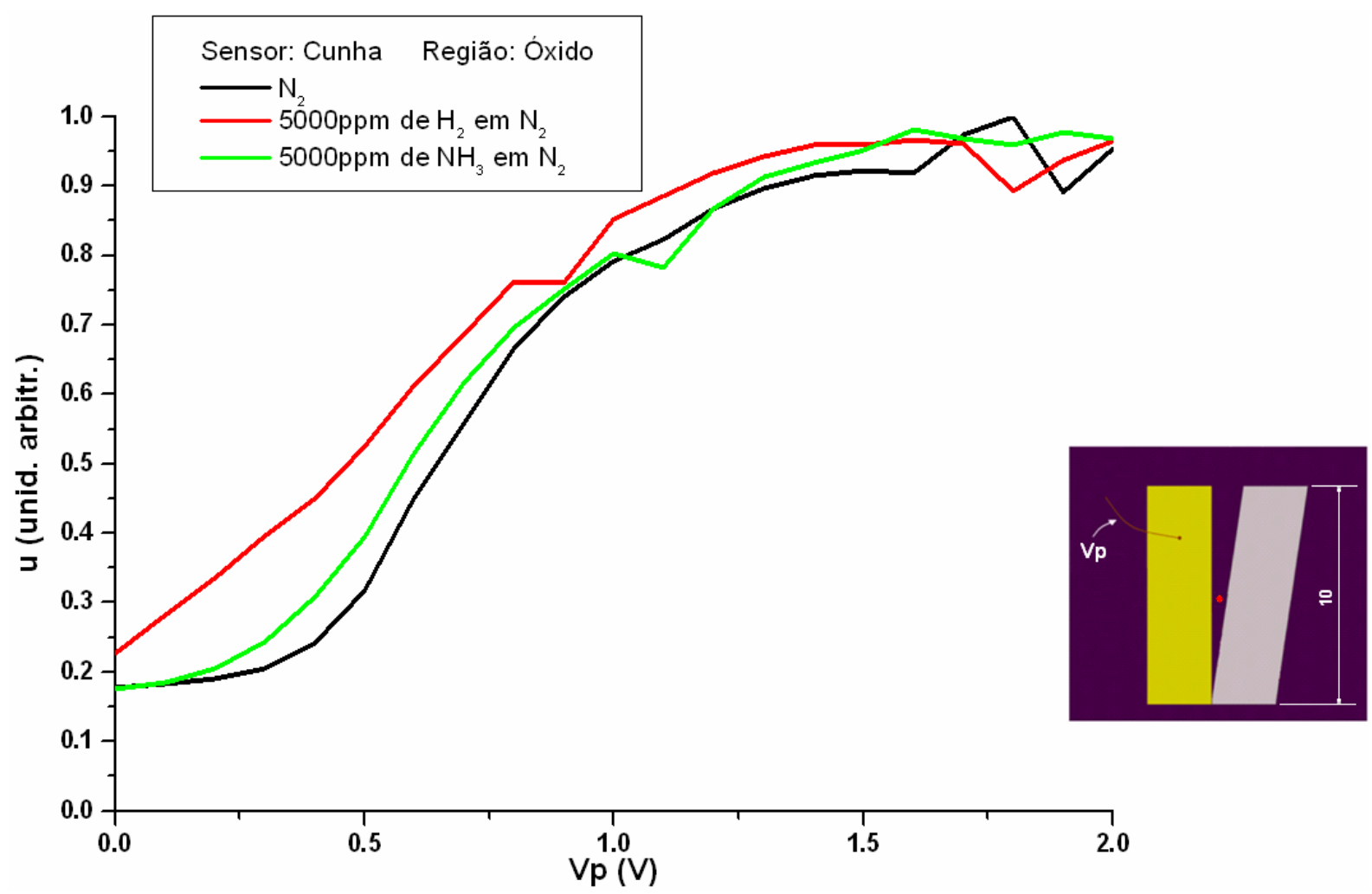

Figura 46 - Curva u x Vp sob exposição na região de ouro, a 5000 ppm de $\mathrm{H}_{2}$ (linha vermelha), a $5000 \mathrm{ppm}$ de $\mathrm{NH}_{3}$ (linha verde) e a $\mathrm{N}_{2}$ (linha preta) com o dispositivo aquecido a $90^{\circ} \mathrm{C}$. 0 local de incidência do laser é indicado na representação ao lado (ponto vermelho).

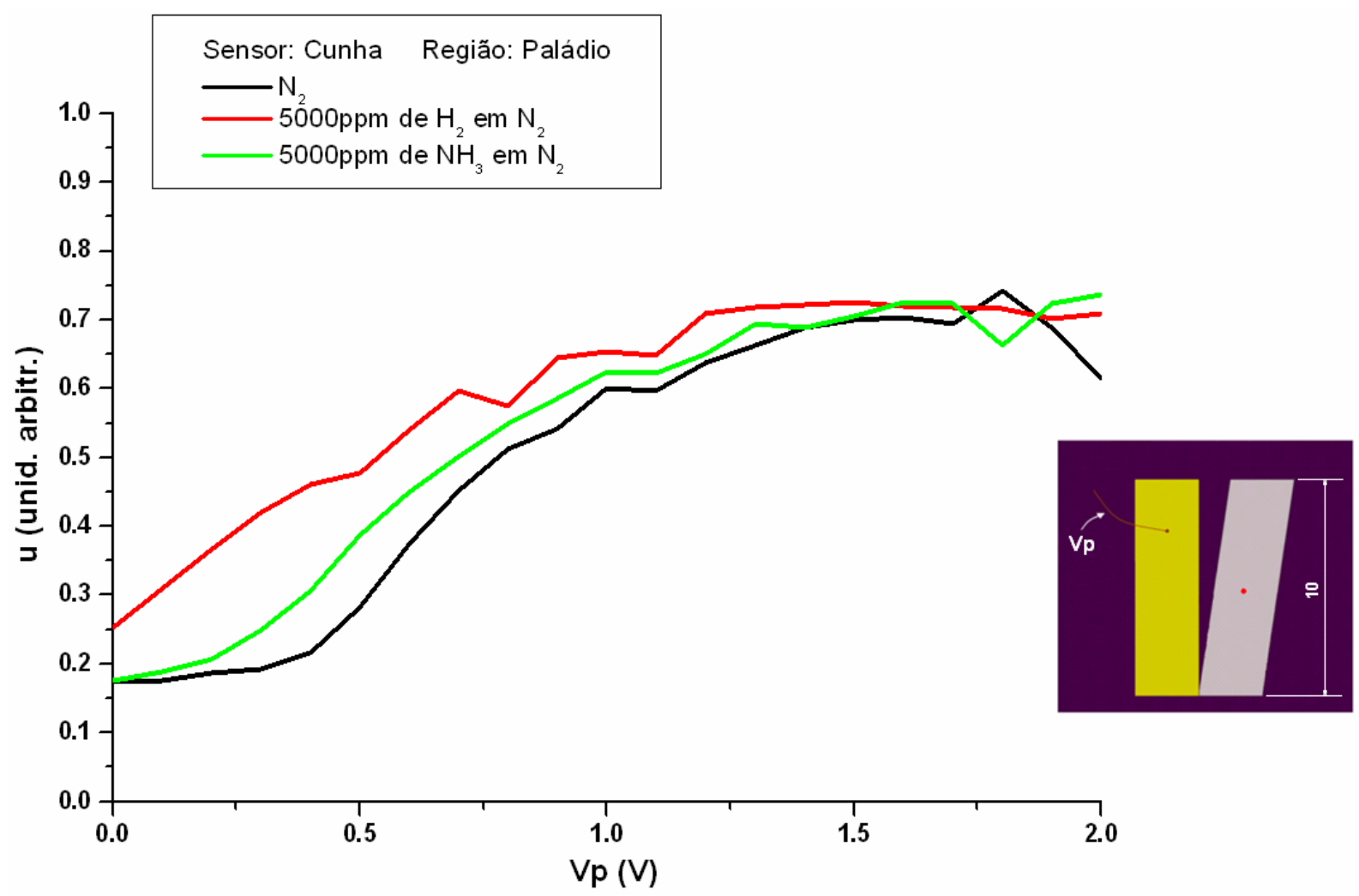

Figura 47 - Curva u $x$ Vp sob exposição na região de ouro, a 5000 ppm de $\mathrm{H}_{2}$ (linha vermelha), a $5000 \mathrm{ppm}$ de $\mathrm{NH}_{3}$ (linha verde) e a $\mathrm{N}_{2}$ (linha preta) com o dispositivo aquecido a $90^{\circ} \mathrm{C}$. $\mathrm{O}$ local de incidência do laser é indicado na representação ao lado (ponto vermelho). 
A sensibilidade da resposta dos sensores em relação ao potencial de polarização foi determinada através da derivada de "u" em relação ao potencial de polarização "Vp". Os gráficos das curvas de du/dV em função de Vp são apresentadas na Figura $48 \mathrm{e}$ na Figura 49 que correspondem aos sensores com geometria elíptica e de cunha respectivamente, para diferentes ambientes de gás $\left(\mathrm{N}_{2}, \mathrm{NH}_{3}\right.$ e $\left.\mathrm{H}_{2}\right)$. A partir das curvas da Figura 48 e da Figura 49, foi identificada a região sensível que está entre $0,5 \mathrm{~V}$ e $1,0 \mathrm{~V}$, incluindo neste intervalo a localização do ponto máximo de sensibilidade encontrado na curva que é dependente da região sobre a superfície do sensor e do ambiente de gás à qual foi submetido. Neste sentido, no presente trabalho foram utilizados potenciais de polarização correspondente à região entre $0,5 \mathrm{~V}$ e 1,0 V. A Figura 48 e a Figura 49 mostram que o máximo da função du/dV está situada em torno de 0,6 $\mathrm{V}$ para ambos os dispositivos em ambiente de $\mathrm{N}_{2}$ (inerte). Retornando aos resultados das curvas CxV (Figura 39 e Figura 41) observase que a região de inversão forte começa aproximadamente em torno de 0,6 V. Esta região caracteriza-se assim porque a camada de depleção atinge sua largura máxima (em média $5,610^{-5} \mathrm{~cm}$ ), o que faz com que a capacitância de alta freqüência do dispositivo MOS permaneça constante e com seu valor mínimo. Como a fotocorrente induzida depende da largura da camada de depleção, o comportamento máximo de du/dV mostra que a mudança da largura da camada de depleção é muito sensível às mudanças de $\mathrm{V} p$ quando esta se aproxima de seu valor máximo. Para evitar a saturação prematura da sensibilidade dos sensores, no presente trabalho, os dispositivos foram polarizados com potenciais menores que $0,6 \mathrm{~V}$ (especificamente, foram polarizados com $0,5 \mathrm{~V}$ ).

$\mathrm{O}$ máximo valor de du/dV, para sensores em ambientes de gás de $\mathrm{H}_{2}$ e $\mathrm{NH}_{3}$ (não inertes), mostrou um deslocamento no sentido de potenciais menores. Adicionalmente, neste caso, a sensibilidade apresentou menor valor se comparada com a obtida em ambiente de $\mathrm{N}_{2}$. Estes resultados sugerem que as moléculas de gás adsorvidas na interface $\mathrm{SiO}_{2} / \mathrm{Si}$ mudam o potencial de superfície $\psi_{\mathrm{S}}$ do $\mathrm{Si}$ na interface. Este efeito não compromete a aplicação do dispositivo MOS como sensor, desde que a mudança da sua resposta seja provocada pelas moléculas adsorvidas. 


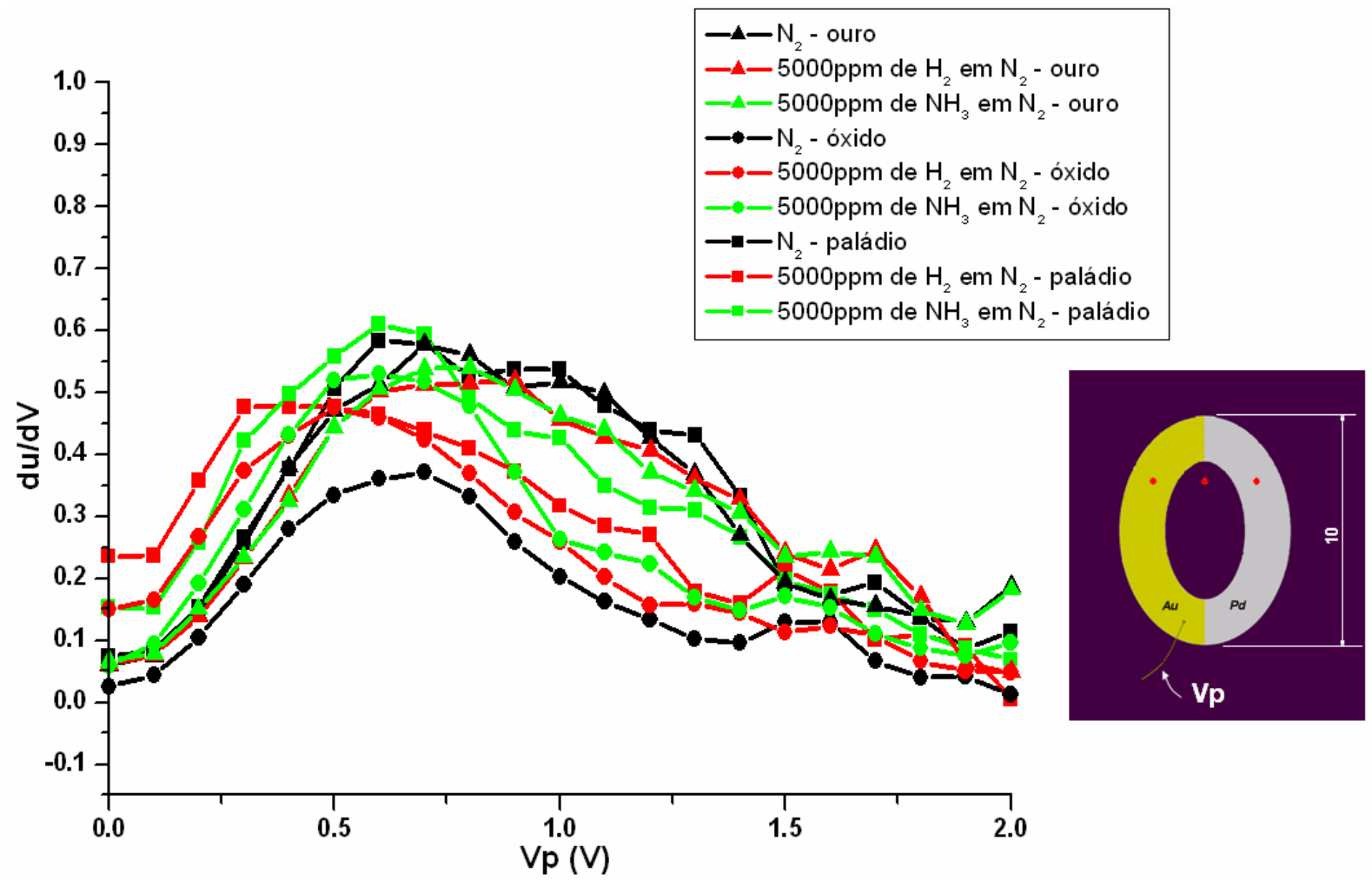

Figura 48 - Curva derivativa u $x$ Vp sob exposição nas regiões de ouro, óxido e paládio (elipse), a $5000 \mathrm{ppm}$ de $\mathrm{H}_{2}$ (linha vermelha), a $5000 \mathrm{ppm}$ de $\mathrm{NH}_{3}$ (linha verde) e a $\mathrm{N}_{2}$ (linha preta) com o dispositivo aquecido a $90^{\circ} \mathrm{C}$. Os locais de incidência do laser são indicados na representação ao lado (pontos vermelhos).

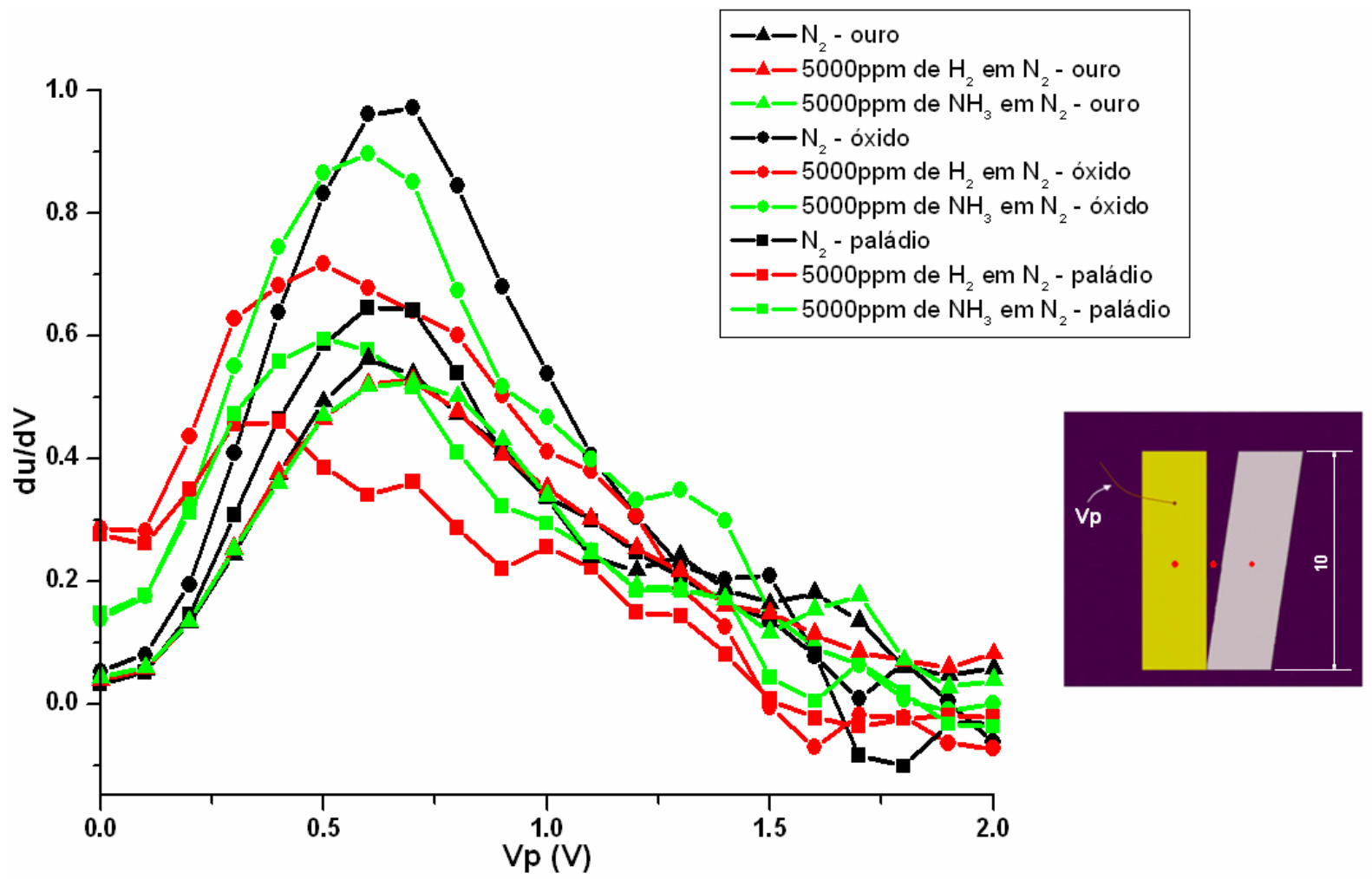

Figura 49 - Curva derivativa u $x$ Vp sob exposição nas regiões de ouro, óxido e paládio (cunha), a $5000 \mathrm{ppm}$ de $\mathrm{H}_{2}$ (linha vermelha), a 5000 ppm de $\mathrm{NH}_{3}$ (linha verde) e a $\mathrm{N}_{2}$ (linha preta) com o dispositivo aquecido a $90^{\circ} \mathrm{C}$. Os locais de incidência do laser são indicados na representação ao lado (pontos vermelhos). 


\subsection{Estudo do tempo de adsorção e dessorção aos gases de hidrogênio e amônia nos dispositivos MOS}

Um outro indicador de mérito de sensores refere-se ao tempo de resposta às mudanças de ambiente. Nesse sentido, foram realizados ensaios de tempo de resposta a processos de adsorção e dessorção de gases. Neste ensaio, a fotocorrente induzida foi gerada na região de maior sensibilidade do sensor, isto é, na região do metal de $\mathrm{Pd}$.

Para tal fim, o sensor foi condicionado a um fluxo constante de ar seco de $1 \mathrm{l} / \mathrm{min}$, durante 30 minutos, sob condições de pressão atmosférica. Os processos de adsorção e dessorção foram analisados para duas diferentes temperaturas: o primeiro ensaio foi realizado à temperatura de $26{ }^{\circ} \mathrm{C}$ e o segundo ensaio foi realizado à temperatura de $90^{\circ} \mathrm{C}$. Logo após o condicionamento inicial do sensor, iniciou-se o ensaio de adsorção, injetando-se repentinamente na câmara os gases de $\mathrm{H}_{2}$ ou $\mathrm{NH}_{3}$ e monitorando-se a resposta dos sensores até atingir seu nível de saturação. O processo de dessorção foi realizado após fechamento abrupto do rotâmetro correspondente ao gás ensaiado $\left(\mathrm{H}_{2}\right.$ ou $\left.\mathrm{NH}_{3}\right)$. Os ensaios foram realizados de acordo com os parâmetros mostrados nas tabelas Tabela 4 e Tabela 5.

Tabela 4 - Parâmetros de ensaio para estudo do tempo de adsorção e dessorção ao gás de hidrogênio no sensor em forma de elipse e cunha.

\begin{tabular}{c|c|c}
\hline Período & Gás inserido na câmara & Fluxo \\
\hline $0-60 \mathrm{~s}$ & ar seco & $1 \mathrm{l} / \mathrm{min}$ \\
$60-135 \mathrm{~s}$ & $5000 \mathrm{ppm} \mathrm{de} \mathrm{H}_{2}+\mathrm{N}_{2}$ & $100 \mathrm{ml} / \mathrm{min}$ \\
$135-600 \mathrm{~s}$ & ar seco & $1 \mathrm{l} / \mathrm{min}$ \\
\hline
\end{tabular}

Tabela 5 - Parâmetros de ensaio para estudo do tempo de adsorção e dessorção ao gás de amônia no sensor em forma de elipse e cunha.

\begin{tabular}{c|c|c}
\hline Período & Gás inserido na câmara & Fluxo \\
\hline $0-60 \mathrm{~s}$ & ar seco & $1 \mathrm{~L} / \mathrm{min}$ \\
$60-210 \mathrm{~s}$ & $5000 \mathrm{ppm} \mathrm{de} \mathrm{NH}_{3}+\mathrm{N}_{2}$ & $100 \mathrm{ml} / \mathrm{min}$ \\
$210-600 \mathrm{~s}$ & ar seco & $1 \mathrm{~L} / \mathrm{min}$ \\
\hline
\end{tabular}

Neste ensaio, o laser foi mantido em uma única posição no eixo $\mathrm{Y}$, e conforme programação da varredura, efetuaram-se leituras dos valores da magnitude "u" ao longo do eixo X para as regiões de ouro, óxido e paládio, respectivamente. 
Os pontos de incidência do laser, utilizados para obtenção do tempo de adsorção e dessorção aos gases de $\mathrm{H}_{2}$ e $\mathrm{NH}_{3}$ sobre os sensores MOS, são ilustrados na Figura 50 e na Figura 51.

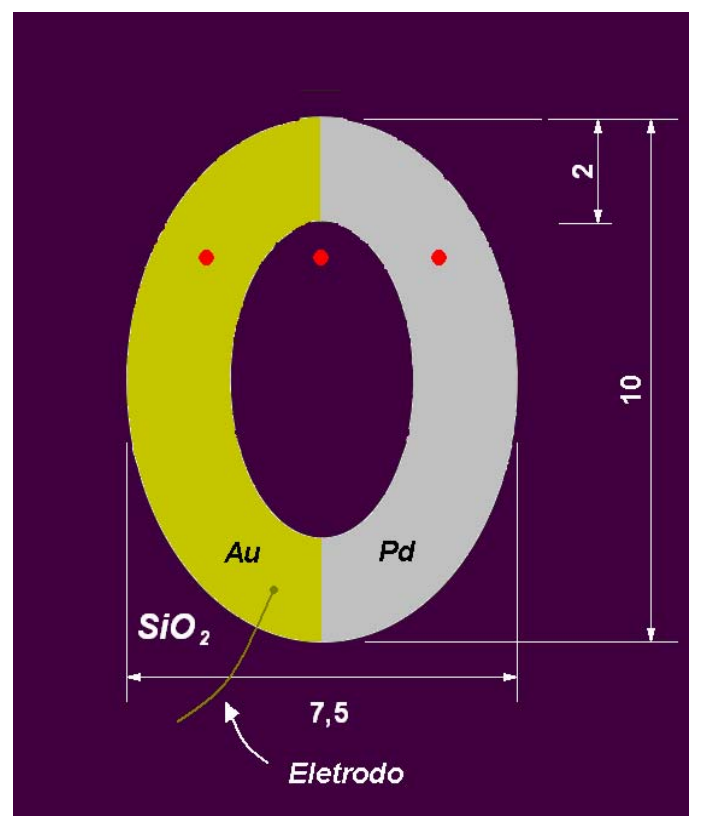

Figura 50 - Os pontos em vermelho sobre o sensor, no formato de elipse, representam os locais de incidência do laser para obtenção do tempo de adsorção e dessorção aos gases analisados.

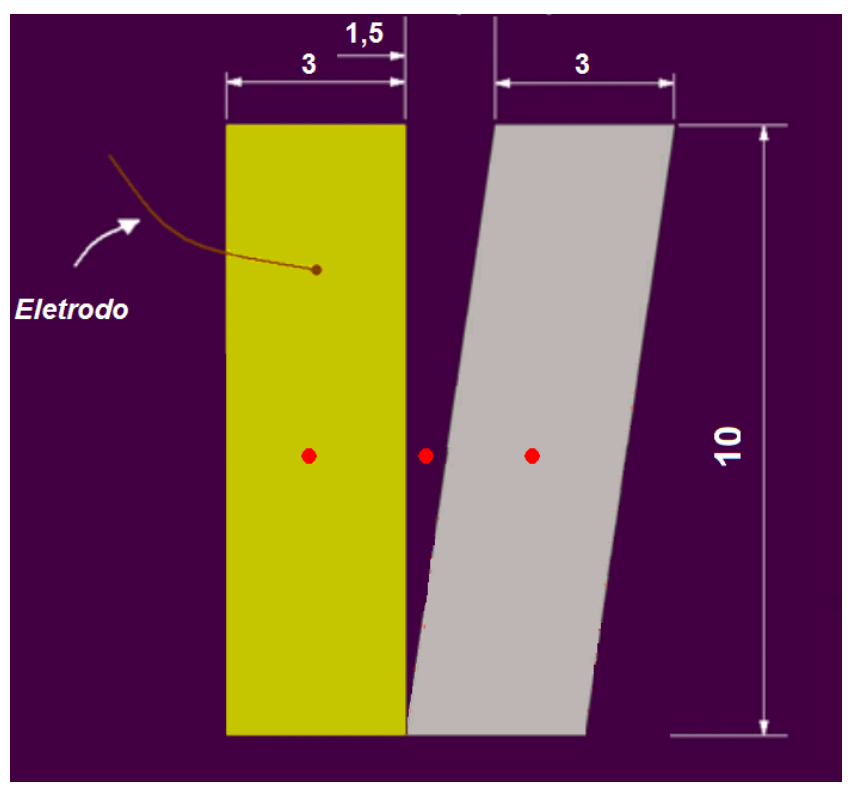

Figura 51 - Os pontos em vermelho sobre o sensor, no formato de cunha, representam os locais de incidência do laser para obtenção do tempo de adsorção e dessorção aos gases analisados.

O intervalo médio de cada seqüência de leitura dos pontos foi igual a $1 \mathrm{~s}$. 
Dentre as respostas de interação dos gases $\left(\mathrm{H}_{2}\right.$ e $\left.\mathrm{NH}_{3}\right)$ nos pontos avaliados, constatamos que a região de incidência do laser sobre o paládio foi a que apresentou maior amplitude para os valores de "u". Pôde-se observar também que os processos de adsorção e dessorção foram mais rápidos quando o gás utilizado no ensaio foi o hidrogênio, se comparado ao de amônia. Dessa forma, apenas serão apresentados os gráficos do estudo do tempo de adsorção e dessorção aos gases de $\mathrm{H}_{2}$ e $\mathrm{NH}_{3}$ na região do filme de paládio.

A seguir, na Figura 52 e na Figura 55, são apresentados os gráficos da resposta transiente dos sensores na região do paládio devido à adsorção dos gases de $\mathrm{H}_{2} \mathrm{e}$ $\mathrm{NH}_{3}$ para as temperaturas de $26^{\circ} \mathrm{C}$ e $90^{\circ} \mathrm{C}$, respectivamente.

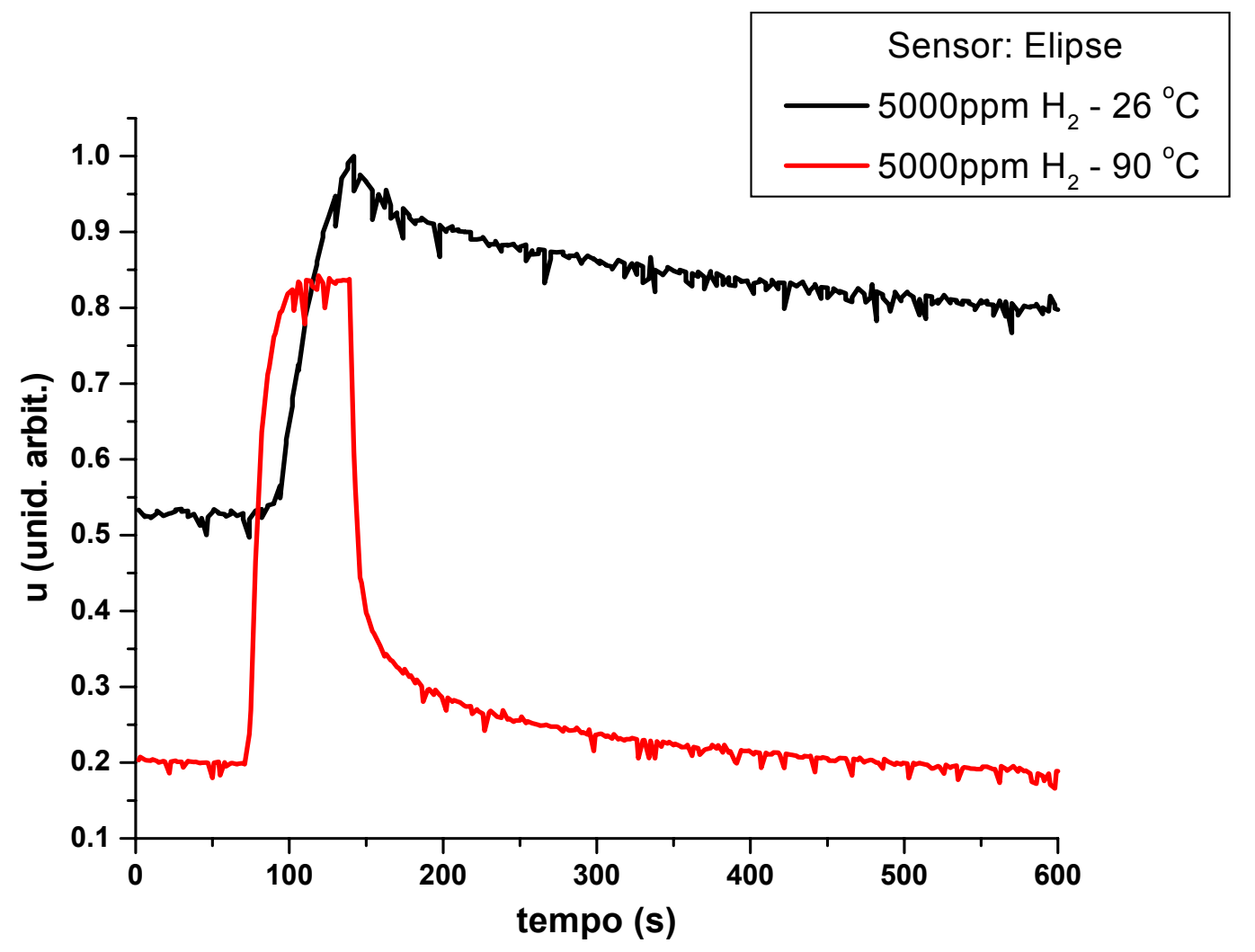

Figura 52 - Curva de resposta da interação dos gases de $\mathrm{H}_{2}$ na região do paládio para o sensor em formato de elipse. 


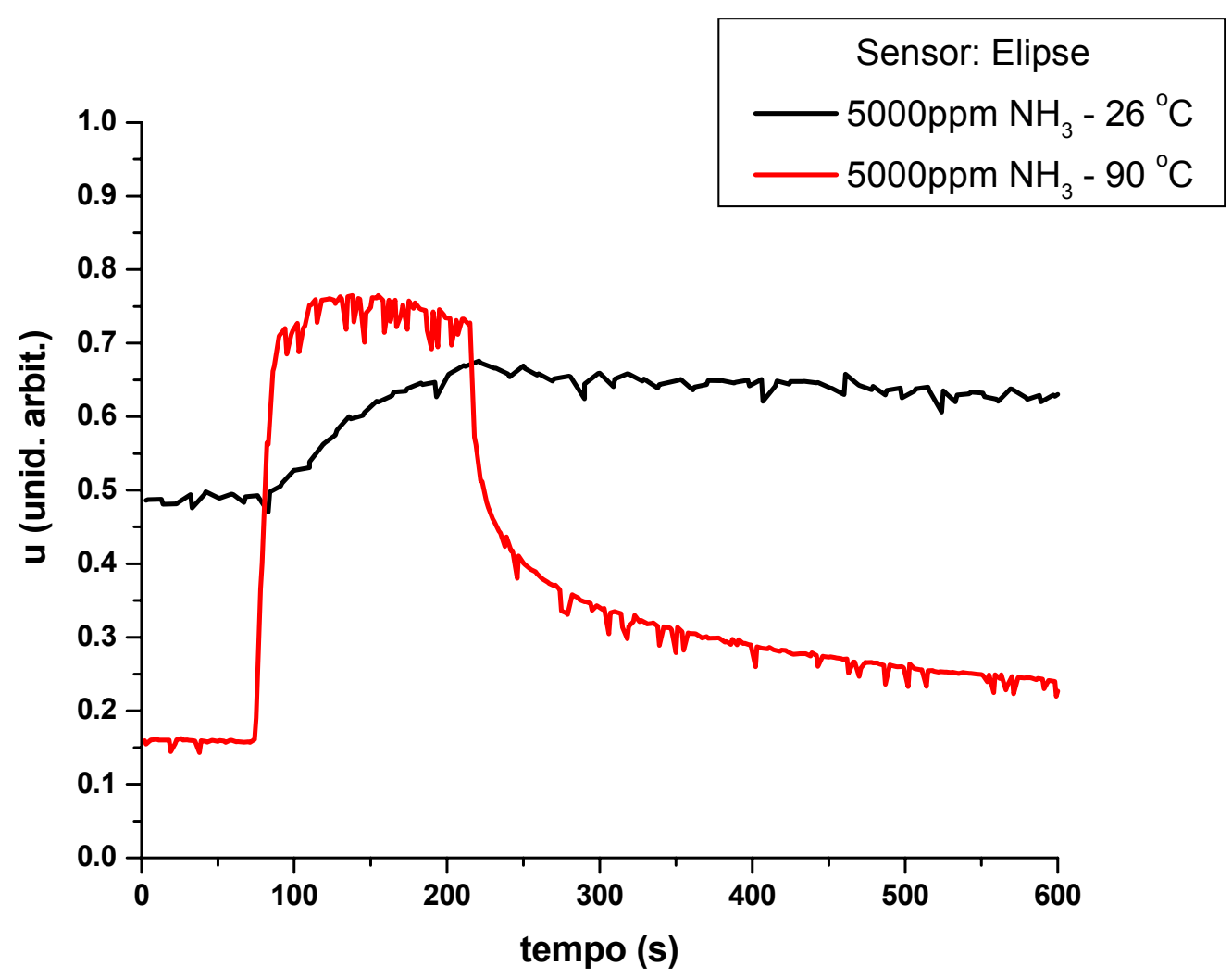

Figura 53 - Curva de resposta da interação dos gases de $\mathrm{NH}_{3}$ na região do paládio para o sensor em formato de elipse.

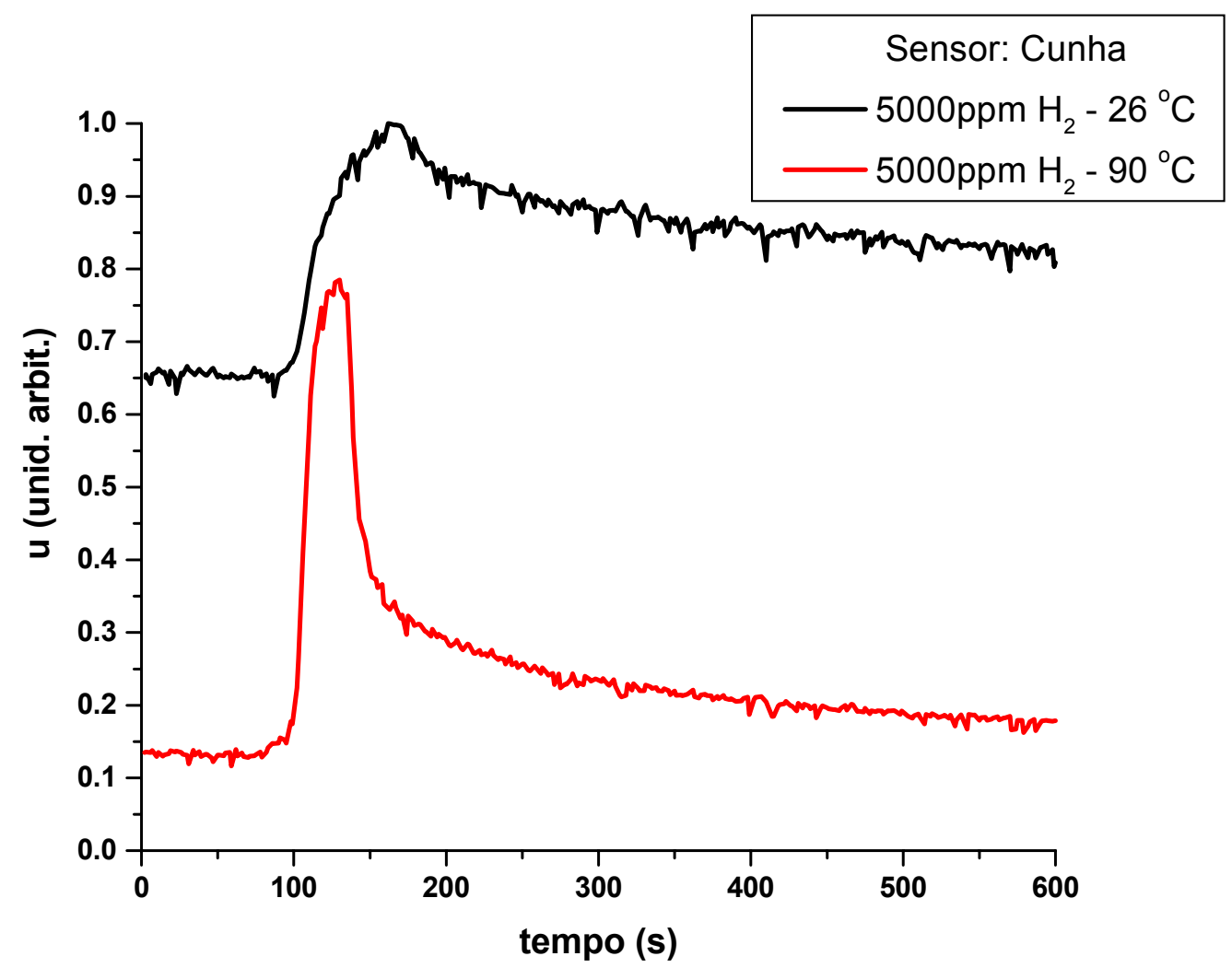

Figura 54 - Curva de resposta da interação dos gases de $\mathrm{H}_{2}$ na região do paládio para o sensor em formato de cunha. 


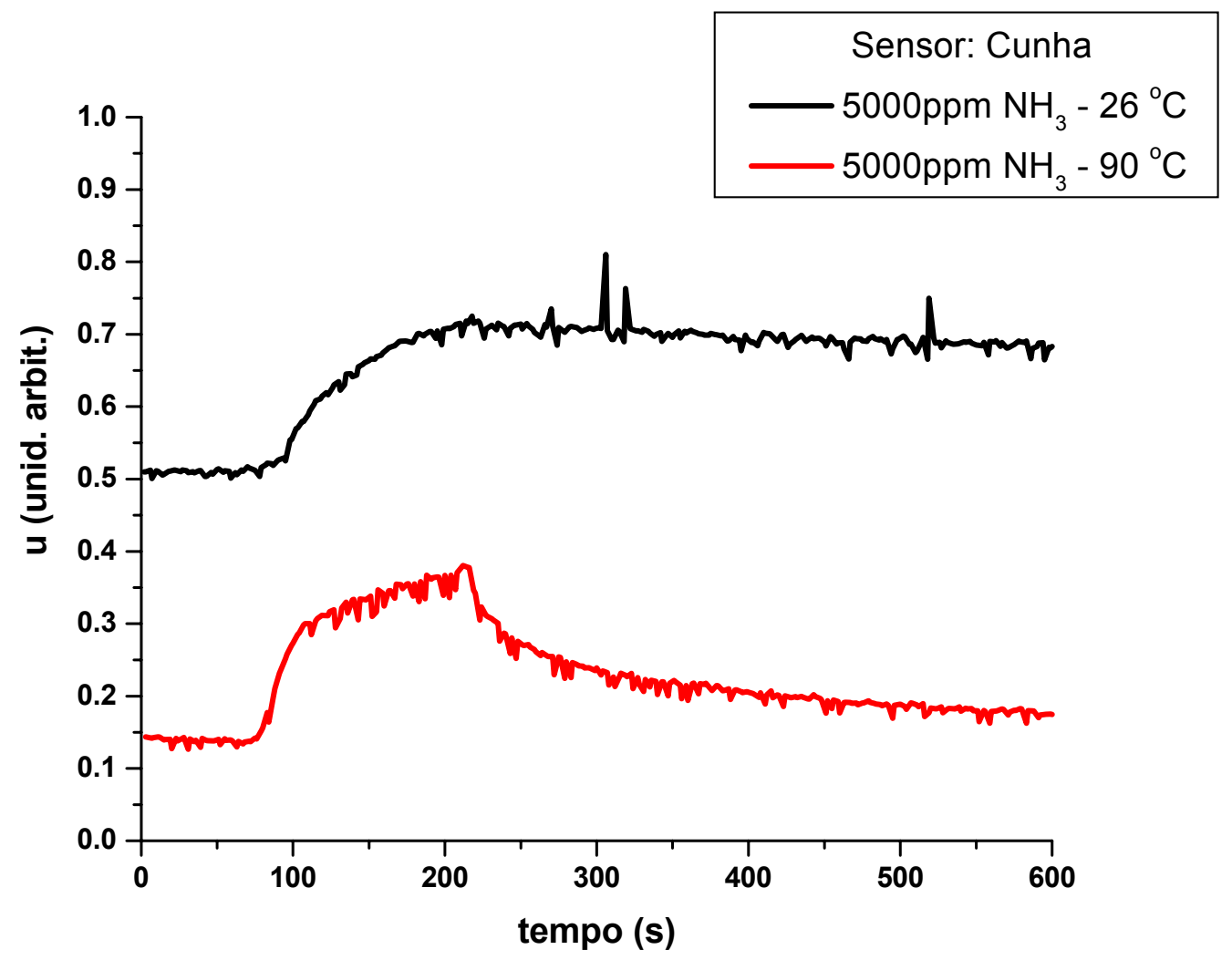

Figura 55 - Curva de resposta da interação dos gases de $\mathrm{NH}_{3}$ na região do paládio para o sensor em formato de cunha.

O tempo de subida da resposta do sensor com eletrodos em forma de elipse, após a injeção de gás (Figura 52 e Figura 53), apresentou valores em torno de $9 \mathrm{~s}$, tanto para $\circ \mathrm{H}_{2}$ quanto para $\circ \mathrm{NH}_{3}$, quando a temperatura de ensaio foi de $90{ }^{\circ} \mathrm{C}$. $\mathrm{Na}$ temperatura de ensaio de $26{ }^{\circ} \mathrm{C}$, os tempos de subida foram de $27 \mathrm{~s}$ e $63 \mathrm{~s}$ para os gases de $\mathrm{H}_{2}$ e $\mathrm{NH}_{3}$, respectivamente. Deve-se mencionar que o tempo de subida foi determinado como: o intervalo de tempo desde o valor inicial da resposta imediatamente antes da injeção dos gases, até o instante em que o valor de resposta atingiu $63 \%$ do seu valor de saturação. O comportamento do sinal de resposta na subida em função da temperatura pode ser explicado através do modelo da isoterma de Langmuir (LUNDSTRÖM, 1981). Neste modelo, representado na Figura 56, o processo de adsorção depende da temperatura, da pressão (fluxo: F) e dos sítios disponíveis para a adsorção. Para um modelo simples, considera-se que estatisticamente existem $\sigma_{\circ}$ sítios de adsorção na superfície externa do metal Pd. 


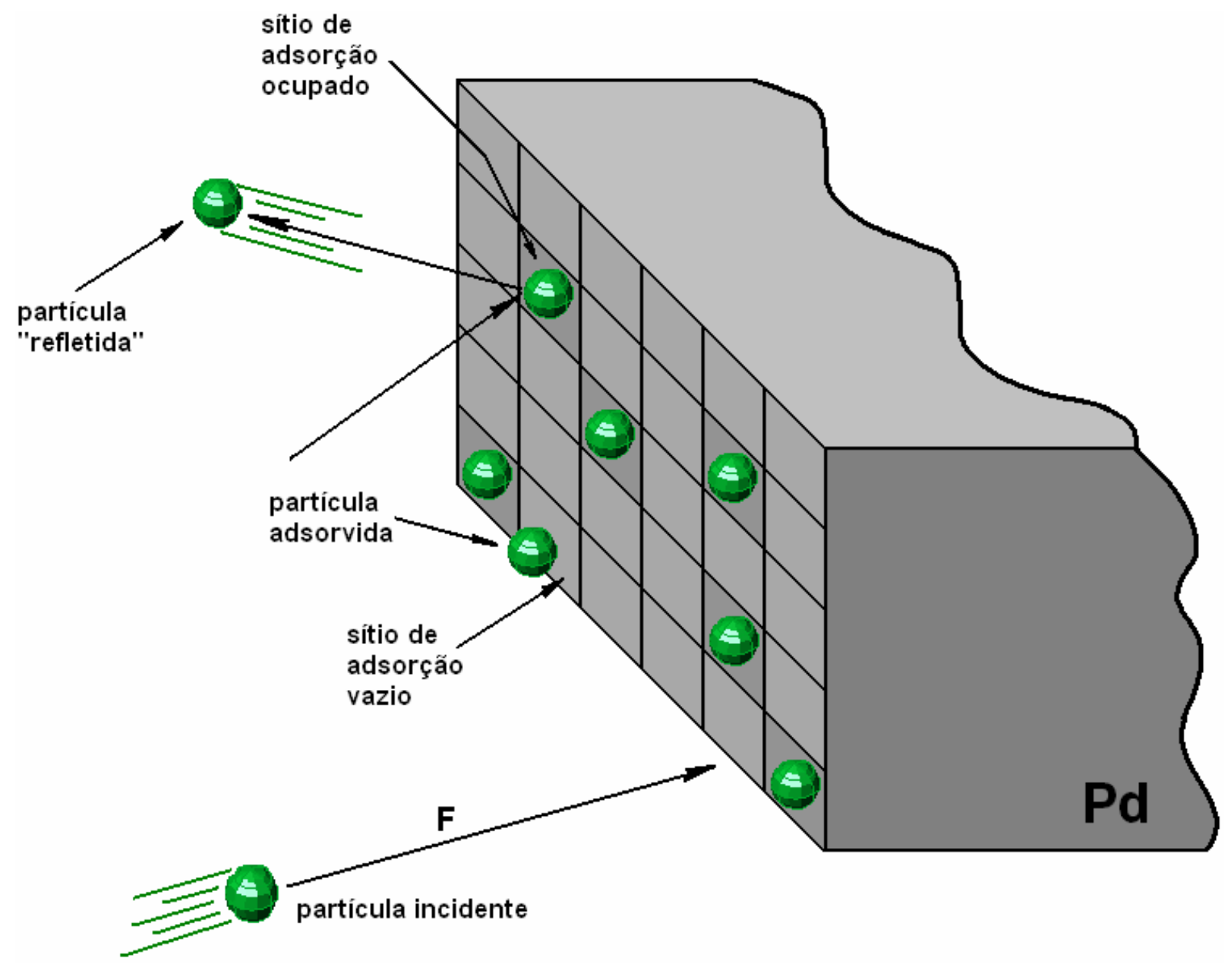

Figura 56 - Superfície do material adsorvente como um conjunto de "caixas". Cada caixa possui um sítio de adsorção (BARATTO, 1993).

Dentre estes sítios, $\sigma$ já estão ocupados e não terão chances de adsorver nenhum outro componente do fluxo $\mathrm{F}$ de gás inserido à câmara. Desse fluxo incidente à superfície, $\left(\sigma / \sigma_{\circ}\right) . F$ partículas serão "refletidas", restando, portanto, $\left(1-\sigma / \sigma_{\circ}\right) . F$ partículas que ainda poderão ser adsorvidas. Assim, a probabilidade de uma dessas partículas ser adsorvida será proporcional a este último fator, vezes o tempo de adsorção $(\tau)$ (SOMORJAI, 1972 \& BARATTO, 1993):

$$
\sigma=\left\{1-\frac{\sigma}{\sigma_{o}}\right\} \cdot F \cdot \tau
$$

ou

$$
\sigma=\frac{\sigma_{o} \cdot F \cdot \tau}{\sigma_{o}+F \cdot \tau}
$$


Baseado na teoria cinética dos gases, o fluxo $\mathrm{F}$ de partículas de um gás sobre uma superfície será:

$$
F=\frac{N A \cdot p}{\sqrt{2 \cdot \pi \cdot M \cdot R \cdot T}}
$$

Onde:

NA = Número de Avogrado

$\mathbf{p}=$ Pressão do gás

$\mathbf{M}=$ Massa da partícula

$\mathbf{R}=$ Constante dos gases ideais

$\mathbf{T}=$ Temperatura

Considerando-se que o processo de adsorção está em equilíbrio termodinâmico, o tempo de adsorção relacionado com a razão entre as taxas de adsorção e dessorção pode ser expresso pela seguinte equação (SOMORJAI, 1972; BARATTO, 1993 \& LUNDSTROM, 1982):

$$
\tau=\tau_{0} \cdot e^{\left\{\frac{\Delta H^{o}}{R \cdot T}\right\}}
$$

Onde:

$\Delta \mathbf{H}^{\circ}{ }_{\text {ad }}=$ Entalpia de adsorção

A partir da eq.(30) e da eq.(32) pode-se observar que a superfície metálica estará completamente ocupada num processo a baixa temperatura.

No entanto, o tempo de adsorção expressa pela eq.(32) mostra que os tempos de adsorção em processos de baixa temperatura apresentaram valores altos. Contrariamente, em processos de alta temperatura, o tempo de adsorção aproximase ao seu valor mínimo $\left(\tau_{0}\right)$. Este modelo explica satisfatoriamente o tempo de subida da resposta do sensor após a injeção dos gases. Para a temperatura de $90{ }^{\circ} \mathrm{C}$, o tempo de subida observado em ambos os casos $\left(\mathrm{H}_{2}\right.$ e $\left.\mathrm{NH}_{3}\right)$ foi aproximadamente igual. Isto pode ser devido à utilização de elevadas concentrações (5000 ppm) dos gases ensaiados, já que em LUNDSTRÖM, 1981, foi mostrado que 
o tempo de resposta de um sensor Pd-MOS depende também da concentração do gás de hidrogênio. A diferença nos tempos de subida para os ensaios à baixa temperatura $\left(26{ }^{\circ} \mathrm{C}\right.$ ), pode ser devido ao gás $\mathrm{NH}_{3}$ ter sido dissociado antes dos átomos de $\mathrm{H}$ serem adsorvidos. Existe um processo intermediário (eq.(9), seção 2.2) que deve ser lento à baixas temperaturas e muito rápido em altas temperaturas.

O intervalo de tempo de descida do sinal da resposta do sensor, com formato de elipse, à temperatura de $90{ }^{\circ} \mathrm{C}$, foi de $8 \mathrm{~s}$. No caso do gás $\mathrm{H}_{2}$, este intervalo foi determinado a partir do fechamento do fluxo de $\mathrm{H}_{2}$ até o instante em que a resposta do sensor caiu para $37 \%$ de seu valor inicial (injeção). Este resultado mostra que o processo de dessorção do Hidrogênio à temperatura de $90{ }^{\circ} \mathrm{C}$ pode ser representado pelo mesmo tipo de expressão utilizada para a adsorção (eq.(32)), é dizer pela seguinte expressão:

$$
\tau_{d e s s}=\tau_{0 d e s s} \exp \left(\frac{\Delta H_{a d}}{K T}\right)
$$

No caso do gás de $\mathrm{NH}_{3}$, o tempo de descida da resposta do sensor foi de aproximadamente $59 \mathrm{~s}$. Se considerarmos que a resposta do sensor é devida essencialmente aos átomos dissociados de Hidrogênio, que foram adsorvidos primeiro na superfície do $\mathrm{Pd} \mathrm{e}$, posteriormente, foram deslocados para a interface $\mathrm{Pd} / \mathrm{SiO}_{2}$ (processo rápido), o tempo elevado de descida na resposta do sensor no caso de $\mathrm{NH}_{3}$ pode ser devido a que alguns átomos ou moléculas foram adsorvidos na superfície do $\mathrm{Pd}$, bloqueando, assim, o processo de dessorção dos átomos de Hidrogênio. Isto pode ser representado por uma barreira enérgica na superfície de Pd como sugerido em LUNDSTROM, 1981, e assim, o tempo de resposta no processo de dessorção pode ser expressa por:

$$
\tau_{\text {dess }}=\tau_{0 \text { dess }} \exp \left(\frac{E_{b}+\Delta H_{a d}}{K T}\right)
$$

Onde $E_{b}$ representa a altura da barreira de energia devido às moléculas ou átomos adsorvidos na superfície de Pd.

Os tempos de descida do sinal, nos processos de dessorção à temperatura de $26{ }^{\circ} \mathrm{C}$, foram elevados a tal ponto de não ser possível medi-los dentro da escala de 
tempo utilizada no experimento (horas). Este comportamento não pode ser explicado apenas pela eq.(33) ou eq.(34), sugerindo uma dependência mais complexa com a temperatura.

No caso das respostas transientes de adsorção e dessorção do dispositivo em formato de cunha (Figura 54 e Figura 55), estas apresentaram perfis diferentes aos do dispositivo com formato em elipse.

Analisando a resposta transiente ao gás de $\mathrm{NH}_{3}$ a $90^{\circ} \mathrm{C}$ (Figura 55), observa-se que o processo de adsorção apresenta dois intervalos de tempo com comportamentos distintos: no intervalo de $0 \mathrm{~s}$ a $28 \mathrm{~s}$ (injeção de gás), o comportamento da curva mostra-se quase exponencial com subida rápida, já no intervalo de $28 \mathrm{~s}$ a $150 \mathrm{~s}$ (fechamento do fluxo de gás), a resposta do sensor mostra uma característica linear com uma inclinação pequena, ou seja, de subida lenta. A curva $\mathrm{CxV}$, em baixa freqüência neste dispositivo (Figura 41) mostrou uma capacitância na região de acumulação menor que a de alta freqüência. Este resultado pode ser devido à existência de uma densidade significativa de armadilhas no substrato de silício (NICOLLIAN, 1982) que promoveram processos de recombinação, principalmente em experimentos à baixa freqüência. Estas armadilhas podem ser representadas por uma resistência em série $\left(R_{s}\right)$, como a capacitância MOS, de tal forma que a capacitância medida em acumulação resulta menor que o $C_{\text {ox }}$ (NICOLLIAN, 1982). Se considerarmos esta resistência série na resposta transiente do sensor, então a sua resposta será afetada significativamente, já que o produto $C$ vezes $R_{s}$ cresce expressivamente. Isto explicaria a resposta transiente do sensor em formato de cunha. 


\subsection{Estudo do perfil de resposta espacial do sensor aos gases de hidrogênio e amônia nos dispositivos MOS}

Para o estudo do perfil de resposta espacial dos dispositivos aos gases de $\mathrm{H}_{2}$ e $\mathrm{NH}_{3}$, a amostra foi submetida à varredura do laser para extração dos valores de "u". Esses valores foram armazenados em uma matriz de $32 \times 32$, correspondente aos diferentes pontos de varredura do feixe do laser. Esta matriz foi utilizada para a geração dos gráficos de sensibilidades e dos padrões de imagens químicas representativas às atmosferas aos quais os sensores foram expostos. Os dados de fotocorrentes dos pontos de incidência de cada linha da matriz possibilitam descrever as diferenças na distribuição de "u" em cada região do sensor.

Foram feitas medições em três estados: o primeiro com um fluxo de $200 \mathrm{ml} / \mathrm{min}$ de $\mathrm{N}_{2}$ no interior da câmara, o segundo com um fluxo de $200 \mathrm{ml} / \mathrm{min}$ de 500 ppm de $\mathrm{H}_{2}$ em $\mathrm{N}_{2}$ e o terceiro com fluxo de $200 \mathrm{ml} / \mathrm{min}$ de 500 ppm de $\mathrm{NH}_{3}$ em $\mathrm{N}_{2}$.

Na preparação da câmara de ensaio para o início do ensaio, o sensor permaneceu durante 30 minutos sob fluxo de $\mathrm{N}_{2}$ de $200 \mathrm{ml} / \mathrm{min}$ e temperatura de $90{ }^{\circ} \mathrm{C}$. Em seguida, injetou-se o gás $\mathrm{H}_{2}$ ou o gás $\mathrm{NH}_{3}$ durante todo o período em que houve a varredura do laser modulado sobre o sensor.

Medindo-se " $u$ " a uma tensão de polarização constante de $+0,5 \mathrm{~V}$, um perfil de fotocorrente espacial em $\mathrm{N}_{2}$ pode ser obtido e usado como linha base.

Primeiro foram realizados ensaios e aquisição de fotocorrente induzida fazendo-se uma varredura ao longo de uma linha que atravessa as duas regiões metálicas e uma região intermediária de óxido. As respostas dos sensores submetidos aos diferentes gases neste ensaio são apresentadas na Figura 57 e na Figura 58. 


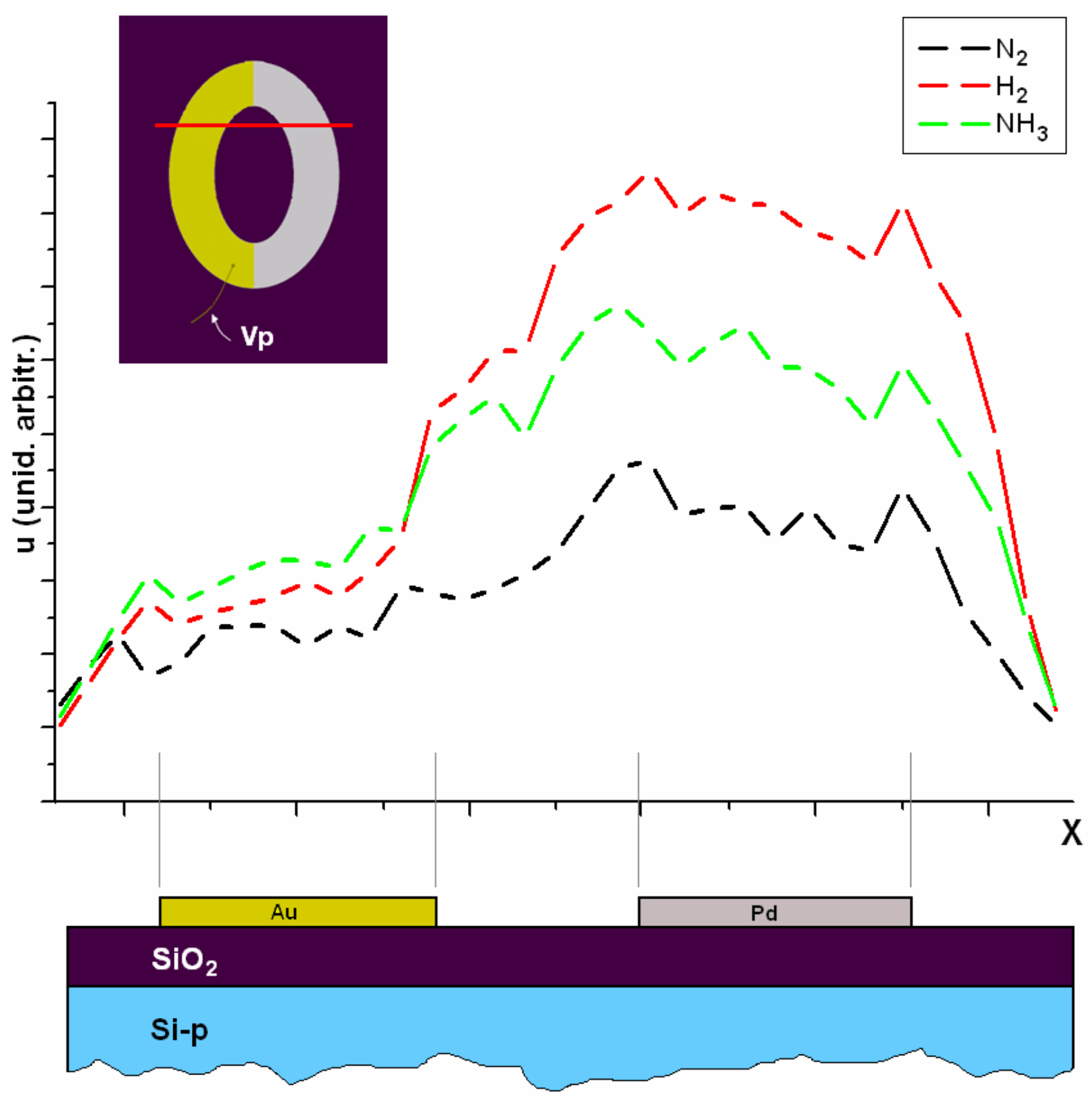

Figura 57 - Amplitude da fotocorrente ao longo de uma linha de escaneamento para o sensor no formato de elipse sob exposição de $500 \mathrm{ppm}$ de $\mathrm{H}_{2}$ (linha vermelha), a $500 \mathrm{ppm}$ de $\mathrm{NH}_{3}$ (linha verde) e $\mathrm{N}_{2}$ (linha preta) com o dispositivo aquecido a $90^{\circ} \mathrm{C}$. Os gases foram fornecidos a um fluxo de $200 \mathrm{ml} / \mathrm{min}$. 


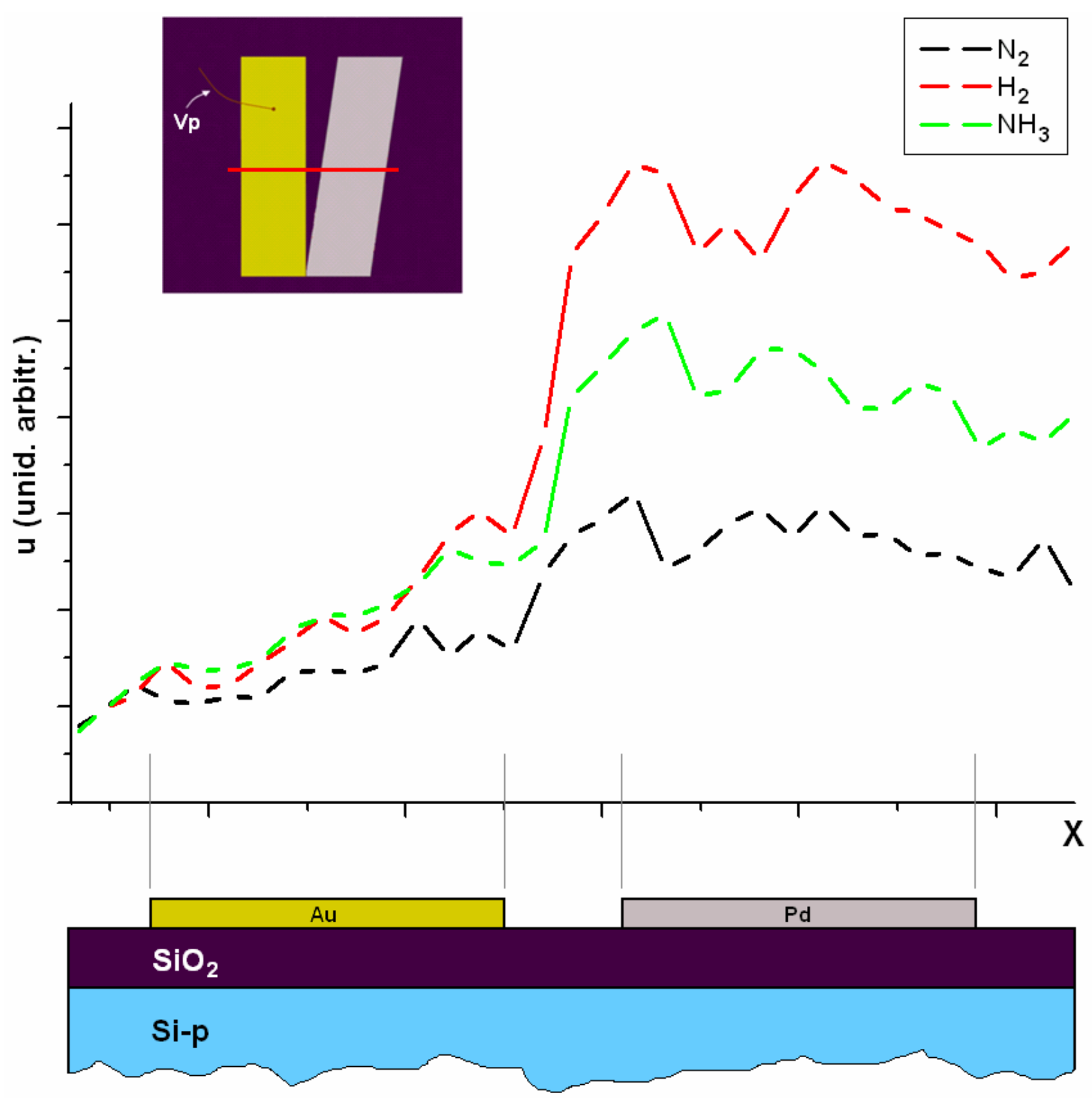

Figura 58 - Amplitude da fotocorrente ao longo de uma linha de escaneamento para o sensor no formato de cunha sob exposição de $500 \mathrm{ppm}$ de $\mathrm{H}_{2}$ (linha vermelha), a $500 \mathrm{ppm}$ de $\mathrm{NH}_{3}$ (linha verde) e $\mathrm{N}_{2}$ (linha preta) com o dispositivo aquecido a $90^{\circ} \mathrm{C}$. Os gases foram fornecidos a um fluxo de $200 \mathrm{ml} / \mathrm{min}$.

Na Figura 57 e na Figura 58 pode-se observar que a resposta dos sensores apresenta maior sensibilidade na região de paládio para ambos os gases, mostrando uma intensificação da resposta na borda dos eletrodos de porta. No entanto, o perfil das curvas de resposta em função da posição muda de um sensor para outro. No caso do sensor tipo cunha, a inclinação de subida da fotocorrente mostra-se mais abrupta do que nas curvas de resposta do sensor com geometria elíptica. Este resultado mostra que um sistema de sensores MOS com diferentes geometrias pode apresentar grandes vantagens no reconhecimento de padrões, principalmente 
quando a resposta é obtida pela construção de uma imagem bidimensional de fotocorrentes, como veremos na seção seguinte.

A obtenção de resposta dos sensores MOS em forma de imagens de fotocorrente foram obtidas por varredura com o feixe de laser em uma região de área dos sensores, como mostrados na Figura 59 e na Figura 60.

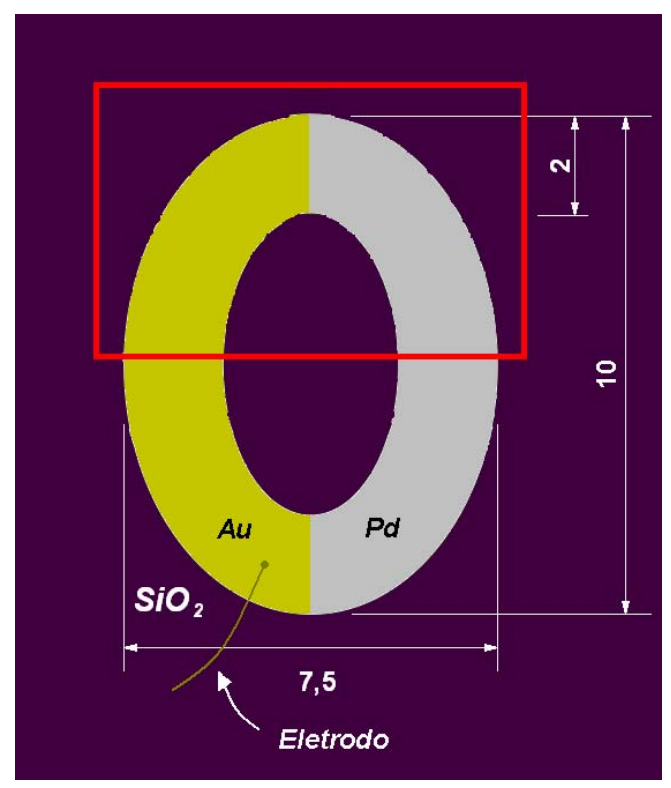

Figura 59 - Região de varredura dos pontos de incidência do laser sobre o sensor no formato de elipse.

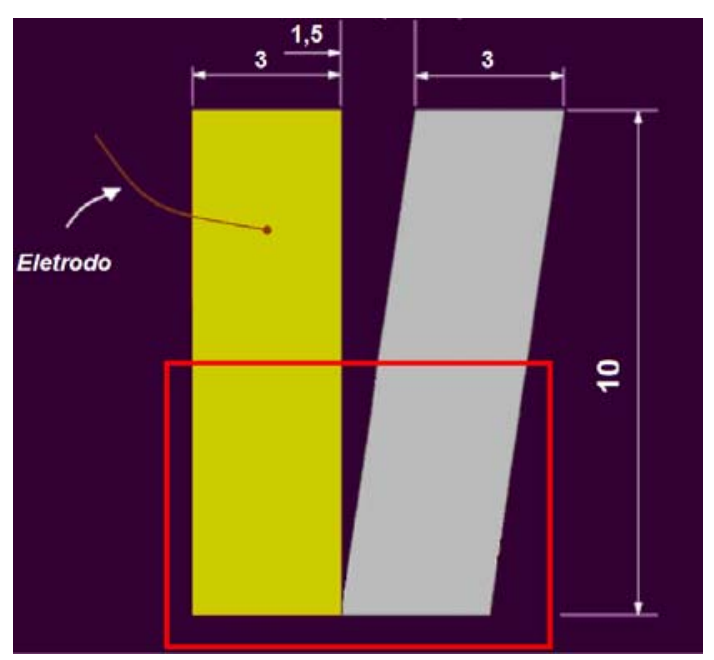

Figura 60 - Região de varredura dos pontos de incidência do laser sobre o sensor no formato de cunha.

As imagens de fotocorrente induzida foram construídas utilizando-se o parâmetro "u" definido no procedimento experimental. Da Figura 61 à Figura 67 são apresentadas as imagens obtidas para três ensaios consecutivos em ambientes contendo $\mathrm{N}_{2}, \mathrm{NH}_{3}$ e $\mathrm{H}_{2}$. Procurou-se conhecer as propriedades qualitativas das respostas das imagens químicas, evidenciando as diferenças para ambos os filmes catalíticos em variadas 
concentrações. Para todos os ensaios, o filme de paládio mostrou-se ter um efeito sensor significativo.

Da Figura 61 à Figura 63 são mostradas as imagens químicas para o sensor em formato de elipse que foram obtidas para ambientes de $\mathrm{H}_{2}$ e $\mathrm{NH}_{3}$, em concentrações de 100, 200, 300, 400 e 500 ppm respectivamente. As imagens correspondem à repetição de três ensaios nas mesmas condições experimentais. Os resultados das imagens mostram que a resposta do sensor é reprodutível, não apresentando problemas de histereses. A resposta do sensor em função da concentração de $\mathrm{NH}_{3}$ mostrou um aumento da intensidade de "u" principalmente na região do paládio para concentrações maiores. Este comportamento foi observado até uma concentração de 300 ppm. Para concentrações acima de 300 ppm, a imagem química mostra que o sensor teve aproximadamente o mesmo perfil daquela com 300 ppm, sugerindo que a resposta do sensor para o gás de $\mathrm{NH}_{3}$ satura-se em torno desta concentração. No caso das imagens químicas obtidas para o gás de $\mathrm{H}_{2}$, os resultados mostraramse aproximadamente iguais para todas as concentrações utilizadas na experiência, sugerindo que a resposta do sensor já fica saturada na concentração de 100 ppm, mostrando assim a elevada sensibilidade do sensor para o gás de $\mathrm{H}_{2}$.

Similarmente, foram realizados ensaios repetidos para o dispositivo sensor em formato de cunha. Neste caso, o comportamento da resposta do sensor mostrou as mesmas características que o do sensor em formato de elipse, como podem ser observados nos resultados das imagens químicas mostradas na Figura 64, Figura 65 e na Figura 66 respectivamente. Por outro lado, é importante destacar que a forma geométrica dos dispositivos pode fornecer detalhes de contorno na borda dos eletrodos que podem auxiliar na classificação das imagens. A origem destes detalhes de borda está relacionada com a característica bidimensional do dispositivo MOS que será discutida a seguir.

O grande potencial dos sensores de imagens químicas, como a proposta no presente trabalho, está relacionada com a capacidade de reconhecimento de padrões que possam auxiliar na identificação de diferentes substâncias. Neste sentido, a partir das imagens químicas obtidas para 500 ppm de $\mathrm{H}_{2}$ ou $\mathrm{NH}_{3}$, foram construídas novas imagens químicas (resultado da diferença das imagens correspondentes aos gases de ensaio de $\left(\mathrm{H}_{2}\right.$ e $\left.\mathrm{NH}_{3}\right)$ em relação à imagem correspondente ao gás de $\mathrm{N}_{2}$ ). As novas imagens normalizadas são mostradas na Figura 67 e na Figura 68, observando-se que a imagem correspondente a cada tipo 
de gás $\left(\mathrm{H}_{2}, \mathrm{NH}_{3}\right)$ é diferente uma da outra, independente do dispositivo utilizado. Adicionalmente, as diferenças dos padrões de imagens químicas observadas para $\mathrm{H}_{2}$ e $\mathrm{NH}_{3}$ mostram-se consistentes com as repetições de medida. $\mathrm{O}$ comportamento do padrão de imagem em função da concentração de gás foi analisado. Para tal fim, cada imagem obtida foi normalizada em relação ao seu próprio máximo de resposta de tal forma a evitar a interferência da concentração no padrão da imagem química. Os resultados dos padrões de imagens obtidas desta maneira foram apresentados na Figura 69 e na Figura 70, correspondentes aos dispositivos em forma de elipse e cunha respectivamente. Na Figura 69, o padrão de resposta para o gás de $\mathrm{NH}_{3}$ (dispositivo elipse) mostrou-se qualitativamente semelhante para as diferentes concentrações do gás, exceto para a concentração de 100 ppm. No caso do padrão de resposta para $\mathrm{o} \mathrm{H}_{2}$, os resultados das imagens foram qualitativamente iguais para todas as concentrações utilizadas no ensaio. Por outro lado, os padrões para cada tipo de gás foram notoriamente diferentes um em relação ao outro, ou seja, o padrão de imagem do $\mathrm{NH}_{3}$ mostrou-se completamente diferente ao padrão do gás de $\mathrm{H}_{2}$. No caso dos padrões de imagem gerados no dispositivo em formato de cunha (Figura 70), observou-se a mesma tendência de comportamento apresentado pelo dispositivo em formato de elipse. Similarmente ao caso anterior; o padrão de imagem foi qualitativamente semelhante para todas as concentrações de gás de $\mathrm{NH}_{3}$, exceto para $100 \mathrm{ppm}$. No caso do $\mathrm{H}_{2}$, os padrões foram semelhantes para todas as concentrações utilizadas no ensaio experimental. Novamente, neste dispositivo, o padrão de imagem do $\mathrm{NH}_{3}$ mostrou-se diferente ao do $\mathrm{H}_{2}$. Estes resultados mostram que os dispositivos MOS com o modo de operação TELP, podem gerar padrões de imagens químicas característicos correspondente a um gás especifico, indicando a possibilidade de implementação de um sistema de nariz eletrônico apenas com um único sensor. 


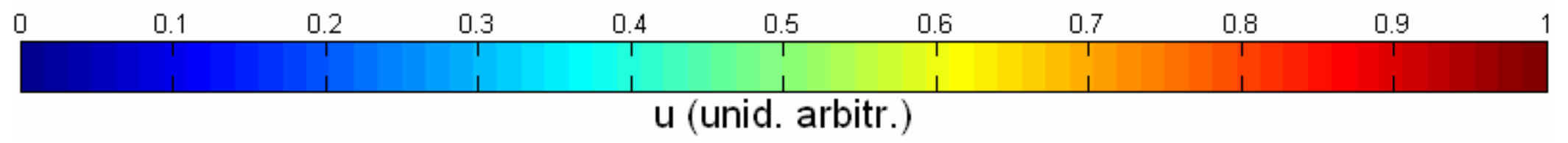

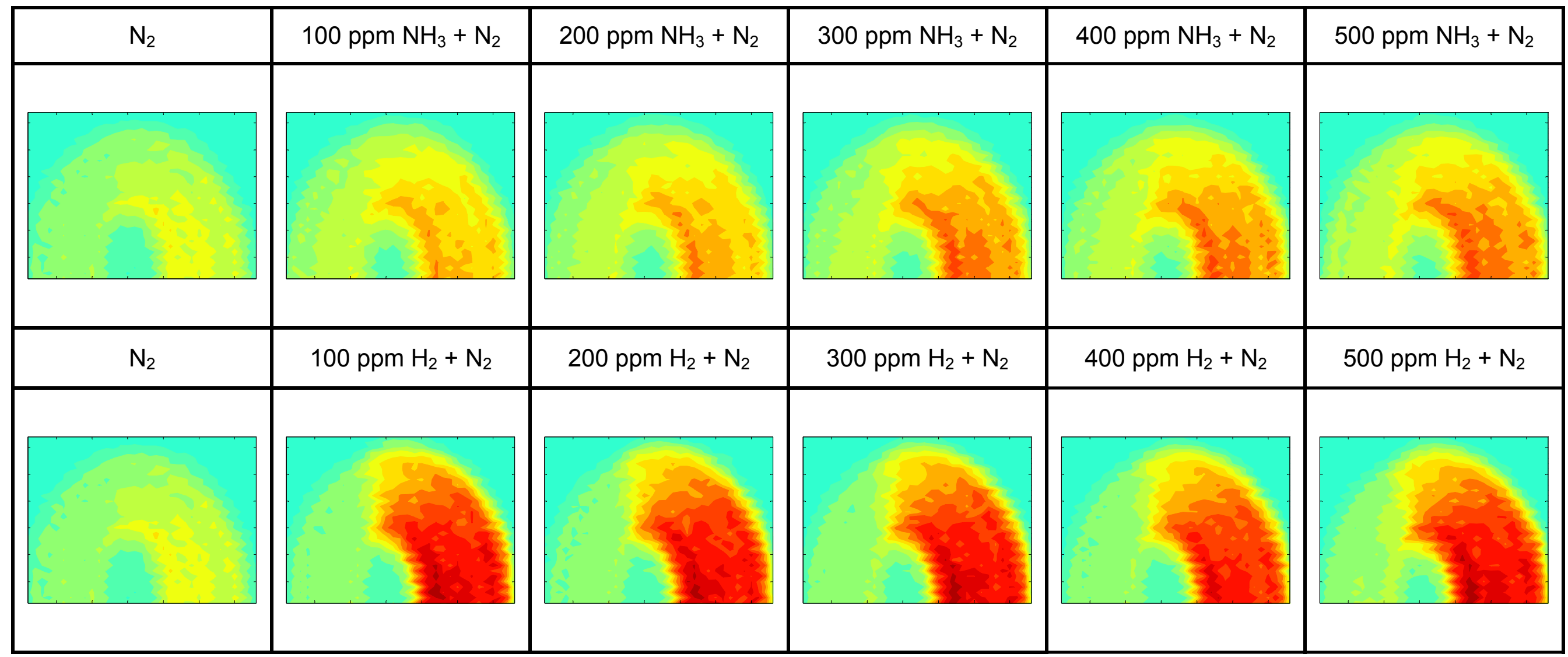

Figura 61 - Imagens químicas obtidas no primeiro ensaio pelo sensor em formato de elipse para diferentes concentrações com o sensor operando numa temperatura de $90^{\circ} \mathrm{C}$. As respostas foram normalizadas pelo máximo valor encontrado nos três ensaios. A escala em RGB codifica a amplitude de "u" aos gases ensaiados. 

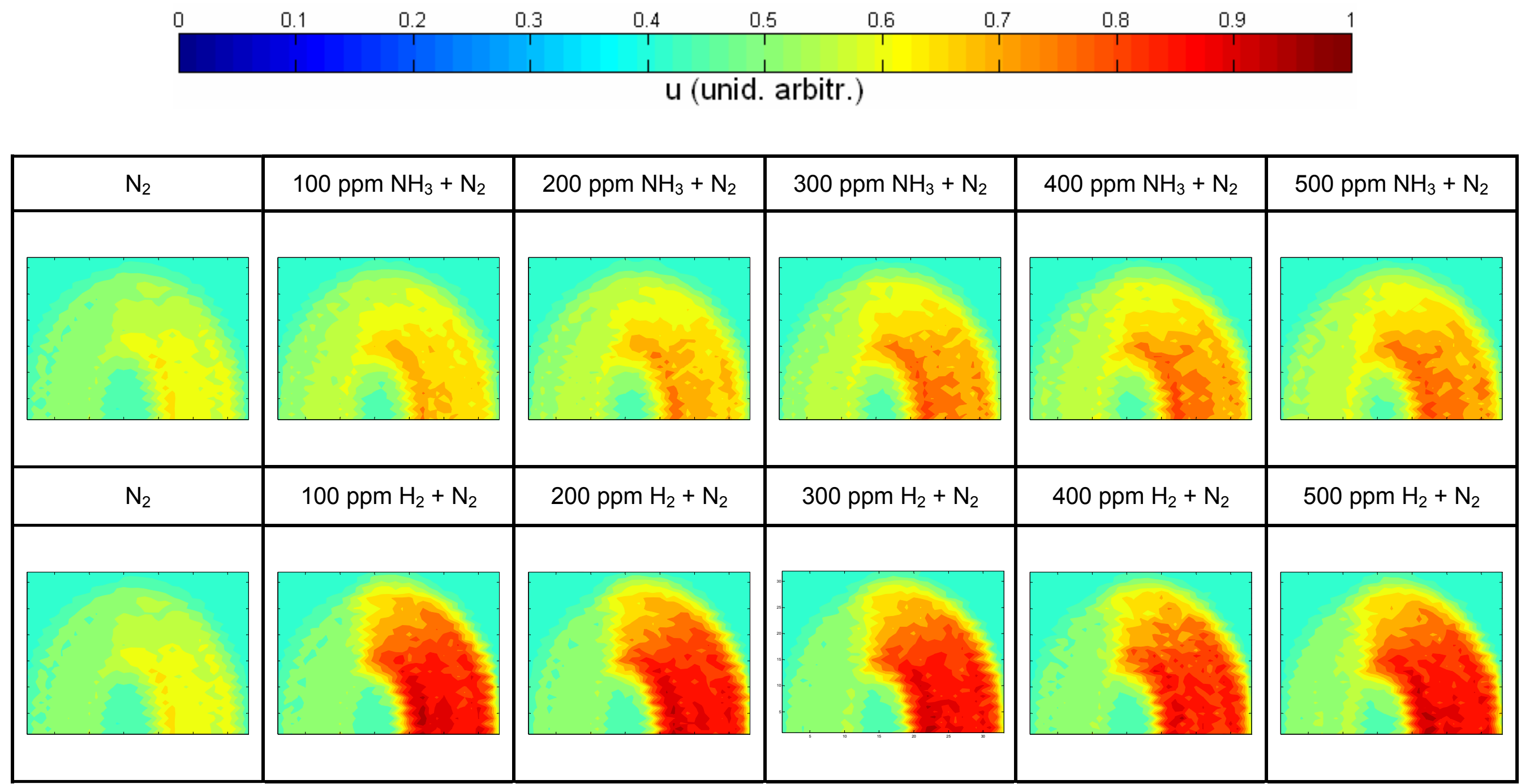

Figura 62 - Imagens químicas obtidas no segundo ensaio pelo sensor em formato de elipse para diferentes concentrações com o sensor operando numa temperatura de $90^{\circ} \mathrm{C}$. As respostas foram normalizadas pelo máximo valor encontrado nos três ensaios. A escala em RGB codifica a amplitude de "u" aos gases ensaiados. 


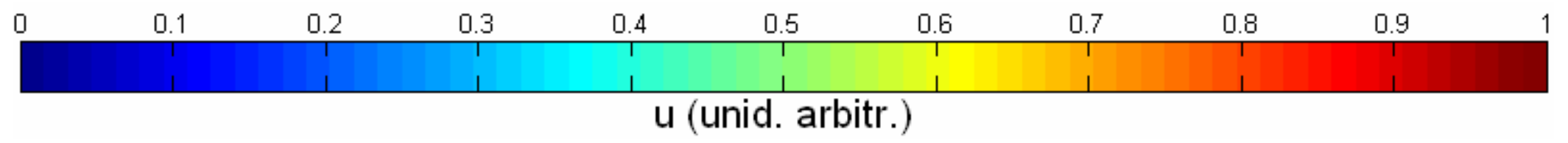

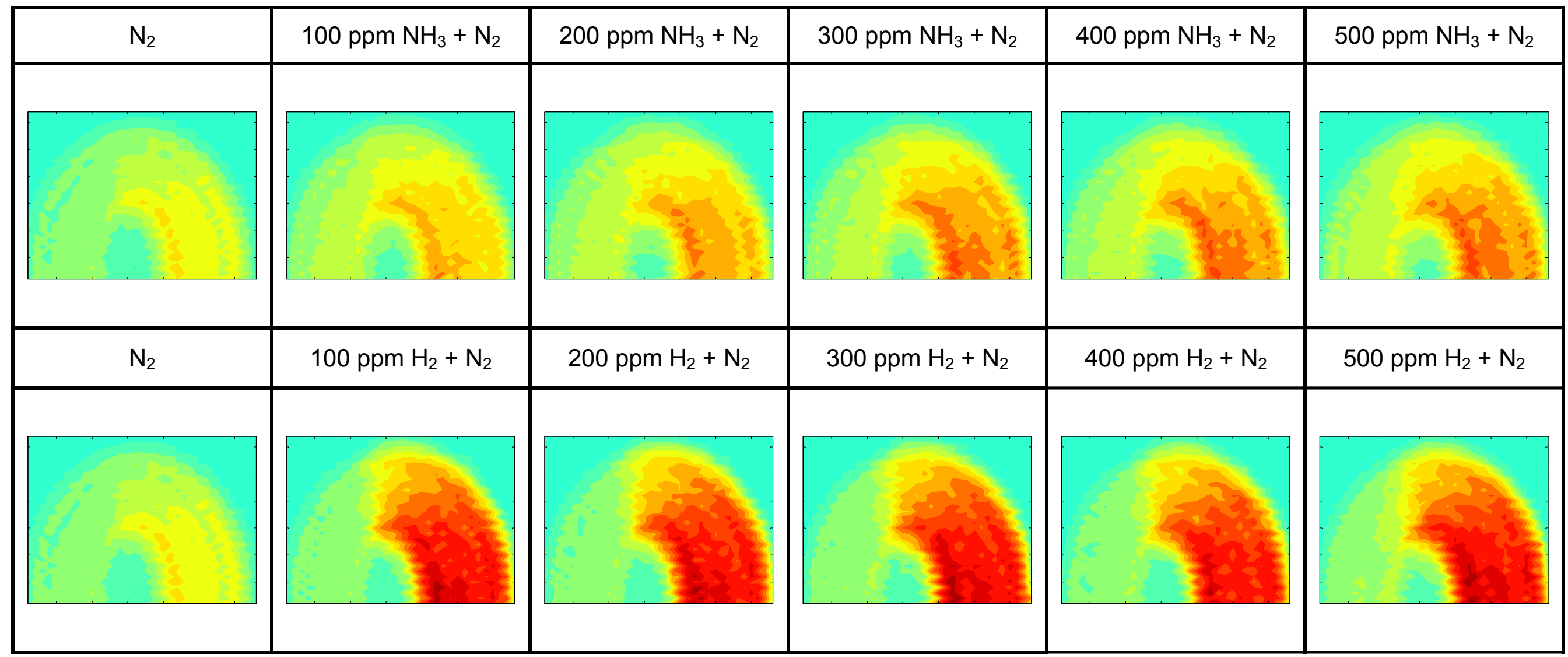

Figura 63 - Imagens químicas obtidas no terceiro ensaio pelo sensor em formato de elipse para diferentes concentrações com o sensor operando numa temperatura de $90^{\circ} \mathrm{C}$. As respostas foram normalizadas pelo máximo valor encontrado nos três ensaios. A escala em RGB codifica a amplitude de "u" aos gases ensaiados. 

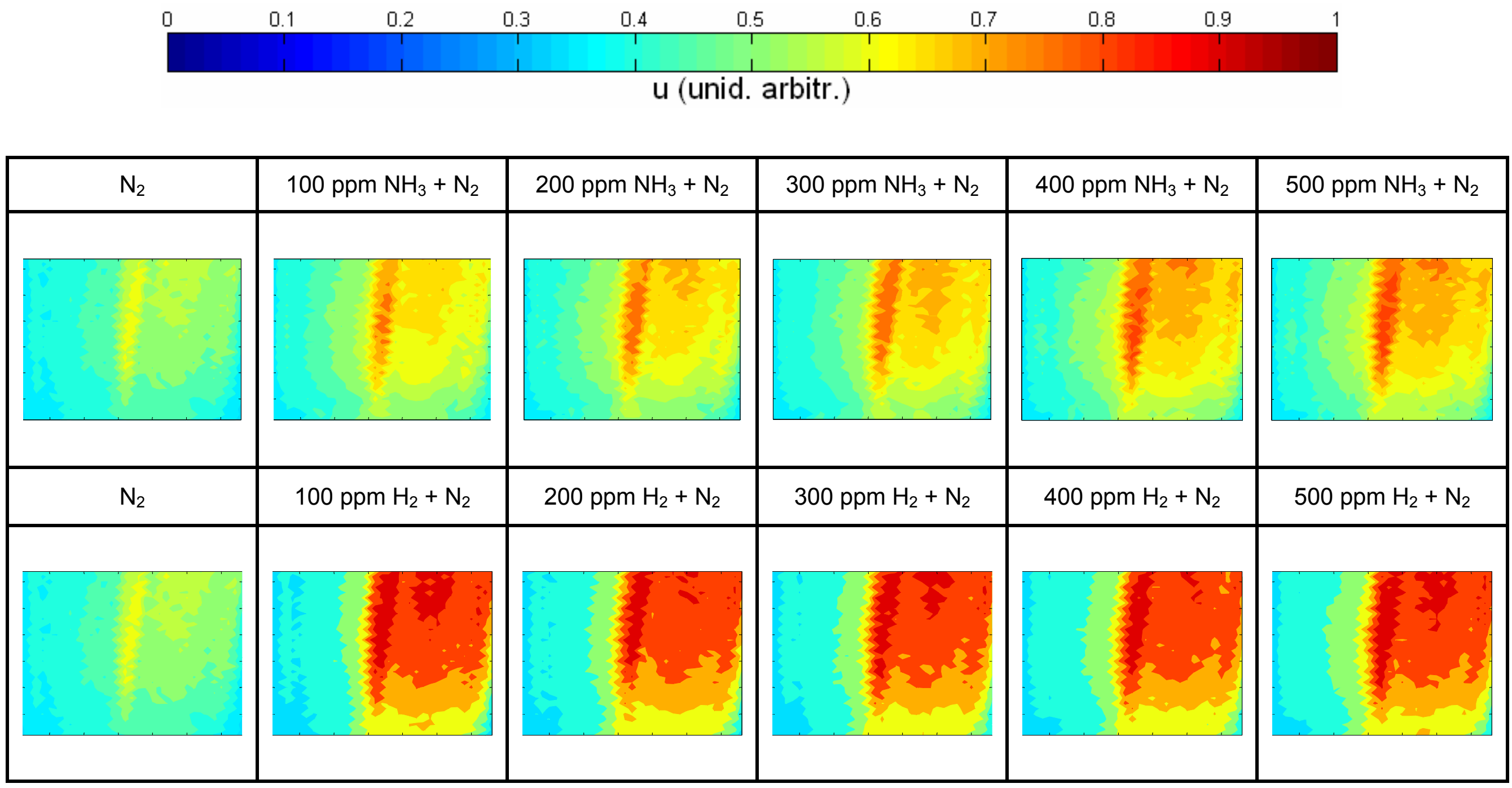

Figura 64 - Imagens químicas obtidas no primeiro ensaio pelo sensor em formato de cunha para diferentes concentrações com o sensor operando numa temperatura de $90^{\circ} \mathrm{C}$. As respostas foram normalizadas pelo máximo valor encontrado nos três ensaios. A escala em RGB codifica a amplitude de "u" aos gases ensaiados. 

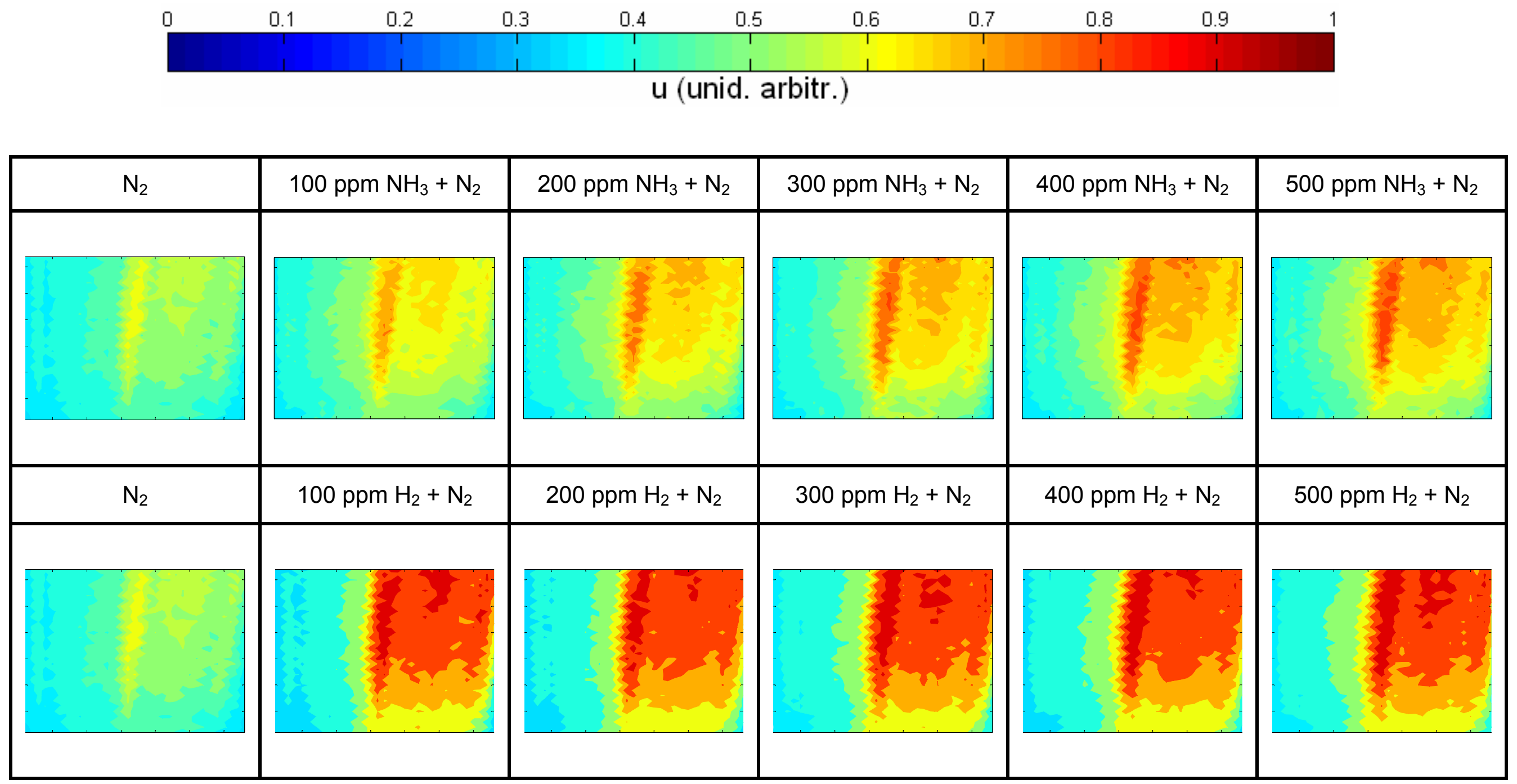

Figura 65 - Imagens químicas obtidas no segundo ensaio pelo sensor em formato de cunha para diferentes concentrações com o sensor operando numa temperatura de $90^{\circ} \mathrm{C}$. As respostas foram normalizadas pelo máximo valor encontrado nos três ensaios. A escala em RGB codifica a amplitude de "u" aos gases ensaiados. 

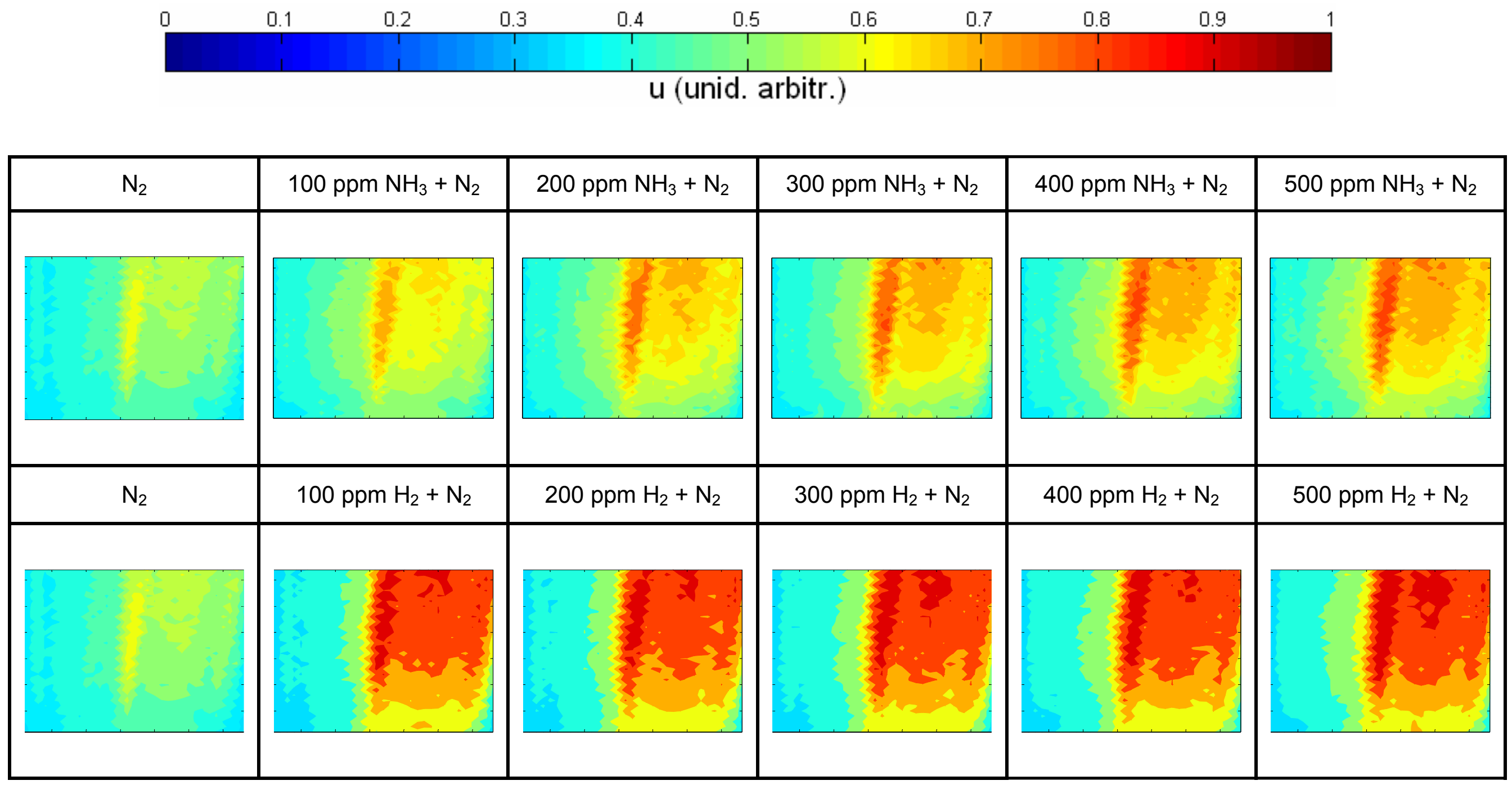

Figura 66 - Imagens químicas obtidas no terceiro ensaio pelo sensor em formato de cunha para diferentes concentrações com o sensor operando numa temperatura de $90^{\circ} \mathrm{C}$. As respostas foram normalizadas pelo máximo valor encontrado nos três ensaios. A escala em RGB codifica a amplitude de "u" aos gases ensaiados. 


\begin{tabular}{|ccccccccccc}
0 & 0.1 & 0.2 & 0.3 & 0.4 & 0.5 & 0.6 & 0.7 & 0.8 & 0.9 & 1 \\
\hline & 1 & 1 & 1 & 1 & 1 & 1 & 1 & 1 & 1 \\
\hline
\end{tabular}

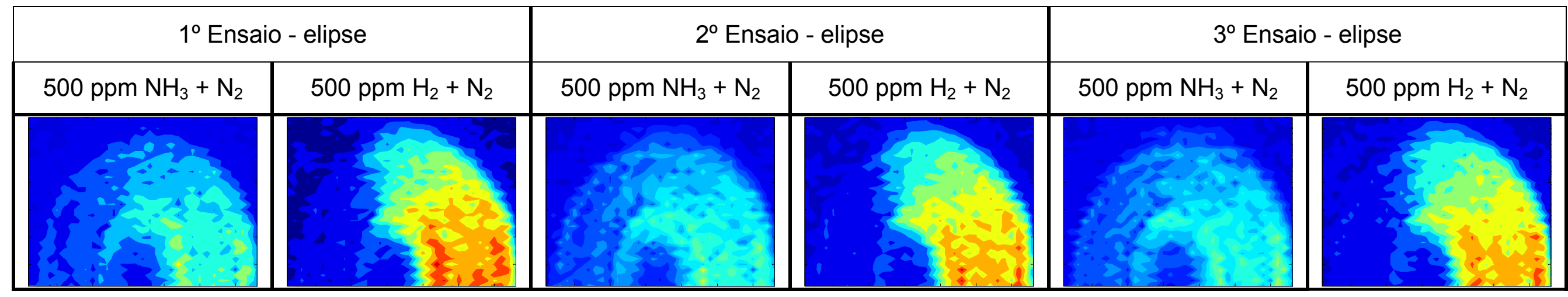

Figura 67 - Imagens químicas da diferença dos gases de $\mathrm{NH}_{3}$ e $\mathrm{H}_{2}$ em relação à ambiente inerte de $\mathrm{N}_{2}$ com o sensor operando numa temperatura de $90^{\circ} \mathrm{C}$ (sensor elipse). As respostas foram normalizadas pelo máximo valor das diferenças encontradas nos três ensaios. A escala em RGB codifica a amplitude de "u" aos gases ensaiados.

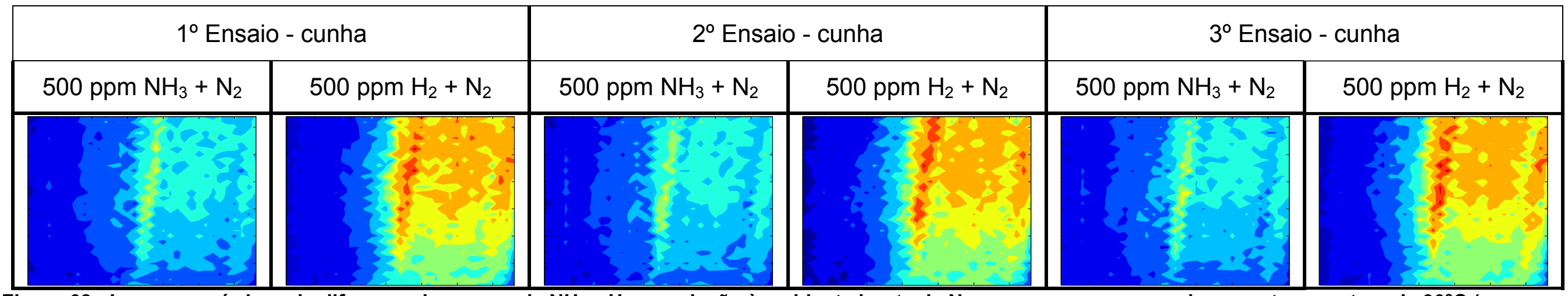

Figura 68 - Imagens químicas da diferença dos gases de $\mathrm{NH}_{3}$ e $\mathrm{H}_{2}$ em relação à ambiente inerte de $\mathrm{N}_{2}$ com o sensor operando numa temperatura de $90^{\circ} \mathrm{C}$ (sensor cunha). As respostas foram normalizadas pelo máximo valor das diferenças encontradas nos três ensaios. A escala em RGB codifica a amplitude de "u" aos gases ensaiados. 

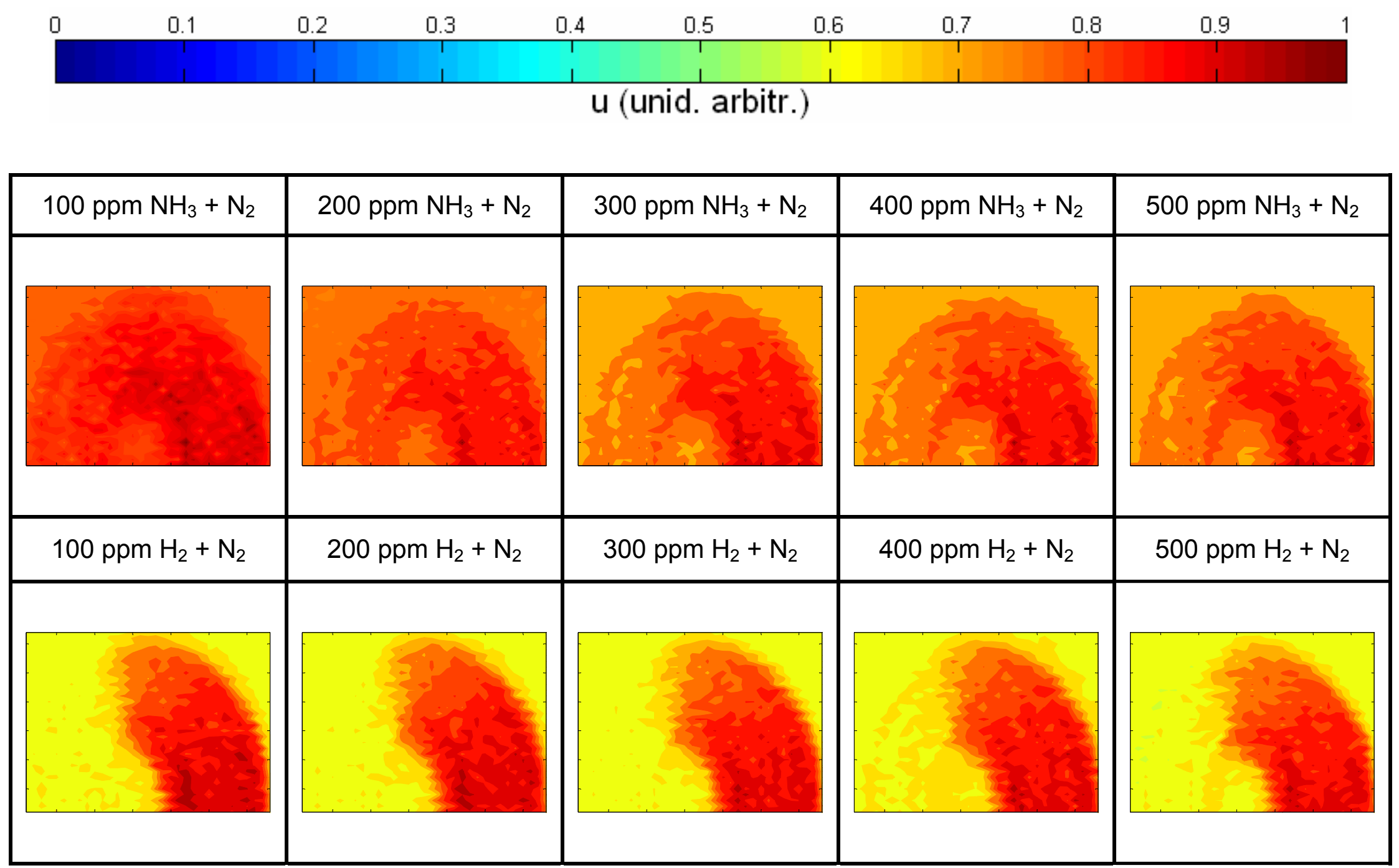

Figura 69 - Imagens químicas da diferença dos gases de $\mathrm{NH}_{3}$ e $\mathrm{H}_{2}$ em relação à ambiente inerte de $\mathrm{N}_{2}$ com o sensor operando numa temperatura de $90^{\circ} \mathrm{C}$ (sensor elipse). As respostas foram normalizadas pelo máximo valor das diferenças encontradas em cada ensaio individualmente. A escala em RGB codifica a amplitude de " $u$ " aos gases ensaiados. 

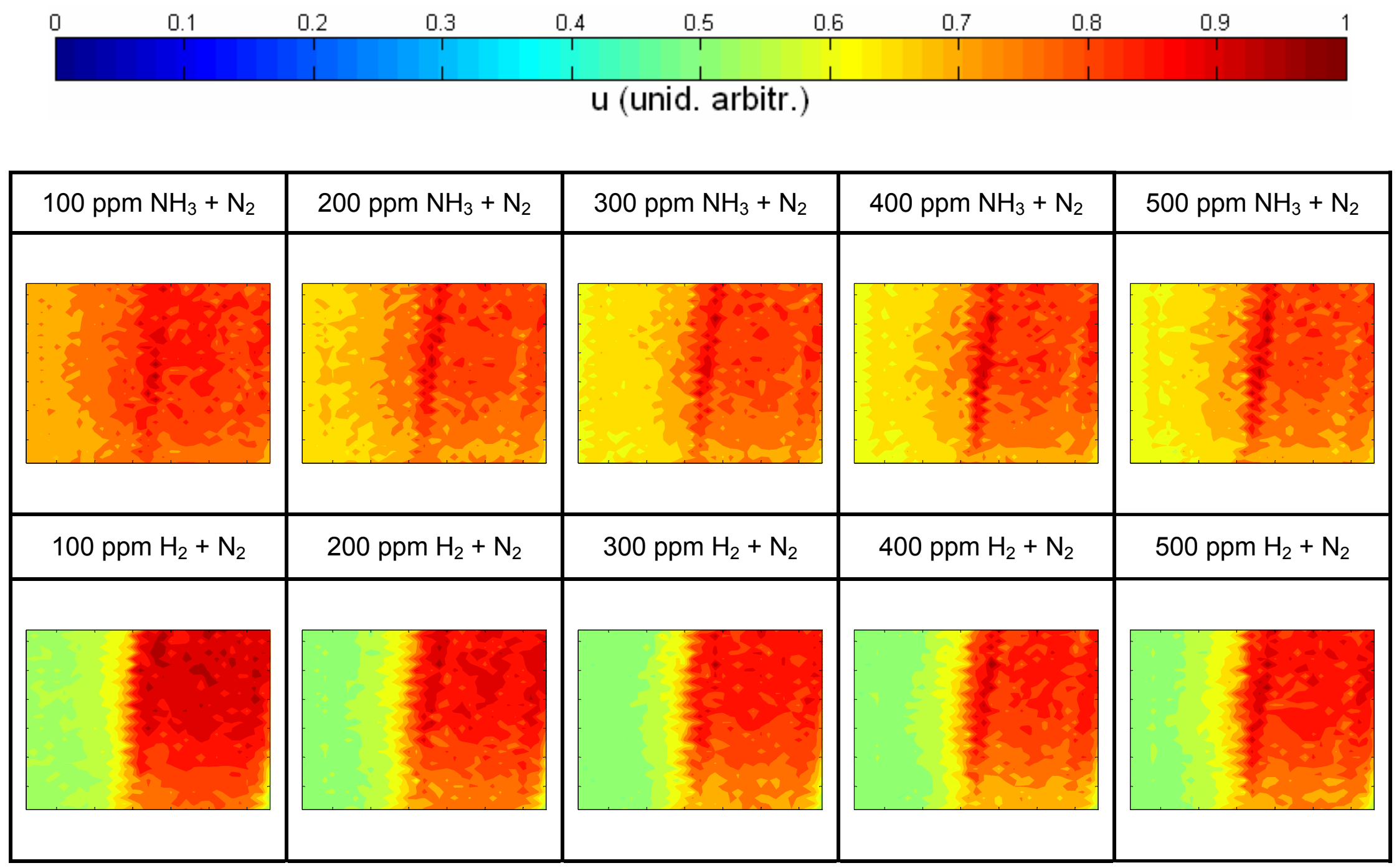

Figura 70 - Imagens químicas da diferença dos gases de $\mathrm{NH}_{3}$ e $\mathrm{H}_{2}$ em relação à ambiente inerte de $\mathrm{N}_{2}$ com o sensor operando numa temperatura de $90^{\circ} \mathrm{C}$ (sensor cunha). As respostas foram normalizadas pelo máximo valor das diferenças encontradas em cada ensaio individualmente. A escala em RGB codifica a amplitude de "u" aos gases ensaiados. 
Uma análise quantitativa dos padrões de imagem da resposta dos sensores permitiria sua implementação em sistemas de nariz eletrônico. Para tal fim, será necessário o processamento de sinais e imagens nos dados experimentais, estando este assunto fora da proposta do presente trabalho. No entanto, alguns pontos importantes dos padrões de imagem podem ser indicados. As imagens químicas obtidas em geral apresentam características de contorno e de bordas peculiares como resposta ao ambiente de gás. Por exemplo, na Figura 71 é mostrado o perfil da imagem química do sensor em forma de elipse como resposta ao gás de Hidrogênio. Observa-se na figura que a região correspondente a sinais com fotocorrente com intensidade diferente de zero abrange uma área maior que a do eletrodo bimetálico indicado pela curva de linha preta. Os detalhes de fronteira podem ser elementos importantes na classificação de padrões das imagens correspondentes a diferentes gases. O comportamento da fotocorrente além das regiões metálicas pode ser explicado através de um modelo de linha de transmissão do dispositivo MOS, como sugerido em (NICOLLIAN, 1982). Como o dispositivo MOS, no processo TELP, apresenta um caráter bidimensional, então o circuito equivalente do dispositivo poderá ser representado por uma linha de transmissão (Figura 72).

Os valores da fotocorrente nas regiões dos metais tiveram valores muito semelhantes, observadas as acentuações nas bordas dos filmes. Na Figura 71 é mostrada a imagem química obtida pelo sensor no formato de elipse para 500 ppm de $\mathrm{H}_{2}$ em $\mathrm{N}_{2}$. Embora respostas externas tenham respostas similares, fora da porta de ouro, a amplitude mostrou-se quase insensível ao hidrogênio, enquanto que nas regiões de óxido circunvizinhas ao paládio, existiram sinais que podem ser atribuídos à resposta lateral do hidrogênio (HOLMBERG \& LUNDSTRÖM, 2000). 




Figura 71 - Identificação da região metálica evidenciando a resposta lateral dos átomos de hidrogênio em regiões circunvizinhas ao filme de paládio.

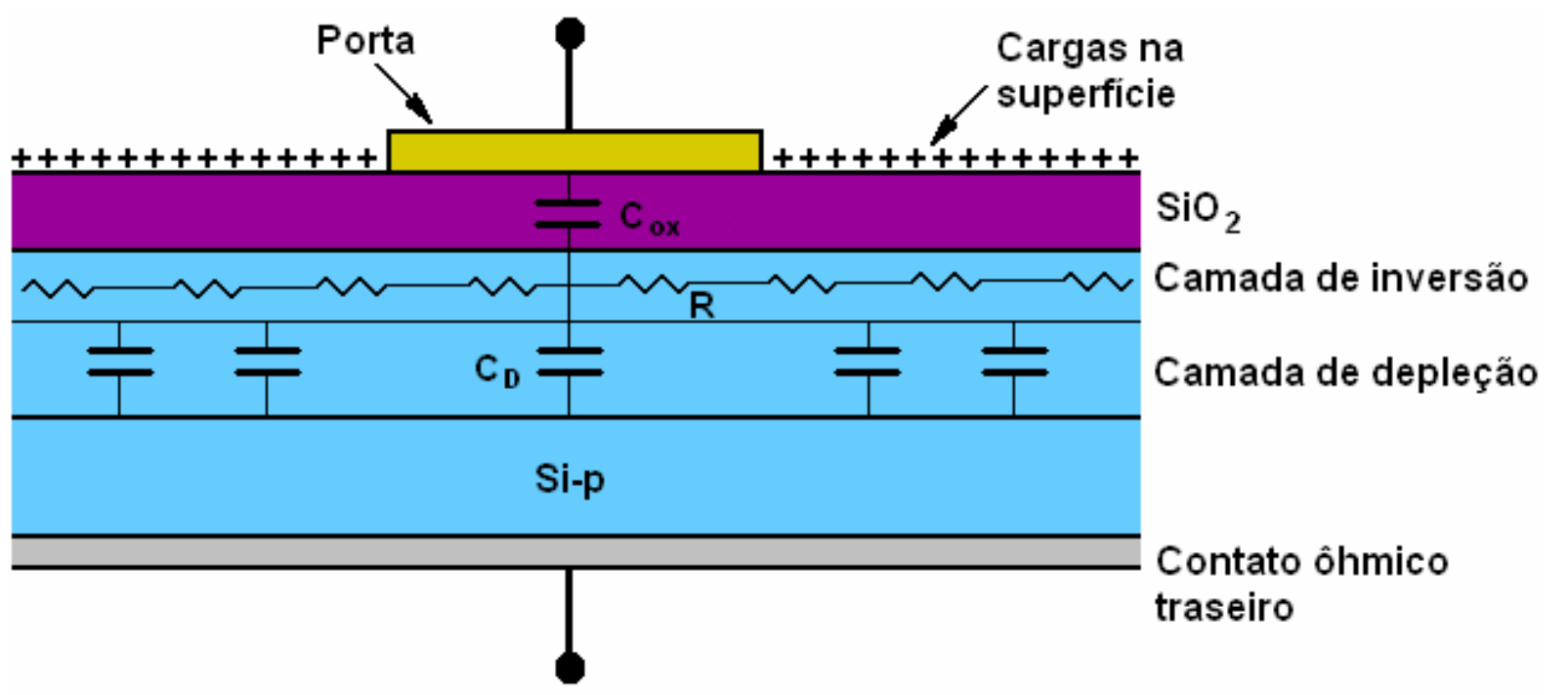

Figura 72 - Modelo esquemático de um dispositivo MOS bidimensional representado por uma linha de transmissão.

A característica do sinal na região lateral fora da região metálica dependerá da resistência elétrica na interface $\mathrm{SiO}_{2} / \mathrm{Si}$ representada na linha de transmissão da Figura 72 pelas resistências que conectam as capacitâncias paralelas. Estas resistências dependem do gás adsorvido na superfície não metálica $\left(\mathrm{SiO}_{2}\right)$, podendo desta forma gerar sinais de fotocorrente de borda com características particulares a 
cada tipo de gás. Um outro parâmetro importante no modelo de linha de transmissão está relacionado com a geometria dos eletrodos bimetálicos, principalmente com sua distância relativa. Em efeito, os perfis unidimensionais dos sinais de fotocorrente mostrados na Figura 57 e na Figura 58 apresentam características distintas. Na Figura 57, no dispositivo em formato de elipse, o sinal de fotocorrente na região de $\mathrm{SiO}_{2}$, desde a borda do eletrodo de Au até a borda do eletrodo de Pd, mostra uma inclinação menos acentuada se comparada com a mesma região do dispositivo em formato de cunha da Figura 58. Neste caso particular, a diferença geométrica basicamente está na distância entre os eletrodos de $\mathrm{Au}-\mathrm{Pd}$, sendo esta maior no caso do dispositivo em formato de elipse, sendo este fato concordante com o modelo de linha de transmissão, desde que maior região de $\mathrm{SiO}_{2}$ sugere maior resistência da linha.

Os resultados acima discutidos mostram o potencial do dispositivo MOS em modo de operação TELP para aplicação em um sistema de nariz eletrônico implementado com um único sensor. 


\section{CONSIDERAÇÕES FINAIS}

\subsection{CONCLUSÕES}

Os resultados reportados no presente trabalho mostraram o grande potencial do dispositivo MOS para aplicação em sensores de imagem química baseado na técnica de escaneamento de luz pulsada (TELP). As imagens químicas foram obtidas a partir das intensidades de fotocorrente local induzida pelo feixe de luz pulsada. Estas fotocorrentes induzidas mostraram uma dependência com o gás adsorvido na superfície do sensor e ao tipo de metal utilizado como porta do dispositivo MOS resultando assim em imagens químicas bidimensionais com características particulares para cada gás utilizado nos ensaios experimentais.

O arranjo experimental proposto para a aquisição de dados do sensor de imagens químicas MOS possibilitou projetar um sistema eletrônico de controle de posição XY, para a varredura do feixe pulsado de Laser, utilizando-se a técnica de controle PID. O Pré-condicionamento do sinal do sensor foi realizado através de um amplificador de transimpedância. Esta unidade simultaneamente foi utilizada para polarizar o dispositivo MOS, tendo sido proposta com esta finalidade uma arquitetura de modo comum para o amplificador operacional de entrada que é parte constitutiva da unidade de amplificação de transimpedância. Os controles de posição $X Y$ e a aquisição de sinais foram automatizados por instrumentos virtuais definidas com o software Labview $囚$.

No ensaio de determinação das características construtivas dos sensores MOS obtidas pelo método de caracterização $\mathrm{CxV}$ em baixa e alta freqüência foram encontrados os valores de densidade efetivas do óxido e concentração efetiva do substrato na ordem de $10^{11}$ e $10^{15}$ respectivamente. Adicionalmente foi determinada a tensão de banda plana resultando em um valor da ordem de $-0,5 \mathrm{~V}$. Tais parâmetros mostraram que os dispositivos atenderam às especificações de projeto. O valor de tensão de banda plana diferente de zero não compromete a eficiência do sensor já que para operação no modo TELP a polarização do sensor foi ajustada convenientemente escolhendo a região de maior sensibilidade. 
A curva de sensibilidade (du/dv vs $V$ ), para a fotocorrente induzida no dispositivo MOS, foi obtida a partir das curvas $u \times V p$. A curva du/dV do sensor MOS em ambiente inerte $\left(\mathrm{N}_{2}\right)$ apresentou seu máximo valor quando a camada de depleção atingiu seu valor máximo, fato que acontece quando o dispositivo é polarizado com uma tensão de 0,6 V. Em ambientes de $\mathrm{H}_{2}$ e $\mathrm{NH}_{3}$, o máximo de sensibilidade foi deslocado para tensões menores a $0,6 \mathrm{~V}$ atribuindo-se este comportamento à adsorção de átomos de Hidrogênio na interface $\mathrm{SiO}_{2} / \mathrm{Si}$. A aquisição de dados para a construção de imagens químicas foi obtida com o dispositivo polarizado com tensão de $0,5 \mathrm{~V}$ um pouco abaixo da máxima sensibilidade evitando desta forma a saturação prematura na resposta do sensor.

A resposta transiente dos sensores a temperatura de $90{ }^{\circ} \mathrm{C}$ mostrou que a taxa de adsorção de átomos de hidrogênio na região de paládio apresenta aproximadamente o mesmo valor quando o ambiente é de $\mathrm{H}_{2}$ ou $\mathrm{NH}_{3}$ respectivamente. Este processo segundo, LUNDSTRÖM, 1981, obedece ao processo de Langmuir. O processo de dessorção a esta temperatura mostrou-se dependente do tipo de gás com resposta rápida para um ambiente de $\mathrm{H}_{2}$ e lenta no caso do ambiente de $\mathrm{NH}_{3}$. Desde que na interface de $\mathrm{SiO}_{2} / \mathrm{Si}$ os átomos adsorvidos são de Hidrogênio mesmo em ambiente de $\mathrm{NH}_{3}$ foi sugerida a existência de uma barreira energética na superfície do Pd que evita o processo de dessorção dos átomos de Hidrogênio quando o ambiente é de gás de $\mathrm{NH}_{3}$. Nos processos de adsorção, a temperatura de $26{ }^{\circ} \mathrm{C}$, foram observados distintos tempos de subida do sinal de resposta para o $\mathrm{H}_{2}$ e $\mathrm{NH}_{3}$ respectivamente, sendo o tempo de subida em ambiente de $\mathrm{H}_{2}$ menor em relação ao ambiente de $\mathrm{NH}_{3}$. Esta diferença foi atribuída à baixa taxa de dissociação das moléculas de $\mathrm{NH}_{3}$ a temperatura de $26{ }^{\circ} \mathrm{C}$. O processo dessorção a esta temperatura mostrou-se lento para ambos ambientes de gás $\left(\mathrm{H}_{2}\right.$ e $\left.\mathrm{NH}_{3}\right)$ não sendo possível dimensioná-lo na escala de tempo utilizado no ensaio experimental (Horas). $O$ ensaio das respostas transientes em função da temperatura mostrou que o dispositivo sensor de imagem MOS opera eficientemente a temperaturas acima de $90^{\circ} \mathrm{C}$.

As imagens químicas obtidas a partir da resposta do sensor MOS em modo de operação TELP para ambientes de $\mathrm{H}_{2}$ e $\mathrm{NH}_{3}$ respectivamente apresentaram padrões característicos a cada tipo de gás independentemente da concentração utilizada. Os padrões de imagens normalizados permitem a classificação plena do tipo de gás se $\mathrm{H}_{2}$ ou $\mathrm{NH}_{3}$. Adicionalmente, as imagens químicas oferecem detalhes de contorno característicos na região de fronteira dos eletrodos metálicos que podem ser 
utilizados no refinamento quantitativo da classificação de gases. Os detalhes de contorno foram atribuídos a efeitos bidimensionais do dispositivo que podem ser modelados por linhas de transmissão.

\subsection{PERSPECTIVAS FUTURAS}

Os resultados obtidos no presente trabalho sugerem a possibilidade de implementação de um sistema de nariz eletrônico apenas utilizando um único sensor, sendo necessário neste caso o projeto de dispositivos MOS com porta multimetálica constituídos de metais catalíticos tipo Pd, Pt, Ni, Ir, Rh etc e geometrias diferentes. Para a melhoria da sensibilidade deste tipo de sensores poderão ser utilizados filmes metálicos porosos ou nano-estruturados e substrato de silício com baixa dopagem próximo do nível intrínseco.

Os dispositivos MOS para obtenção de imagens químicas podem ser aplicados como microscópios elétricos em células eletroquímicas de tal forma a poder monitorar culturas biológicas ou outros eventos eletroquímicos. 


\section{REFERÊNCIAS}

ALBERTIN, K. F. Estudo e fabricação de capacitores MOS com camada isolante de SiOxNy depositada por PECVD. Dissertação de Mestrado, EPUSP, 2003.

BARATTO, G.; FERNANDES, F. J. R. Transistor MOS com porta metálica de paládio sensível ao hidrogênio. Dissertação de Mestrado, EPUSP, 1993.

DISTEFANO, T. H.; VIGGIANO, J. M. Interface Imaging by Scanning Internal Photoemission IBM J. Res. Develop., março 1974, p. 94-99.

EKLÖV, T.; Sundgren, H.; Lundström, I. Distributed chemical sensing Sensor and Actuators B, v. b45, p. 71-77, 1997.

EKLÖV, T.; Lundström, I. Gas mixture analysis using a distributed chemical sensor system Sensor and Actuators B, v. b57, p. 274-282, 1999.

ENGSTRÖM, O.; CARLSSON, A. Scanned light pulse technique for the investigation of insulator-semiconductor interfaces, Journal of Applied Physics, v. 54, p. 5245$5251,1983$.

ERIKSSON, M.; EKEDAHL, L.-G. The influence of $\mathrm{CO}$ on the response of hydrogen sensitive Pd-MOS devices. Sensors and Actuators B, v. 42, p. 217-23, 1997.

ERIKSSON, M.; EKEDAHL, L.-G. Real time measurements of hydrogen desorption and absorption during $\mathrm{CO}$ exposures of $\mathrm{Pd}$ : hydrogen sticking and dissolution, Applied Surface Science, v.133, p. 89-97, 1998.

ERIKSSON, M.; LUNDSTRÖM, I.; EKEDAHL, L. G. A model of the Temkin isotherm behavior for hydrogen adsorption at Pd-SiO2 interfaces Journal of Applied Physics, v. 82, n.6, p.3143-3146, 1997.

ERIKSSON, M.; SALOMONSSON, A.; LUNDSTRÖM, I. The influence of the insulator surface properties on the hydrogen response of field-effect gas sensors Journal of Applied Physics, v. 98, 034903, p. 1-6, 2005. 
FILLIPINI, D.; ARAGÓN, R.; WEIMAR, U. Gas sensing properties of copper gate metal-oxide-semiconductor capacitors. Journal of Vacuum Science \& Technology B: Microelectronics and Nanometer Structures, v. 19, n. 3, p. 825-828, 2001a.

FILLIPINI, D. et al. New $\mathrm{NO}_{2}$ sensor based on $\mathrm{Au}$ gate field effect devices. Sensor and Actuators B, v. b78, p.195-201, 2001b.

FILIPPINI, D.; LUNDSTRÖM, I. Distinctive chemical image generation by a compact scanning light pulse technique, Ninth International Symposium on Olfaction and Electronic Nose - ISOEN'02 - 2002.

FILIPPINI, D.; LUNDSTRÖM, I. Distinctive photocurrent chemical images on bare $\mathrm{SiO}_{2}$ between continuous metal gates. Sensors and Actuators B, v. b95, p. 116-122, 2003.

FILIPPINI, D.; LUNDSTRÖM, I. Hydrogen detection on bare $\mathrm{SiO}_{2}$ between metal gates. Journal of Applied Physics, v. 91, n.6, p.3896-3903, 2001.

FOGELBERG, J. et al. Kinetic modeling of hydrogen adsorption/absorption in thin films on hydrogen-sensitive field-effect devices: Observation of large hydrogeninduced dipoles at the $\mathrm{Pd}-\mathrm{SiO}_{2}$ interface Journal of Applied Physics, v. 78, n.2, p.988996, 1995.

GÖPEL, W. Chemical imaging: I. Concepts and visions for electronic and bioelectronic noses. Sensors and Actuators B, v. b52, p.125-142 (1998).

GRABER, N.; LÜDI, H.; WIDMER, H. M. The Use of Chemical Sensors in Industry. Sensors and Actuators B, v. b1, p.239-243, 1990.

HOLMBERG, M.; LUNDSTRÖM, I. A new method for the detection of hydrogen spillover. Applied Surface Science, v. 93, p.67-76, 1995.

HORNIK, W. A novel structure for detecting organic vapours and hydrocarbons based on a Pd-MOS sensor. Sensor and Actuators B, v. b1, p.35-39, 1990. 
HUGHES, R. C. et al. Thin-film palladium and silver alloys and layers for metalinsulator-semiconductor sensors. Journal of Applied Physics, v. 62, n.3, p. 1074-83, 1987.

HUGHES, R. C.; SCHUBERT, W. K. Thin films of Pd/Ni alloys for detection of high hydrogen concentrations. Journal of Applied Physics, v. 71, n.1, p. 542-544, 1992.

LÖFDAHL, M.; LUNDSTRÖM, I. Monitoring of hydrogen consumption along a palladium surface by using a scanning light pulse technique. Journal of Applied Physics, v. 86, n.2, p. 1106-13, 1999.

LÖFDAHL, M.; ERIKSSON, M.; LUNDSTRÖM, I. Chemical Images. Sensor and Actuators B, v. b70, p.77-82, 2000.

LUNDSTRÖM, I.; ARMGARTH, M.; PETERSSON, L. C. Physics with catalytic metal gate chemical sensors. CRC Critical Reviews in Solid State and Materials Sciences, v.15, n.3, p.201-278, 1989.

LUNDSTRÖM, I. et al. A hydrogen-sensitive MOS field-effect transistor. Applied Physics Letters, v. 26, n.2, p.55-57, 1975.

LUNDSTRÖM, I. et al. Artificial "olfactory" images from a chemical sensor using a light-pulse technique. Nature, v. 352, p.47-50, 1991.

LUNDSTRÖM, I. Hydrogen sensitive MOS-STRUCTURES Part. 1: Principles and Applications. Sensor and Actuators, v. 1, p.403-26, 1981.

LUNDSTRÖM, I. Hydrogen sensitive MOS-STRUCTURES Part. 2: Characterization. Sensor and Actuators, v. 2, p.105-38, 1982.

LUNDSTRÖM, I.; SHIVARAMAN, M. S.; SVENSSON, C. A hydrogen-sensitive Pdgate MOS transistor. Journal of Applied Physics, v. 46, n.9, p. 3876-81, 1975.

LUNDSTRÖM, I.; SHIVARAMAN, M. S.; SVENSSON, C. Chemical reactions on palladium studied with Pd-MOS structures. Surface Science, v.64, p. 497-519, 1977. 
LUNDSTRÖM, I. et al. Twenty-five years of field effect gas sensor research in Linköping. Sensors and Actuators B, v.121, p. 247-62, 2007.

MEIXNER, H.; GERBLINGER, J.; FLEISCHER, M. Sensor for Monitoring Environmental Pollution. Sensors and Actuators B, v. b15, n.1-3, p.45-54, 1993.

MIZSEI, J. Chemical imaging by direct methods. Thin Solid Films, v.436, p.25-33, 2003.

MIZSEI, J. $\mathrm{H}_{2}$-induced surface and interface potentials on Pd-activated $\mathrm{SnO} 2$ sensor films, Sensors and Actuators B, v. 28, p129-33, 1995.

MIZSEI, J.; LANTTO, V. Simultaneous response of work function and resistivity of some $\mathrm{SnO}_{2}$-based samples to $\mathrm{H} 2$ and $\mathrm{H} 2 \mathrm{~S}$, Sensors and Actuators B, v. 4, p.163168, 1991.

NICHOLLIAN, E.H.; BREWS, J.R. MOS Physics and Technology, New York, Wiley Interscience Piblication, 2, 1982.

OGATA, K. Engenharia de controle moderno. São Paulo, Pearson Education do Brasil, 4 ed., 2005.

PETERSSON, L. C.; DANNETUN, H. M.; LUNDSTRÖM, I. Hydrogen detection during catalytic surface reactions: evidence for actived lateral hydrogen mobility in the water-forming reaction on Pd. Physical Rewiew Letters, v.52, n.20, p.1806-09, 1984.

PILLING, R. S. et al. Quantifying gas sensor and delivery system response time using GC/MC. Sensors and Actuators B, v.96, p. 200-14, 2003.

SALOMONSSON, A.; ERIKSSON, M.; DANNETUN, H. Hydrogen interaction with platinum and palladium metal-insulator-semiconductor devices Journal of Applied Physics, v. 98, 014505, p. 1-10, 2005.

SOMORJAI, G. Principles of surface chemistry. Prentice-Hall, p.187-257, 1972. 
SPETZ, A.; ARMGARTH, M.; LUNDSTRÖM, I. Hydrogen and ammonia response of metal-silicon dioxide-silicon structures with thin platinum gates. Journal of Applied Physics, v. 64, n.3, p.1274-83, 1988.

SZE, S. M. VLSI Technology . McGraw-Hill, p. 42-44, 1983.

WAGNER, T. V.; WIRTH, G. I. Tecnologia de Implementação CMOS. In: Ricardo Augusto da Luz Reis. (Org.). Concepção de Circuitos Integrados. 2 ed. Porto Alegre: Editora Sagra Luzzatto - Série Livros Didáticos Inf. UFRGS, v. , p. 9-12, 2000.

WISQUIST, F. et al. Modified palladium metal-oxide-semiconductor structures with increased ammonia gas sensitivity. Applied Physics Letters, v.43, n.9, p.839-41, 1983.

WOLF, H. F. Silicon Semiconductor Data. Pergamon Press, v.9, p. 523-602, 1969.

YOSHINOBU, T. et al. Chemical imaging sensor and its application to biological systems. Electrochimica Acta, v. 47, p. 259-63, 2001.

ZUBKANS, J. et al. In Situ Modification of the $\mathrm{NO}_{\mathrm{x}}$ and $\mathrm{CO}$ sensitivity of thin Pt-Gate MOSFET's The 8th International Conference on Solid-State Sensors and Actuators, and Eurosensors IX, 1995. 


\section{ANEXO A - Código Fonte do Sistema de Posicionamento X Y para Obtenção das Imagens Químicas através da TELP}

$\mathrm{Na}$ Figura 1 são apresentadas as funções que compõem o programa correspondente ao sistema de posicionamento $\mathrm{X} Y$, pré-processamento do sinal (cálculo da integral de semiciclos da fotocorrente) e controle PID. Nas próximas seções serão detalhados os blocos do programa individualmente. 


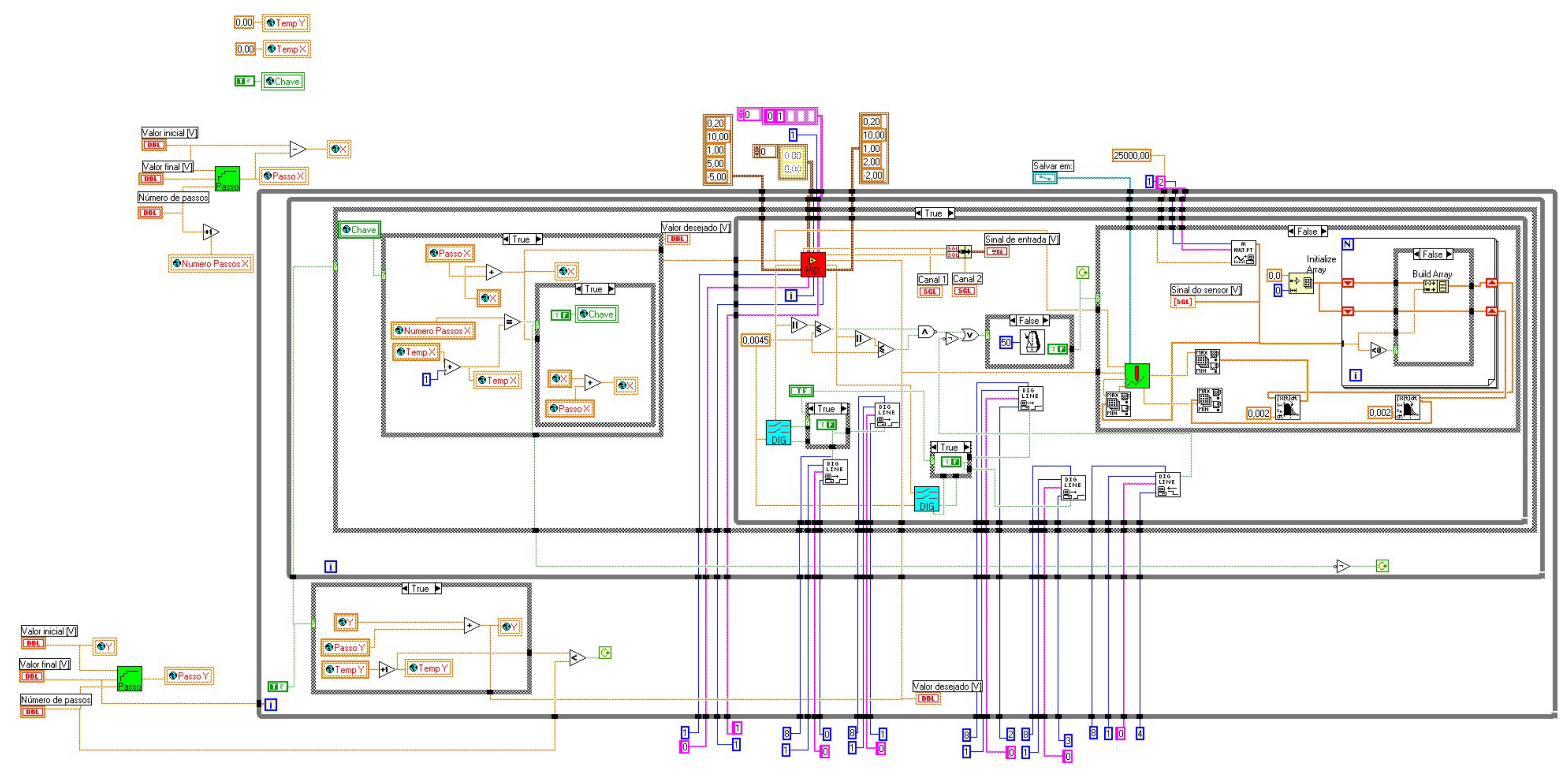

Figura 1 - Código desenvolvido no ambiente LabVIEW®. 


\section{Código do sistema de posicionamento $X Y$ utilizando o software LabVIEW®.}

\subsection{Geração de valores para o eixo X}

\subsubsection{SubVI Passo}

Para a geração dos valores buscados pelo controlador, foi criado o subVI Passo (Figura 2). Ele recebe os valores inicial e final e o número de passos desejados e, a partir desses dados, calcula o intervalo entre os valores de posição que serão gerados automaticamente em tempo de execução.

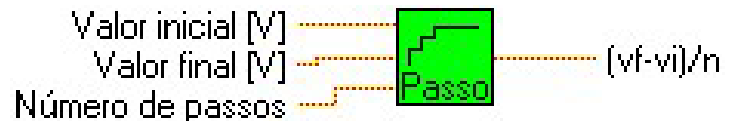

Figura 2 - VI Passo.

A Figura 3 mostra o fluxograma do cálculo do valor do passo entre os valores que serão gerados para formar a rampa de posições. A Figura 4 mostra o código desenvolvido em Labview ${ }^{\circledR}$. 


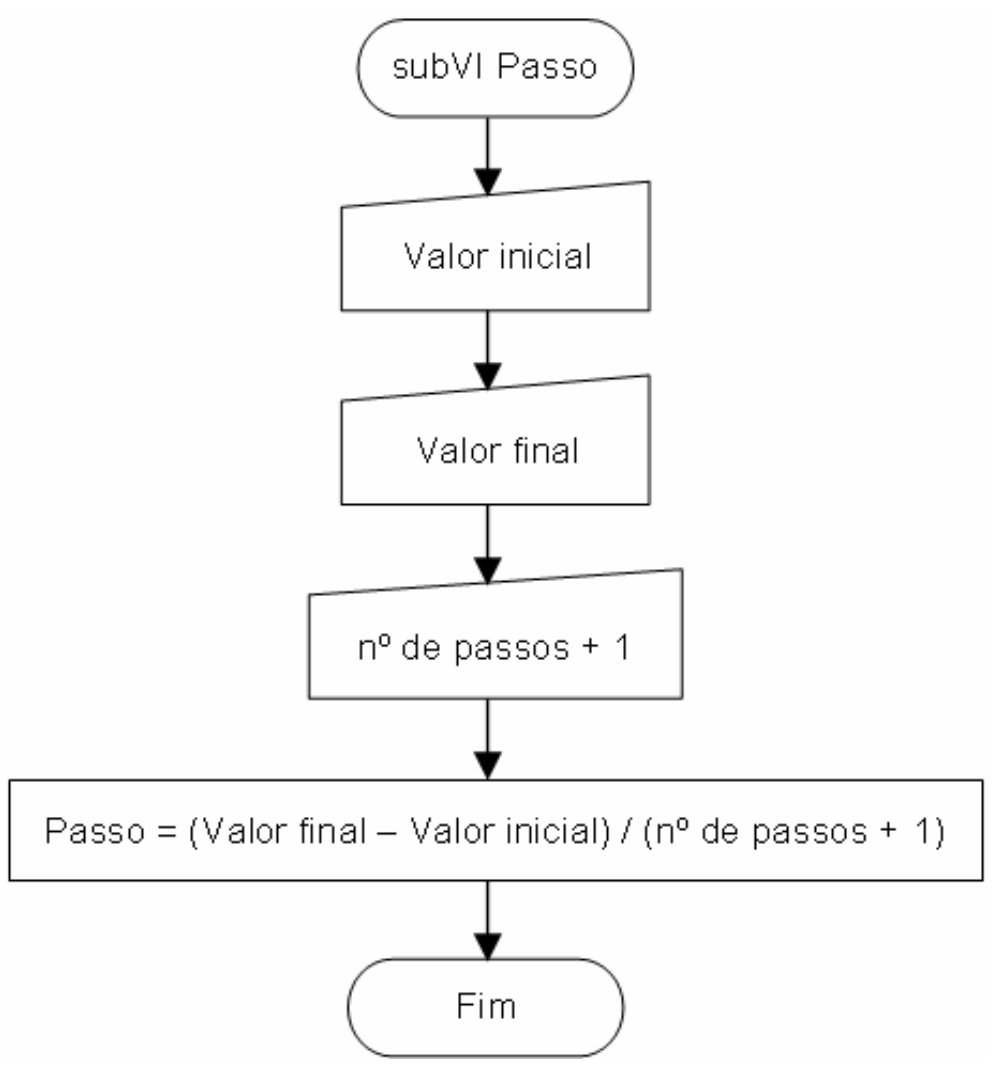

Figura 3 - Fluxograma do subVI Passo.

Valor inicial [V]

DBB



Figura 4 - Calcula o intervalo entre os valores de posição que serão lidos.

\subsubsection{Geração do valor inicial para o eixo X}

O subVI Passo é inserido no programa principal como mostra a Figura 5. O valor do passo calculado por esse subVI é armazenado na variável global Passo X. 


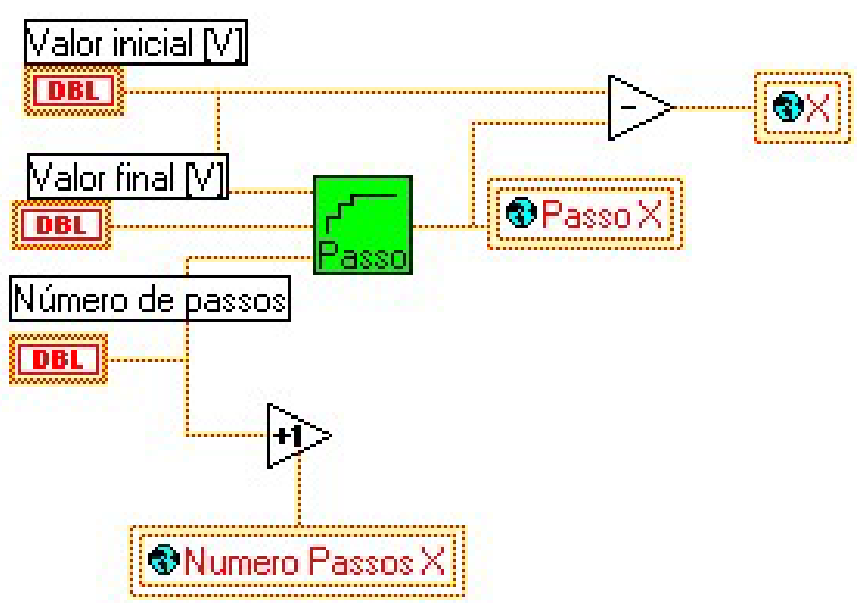

Figura 5 - SubVI Passo no programa principal.

O passo calculado é subtraído do valor inicial e armazenado na variável X, que é a responsável por indicar qual valor de posição deve ser lido. O fluxograma desta etapa do programa é mostrado na Figura 6.

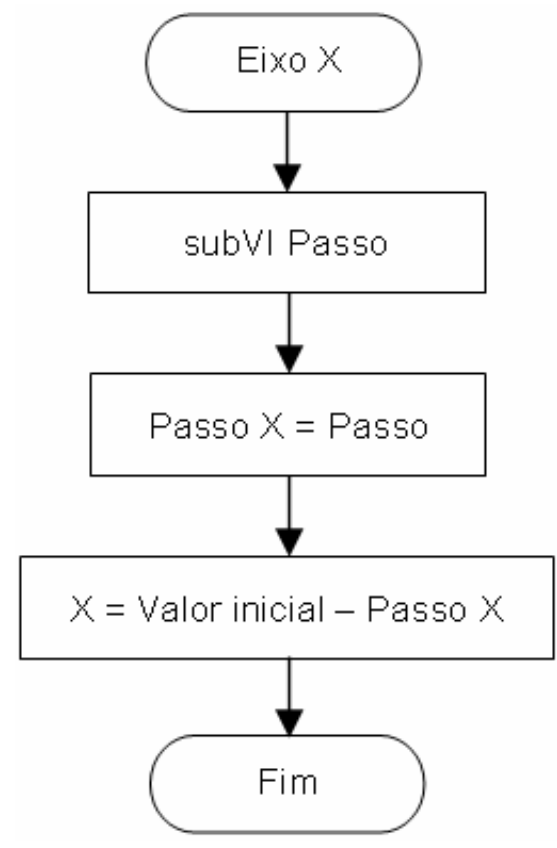

Figura 6 - Geração do valor inicial para o eixo X.

\subsubsection{Cálculo dos valores crescentes e decrescentes para o eixo $X$}

O programa desenvolvido deve garantir que os valores de posição sejam gerados sempre na mesma seqüência em ordem crescente ou decrescente. As funções desenvolvidas para que isso ocorra utilizam a variável booleana Chave para habilitar o cálculo dos valores crescentes quando o status dessa variável for true (Figura 7) e 
decrescentes quando o status for false (Figura 8). Quando a leitura dos dados de uma seqüência inteira de posições é realizada, o valor da variável Chave é alterado para que uma nova seqüência seja iniciada.

A variável TempX armazena o número de vezes que a função é executada, este valor é comparado com o número de passos realizados para verificar se todos os pontos de uma seqüência foram obtidos.

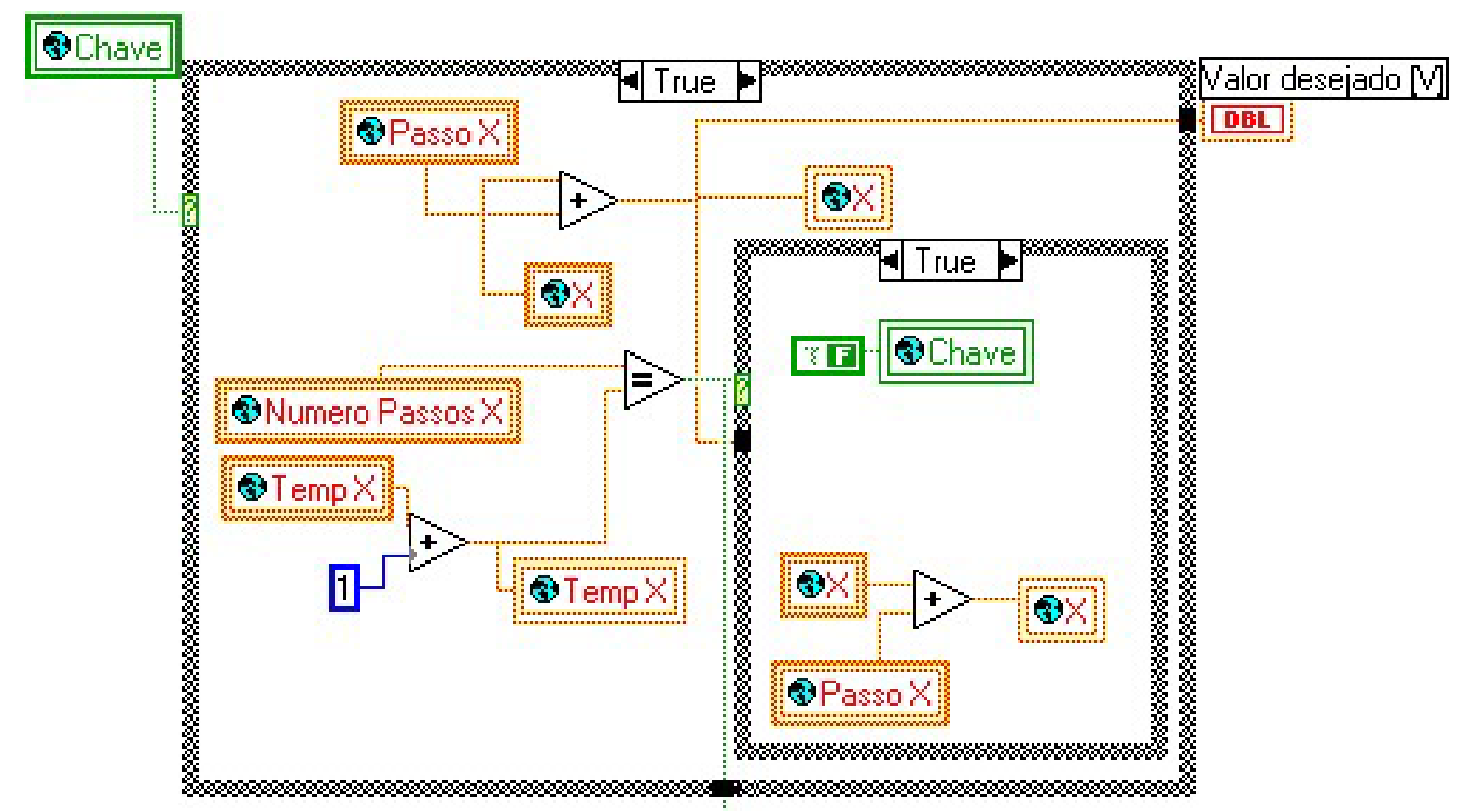

Figura 7 - Geração de valores crescentes.

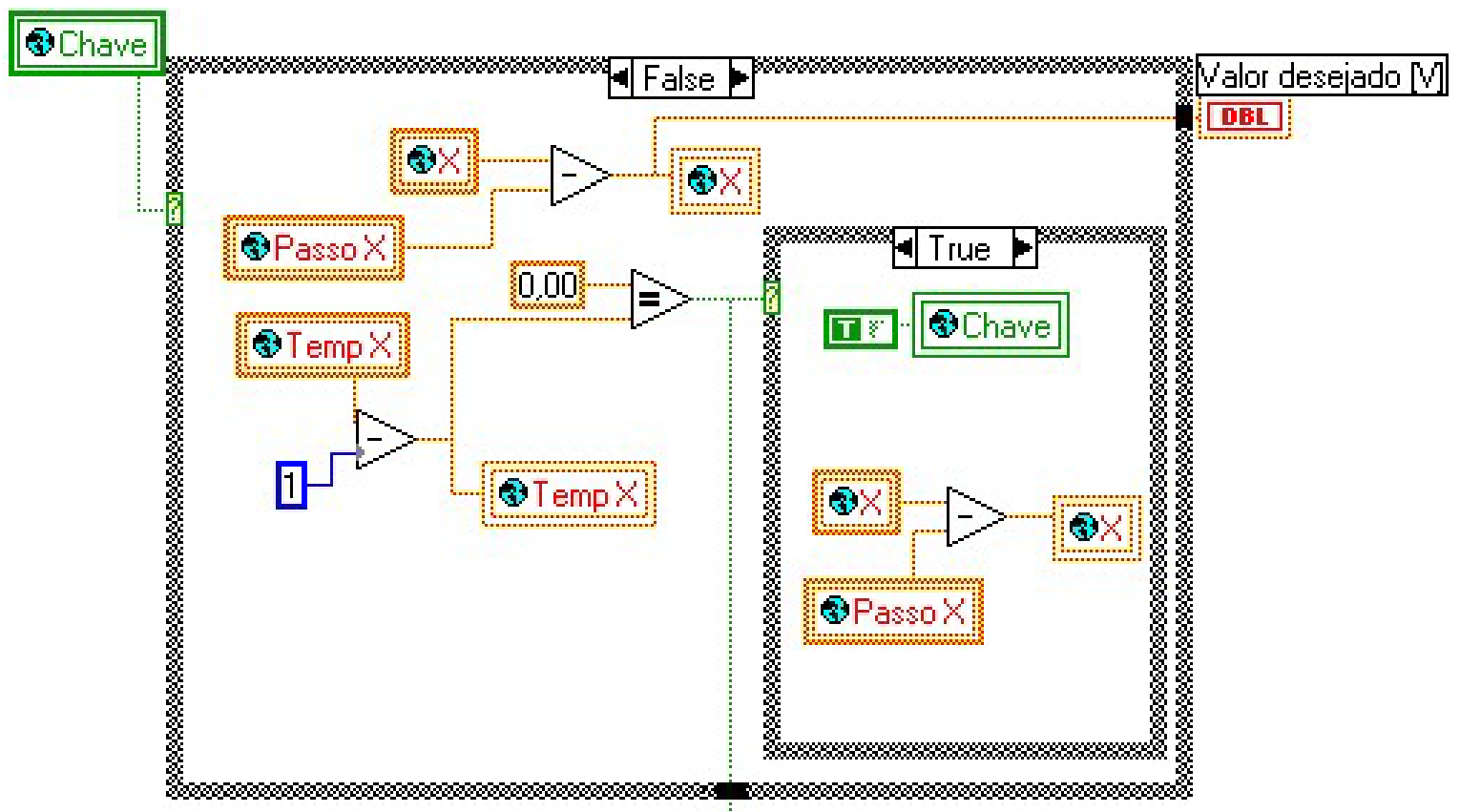

Figura 8 - Geração de valores decrescentes. 
O fluxograma da Figura 9 mostra a lógica seguida para a geração dos valores de posição para o eixo X em tempo de execução.

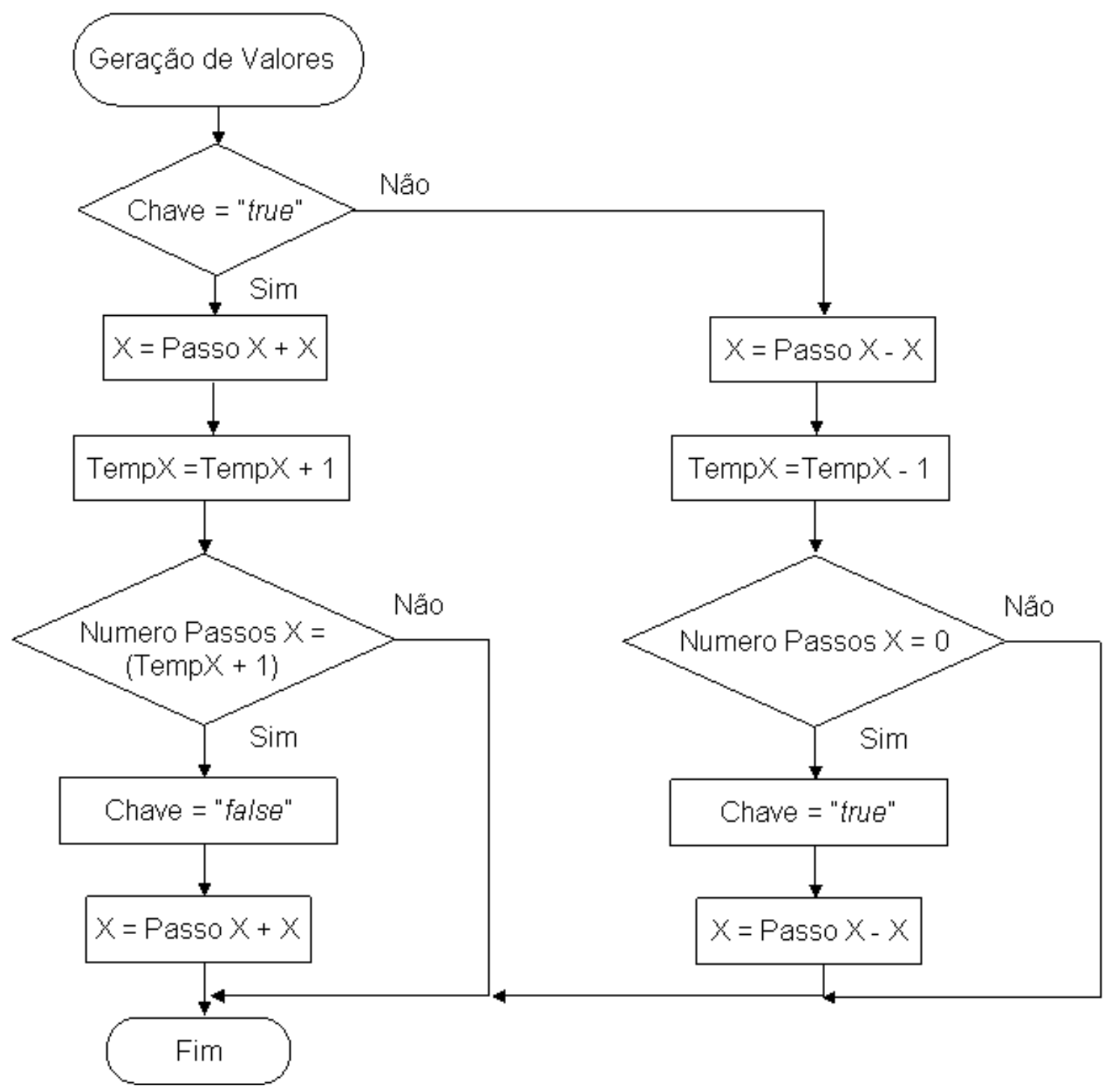

Figura 9 - Fluxograma da lógica para a geração dos valores de posição para o eixo X.

\subsection{Geração de valores para o eixo $Y$}

No cálculo dos valores de posição que devem ser lidos pelo eixo $Y$, também é utilizado o subVI Passo. O valor calculado por esse subVI é armazenado na variável PassoY e subtraído do valor da posição inicial, para que seja determinado o valor inicial da variável $Y$, que é responsável por indicar qual posição deve ser buscada. (Figura 10). 


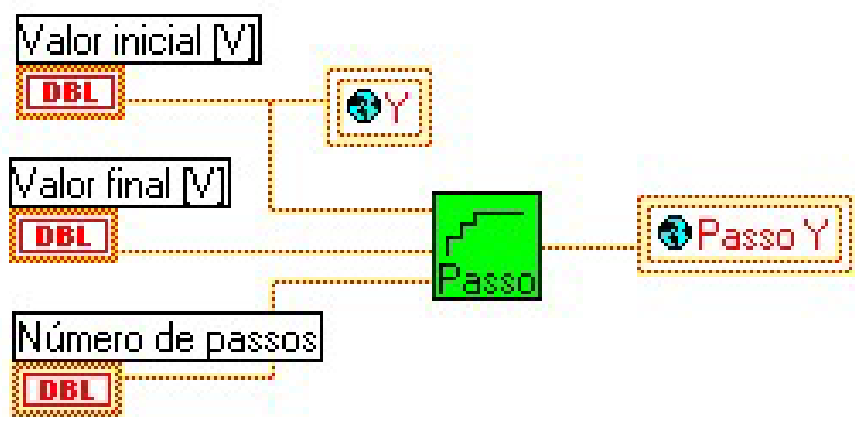

Figura 10 - SubVI Passo inserido no programa principal.

O fluxograma da Figura 11 mostra o cálculo do passo e a determinação do valor inicial do eixo $\mathrm{Y}$.

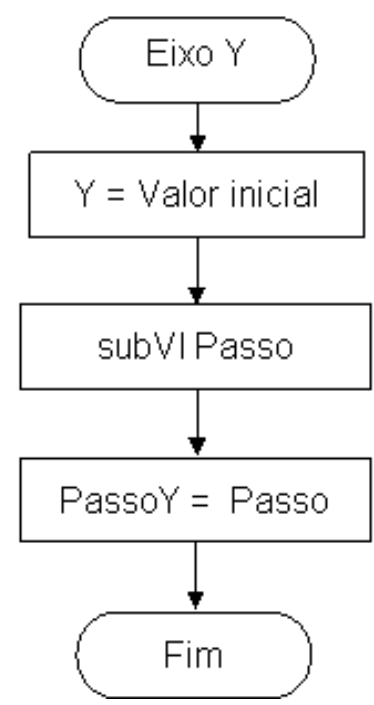

Figura 11 - Cálculo do passo e a determinação do valor inicial do eixo $Y$

A Figura 12 mostra a lógica seguida para controlar o número de vezes que o programa é executado e o cálculo dos valores de posição do eixo Y. 


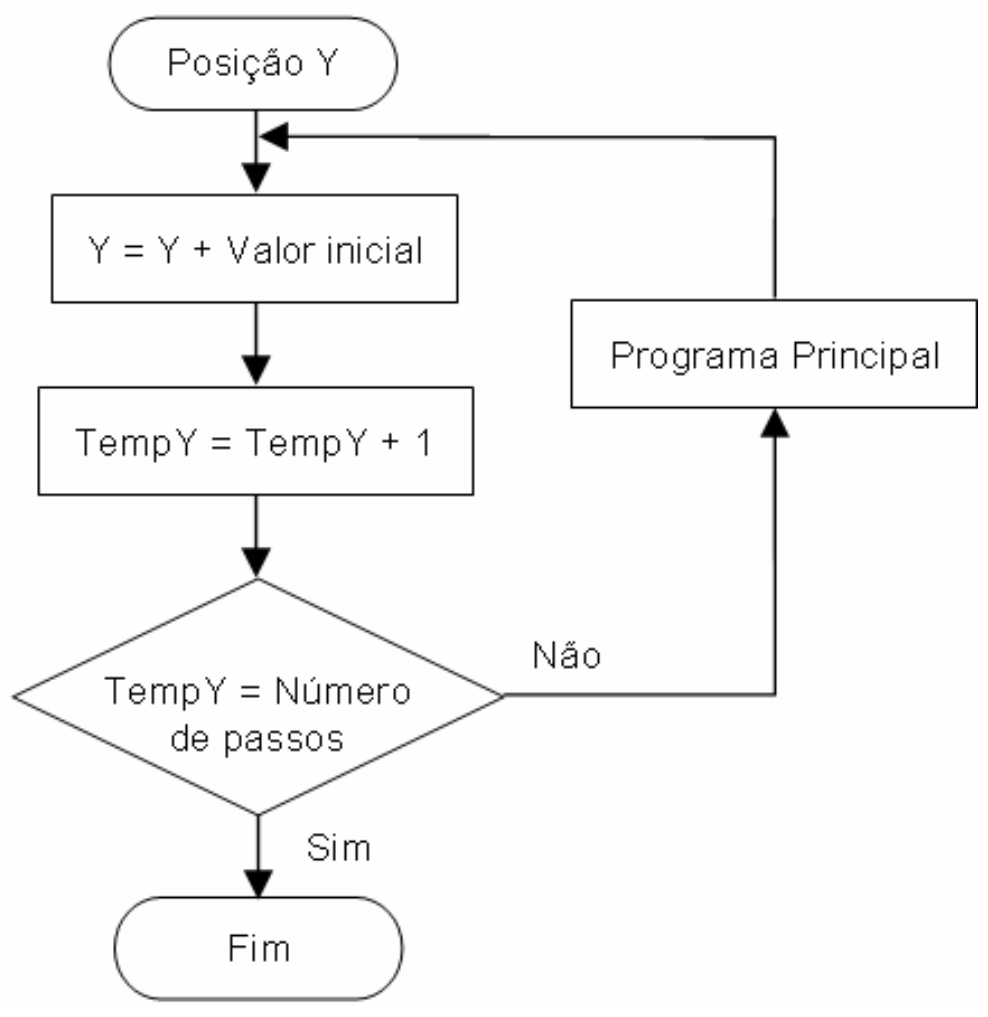

Figura 12 - Controle do número de vezes que o programa é executado e o cálculo dos valores de posição do eixo $\mathrm{Y}$.

\subsubsection{Cálculo dos valores de posição para o eixo $Y$}

Os valores de posição calculados para esse eixo são sempre crescentes. A função criada para garantir isso soma o valor inicial e o passo calculado e armazena o resultado na variável Y. Quando o botão "Iniciar varredura" é acionado, a variável TempY recebe a informação do número de vezes que a função deve ser executada. Esse valor é comparado, a cada ciclo realizado, com o número de passos para verificar se o programa foi executado o número de vezes desejado. (Figura 13)

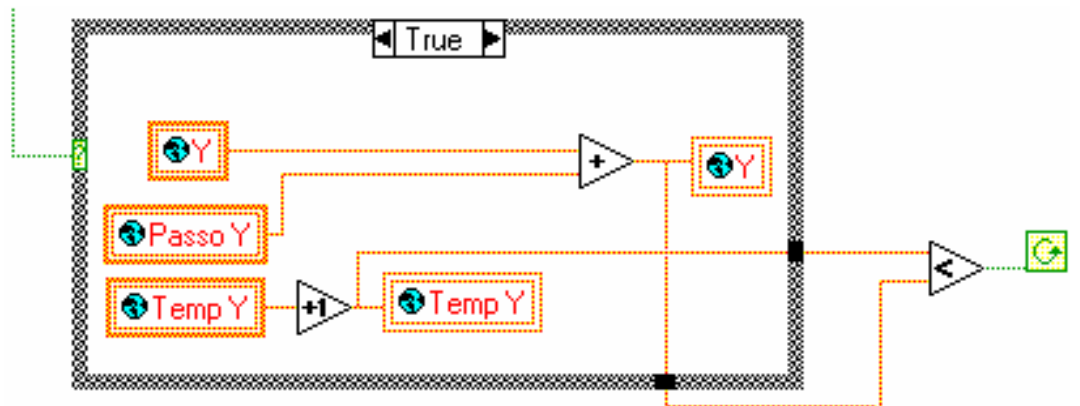

Figura 13 - Cálculo dos valores para o eixo Y. 


\subsection{Controlador}

\subsubsection{SubVI PID}

O controle escolhido para este projeto é o PID. Para que ele fosse implementado criou-se o subVI PID (Figura 14), uma vez que a versão 5 do LabVIEW® não possui um bloco pronto com esta função, que possui os seguintes parâmetros:

- Ganhos e limites do controlador PID para os eixos X e Y;

- Valor desejado Y: posição desejada para o eixo Y;

- Valor desejado X: posição desejada para o eixo X;

- Canais (0): número dos canais da placa de aquisição de dados configurados para adquirir dados dos eixos $\mathrm{X}$ e $\mathrm{Y}$;

- Canal Y: número do canal que está enviando dados para o eixo Y;

- Canal X: número do canal que está enviando dados para o eixo X;

- Erro X: valor calculado do erro para o eixo X;

- Erro Y: valor calculado do erro para o eixo $\mathrm{Y}$;

- Dispositivo: número de dispositivos de aquisição de dados utilizados.

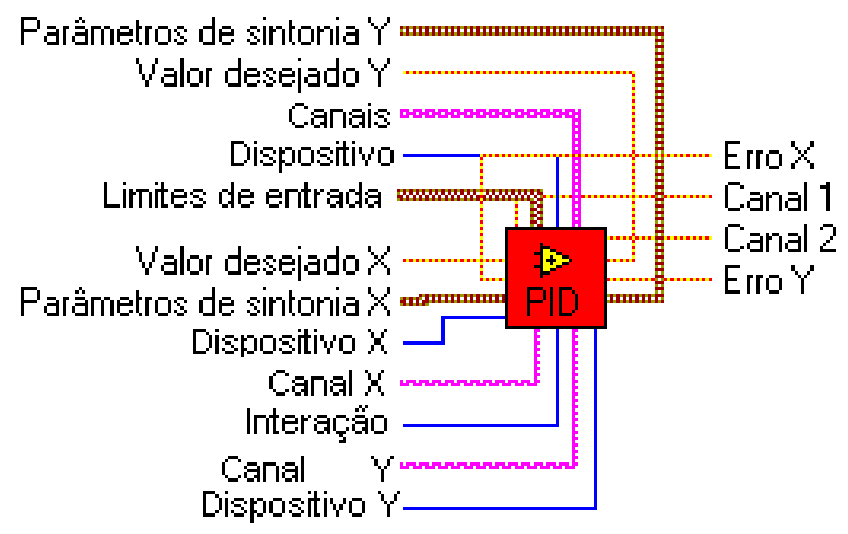

Figura 14 - SubVI PID. 


\subsubsection{Diagrama do controlador}

O diagrama da Figura 15 mostra a lógica do subVI PID, que foi construído com as funções e as variáveis mostradas na Figura 16. Elas fazem parte da biblioteca de funções para aquisição e envio de dados analógicos do LabVIEW ${ }^{\circledR}$.

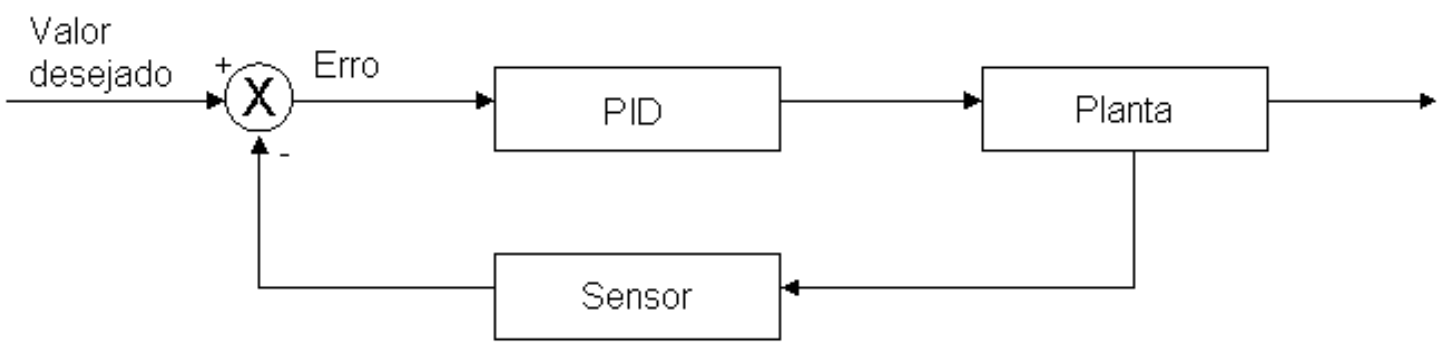

Figura 15 - Diagrama do controlador.

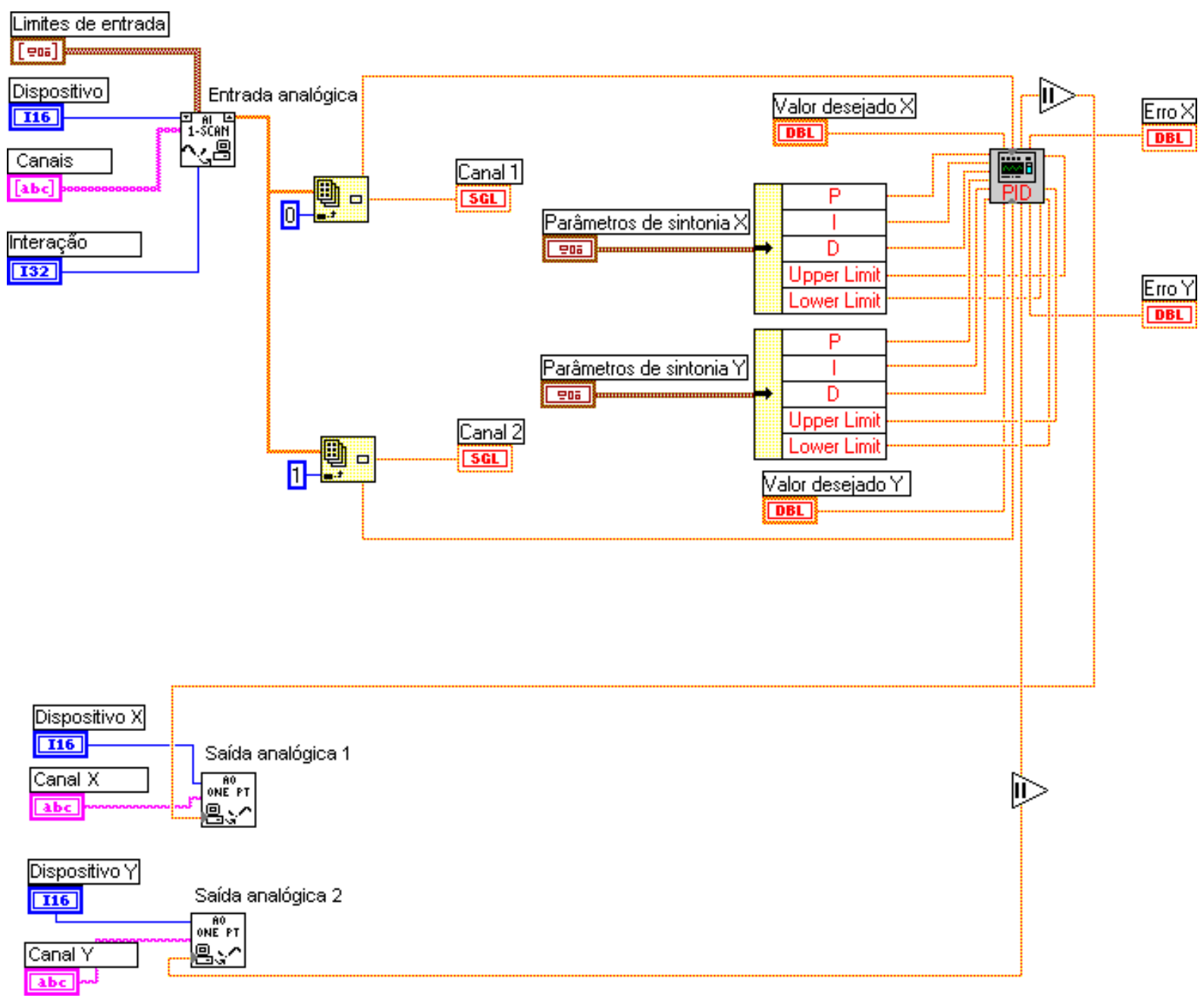

Figura 16 - Estrutura interna do subVI PID.

O bloco PID recebe o valor de erro de cada eixo e calcula o sinal de controle que deve ser enviado aos motores, de acordo com os ganhos determinados para o 
controlador. Para saber a direção em que o motor deve girar, foi criado o subVI Chave Digital (Figura 17).

\subsubsection{SubVI Chave Digital}

No subVI Chave Digital, o módulo do erro é comparado a 0,0045 [V], que foi determinado como um valor de desvio aceitável, pois equivale a menos de 20,0 $\mu \mathrm{m}$, o que o torna desprezível para o sistema construído devido à exatidão requerida para o arranjo da TELP, dada as dimensões da superfície de varredura do sensor.

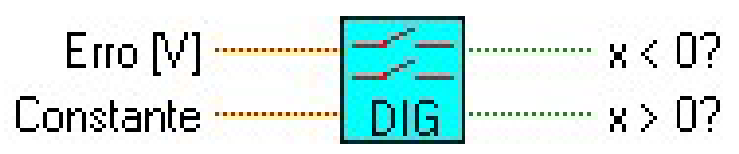

Figura 17 - SubVI Chave Digital.

O fluxograma do subVI Chave Digital é mostrado na Figura 18. Se o valor de posição estiver dentro da margem aceitável de erro, o motor é parado (Figura 19), se não, o sinal é comparado a zero. Se maior que zero, gira para um lado. Se menor, para o outro (Figura 20). Desta maneira, o erro de posição é corrigido.

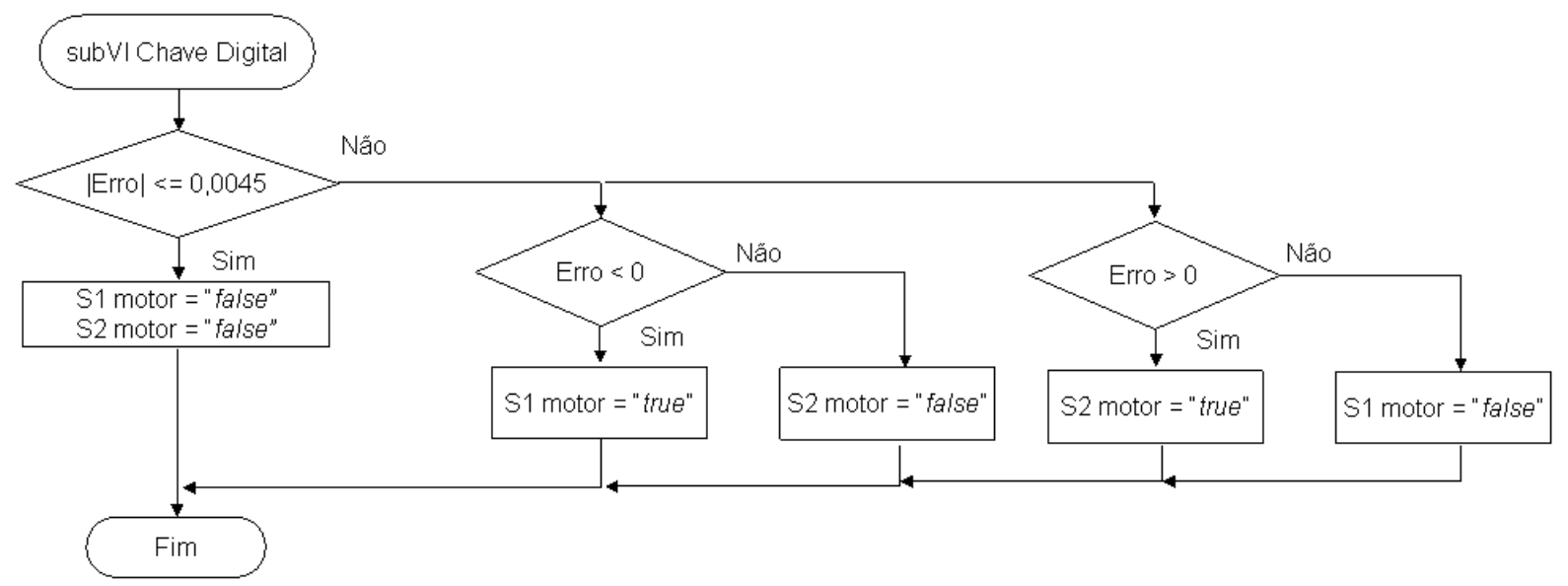

Figura 18 - Fluxograma do subVI Chave Digital. 


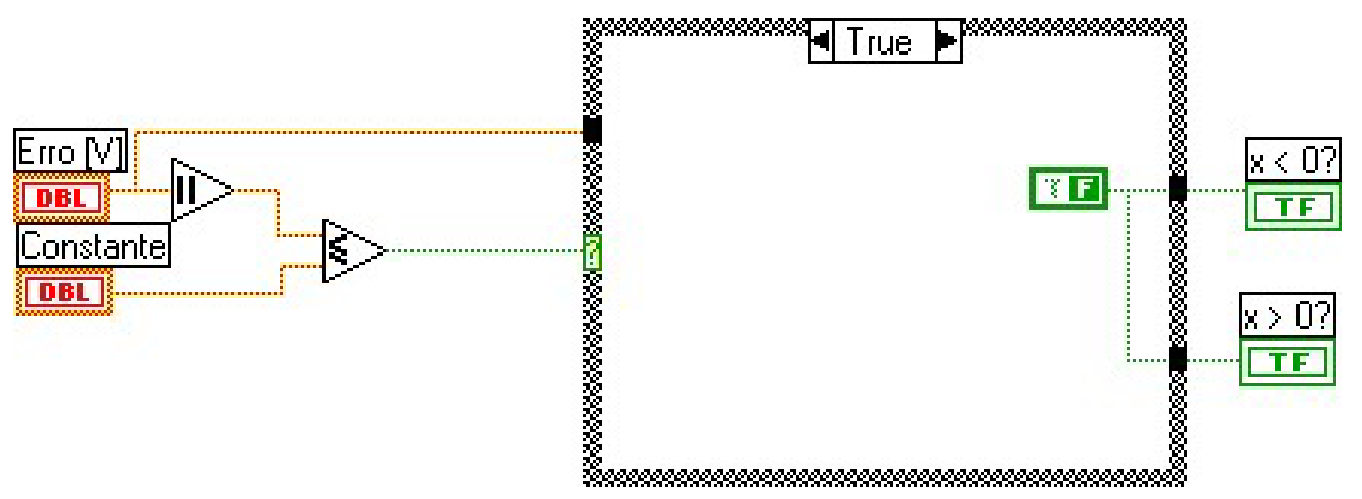

Figura 19 - Estrutura interna do VI Chave Digital - Condição igual a true.

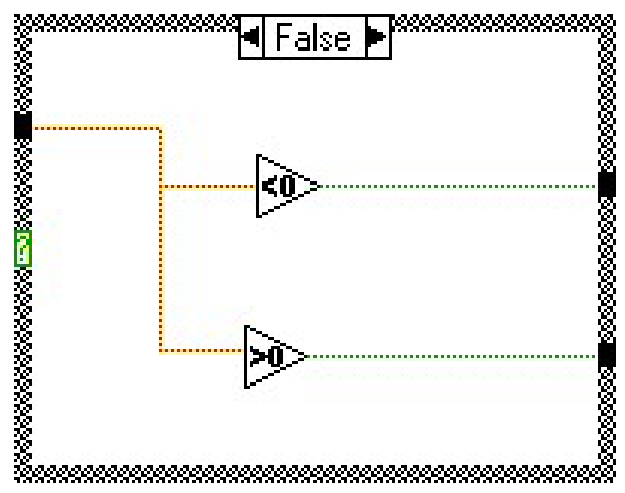

Figura 20 - Estrutura interna do VI Chave Digital - Condição igual a false.

\subsection{Aquisição e tratamento do sinal}

Os sinais de fotocorrente adquiridos devem ser tratados a fim de determinar os valores de integral dos semiciclos e dos picos positivo e negativo do sinal. A Figura 21 mostra a função criada para este objetivo. Para ela ser habilitada, o laser deve estar posicionado corretamente e o sistema ter recebido o sinal de sincronismo que vem do chopper. 


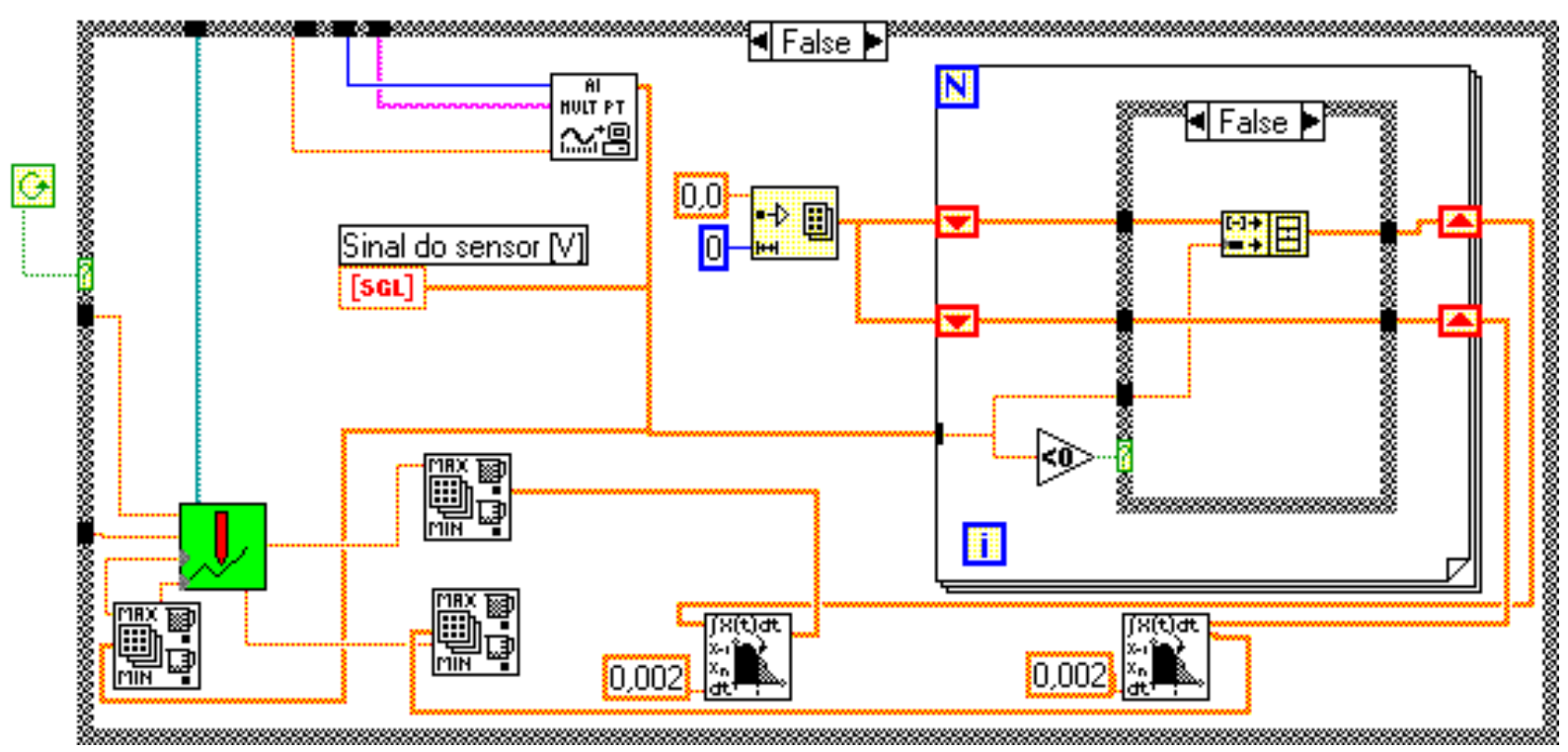

Figura 21 - Estrutura da função criada para o tratamento do sinal.

Por segurança, os dados são adquiridos a uma taxa 10 vezes maior que a freqüência do sinal que se deseja reconstituir, neste caso $250 \mathrm{~Hz}$. O bloco do Labview de aquisição de sinais analógicos foi configurado, então, para adquirir os dados do sensor a uma freqüência de $2,5 \mathrm{kHz}$.

Para se obter os valores da integral de u positiva e da integral de u negativa, colocou-se um filtro para separar os valores maiores dos menores que zero. $\mathrm{O}$ período da integração de um semiciclo da onda foi calculado da seguinte forma (eq. 1 e eq. 2$)$ :

$$
T=\frac{1}{f}=\frac{1}{250}=0,004 s
$$

que é o período da onda completa. Para se obter o período do semiciclo:

$$
\frac{T}{2}=0,002 s
$$

A Figura 22 mostra o fluxograma do cálculo da integral dos valores positivos e da integral dos valores negativos. Para determinar os valores de pico positivo e de pico negativo foi utilizada uma função do LabVIEW $^{\circledR}$, que compara todos os dados de uma amostra e retorna o maior e o menor valor. Esses dados são gravados em um arquivo pelo subVI Dados Leitura para que sejam analisados e as imagens geradas. 


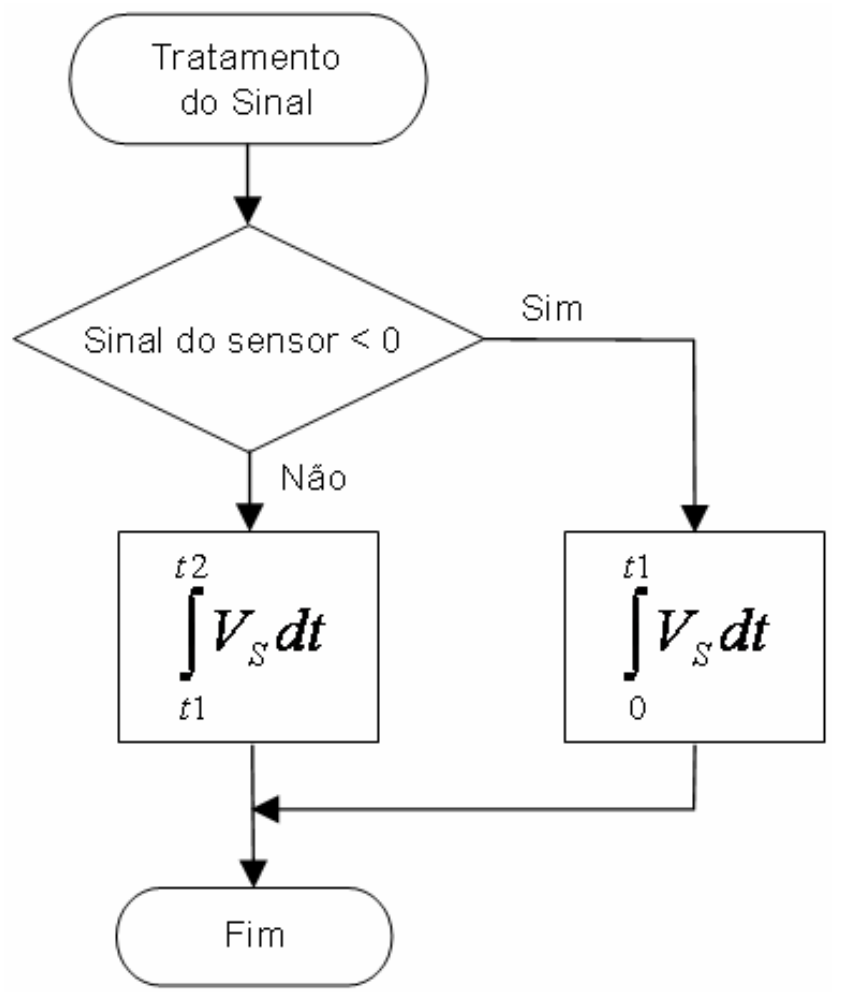

Figura 22 - Cálculo da integral de $u$.

\subsubsection{SubVI Dados Leitura}

Os dados tratados e a posição em que foram obtidos são armazenados pelo VI Dados Leitura (Figura 23 e Figura 24).

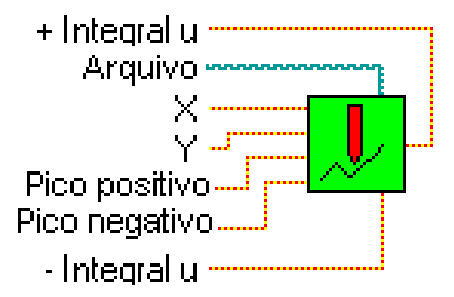

Figura 23 - SubVI Dados Leitura

Esse subVI organiza a seqüência e o formato em que os dados serão gravados. 


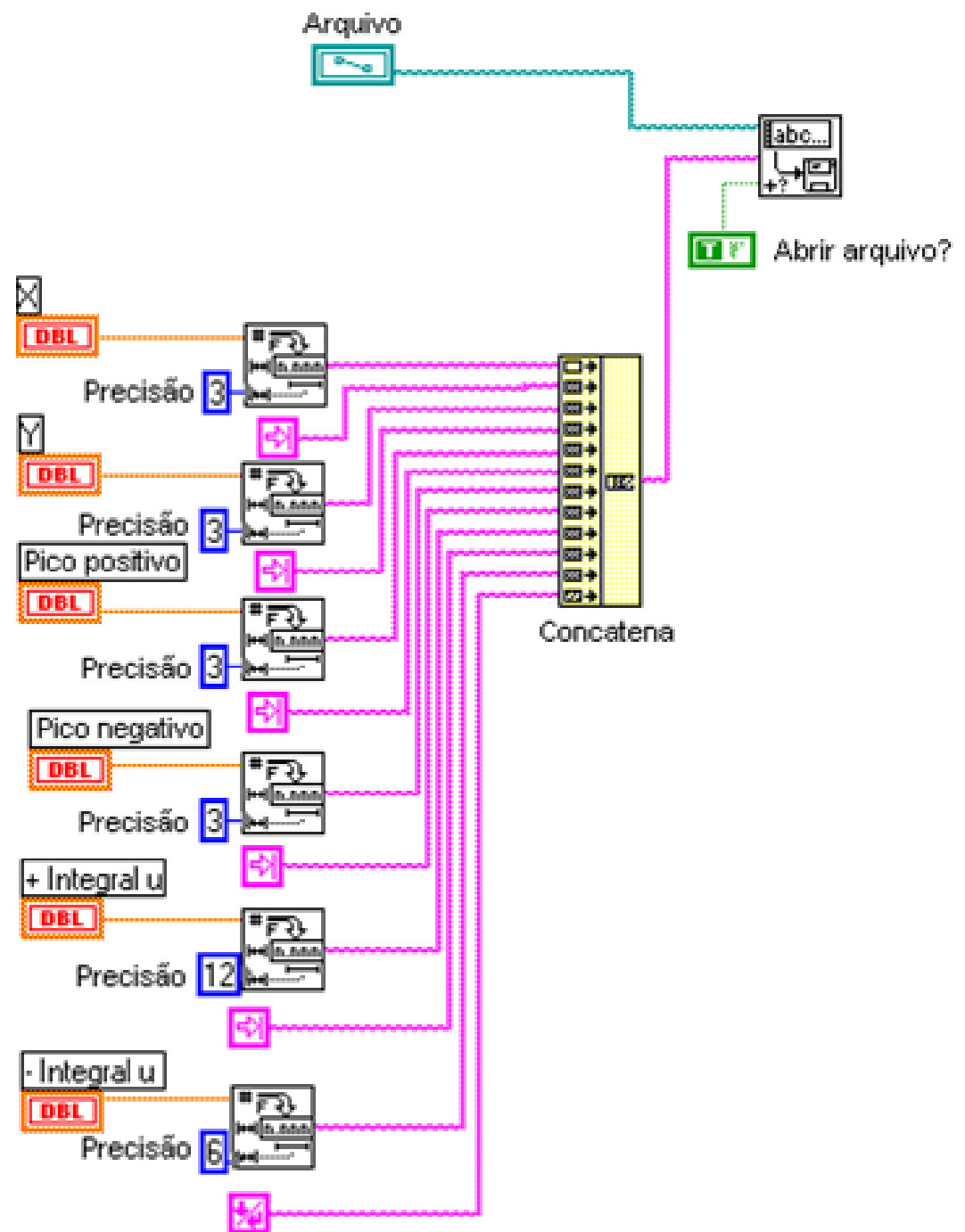

Figura 24 - Código do subVI Dados Leitura. 


\section{Testes do controlador construído com instrumentação virtual}

Realizaram-se testes para verificar o desempenho do controlador construído com uso da instrumentação virtual. Foram aplicadas diversas combinações aleatórias de ganhos possíveis para o ajuste do controlador para que o seu desempenho fosse analisado. Abaixo são mostrados alguns resultados e conclusões obtidos. Os valores escolhidos para $K_{P}, K_{i}$ e $K_{D}$ foram inicialmente aplicados a cada eixo independentemente para que fosse verificada a resposta do controlador desenvolvido.

\subsection{Controlador $\mathbf{P}$}

Os primeiros testes realizados utilizavam controle $\mathrm{P}$ e os resultados apresentados nas figuras a seguir mostram que erro de regime do sistema com $K_{P}=0,2$ foi maior que com $K_{P}=1,0$, pois o ganho não foi suficiente para alcançar o valor desejado, o que é uma característica deste tipo de controlador. Além disso, nota-se que houve uma demora para iniciar a atuação do controle em ambos os casos, devida à inércia do sistema. 


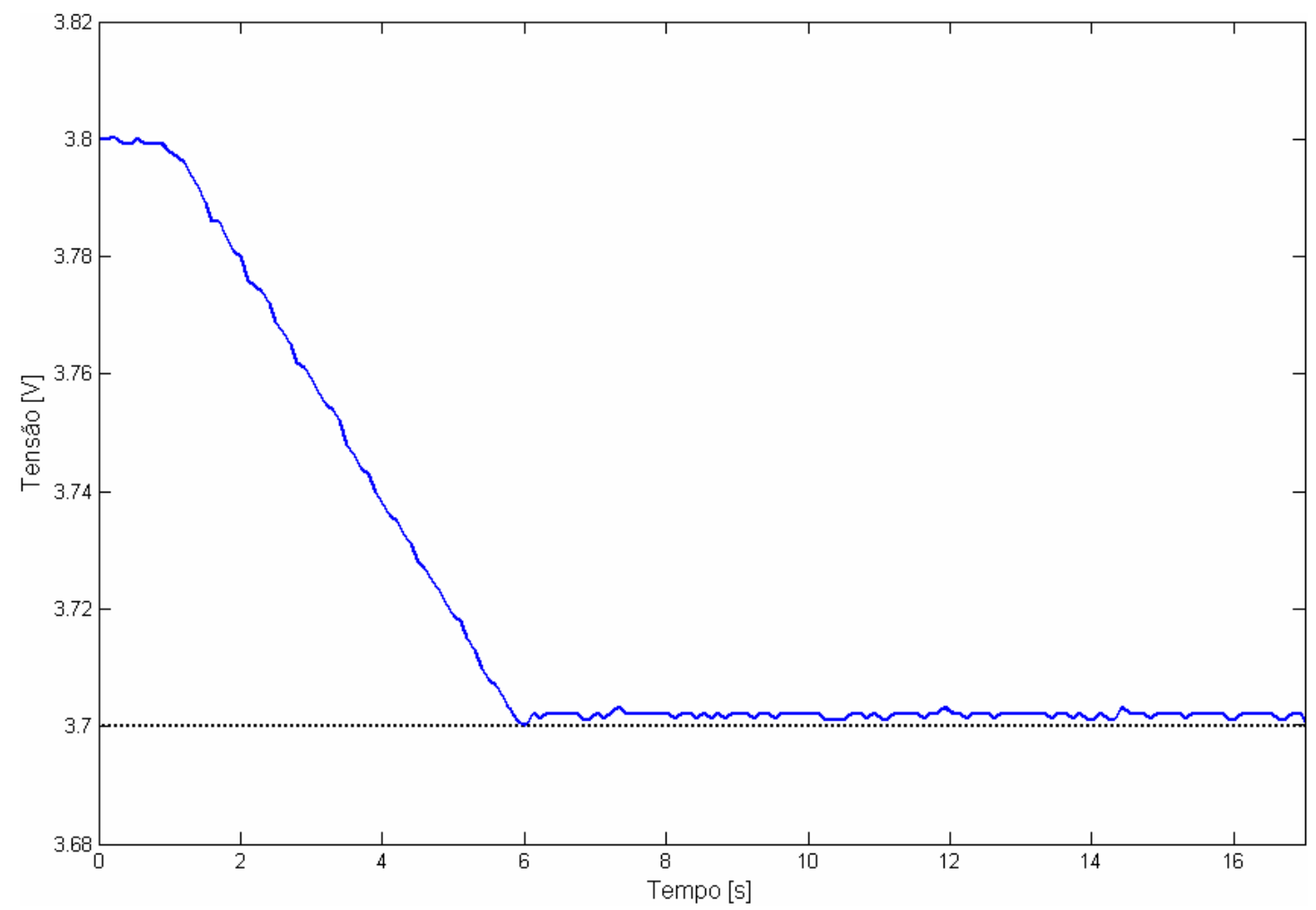

Figura 25 - Resultado $X: K_{P}=0,2$.

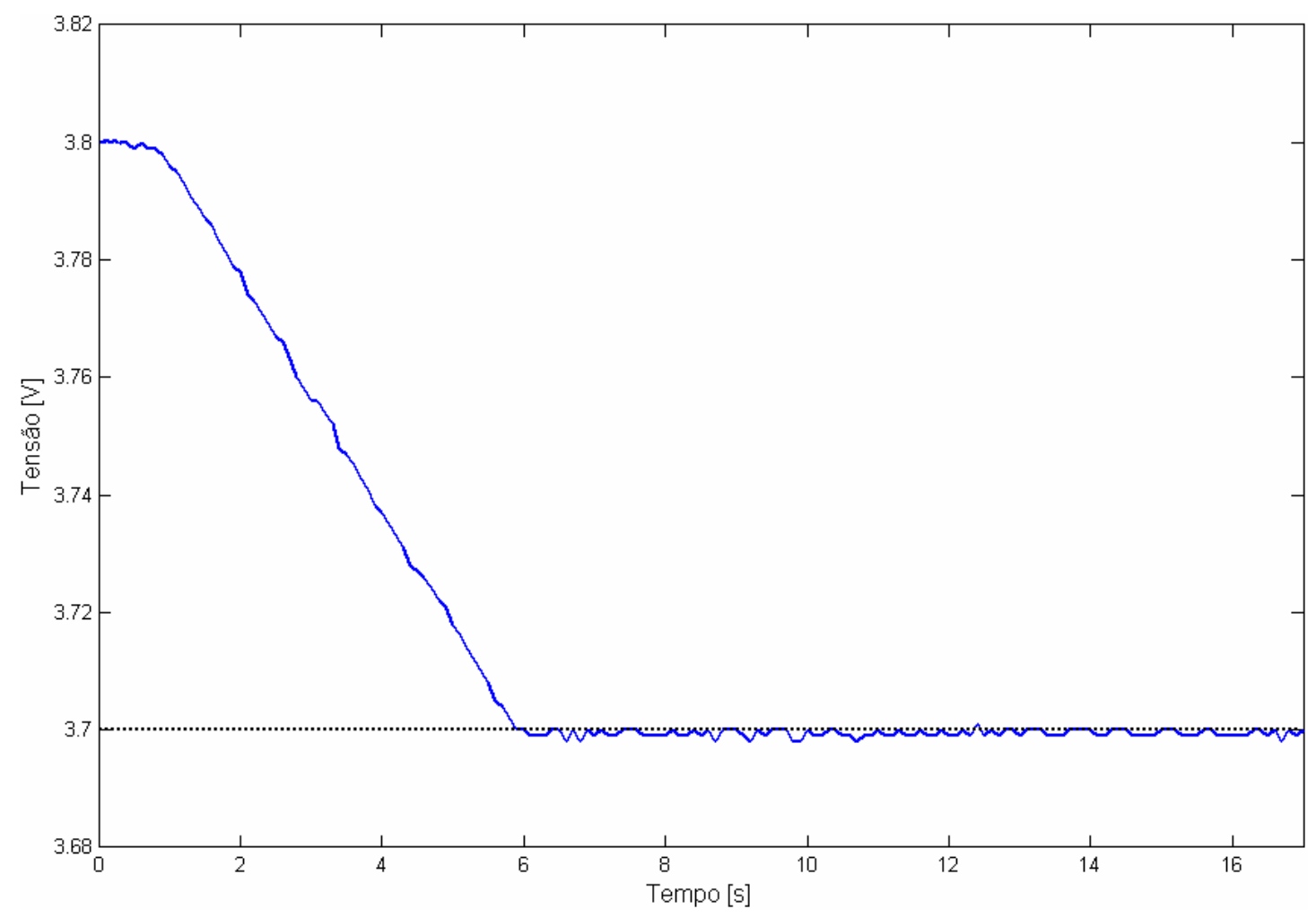

Figura 26 - Resultado $X: K_{P}=1,0$. 


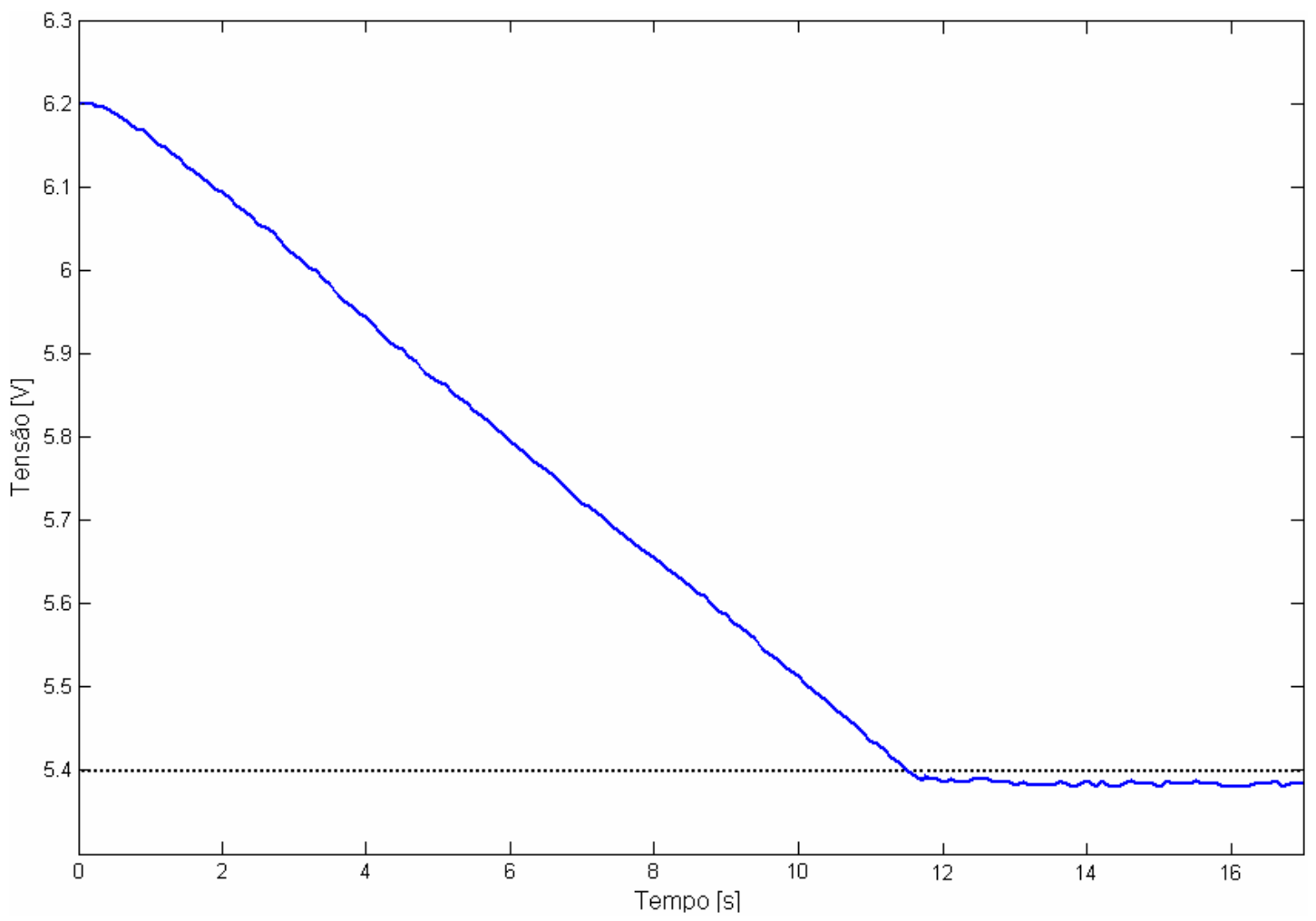

Figura 27 - Resultado $Y: K_{P}=0,2$.

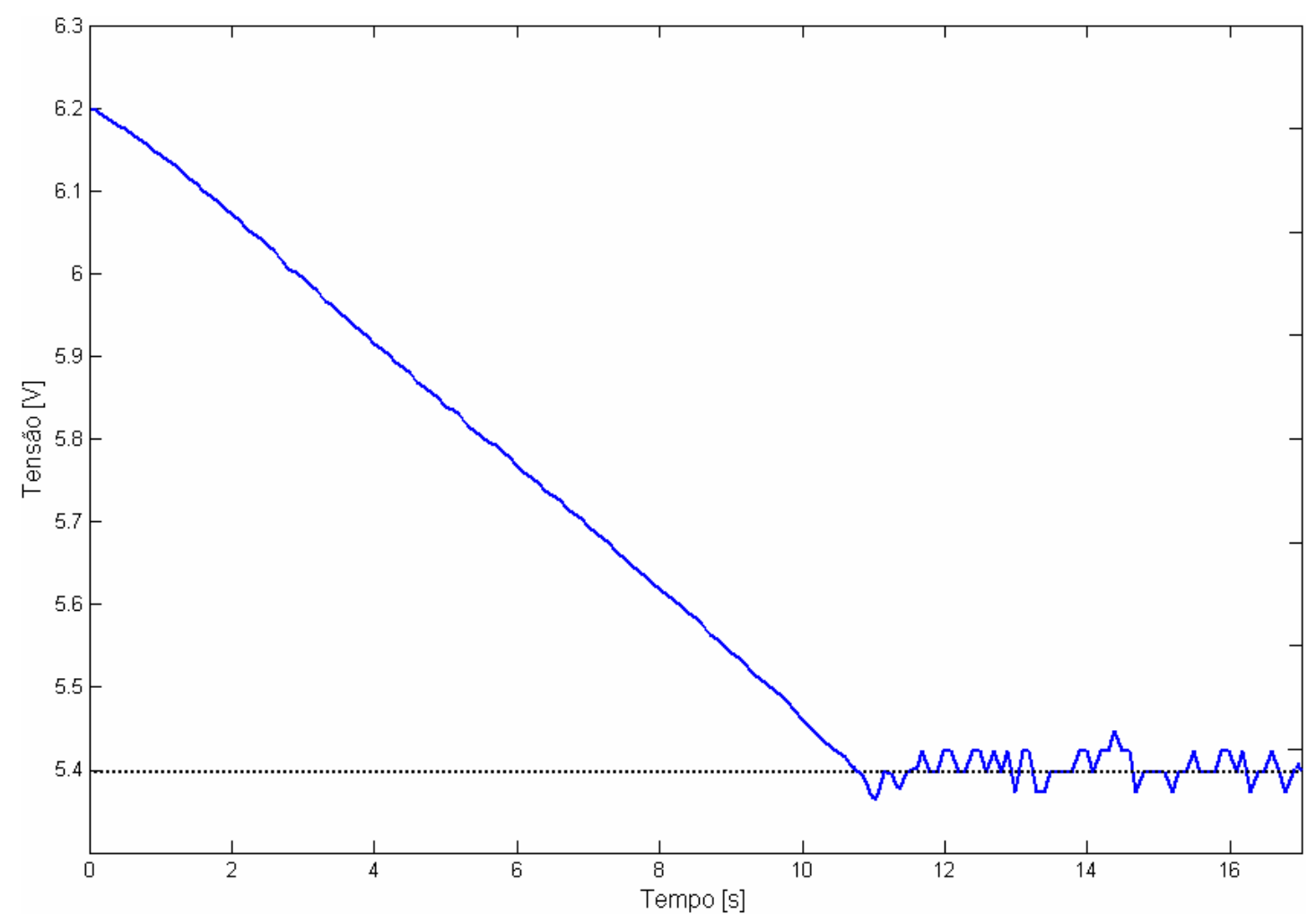

Figura 28 - Resultado $Y: K_{P}=1,0$.

Para o eixo $\mathrm{Y}$, pode-se observar que com $\mathrm{K}_{\mathrm{P}}=1$ houve uma resposta mais rápida ao sistema, em relação a $K_{P}=0,2$, porém ocasionou uma instabilidade maior. Em 
contrapartida, com um $\mathrm{K}_{\mathrm{P}}$ menor, surgiu, de maneira semelhante ao eixo $\mathrm{X}$, um erro de regime permanente relativamente grande.

\subsection{Controlador PI}

Foram realizados testes com controle $\mathrm{PI}$. Os resultados apresentados nas figuras a seguir mostram que o controlador PI melhorou a característica de regime para o eixo $X$. Pode-se observar que para estes valores, apesar de muito diferentes entre si, o tempo de resposta permaneceu praticamente o mesmo. 


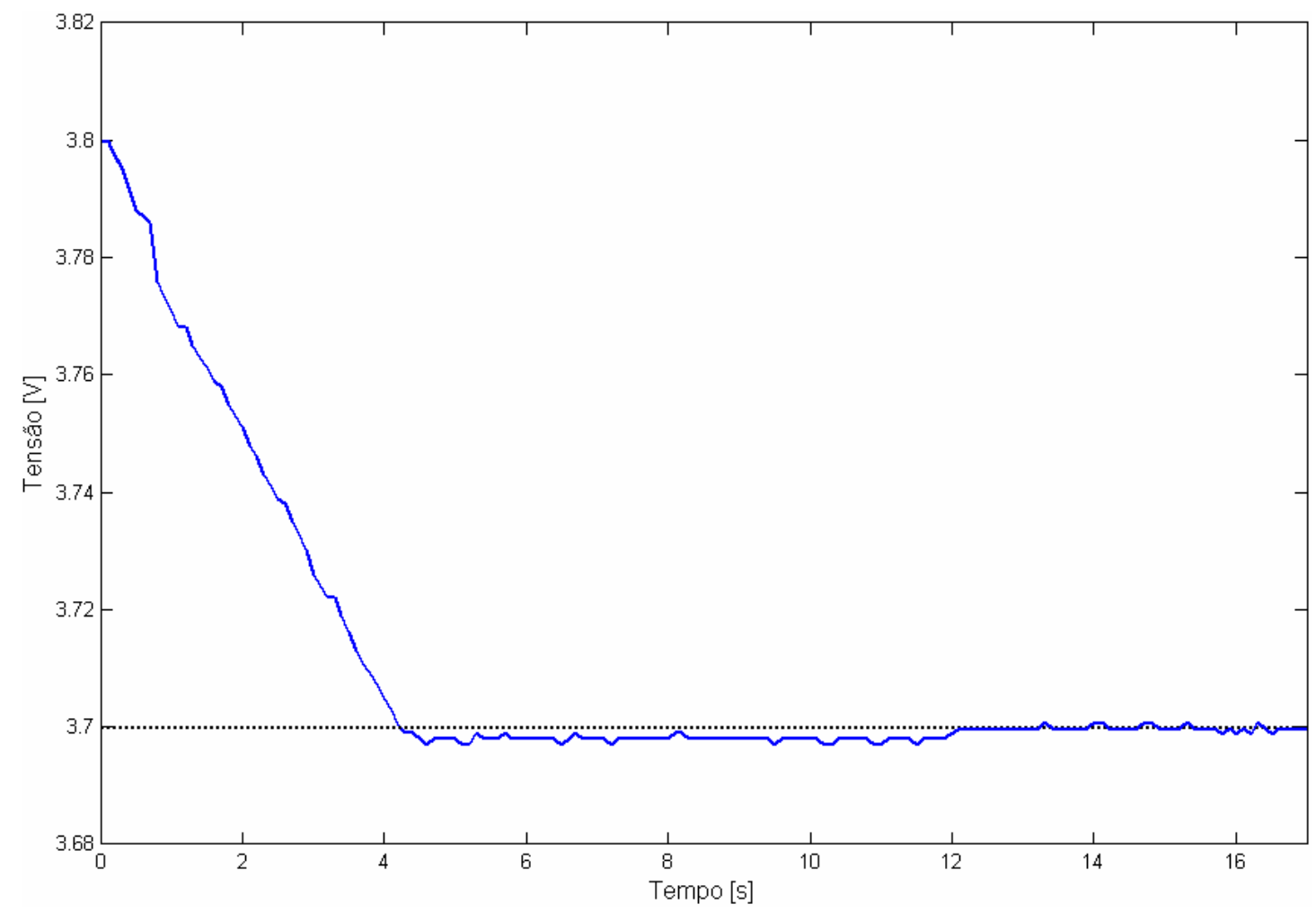

Figura 29 - Resultado $X: K_{P}=0,2$ e $K_{i}=1,0$.

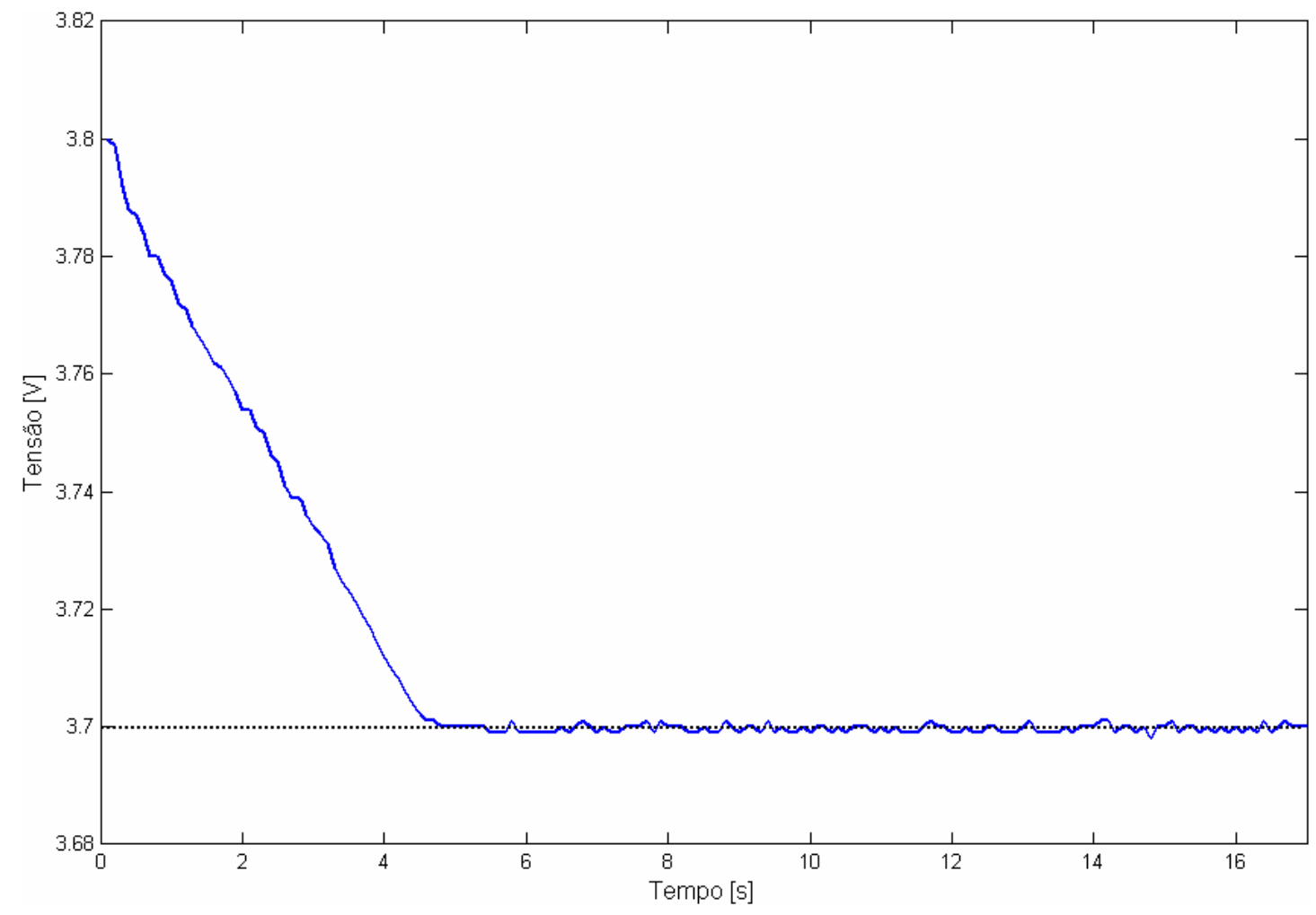

Figura 30 - Resultado $X: K_{P}=0,2$ e $K_{i}=10$. 


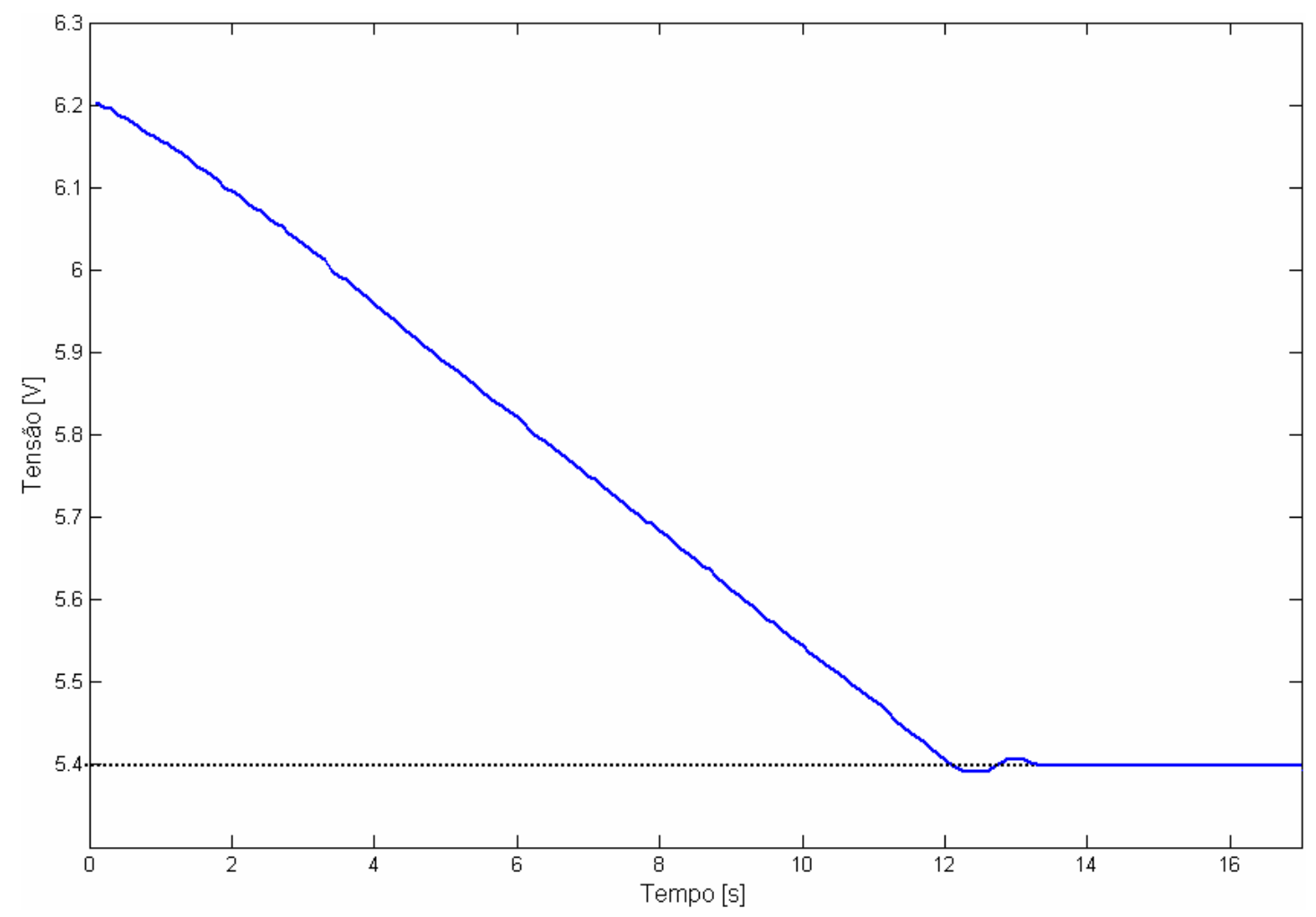

Figura 31 - Resultado $Y: K_{P}=0,2$ e $K_{i}=1,0$.



Figura 32 - Resultado $\mathrm{Y:} \mathrm{KP}=\mathbf{0 , 2}$ e $\mathrm{Ki}=\mathbf{5 , 0}$.

Para o eixo $\mathrm{Y}$, quando aplicado $\mathrm{K}_{\mathrm{P}}=0,2$ e $\mathrm{K}_{\mathrm{i}}=1,0$, o sistema apresentou um sobresinal e estabilizou no valor desejado. No teste da Figura 32 verifica-se que o sistema 
oscilou em torno de valor desejado e que o sistema tornou-se instável, isso se deve ao aumento do valor de $\mathrm{K}_{\mathrm{i}}$.

\subsection{Controlador PID}

Nos testes utilizando controle PID, foram obtidos os resultados mostrados nas figuras a seguir. No primeiro teste realizado para o eixo $X$ (Figura 33) verificou-se que o sistema se estabilizou no valor desejado e que não apresentou sobre-sinal, observou-se portanto, uma melhora no desempenho transitório e no regime estacionário pela aplicação destes valores nas três ações de controle. No segundo caso (Figura 34), aumentou-se o valor de $\mathrm{K}_{\mathrm{i}}$, o que ocasionou uma pequena instabilidade no sistema e tornou a resposta mais lenta que no primeiro caso. 


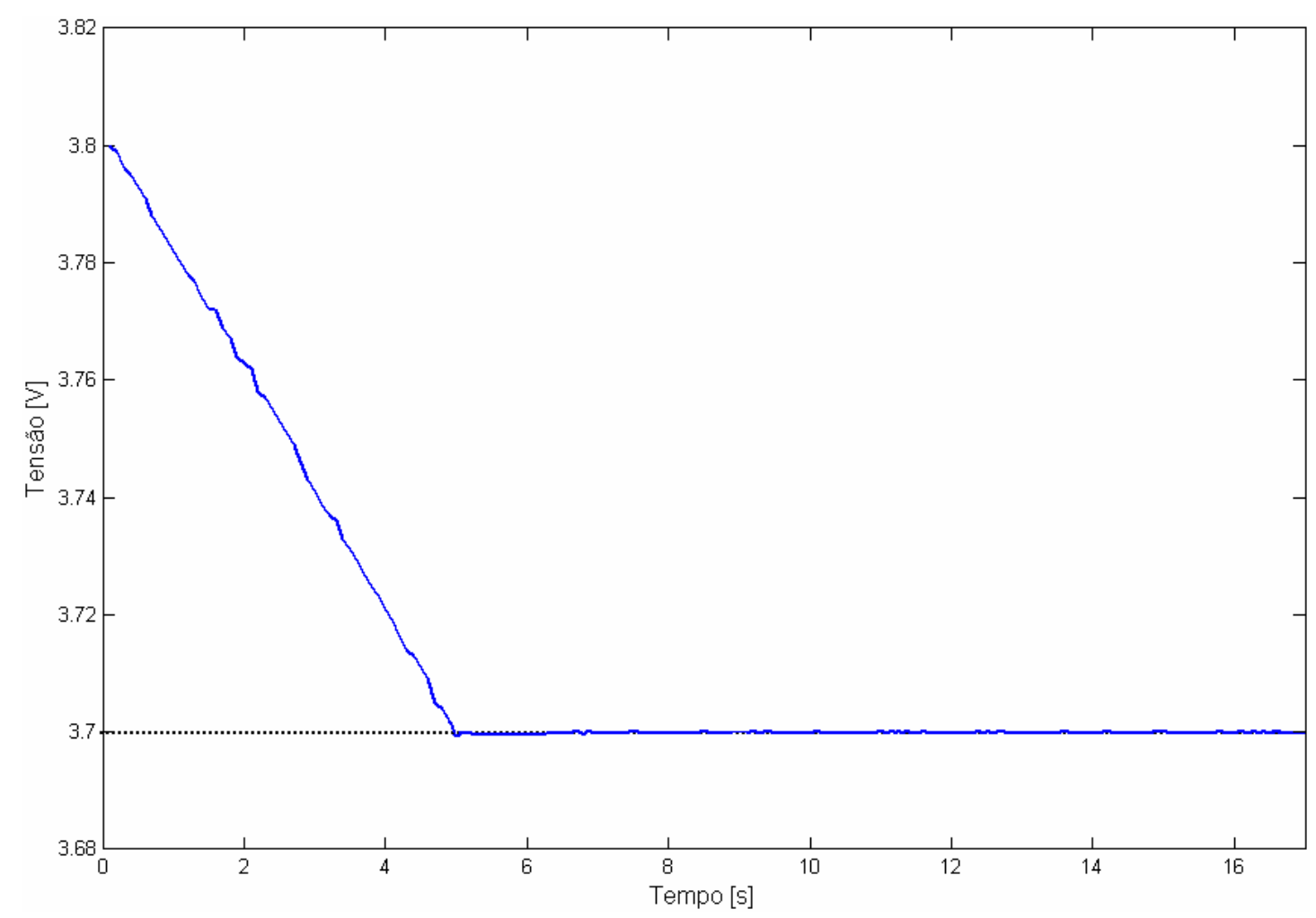

Figura 33 - Resultado $X: K_{P}=0,2$ e $K_{i}=10 K_{D}=1,0$.

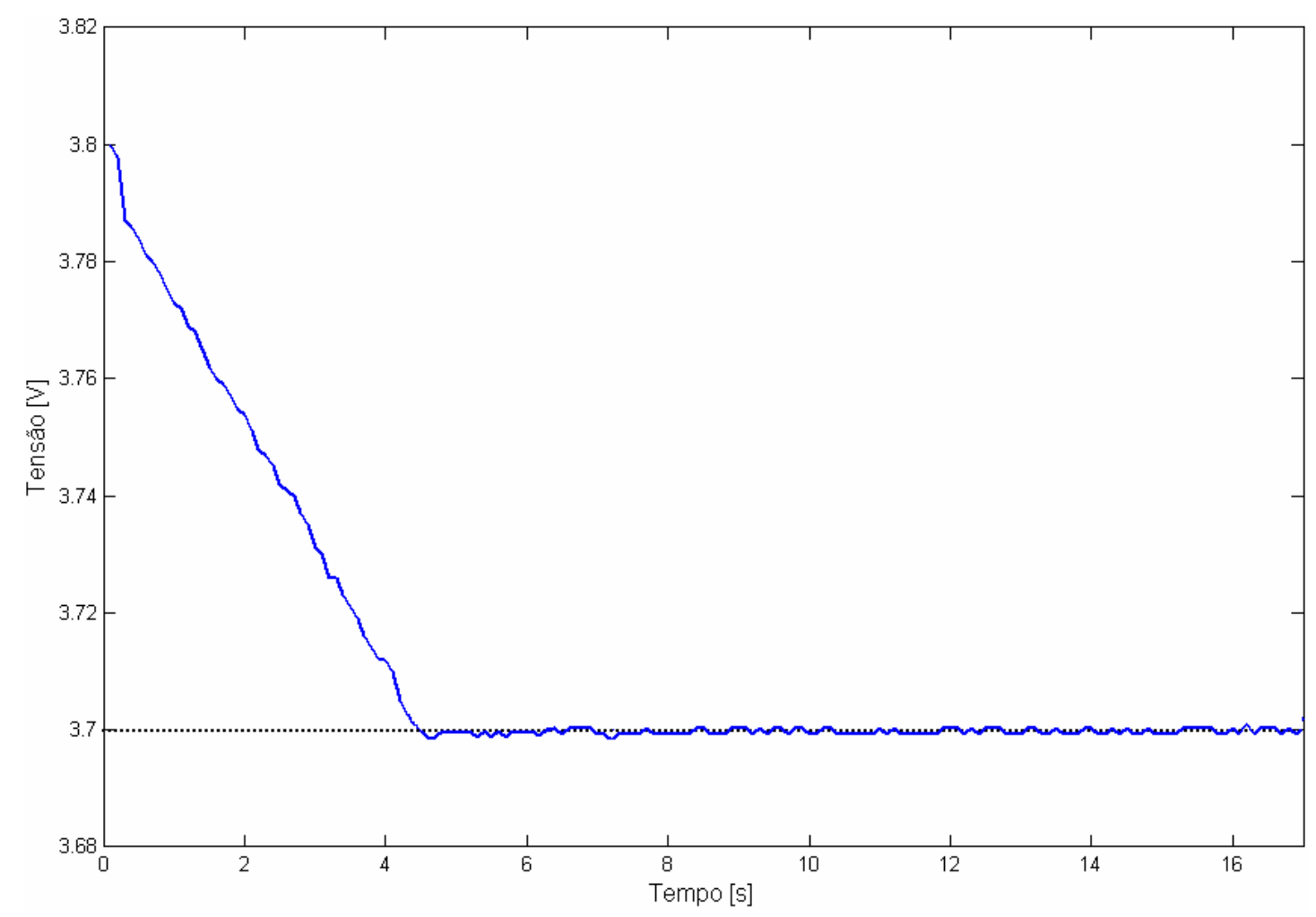

Figura 34 - Resultado $X: K_{P}=1,0$ e $K_{i}=10 K_{D}=5,0$. 


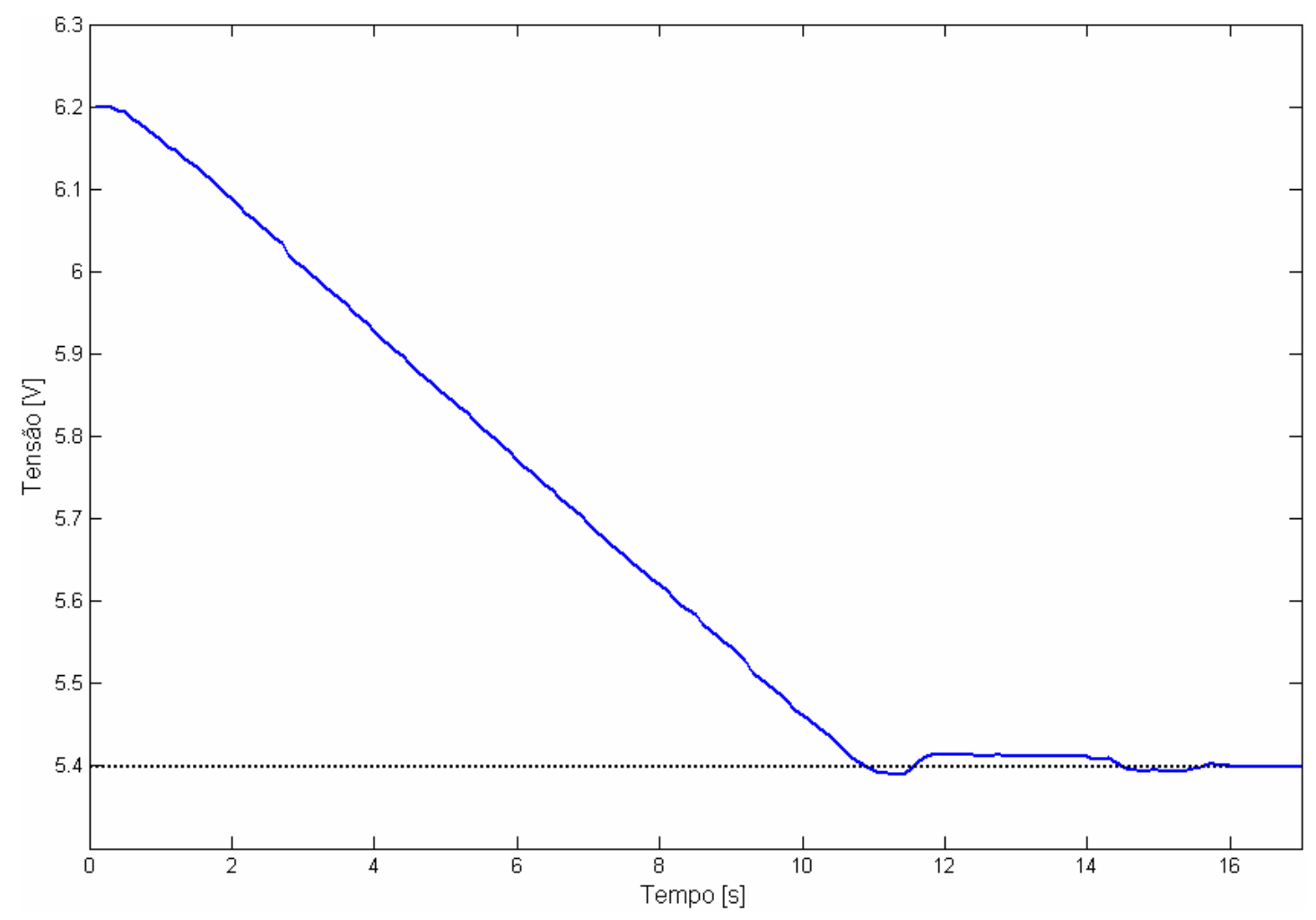

Figura 35 - Resultado $Y: K_{P}=0,2$ e $K_{i}=1,0 K_{D}=1,0$.

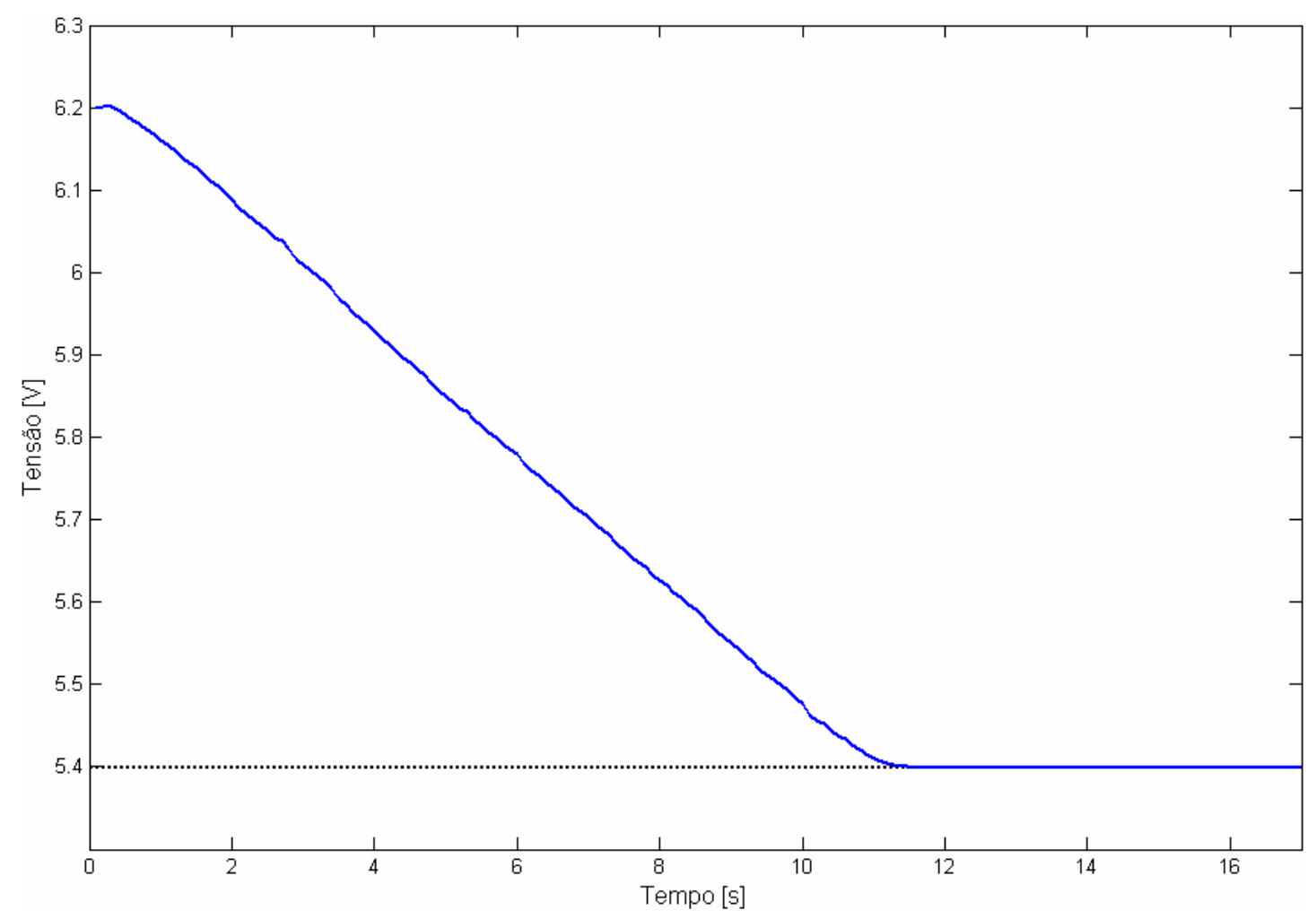

Figura 36 - Resultado $Y: K_{P}=0,2$ e $K_{i}=2,0 K_{D}=3,0$. 
No primeiro teste realizado para o eixo $\mathrm{Y}$, verificou-se que o sistema demorou para se estabilizar no valor desejado e houve um pequeno sobre-sinal. No segundo caso, diminuiu-se os valores de $\mathrm{K}_{\mathrm{P}}$ e de $\mathrm{K}_{\mathrm{i}}$, o que tornou a resposta do sistema lenta, mas alcançou o valor desejado.

\subsection{Discussões sobre os resultados do controlador}

Pelos testes realizados, concluiu-se que o controlador desenvolvido apresenta as seguintes características de um controlador PID convencional:

- estabilidade;

- resposta transiente, incluindo tempo morto e sobre-sinal dentro de limites aceitáveis;

- regime permanente preciso;

- atenuação de distúrbios e robustez em situações inesperadas. 


\section{Aplicação do controlador ao posicionador $X Y$}

Foram realizados diversos testes para a escolha da estratégia de controle (P, PI ou PID) e dos melhores valores para os ganhos do controlador. Inicialmente, tentou-se a sintonia, pelo método Z-N, que não pôde ser empregada devido ao sistema não apresentar uma oscilação sustentada para qualquer valor de $K_{P}$ (OGATA, 2005). Optou-se, então, por empregar o método heurístico para sintonizar o controlador do posicionador $\mathrm{X} Y$. Os melhores resultados obtidos para o controle simultâneo dos dois eixos para cada método são mostrados a seguir.

\subsection{Controle Proporcional}

No ensaio utilizando controle $P$, em que o melhor resultado foi obtido, o programa foi configurado para controlar o processo com os seguintes parâmetros:

$$
\mathrm{K}_{\mathrm{P}}=0,2 \quad \mathrm{~T}_{\mathrm{i}}=\infty \quad \mathrm{T}_{\mathrm{D}}=0
$$


Na Figura 37 é comparada a resposta do eixo $X$ ao valor desejado no intervalo de tempo referente à primeira varredura para valores crescentes. Nota-se que no primeiro momento o sistema apresentou um tempo morto relativamente alto devido à inércia do sistema, mas depois a resposta do eixo tornou-se satisfatória.

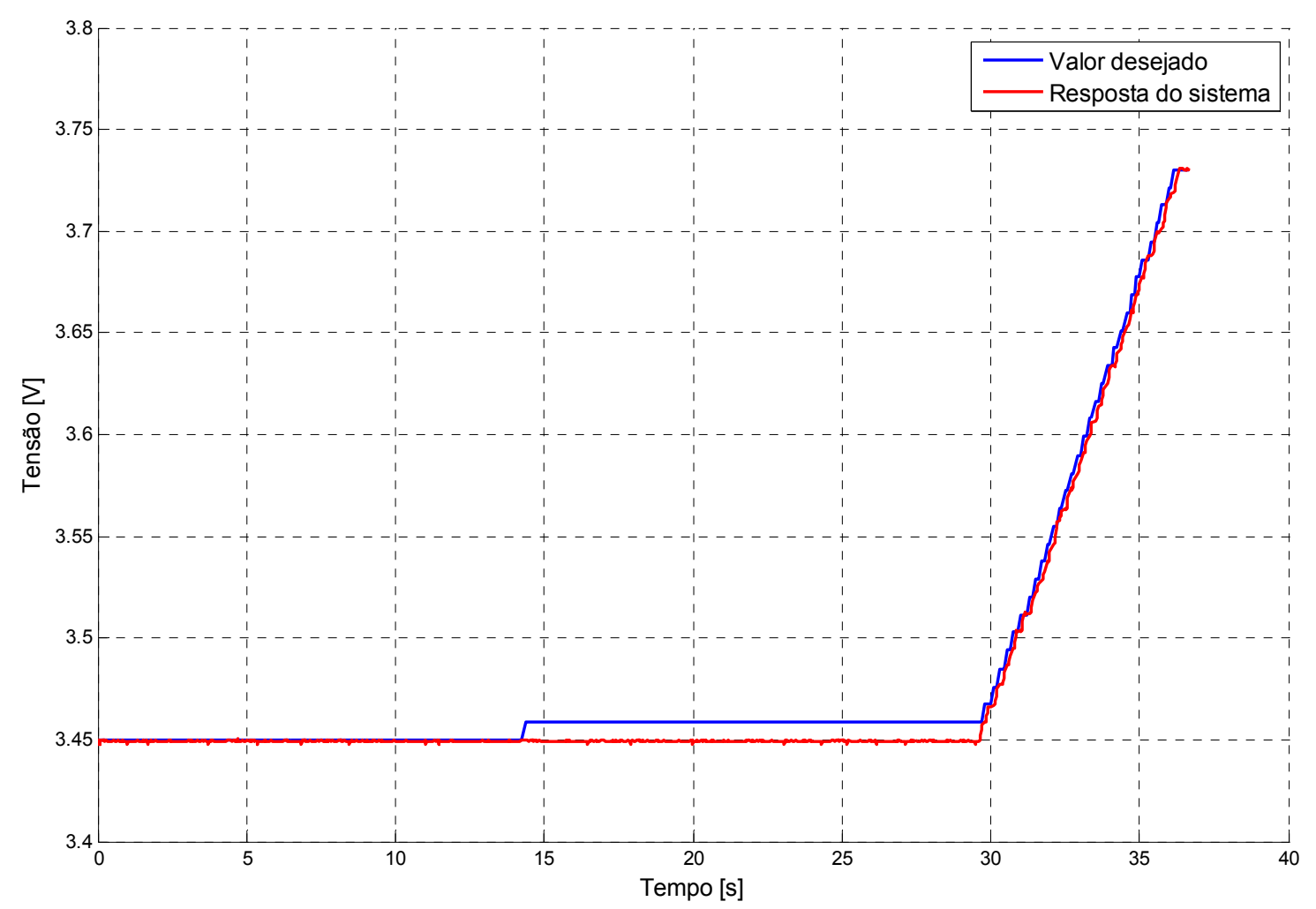

Figura 37 - Resposta do eixo X em um intervalo de tempo para valores crescentes de posição

A Figura 38 mostra o resultado alcançado para valores decrescentes no eixo X. Pela Figura 40 pode-se verificar que o tempo de resposta do eixo $Y$ para alcançar o seu valor desejado provocou a demora na mudança do valor desejado para o eixo X. Isto se deve ao fato de que, para que um novo valor de posição possa ser gerado, os dois eixos devem alcançar a posição pré-determinada. 


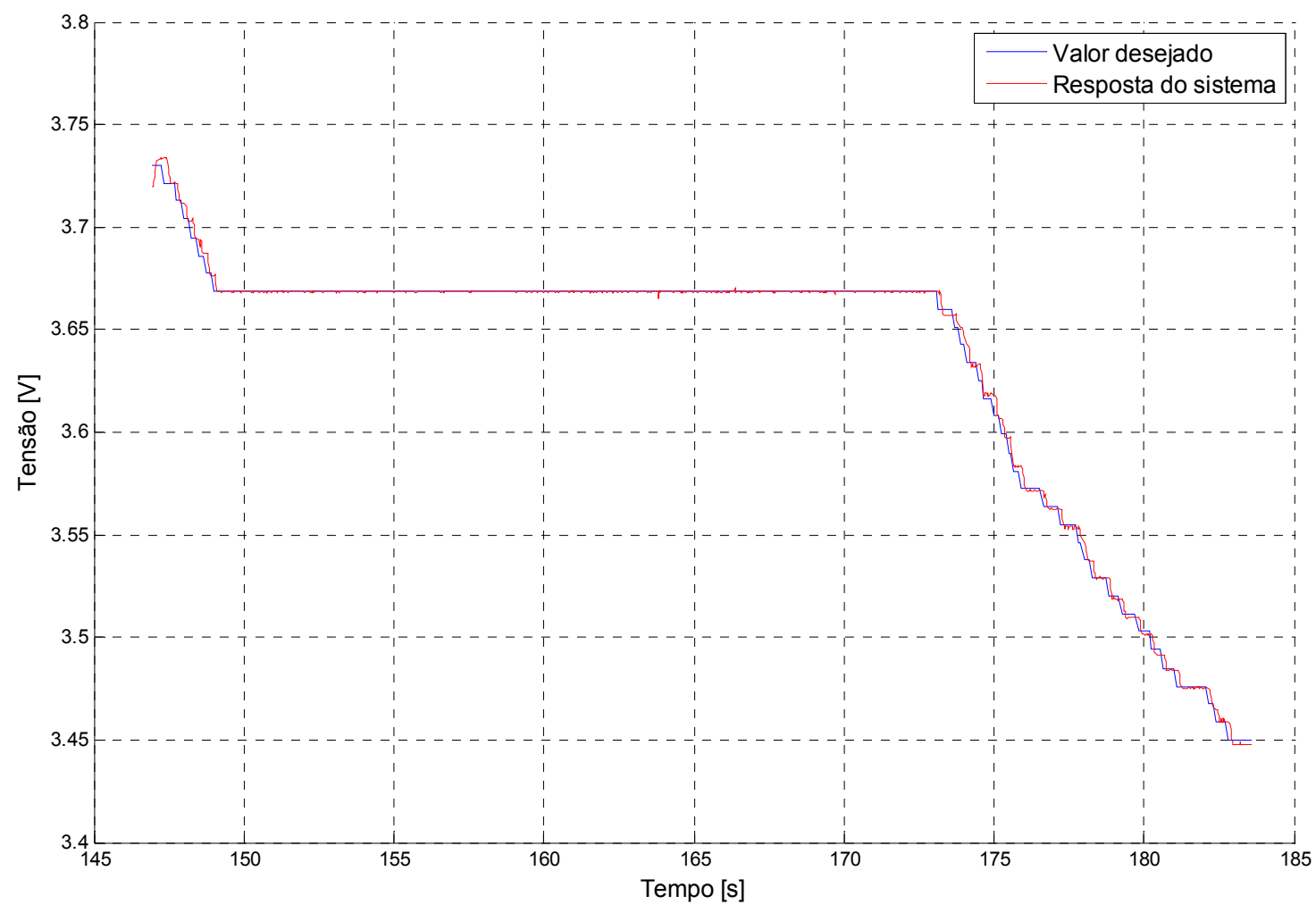

Figura 38 - Resposta do eixo X em um intervalo de tempo para valores decrescentes de posição

$\mathrm{Na}$ Figura 39, pode-se verificar o comportamento do eixo $\mathrm{X}$ em toda a varredura para todos os valores de posição calculados e, na Figura 40, o comportamento do eixo $\mathrm{Y}$, no mesmo intervalo de tempo. 


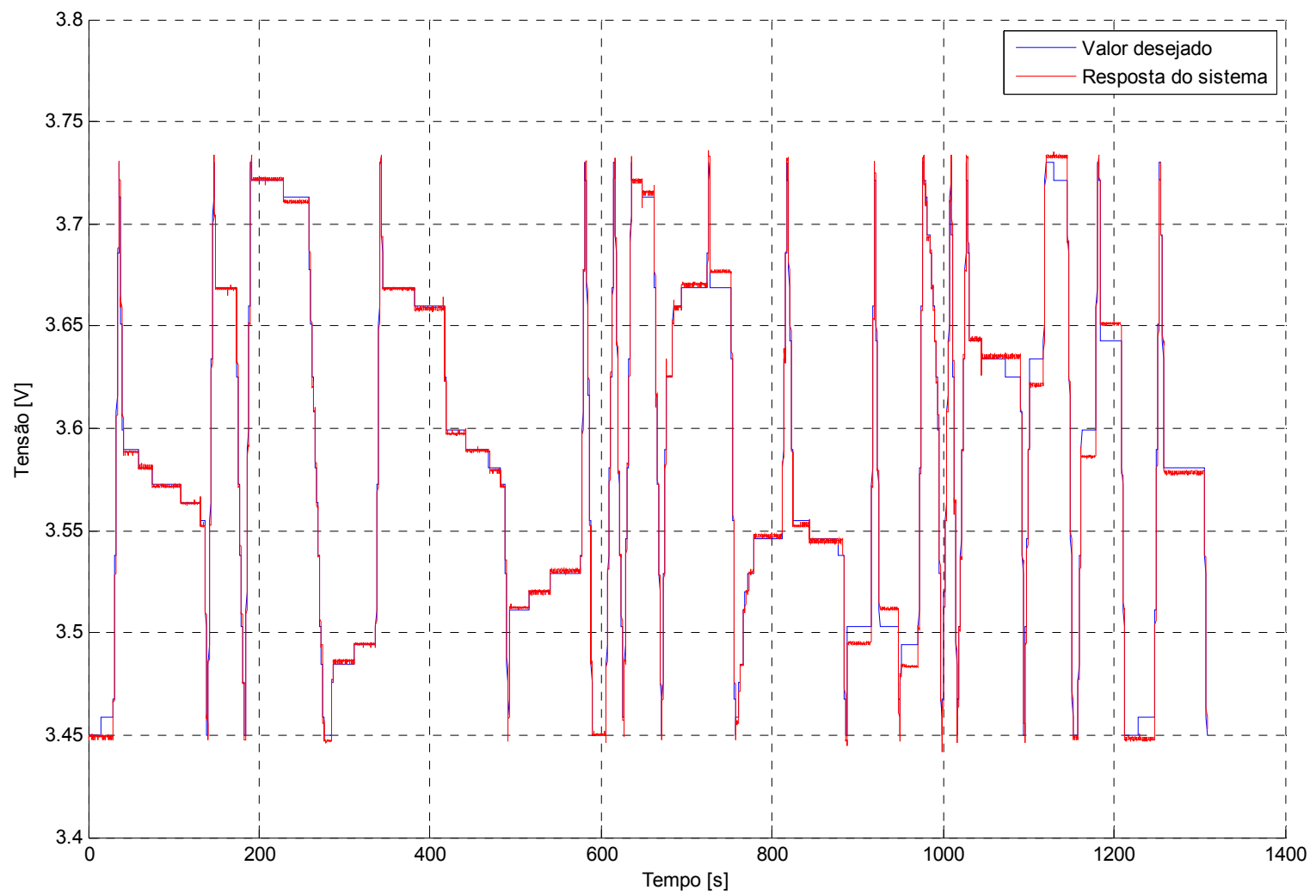

Figura 39 - Resposta do eixo X para todos os valores desejados de posição

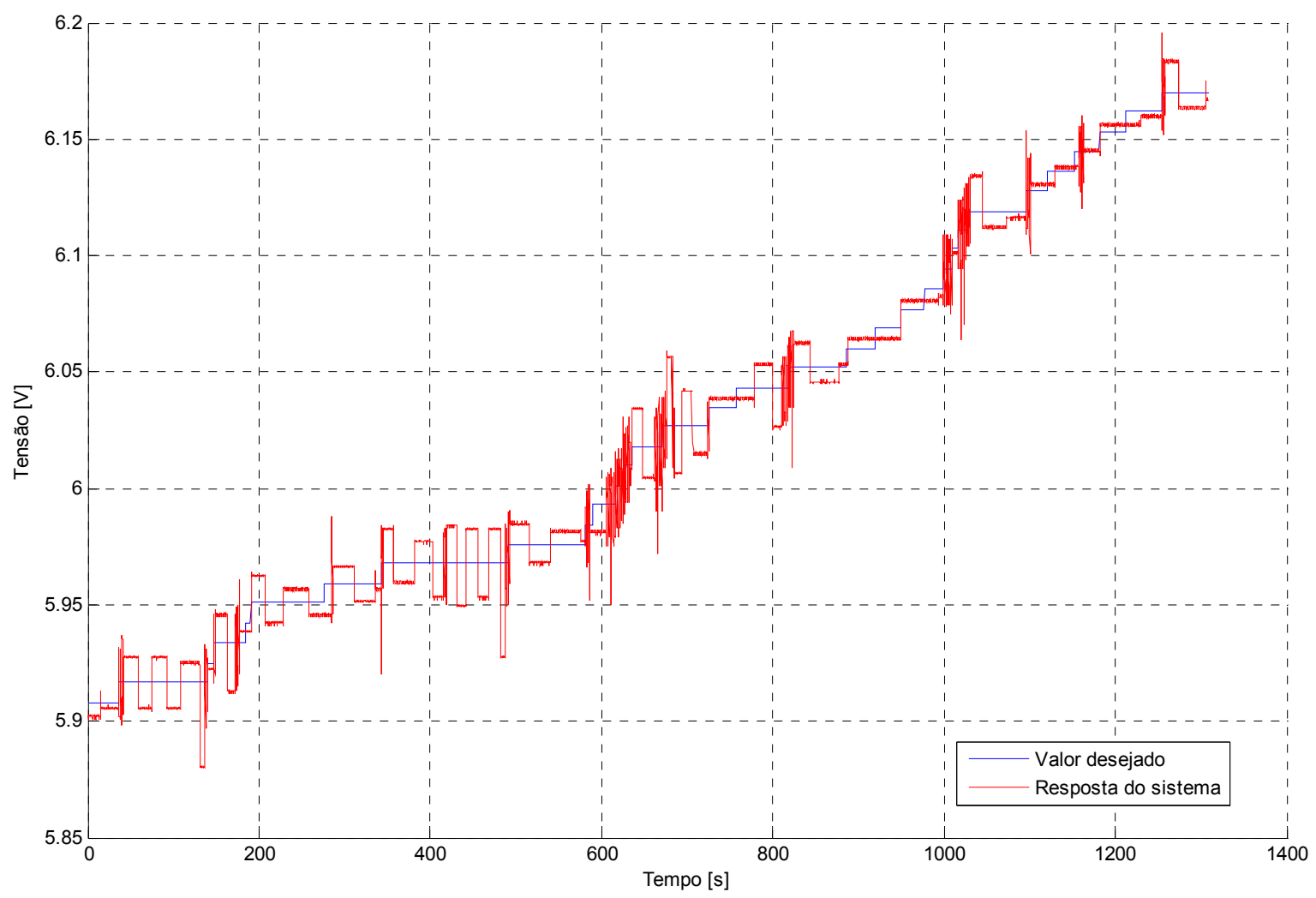

Figura 40 - Resposta do eixo Y para todos os valores de posição calculados

Observa-se que, para esses valores, o sistema tornou-se instável, oscilando ao redor do valor desejado e o tempo de correção do erro de regime foi grande, 
tornando esse método ineficiente para a varredura. $\mathrm{O}$ tempo total da varredura foi 1308.437 segundos.

\subsection{Controle PI}

No ensaio utilizando controle PI, em que foi obtido o melhor resultado, o programa foi configurado para controlar o processo com os seguintes parâmetros:

$$
\mathrm{K}_{\mathrm{P}}=0,2 \quad \mathrm{~T}_{\mathrm{i}}=10 \quad \mathrm{~T}_{\mathrm{D}}=0
$$

Nas Figuras 75, 76 e 77 é comparada a resposta do eixo $X$ ao valor desejado no intervalo de tempo referente à primeira varredura, para valores crescentes. $O$ resultado obtido foi satisfatório, pois melhorou o desempenho no estado transitório e no regime estacionário.

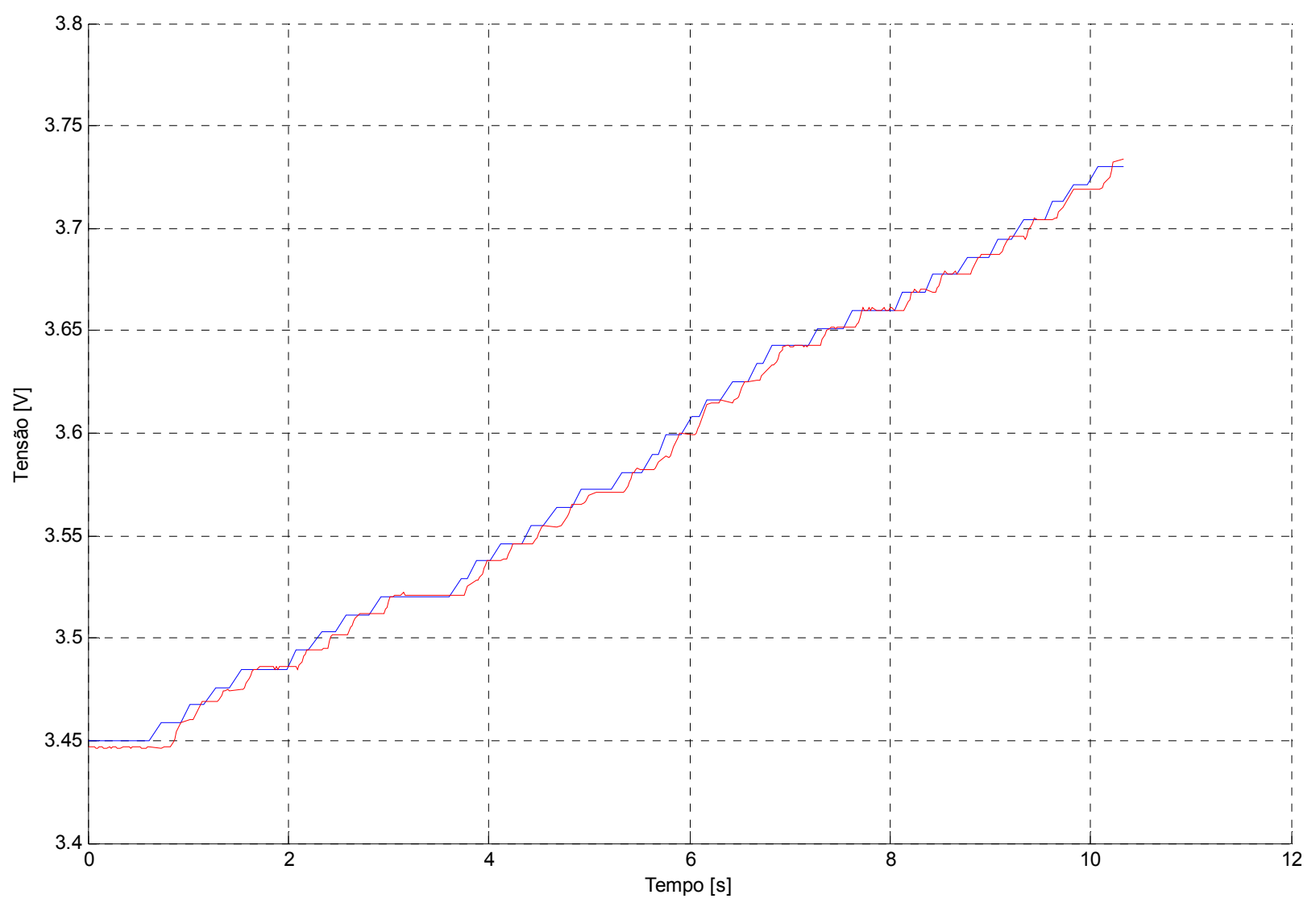

Figura 41 - Resposta do eixo X em um intervalo de tempo para valores decrescentes de posição 


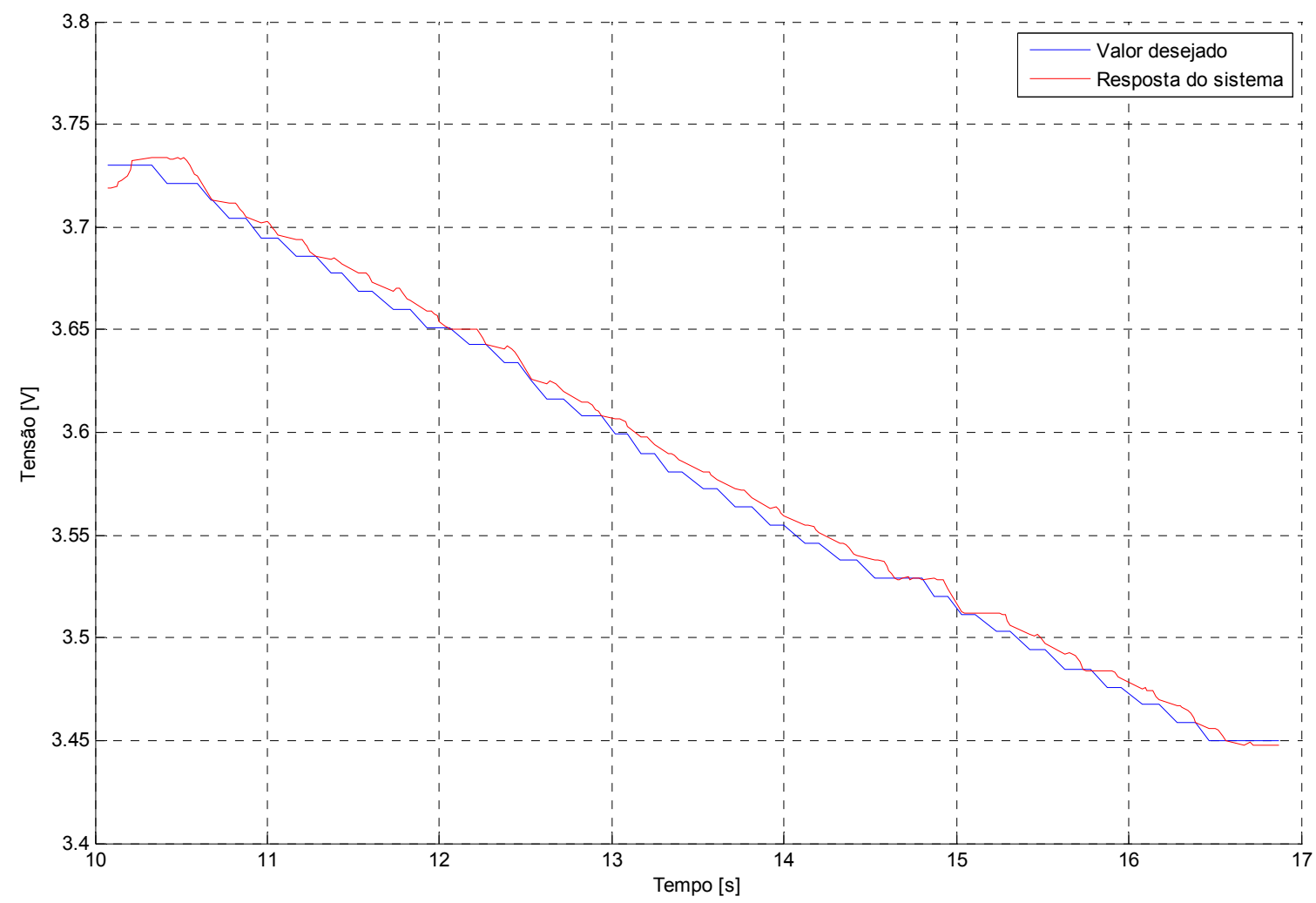

Figura 42 - Resposta do eixo $X$ em um intervalo de tempo para valores decrescentes de posição

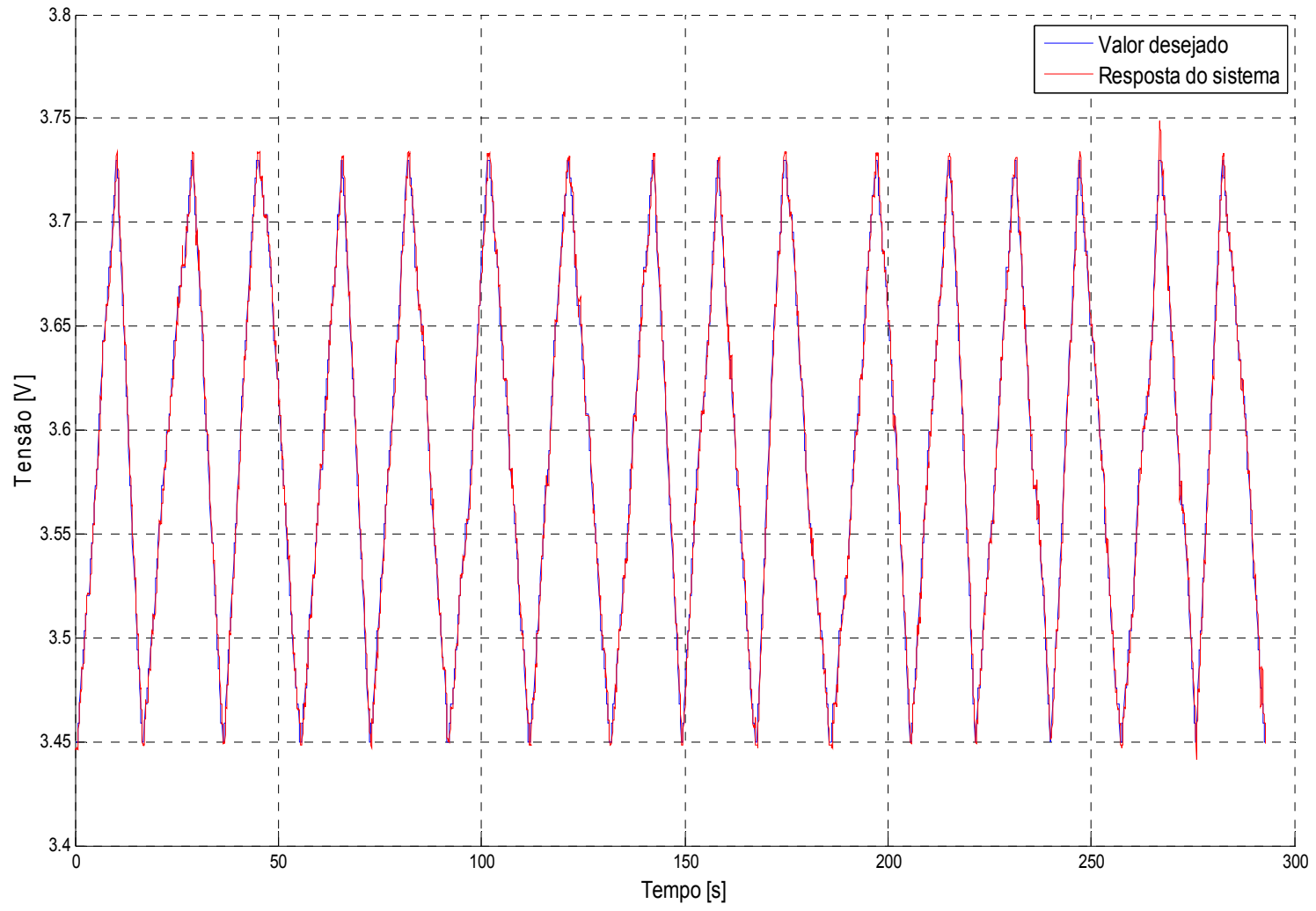

Figura 43 - Resposta do eixo X para todos os valores desejados de posição

A Figura 44 mostra a resposta do eixo Y. Ele tornou-se instável e oscilou ao redor do valor desejado. 


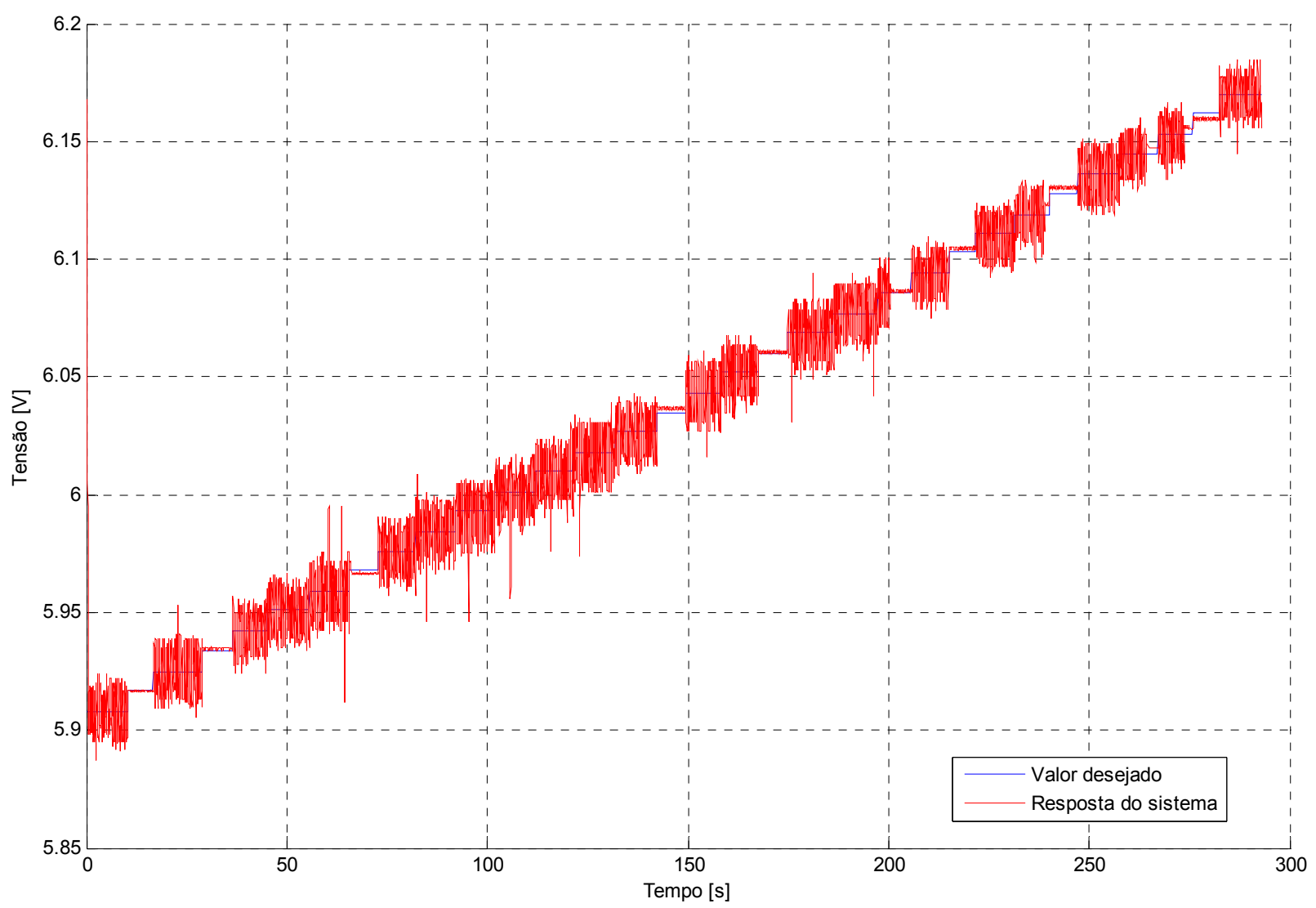

Figura 44 - Resposta do eixo Y para todos os valores gerados de posição

Observa-se que o sistema tornou-se mais estável pela adição da ação Integral e as oscilações em torno do valor desejado para o eixo Y diminuíram consideravelmente. O controlador PI é um compensador de atraso, o que melhora a característica de regime. Entretanto, isso pode resultar em um sistema menos estável, o que foi verificado no eixo Y. O tempo total da varredura foi 292.891 segundos.

\subsection{Controle PID}

No ensaio utilizando controle PID, em que foi obtido o melhor resultado, o programa foi configurado para controlar o processo com os seguintes parâmetros:

$$
\mathrm{K}_{\mathrm{P}}=0,2 \quad \mathrm{~T}_{\mathrm{i}}=10 \quad \mathrm{~T}_{\mathrm{D}}=1
$$

Nas Figuras 79, 80 e 81 é comparada à resposta do eixo $X$ ao valor desejado no intervalo de tempo referente à primeira varredura para valores crescentes. $O$ resultado obtido foi satisfatório, mas a resposta do eixo $\mathrm{Y}$ ocasionou a demora na 
mudança do valor desejado para o eixo X, pois, para um novo valor de posição ser gerado, os dois eixos devem estar na posição desejada.

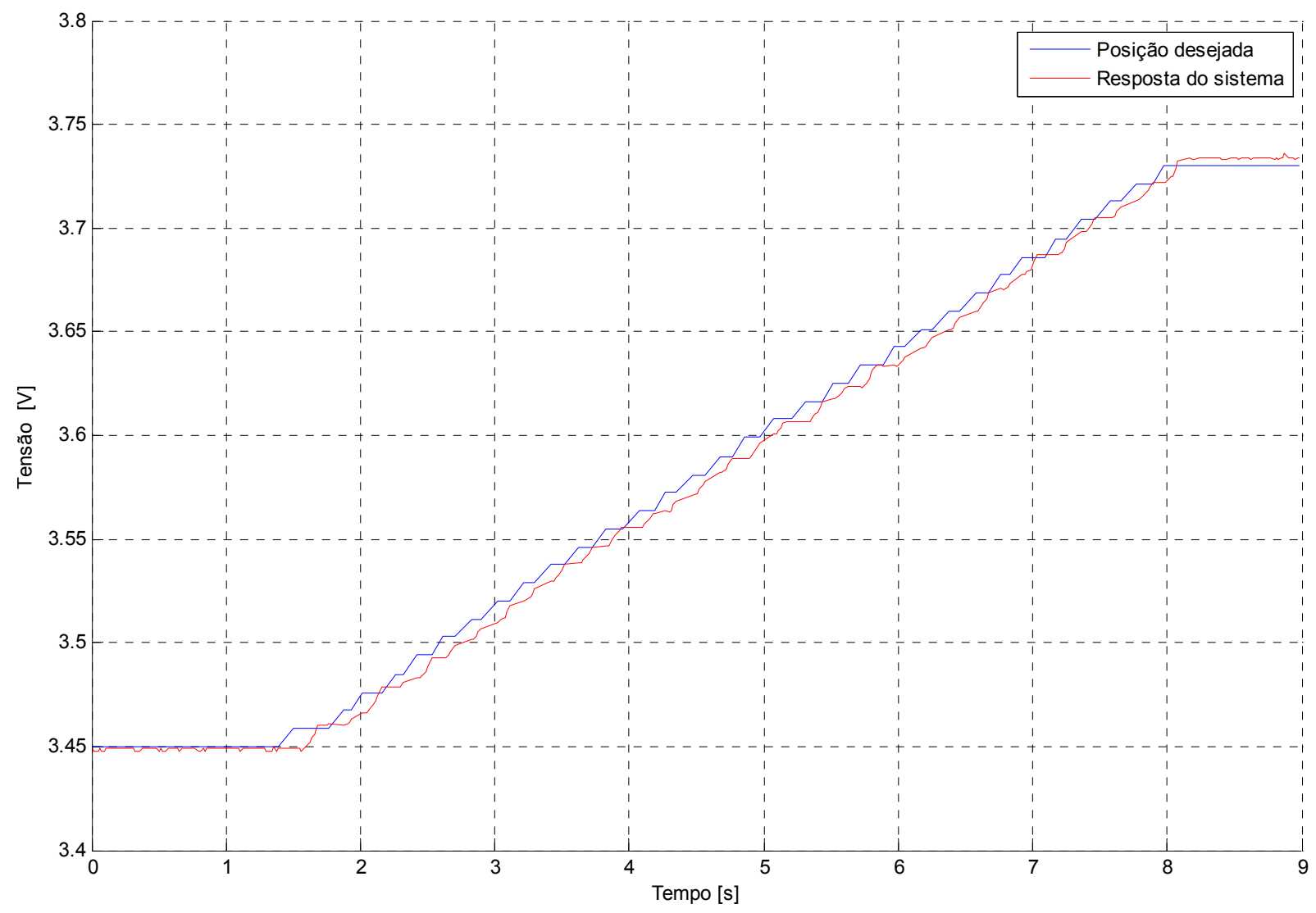

Figura 45 - Resposta do eixo $X$ em um intervalo de tempo para valores crescentes de posição 


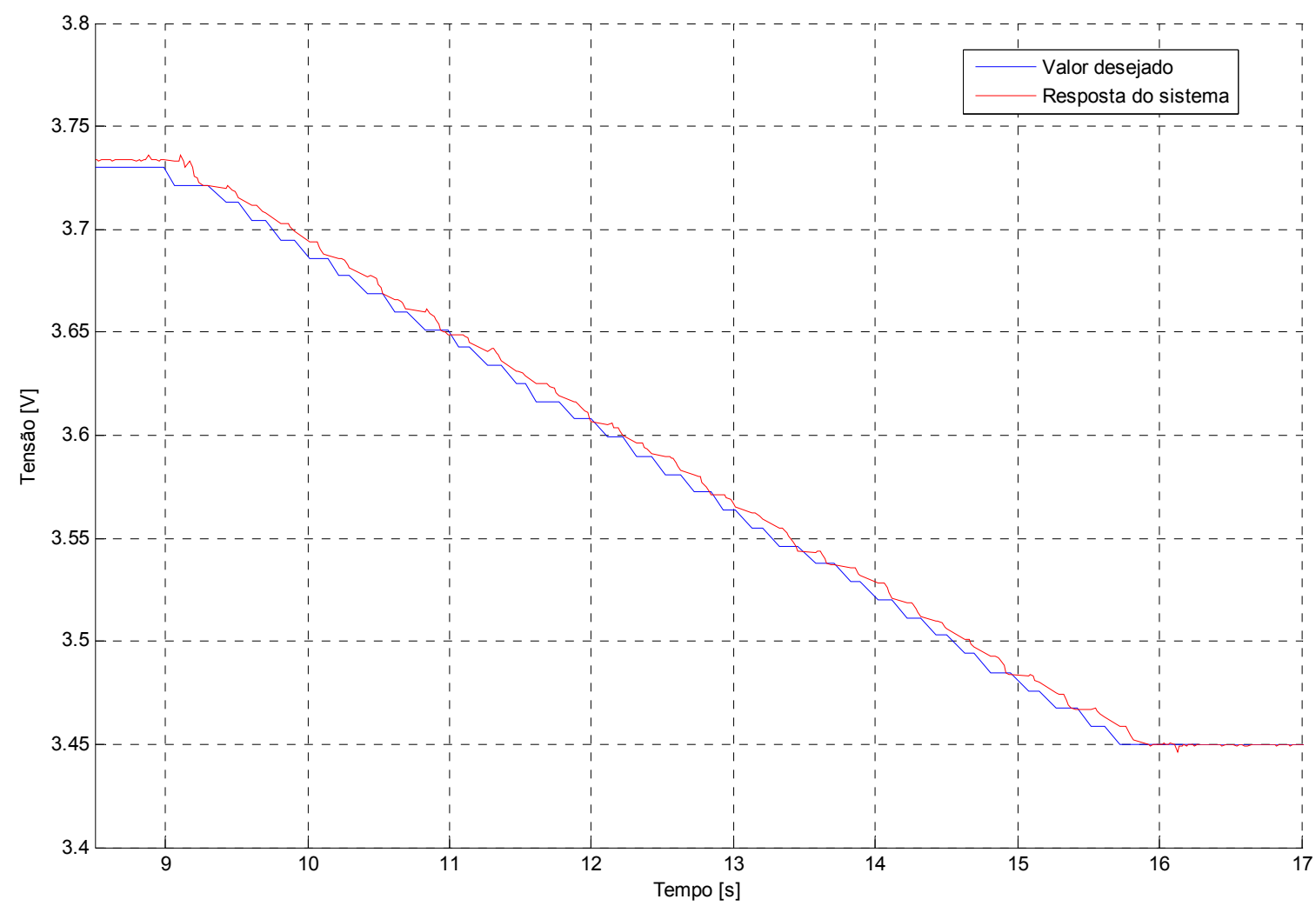

Figura 46 - Resposta do eixo X em um intervalo de tempo para valores decrescentes de posição

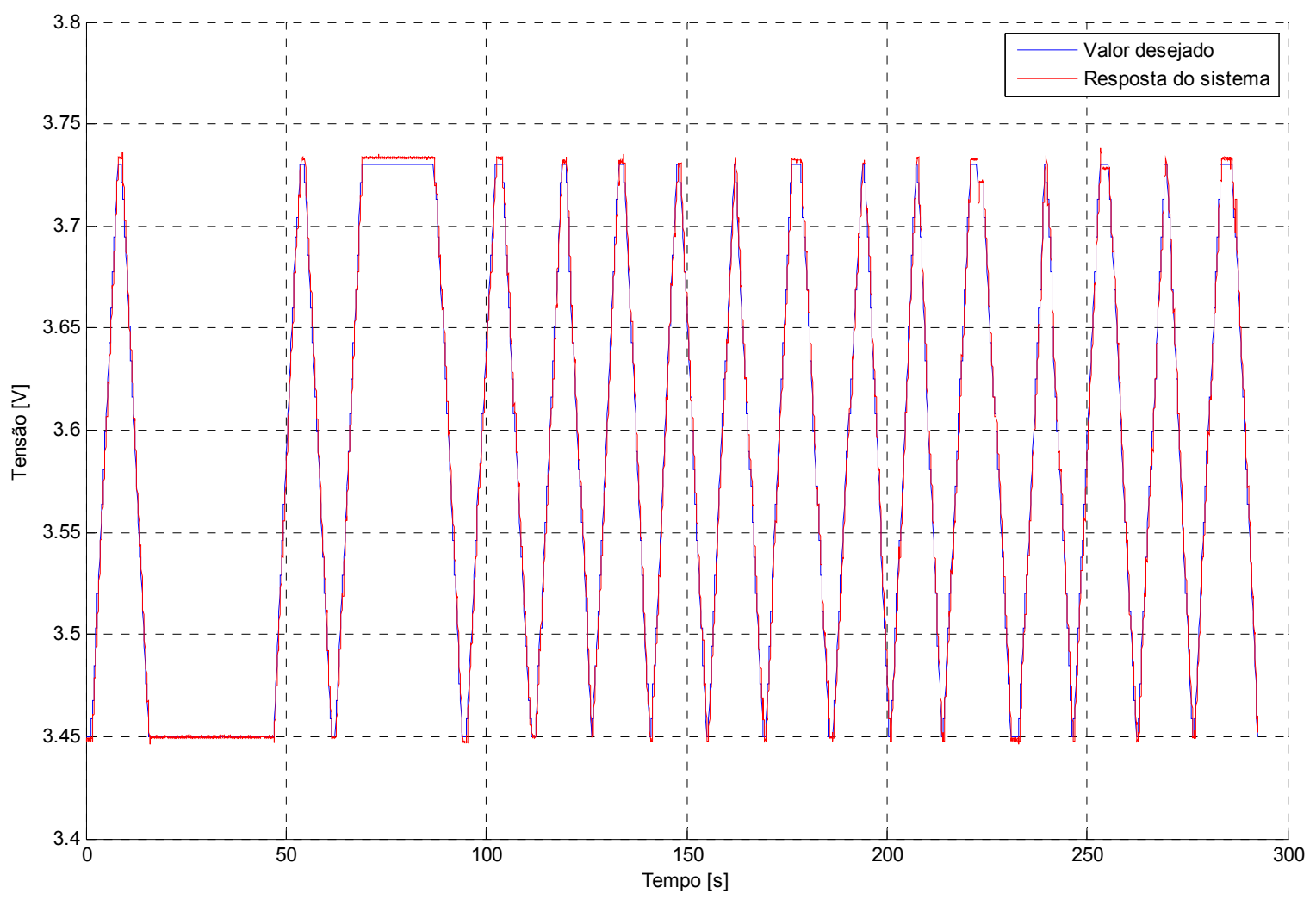

Figura 47 - Resposta do eixo X para todos os valores de posição desejados

A Figura 48 mostra que, pela adição da ação derivativa, a resposta do eixo $Y$ tornouse estável corrigindo a instabilidade gerada pela adição da ação integral. 


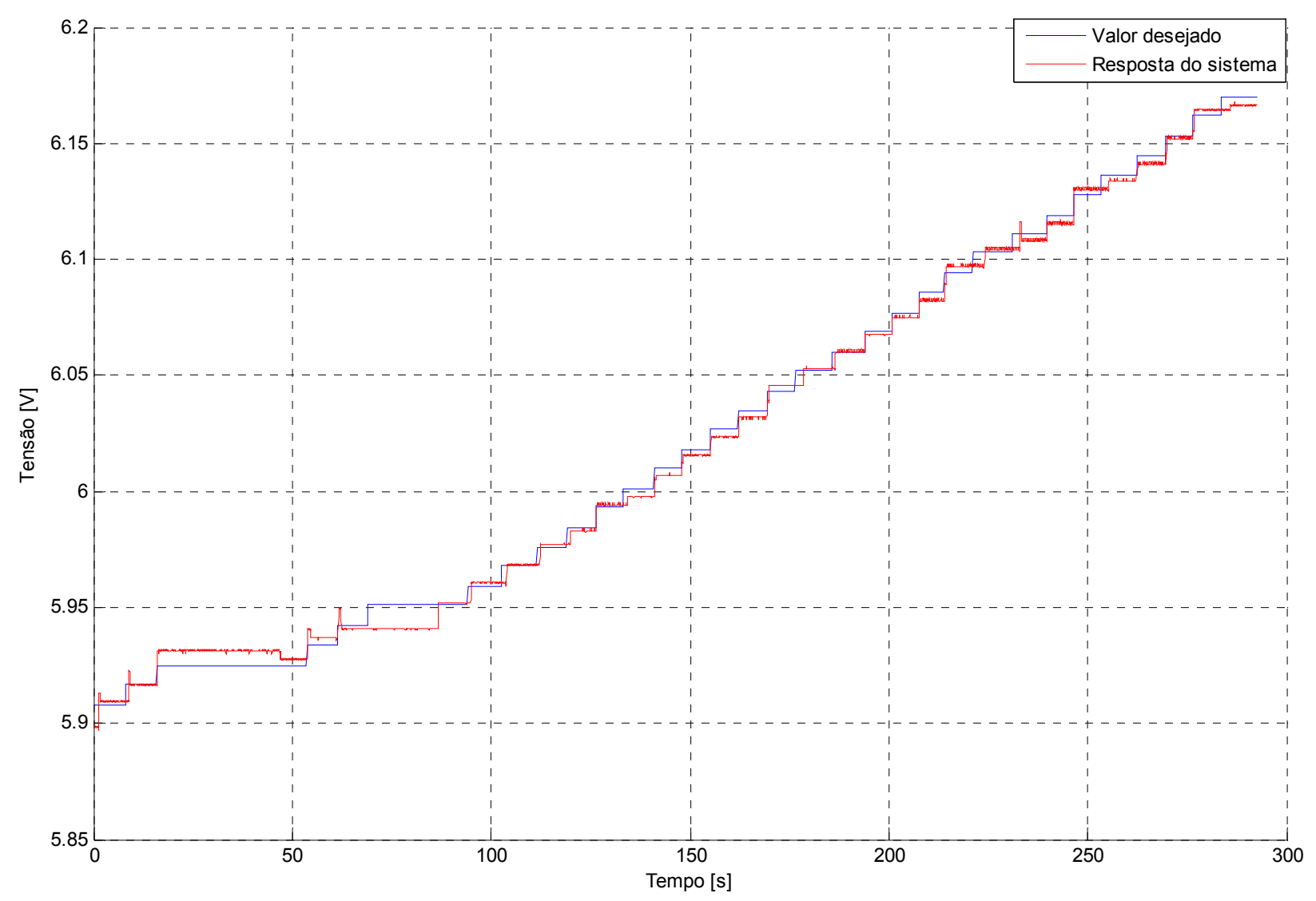

Figura 48 - Resposta do eixo Y para todos os valores gerados de posição

$\mathrm{O}$ eixo $\mathrm{X}$ manteve a estabilidade obtida pelo controle $\mathrm{PI}$, mas em alguns pontos teve o seu tempo de resposta maior. $O$ eixo $Y$ teve sua melhor resposta com esses parâmetros, pois a ação integral melhorou estabilidade e a resposta temporal. O tempo total da varredura foi 292,563 segundos.

\subsection{Discussões sobre o desempenho do software de controle do posicionador}

Quanto ao posicionador, verificou-se, através dos resultados experimentais, que o controle PID trouxe maior estabilidade e menor tempo de resposta para o sistema de posicionamento.

Os diferentes comportamentos observados para os eixos $\mathrm{X}$ e $\mathrm{Y}$ devem-se aos aspectos construtivos do posicionador, uma vez que este utiliza motores e sensores com características diferentes para cada eixo. 


\section{Código fonte utilizado para determinar os pontos inicial e final} da varredura

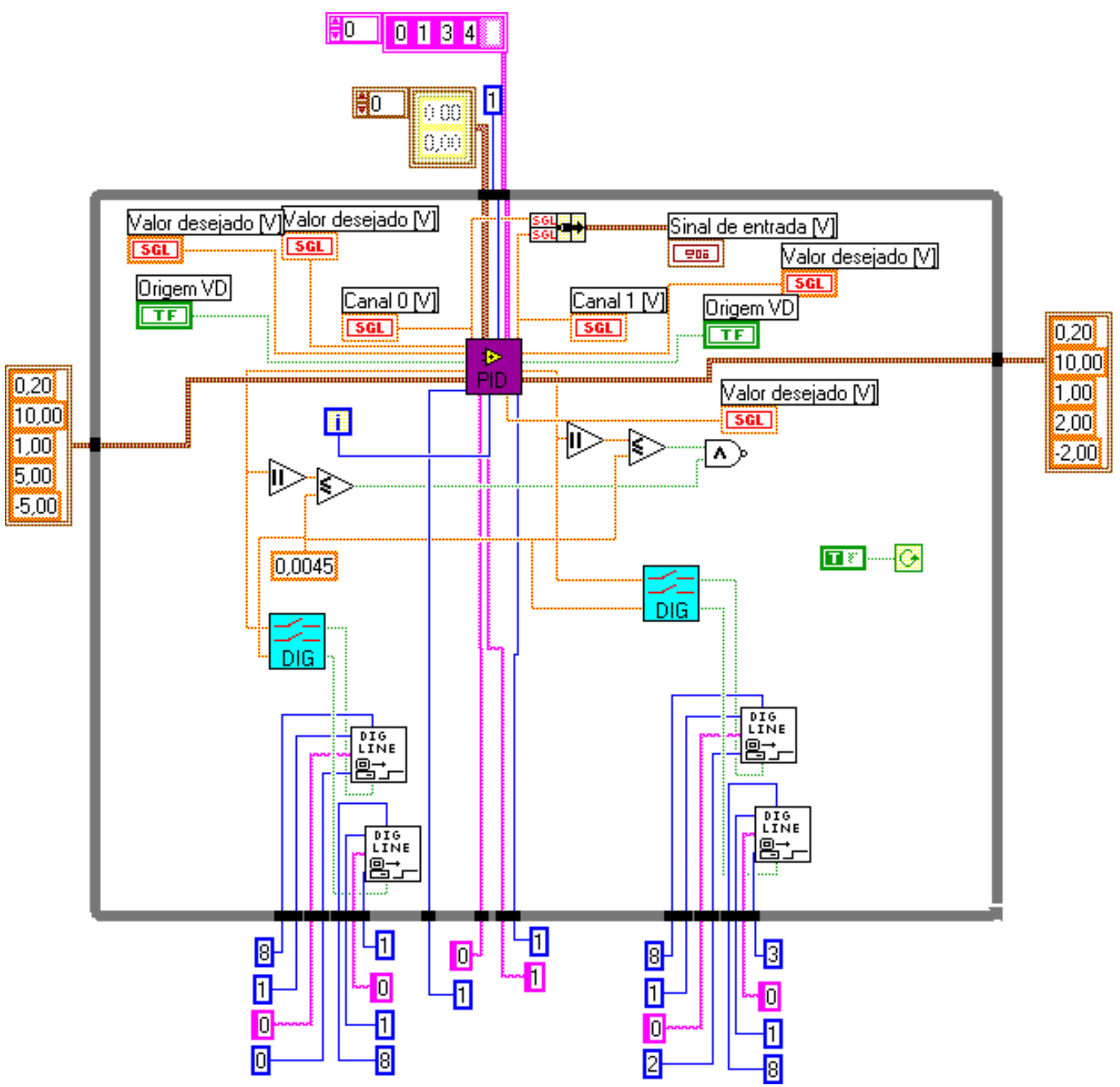

Figura 49 - Código desenvolvido em ambiente LabVIEW®. 
5 Código fonte utilizado para determinar o tempo de adsorção e dessorção de gases no sensor

Na Figura 50 é apresentado o código do programa para determinar os tempos de adsorção e dessorção dos gases analisados pela TELP. 


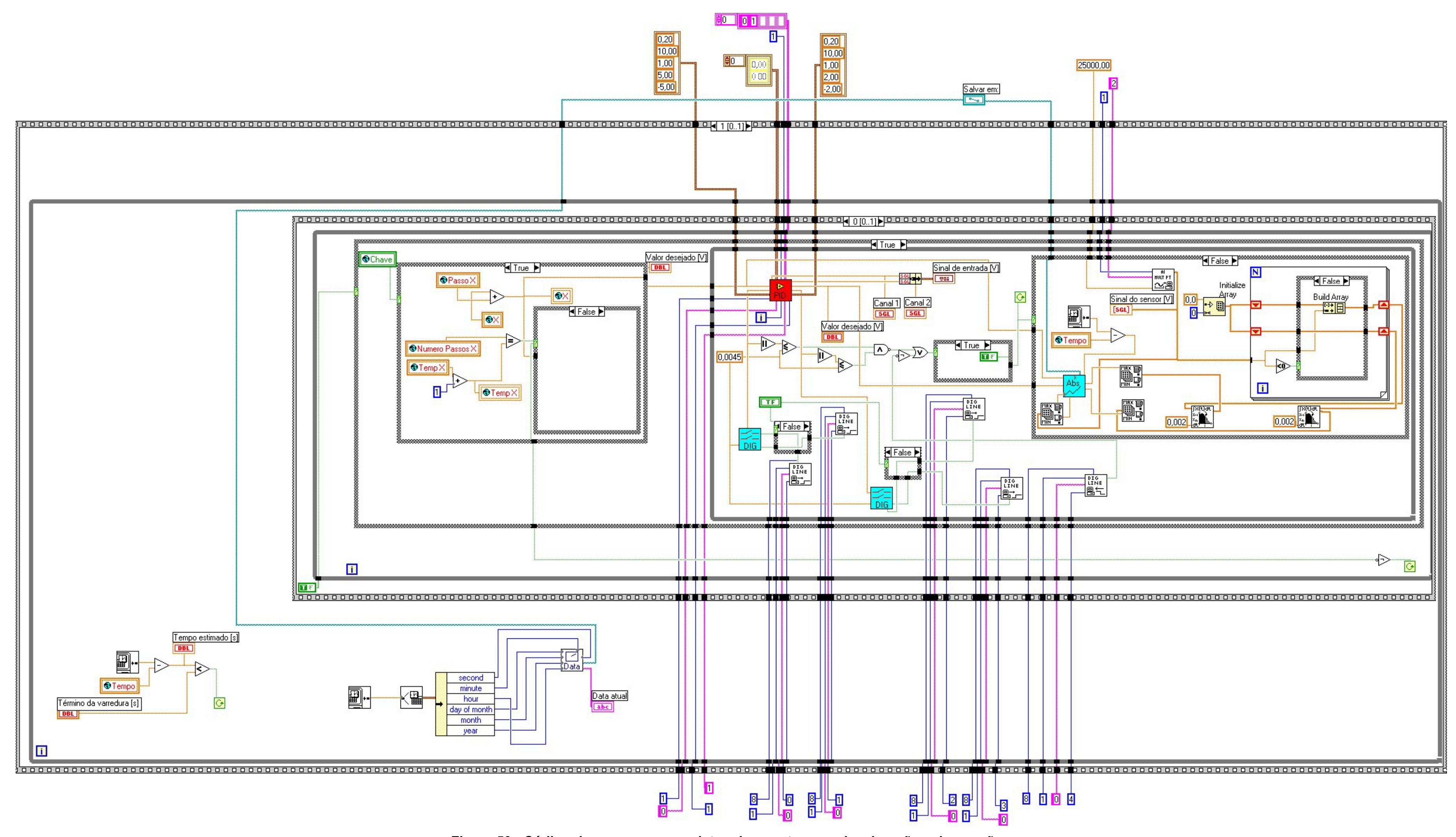

Figura 50 - Código do programa para determinar os tempos de adsorção e dessorção. 
Na primeira etapa do programa é definido o valor inicial para o eixo $X$ da mesma forma que no programa para o controle do posicionador. O horário do início da varredura, em segundos, é armazenado na variável Tempo (Figura 51). O código é mostrado na Figura 52.

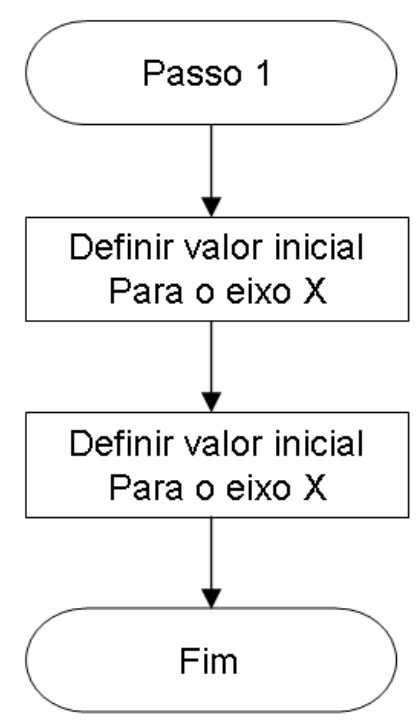

Figura 51 - Primeira etapa do programa para determinar o tempo de adsorção e dessorção de gases no sensor. 


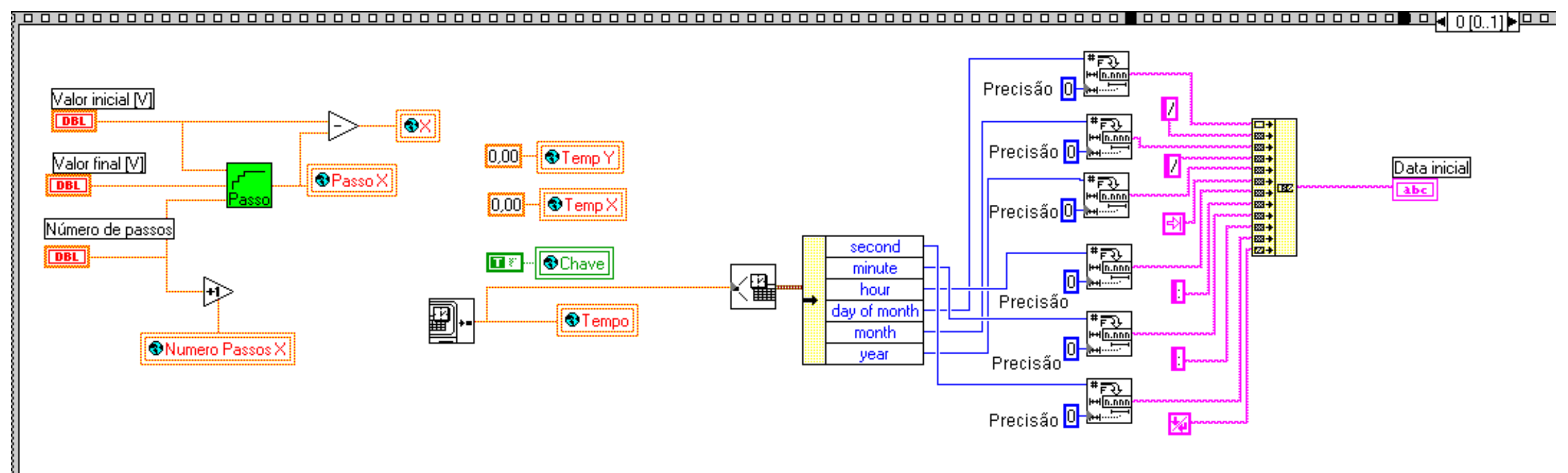

Figura 52 - Código da primeira etapa do programa para determinar o tempo de adsorção e dessorção de gases no sensor. 
Na segunda etapa do programa, a variável Tempo é usada para controlar o tempo de execução do programa, a posição do laser e a aquisição e tratamento do sinal. A estrutura dessa parte do programa é semelhante a do sistema desenvolvido para controlar o posicionador. A diferença está em que o controle do número de execuções do programa é realizado pelo tempo de varredura indicado pelo usuário. Dentro dessa parte é realizado também o controle do intervalo entre as leituras realizadas, de acordo com o valor inserido pelo usuário. (Figura 53)

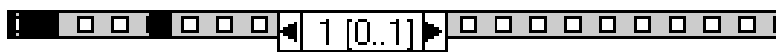

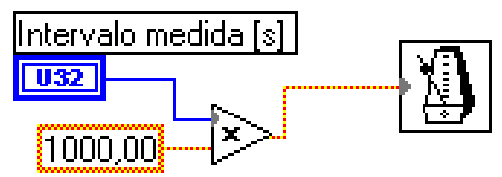

Figura 53 - Controle do intervalo entre as leituras.

Após estas definições, o programa utiliza a mesma estrutura do sistema desenvolvido para controlar o posicionamento $\mathrm{X} Y$.

\subsection{SubVI Dados Adsorção}

Os dados tratados e a posição em que foram obtidos são armazenados pelo VI Dados Adsorção (Figura 54 e Figura 55).

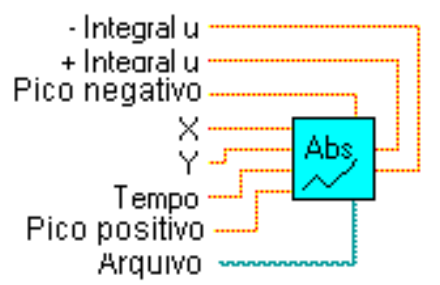

Figura 54 - SubVI Dados Adsorção. 


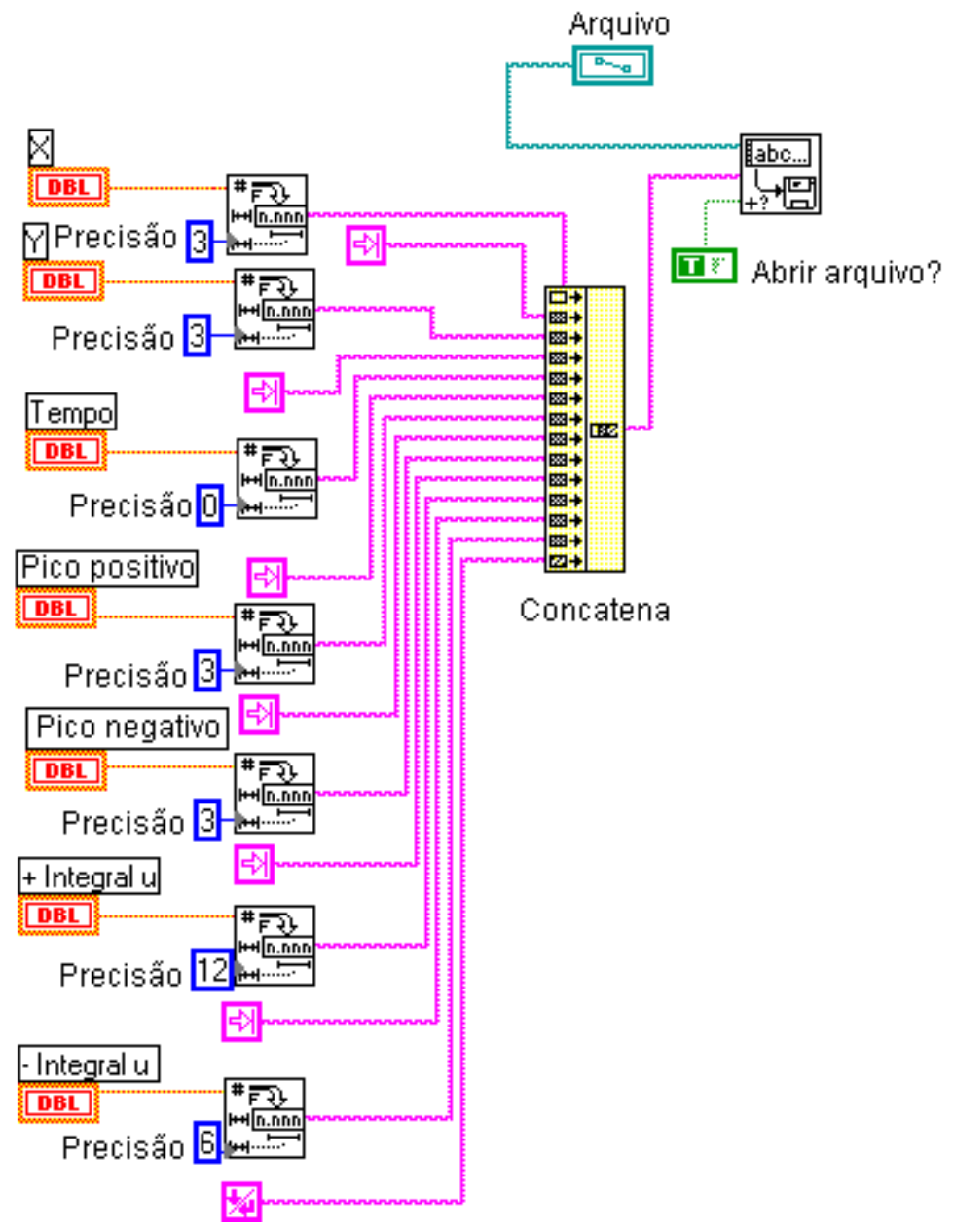

Figura 55 - Código do subVI Dados Adsorção.

\subsection{SubVI Data}

Para o armazenamento da data da varredura, foi construído o VI Data, responsável por ordenar e gravar em um arquivo os dados referentes à data: dia, mês, ano, hora, minuto e segundo. (Figura 56 e Figura 57)



Figura 56 - SubVI Data. 


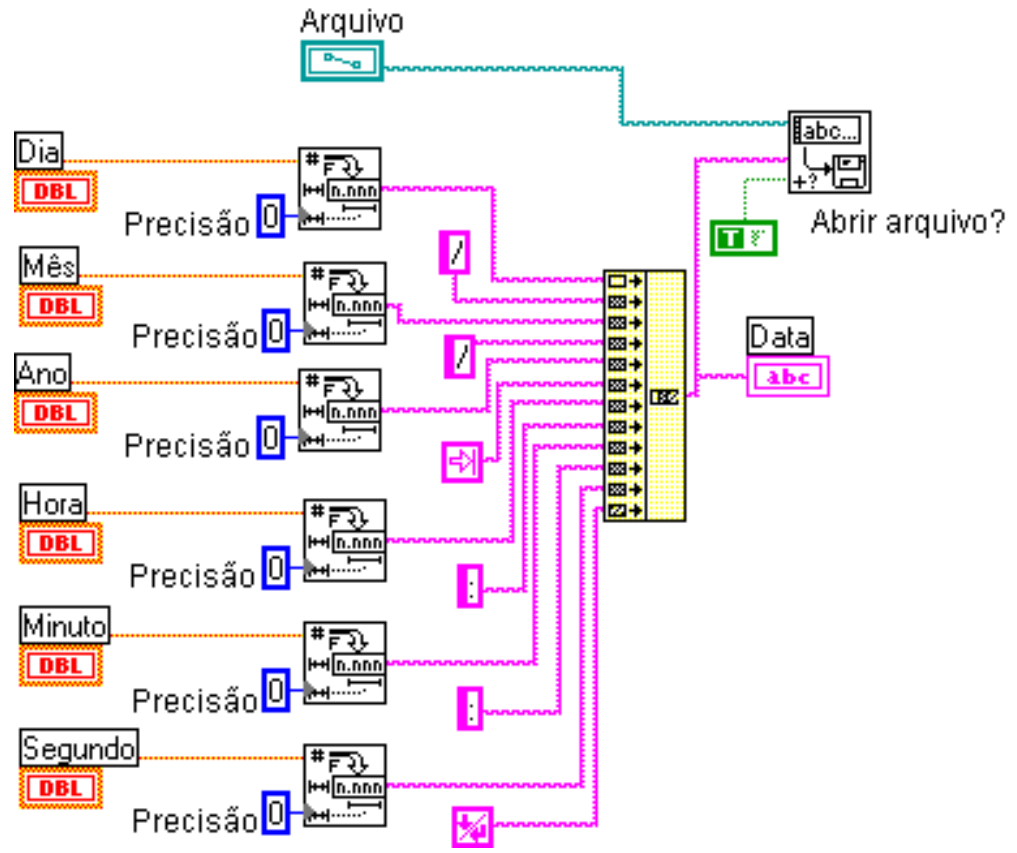

Figura 57 - Código do subVI Data. 